Final Report

FHWA/IN/JTRP-2006/37

\title{
ECONOMIC DEVELOPMENT EFFECTS OF INDOT TRANSPORTATION PROJECTS
}

\author{
By \\ Konstantina Gkritza \\ Graduate Research Assistant \\ Samuel Labi \\ Assistant Professor of Civil Engineering \\ and \\ Kumares Sinha \\ Olson Distinguished Professor of Civil Engineering \\ School of Civil Engineering \\ Purdue University \\ Joint Research Transportation Program \\ Project No. C-36-73AA \\ File No. 3-4-27 \\ SPR-2861 \\ Prepared in cooperation with the \\ Indiana Department of Transportation and the \\ U.S. Department of Transportation \\ Federal Highway Administration
}

The contents of this report reflect the views of the authors who are responsible for the facts and the accuracy of the data presented herein. The contents do not necessarily reflect the official views or policies of the Indiana Department of Transportation or the Federal Highway Administration at the time of publication. This report does not constitute a standard, specification, or regulation.

Purdue University

West Lafayette, Indiana, 47907

April 2007 


\begin{tabular}{|c|c|c|c|c|}
\hline $\begin{array}{l}\text { 1. Report No. } \\
\text { FHWA/IN/JTRP-2006/37 }\end{array}$ & \multicolumn{2}{|c|}{ 2. Government Accession No. } & \multicolumn{2}{|c|}{ 3. Recipient's Catalog No. } \\
\hline \multirow{2}{*}{\multicolumn{3}{|c|}{$\begin{array}{l}\text { 4. Title and Subtitle } \\
\text { Economic Development Effects of INDOT Transportation Projects }\end{array}$}} & \multicolumn{2}{|c|}{$\begin{array}{l}\text { 5. } \quad \text { Report Date } \\
\text { April } 2007\end{array}$} \\
\hline & & & \multicolumn{2}{|c|}{ 6. Performing Organization Code } \\
\hline \multicolumn{3}{|c|}{$\begin{array}{l}\text { 7. Author(s) } \\
\text { Konstantina Gkritza, Samuel Labi, Kumares Sinha }\end{array}$} & \multicolumn{2}{|c|}{$\begin{array}{l}\text { 8. Performing Organization Report No. } \\
\text { FHWA/IN/JTRP-2006/37 }\end{array}$} \\
\hline \multirow[t]{2}{*}{$\begin{array}{l}\text { 9. Performing Organization Name an } \\
\text { Joint Transportation Research } \\
1284 \text { Civil Engineering Buildi } \\
\text { Purdue University } \\
\text { West Lafayette, IN 47907-128 }\end{array}$} & & & \multicolumn{2}{|l|}{ 10. Work Unit No. } \\
\hline & & & \multicolumn{2}{|c|}{$\begin{array}{l}\text { 11. Contract or Grant No. } \\
\text { SPR-2861 }\end{array}$} \\
\hline \multirow{2}{*}{\multicolumn{3}{|c|}{$\begin{array}{l}\text { 12. Sponsoring Agency Name and Address } \\
\text { Indiana Department of Transportation } \\
\text { State Office Building } \\
100 \text { North Senate Avenue } \\
\text { Indianapolis, IN } 46204\end{array}$}} & \multicolumn{2}{|c|}{$\begin{array}{l}\text { 13. Type of Report and Period Covered } \\
\text { Final Report }\end{array}$} \\
\hline & & & \multicolumn{2}{|c|}{ 14. Sponsoring Agency Code } \\
\hline \multicolumn{5}{|l|}{$\begin{array}{l}\text { 15. Supplementary Notes } \\
\text { Prepared in cooperatic }\end{array}$} \\
\hline \multicolumn{5}{|c|}{ 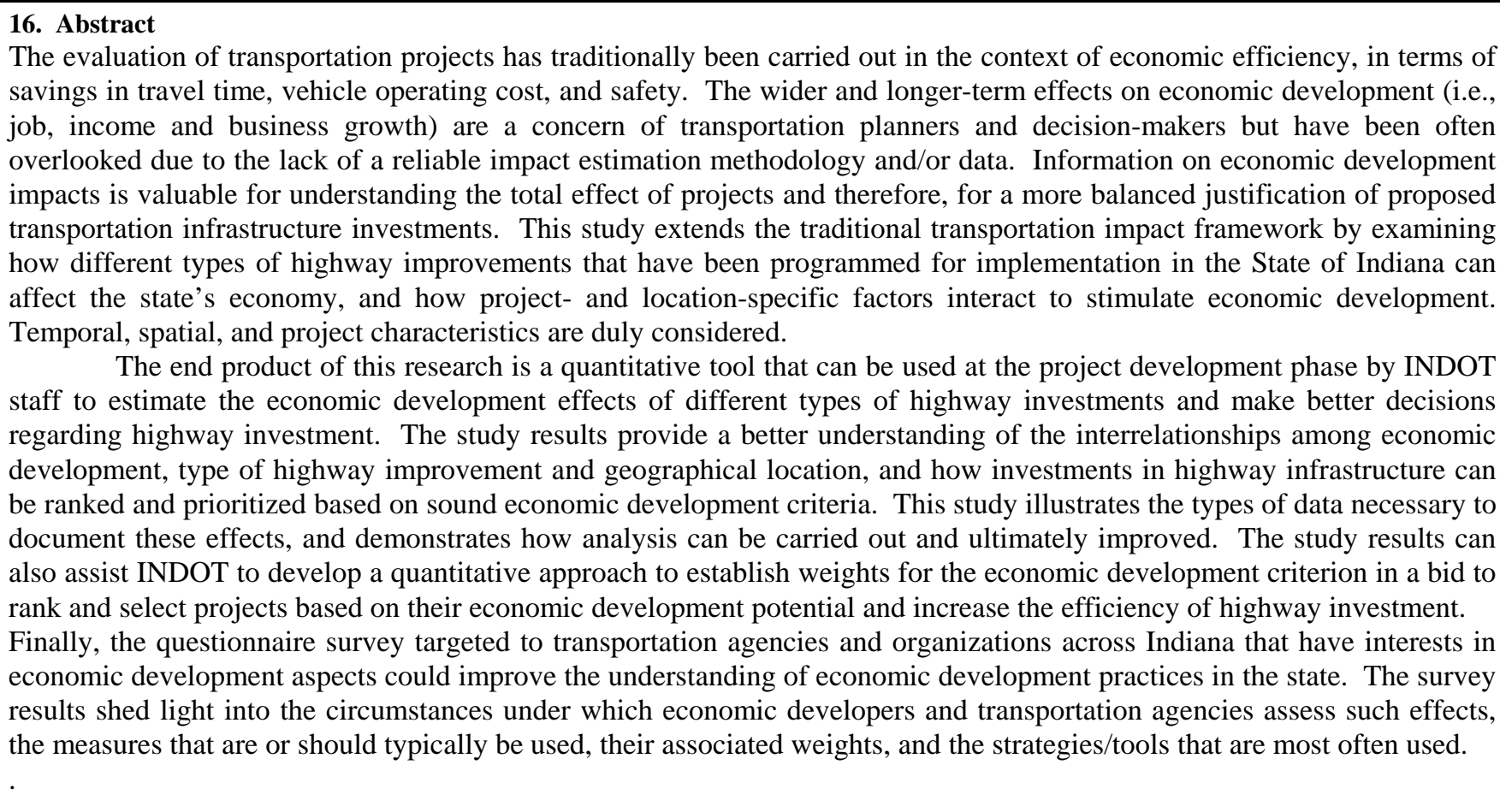 } \\
\hline \multicolumn{2}{|c|}{$\begin{array}{l}\text { 17. Key Words } \\
\text { statewide economic development, highway investment, } \\
\text { project selection }\end{array}$} & \multicolumn{3}{|c|}{$\begin{array}{l}\text { 18. Distribution Statement } \\
\text { No restrictions. This document is available to the public through the } \\
\text { National Technical Information Service, Springfield, VA } 22161\end{array}$} \\
\hline 19. Security Classif. (of this report) & 20. Security Classif. (of & is page) & 21. No. of Pages & 22. Price \\
\hline
\end{tabular}

Form DOT F 1700.7 (8-69) 
TABLE OF CONTENTS

Page

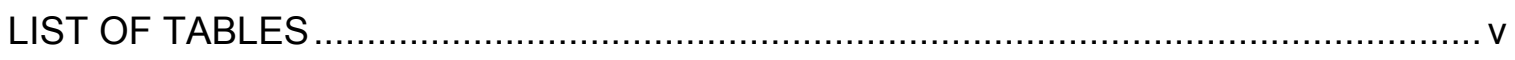

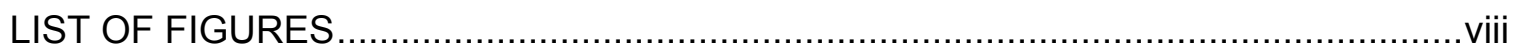

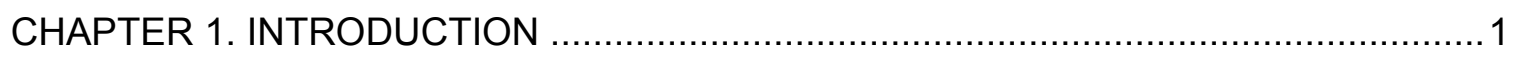

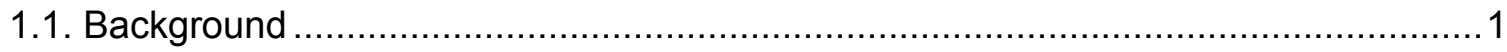

1.2. Motivation for the Present Research Study ………....................................... 3

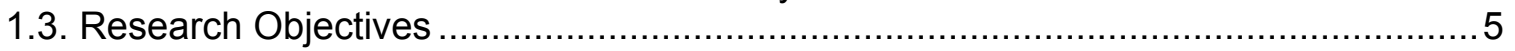

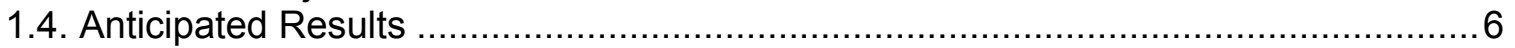

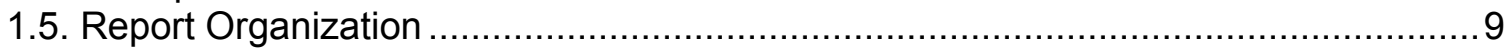

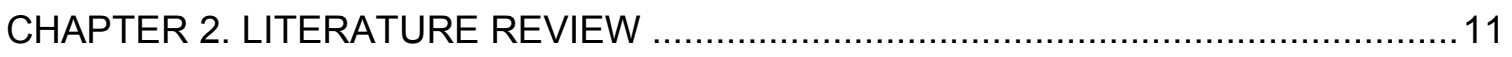



2.1.1. Economic Development .................................................................. 11

2.1.2. Measures of Economic Development Impacts......................................... 12

2.1.3. Measurement Issues........................................................................... 13

2.2. Highway Infrastructure and Economic Development ........................................ 17

2.2.1. Issues on the Highway Investment/Economic Growth Relationship ..............18

2.2.2. Empirical Evidence ......................................................................

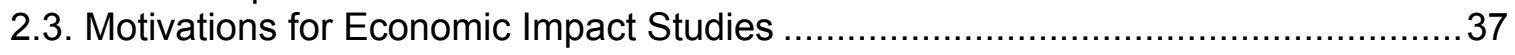

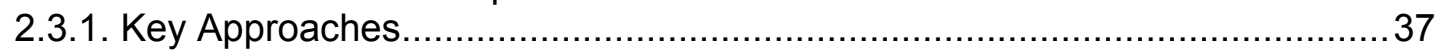

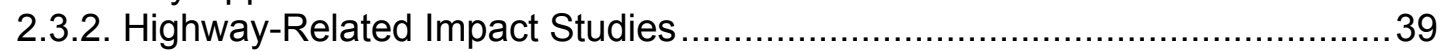



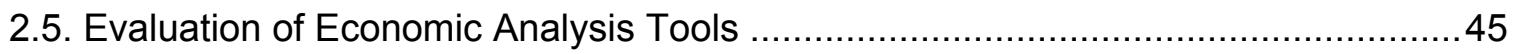

2.5.1. Economic Multiplier Approach/ Input-Output Analysis ..................................46

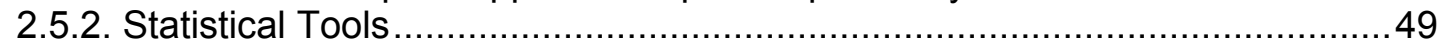

2.5.3. Economic Simulation Models ................................................................. 53

2.5.4. Comparison of Input-Output and Economic Simulation Models ...................57

2.6. Explanatory Variables in Econometric Models .....................................................59

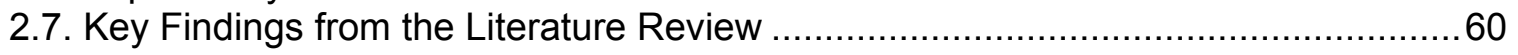

CHAPTER 3. STATE ECONOMIC DEVELOPMENT PRACTICES .............................64 


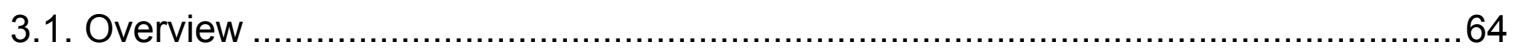



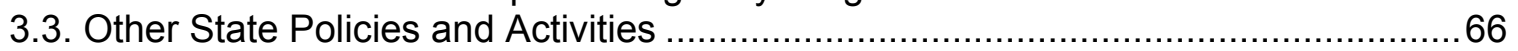

3.4. Distinguished State Practices in Project Prioritization/Ranking ............................66

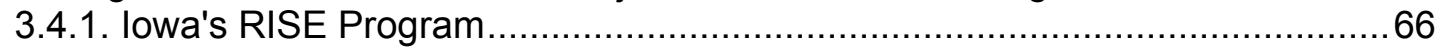

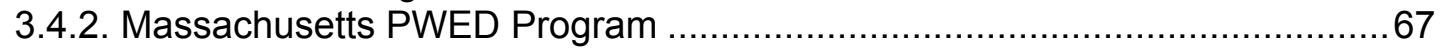

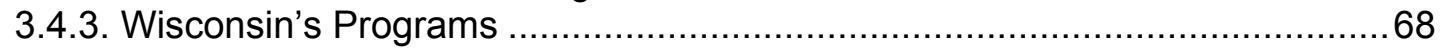

3.4.4. Kansas's System Enhancement Program .............................................. 70

3.4.5. Ohio's Economic Scoring Process ...................................................... 71

3.5. Summary of State Funding Programs and Policies........................................... 72

CHAPTER 4. STUDY METHODOLOGY AND DATA COLLECTION .........................73

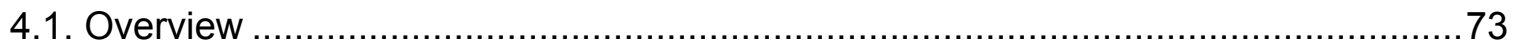

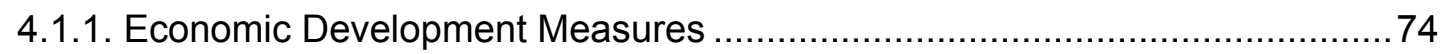

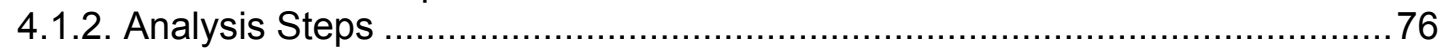

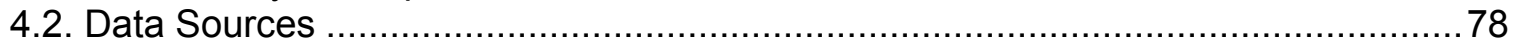

4.2.1. Indiana's 25-Year Long-Range Plan Highway Expansion Projects ...............79

4.2.2. Highway Performing Monitoring System (HPMS) Database......................... 80

4.2.3. Indiana's Economic Profile and Transportation Statistics ............................ 81

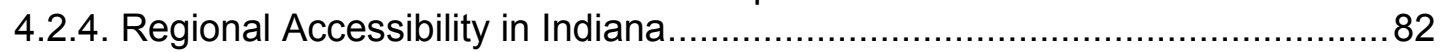

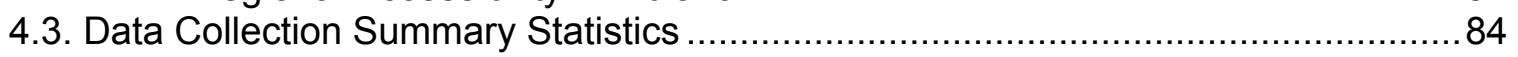

CHAPTER 5. SHORT-TERM EFFECTS OF HIGHWAY INVESTMENT

AND LONG-TERM EFFECTS OF MAJOR CORRIDOR STUDIES IN INDIANA............90

5.1. Estimation of Short-Term Economic Development Effects of Highway

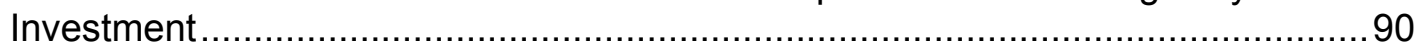

5.2. Long-Term Economic Development Effects of Major Corridor Studies in

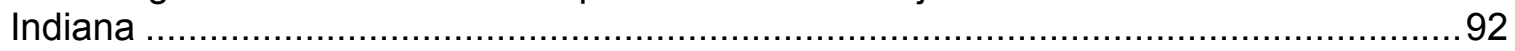

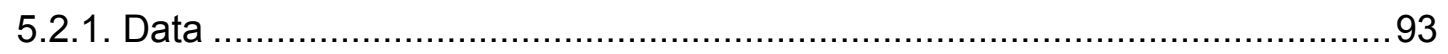

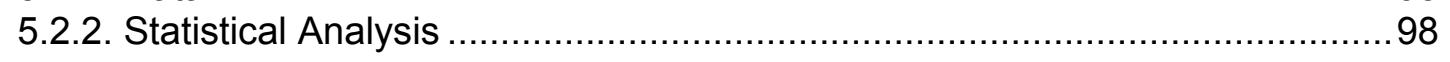

CHAPTER 6. FRAMEWORK FOR LONG-TERM REGIONAL ECONOMIC

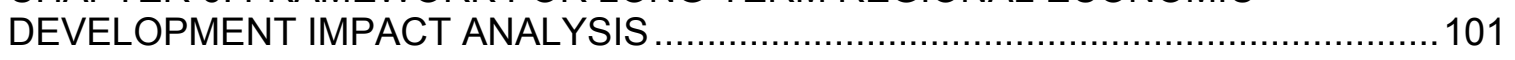

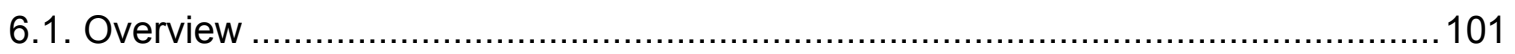

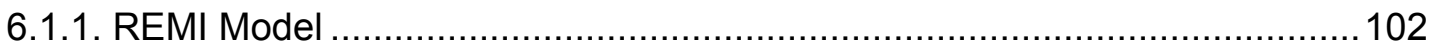

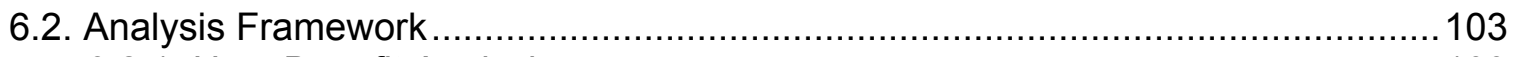

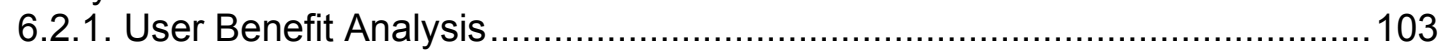

6.2.2. Economic Benefit Analysis......................................................... 114

6.2.3. Estimation of Potential Business Attraction and Tourism ..........................116

6.2.4. Estimation of Long-Term Secondary Economic Development Effects ........118

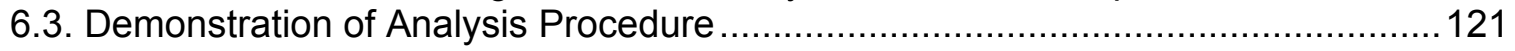

CHAPTER 7. STATEWIDE LONG-TERM ECONOMIC DEVELOPMENT BY HIGHWAY IMPROVEMENT TYPE AND LOCATION 


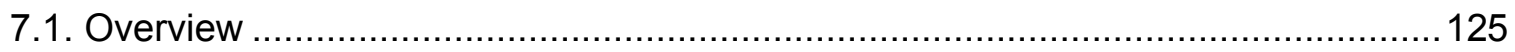

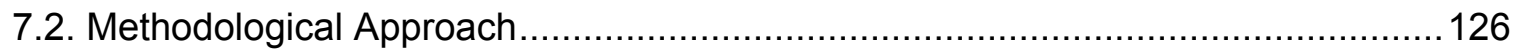

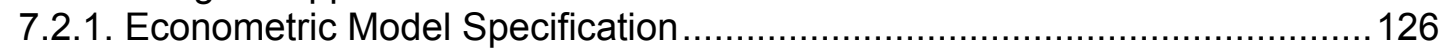

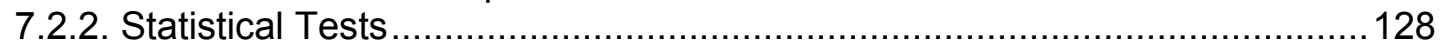

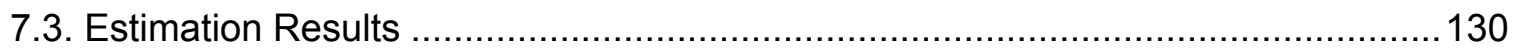

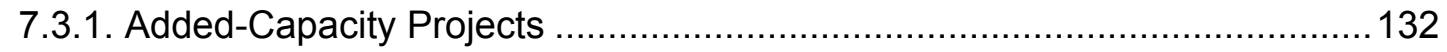

7.3.2. New Road, Median and Interchange Construction Projects ....................... 139

7.4. Comparison of Alternative Parameter Estimators ............................................ 145

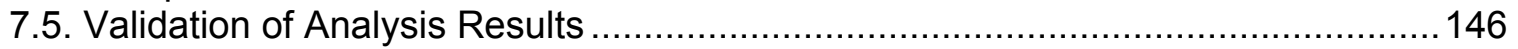

CHAPTER 8. QUESTIONNAIRE SURVEY ON ECONOMIC DEVELOPMENT

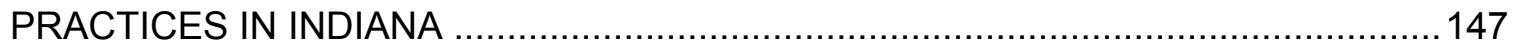

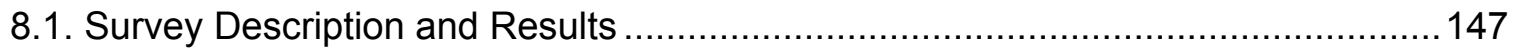

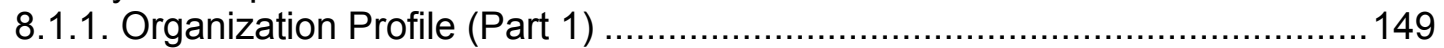

8.1.2. Economic Development Practices (Part 2) ............................................. 150

8.1.3. Use of Specific Methods for Assessing Economic Development Impacts

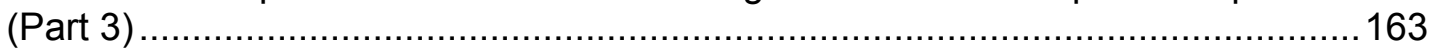

8.1.4. Adequacy of Available Methods, Tools, and Techniques (Part 4) ...............165

8.1.5. Indiana's Economic Development Profile (Part 5) ................................ 166

CHAPTER 9. CONCLUSIONS AND RECOMMENDATIONS ................................ 171

9.1. Contribution of this Research and Implementation ................................... 171

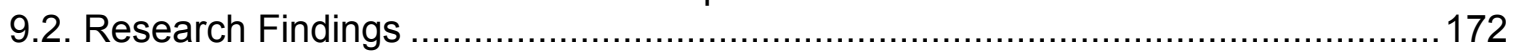

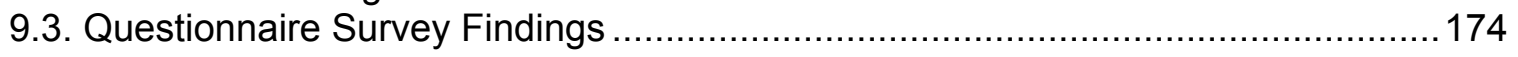

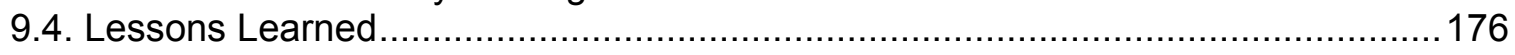

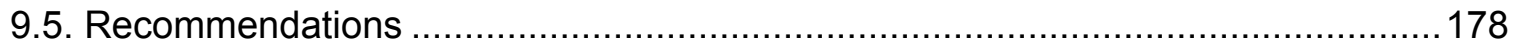

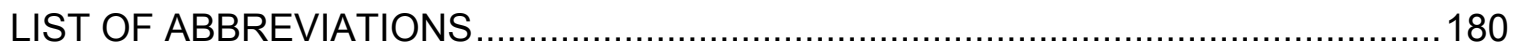

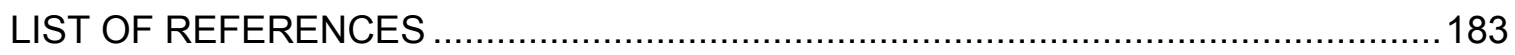

\section{APPENDICES}

Appendix A

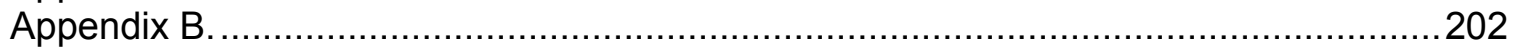

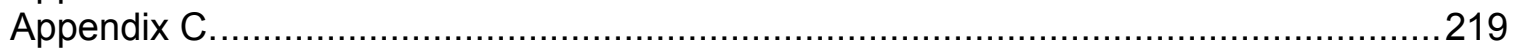

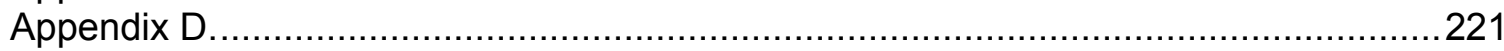

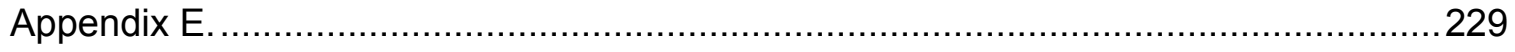




\section{LIST OF TABLES}

Table

Page

2.1 Evidence from Studies of Public Capital Elasticities (Adapted from: Eberts, 2002; Hakfoot, 1996). ....................................................................... 26

2.2 US Case Studies Estimating Economic Growth Resulting from Highway Investments .31

2.3 Evaluation of Data Sources for Economic Impact Analysis (Source: EDRG and CSI, 2001)

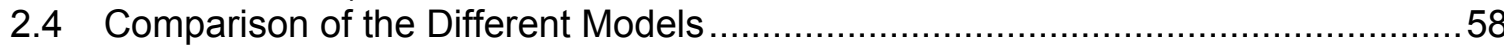

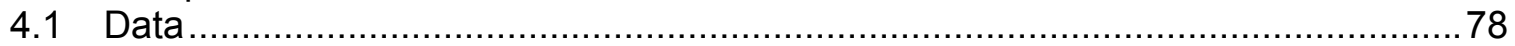

4.2 Classification of Projects by Area and Highway Improvement Type .....................80

4.3 Summary Statistics for Highway Project-Specific, and Location-Specific Variables .85

4.4 Summary Statistics for Highway Project-Specific, and Location-Specific Variables by Highway Improvement Type ..................................................... 88

5.1 Input-Output Economic Multipliers ............................................................ 91

5.2 Summary Statistics for the Short-Term Economic Development Effects of Highway Construction Spending .................................................................. 92

5.3 Summary Statistics for Long-Term Effects of Major Corridor Studies in Indiana ...97

6.1 Duration of Construction by Project Type....................................................... 104

6.2 Unit Values of Travel Time (2003 dollars) (Adapted from CSI, 1998) .................105

6.3 Equations for CPI and PPI (Source: Choocharukul, 2000) ..............................105

6.4 Equations for Fuel and Oil Consumption (Source: McFarland et al., 1993) .......107

6.5 Average Estimates of Truck Weights by Functional Class in Indiana (in thousands Ibs.) (Source: Islam, 2003)...................................................... 108

6.6 Unit Values of Fuel and Oil Costs (2003 dollars) (Adapted from: Choocharukul, 2000) ............................................................................. 108

6.7 Safety Performance Functions including Severity for Highway Facilities in Indiana (Source: Tarko and Kanodia, 2003) ..................................................109

6.8 Crash Costs for Indiana, in 2003 dollars (Source: Tarko and Kanodia, 2003) ....110

6.9 Crash Reduction Factors for Highway Improvements in Indiana (Source: Lamptey et al., 2004; Tarko et al., 2000)........................................................ 110

6.10 Summary Statistics for Economic Development Impacts of Highway

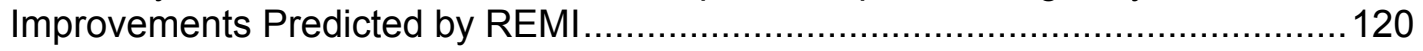

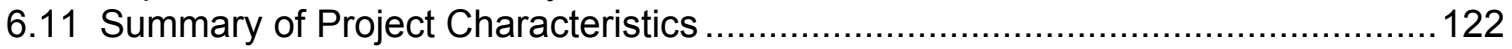

6.12 REMI Estimation Results Associated with Business Expansion ........................123

6.13 REMI Estimation Results, Including Business Attraction ..................................124

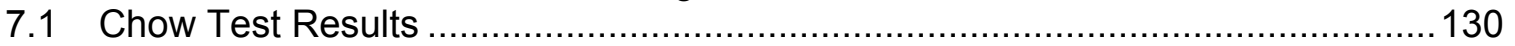

7.2 Summary Statistics for Economic Development Variables Classified by Group of Projects 
7.3 SURE Estimation Results for Highway Investments Involving Adding Travel Lanes (Scenario $4^{*}$ ).....

7.4 SURE Estimation Results for Highway Investments Involving Adding Travel Lanes (Scenario 3*).

7.5 SURE Estimation Results on Economic Development Benefit/Cost Ratios of Added-Capacity Projects (Scenario $4^{*}$ )

7.6 SURE Estimation Results on Economic Development Benefit/Cost Ratios of Added-Capacity Projects (Scenario $3^{*}$ )

7.7 SURE Estimation Results for Highway Investments Involving New Construction-Related Projects (Scenario $4^{*}$ ).

7.8 SURE Estimation Results for Highway Investments Involving New Construction-Related Projects (Scenario $3^{*}$ ).

7.9 SURE Estimation Results on Economic Benefit/Cost Ratios of New Construction-Related Projects (Scenario $4^{*}$ ).

7.10 SURE Estimation Results on Economic Development Benefit/Cost Ratios of New Construction-Related Projects (Scenario $3^{*}$ )

A.1 Summary of State Economic Development Highway Funding Programs and Policies (Adapted from: Weisbrod and Gupta, 2003)

A.2 Summary of State Set-Asides for Economic Development Related Projects (Adapted from: Weisbrod and Gupta, 2003)

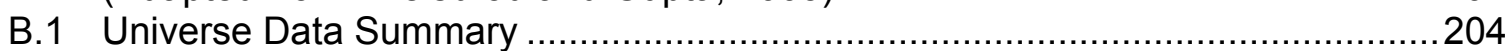

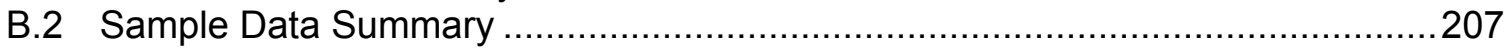

B.3 Indiana Annual Employment, Year 2001 (Source: US Bureau of Economic Analysis Provided by: Indiana Business Research Center, IU Kelley School of Business).

B.4 County-level Location Quotients for Selected Industries in Indiana, Year 2004 (Source: US BLS, 2005).........................................................................211

B.5 Freeway Speeds on an Average Weekday (miles per hour) (Source: Choocharukul, 2000) ...................................................................... 213

C.1 Regression Model Estimation Results for Long term Change in Business Sales (in millions 2001\$) ...................................................................... 219

C.2 Regression Model Estimation Results for Long term Change in Employment .....219

C.3 Regression Model Estimation Results for Long term Change in Real Disposable Income (in millions 2001\$).....................................................220

C.4 Regression Model Estimation Results for Potential Business Attraction (in millions $2001 \$$ in business sales) .......................................................220

C.5 Regression Model Estimation Results for Potential Tourism Attraction (change in annual visitor-days)

D.1 SURE Estimation Results for Highway Investments Involving Adding Travel Lanes (Scenario $4^{*}$ )

D.2 SURE Estimation Results for Highway Investments Involving Adding Travel Lanes (Scenario $3^{*}$ ).....

D.3 SURE Estimation Results on Economic Development Benefit/Cost Ratios of Added-Capacity Projects (Scenario $4^{*}$ ).

D.4 SURE Estimation Results on Economic Development Benefit/Cost Ratios of Added-Capacity Projects (Scenario $3^{*}$ )..... 
D.5 SURE Estimation Results for Highway Investments Involving New Construction-Related Projects (Scenario $4^{*}$ )....

D.6 SURE Estimation Results for Highway Investments Involving New Construction-Related Projects (Scenario $3^{*}$ )

D.7 SURE Estimation Results on Economic Development Benefit/Cost Ratios of New Construction-Related Projects (Scenario $4^{\star}$ )

D.8 SURE Estimation Results on Economic Development Benefit/Cost Ratios of New Construction-Related Projects (Scenario $3^{*}$ ) 


\section{LIST OF FIGURES}

Figure

2.1 Types of Economic Development Impact Mechanisms (Adapted from: Weisbrod, 2000) 15

2.2 Rates of Return Trends US1960-1991 (Source: Eberts, 2002) .........................27

2.3 Approaches to the Analysis of Economic Development Impacts (Adapted from:

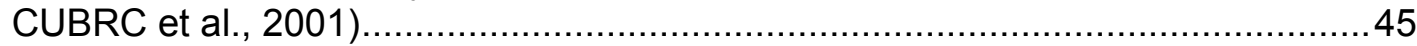

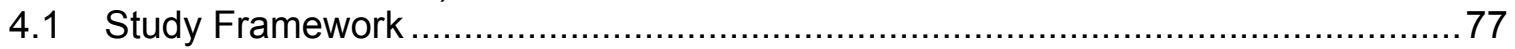

5.1 Regression Analysis Estimates of Long-Term Economic Development

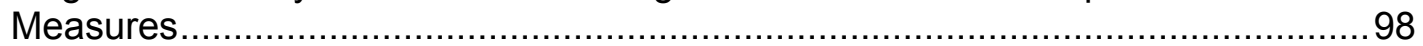

5.2 Regression Analysis Estimates of Potential Business and Tourism Attraction ......99

6.1 User Benefits by Mode, Trip Purpose and Analysis Year (in 2003 dollars) ..........122

7.1 Econometric Analysis Procedure ........................................................... 125

B.1 Indiana Accessibility to Major Airports (Adapted from: CSI and BLA, 2003)......214

B.2 Indiana Accessibility to Employment (Adapted from: CSI and BLA, 2003) ........215

B.3 Indiana Accessibility to Institutions of Higher Education (Adapted from: CSI

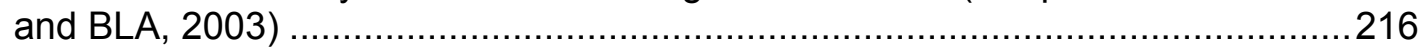

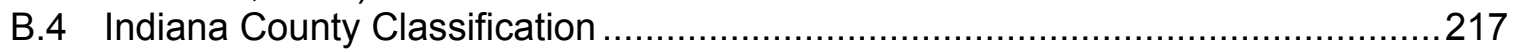

B.5 Indiana Counties Designated as Economic Centers for Transportation Planning

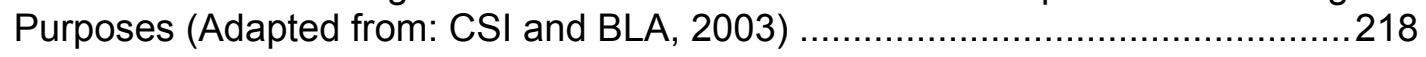




\section{CHAPTER 1. INTRODUCTION}

\subsection{Background}

Transportation planners and decision-makers have long shown concern about how transportation investments and services shape economic development. For large and more complex project in particular (and where the role of public participation is significant), information on the wider economic development impacts of transportation (e.g., changes in the regional industry, commerce, agriculture, and income, etc.) becomes valuable for measuring the total project impacts. Given the aging of the highway infrastructure, increasing demand, uncertainly of sustained funding, and increasing user expectations, the need for balanced decision-making and cost-effective investments have become ever more important. As a result, state transportation agencies continually seek ways of to prioritize alternative investments on the basis of a comprehensive range of impacts including those related to economic development and growth. Moreover, understanding the linkage between transportation investment and economic development offers direct help in identifying cost-effective projects, justifying the value of transportation investment, and could also help point the way to alternative sources of funding. To this context, failure to link transportation investments to various components of the regional economy makes it difficult to incorporate impact assessments into investment planning, programming and budgeting procedures, and may lead to errors in the estimation of impacts (Huddleston and Pangotra, 1990).

The effects of investments in transportation infrastructure-especially highways-on economic development have recently been the subject of more analysis, more discussion, and more interest, including the explicitly stated interest of the US Congress, than at any time in the past several decades. The National Environmental Policy Act (NEPA) of 1969 directed all Federal agencies to make project decisions using a systematic interdisciplinary approach that balances engineering and transportation needs with social, 
economic, and natural environmental factors (FHWA-NEPA). Also, subsequent to the 1998 Transportation Equity Act for the 21st Century (TEA-21), the US Congress has shown increased interest in economic development impacts of projects. TEA-21 contained a provision requiring consideration of economic growth in a large, discretionary program, and recognized economic development as a decision factor in project evaluation. Subsequent conference reports and accompanying appropriate acts designated funding for innumerable economic development projects. In addition, legislation required the FHWA to undertake an economic development highways initiative. During the implementation of this initiative, a substantial number of corridors were studied with proposed highway improvement projects as the focus of the corridor study (Weiss and Figura, 2003).

In response to the federal mandates, several states participate in some type of funding scheme that supports investments that particularly spur economic development, in addition to the basic goal of capacity expansion to meet projected demand. In the evaluation of such investments, project benefits are assessed not only on the basis of expected congestion mitigation or safety enhancement, but also on the basis of anticipated job growth, wage increases, and private investment or local tax base growth (Weisbrod and Gupta, 2003). State agencies such as the Indiana Department of Transportation (INDOT) now routinely consider economic development in project evaluation, listing this decision criterion as a key issue in the long-range plans (CSI and BLA, 2004).

Research on the economics of highway investments suggests that there are economic consequences of either under-investing or over-investing in highway construction. If an agency under-invests in a highway corridor, economic development will be inhibited because real and perceived travel costs will be greater, and competitive position will be hindered. On the other hand, if an agency over-invests in the corridor, overall efficiency will suffer because those funds could have been invested more efficiently elsewhere (other highways could have been built, or existing highways could be maintained at a higher level, etc.). Therefore, there is an economic cost associated with both underinvestment and overinvestment in a highway corridor. Furthermore, limited funds, in view of increasing needs, necessitate careful planning in allocating expenditures for highway construction and maintenance. In this regard, by establishing a significant relationship 
between different types of highway improvements and economic development, the substantial public expenditures required for management of the existing system and its expansion can be better justified (Lombard, 1991).

Of increasing importance is therein how Indiana's infrastructure, and specifically its highways that constitute the major portion of infrastructure investment, can be used to promote economic development. The implementation of such major transportation projects typically result in profound changes in the regional industry, commerce, agriculture and income. However, to date there has not been quantitative approach to establish appropriate weights of the ranking criteria in a prioritization/ranking process. As Indiana embarks on its $\$ 5.2$ billion statewide transportation improvement program, primarily to improve mobility, safety and, according to the state transportation plan ${ }^{1}$, enhance economic growth, an understanding of the potential impact highway investments have on the state's economy is important.

The next section discusses the motivations for the present research study.

\subsection{Motivation for the Present Research Study}

Recent work on the impacts of highway development has been intellectually stimulating to researchers as well as a source of debate within the transportation community. The continuing appeal of highways as economic development tools might give the impression that there is substantial agreement about their likely economic effects. However, understanding of the subject is little, and has been hindered by, among other things, the multitude of other factors that can influence development. Furthermore, the specific nature of the various economic development effects that can be associated with a specific

1 "INDOT has a unique role in sustaining and fostering Indiana's economy and recognizes that policy decisions and transportation infrastructure investments have major effects on economic growth and development. To support economic competitiveness, INDOT will improve upon Indiana's high quality transportation system to reduce the cost of moving people, goods, and freight, connect Indiana with regional, national, and international markets, provide communities with an edge in competing for jobs and business locations, and connect people with economic opportunities" (CSI and BLA, 2004). 
new highway investment is not trivial to address due to the fact that they can vary significantly from project to project depending on highway location, specific economic interests and travel markets served, as well as the highway's impacts on accessibility and systemwide connectivity (EDRG and CSI, 2001). For example, individual highway projects, unless they are of extraordinary scale, are unable to significantly influence a national or multi-state regional economy. Projects that improve local access to employment sites are inherently different from those that improve connectivity between two cities (Weiss and Figura, 2003). As such, a major distinction must be made among projects of different type and purpose. However, to date, research in the US dealing with specific facility type improvements is limited.

Another issue of continuing debate pertains to the long-term benefits of new highway construction and continued highway system expansion. Proponents of new highway investments often cite anticipated benefits such as local or regional job creation, business attraction, and income growth. Opponents often argue that new highway investments at best serve only to redistribute jobs and business activity, and at worst lead to more traffic generation without any real economic benefit to the local area or region. This debate has been further clouded by a "disconnect" between public arguments about the merits of specific highway projects and research studies on the merits of expanding investment in the capital stock of the Nation's highway system. In particular, studies of the general relationship between highway investment and national or regional economic growth are too broad to shed light on the effects of specific individual highway projects, and as such general studies may not be useful for planning and environmental documentation as required by Federal Law (EDRG and CSI, 2001).

Additional significant limitations affecting the ultimate usefulness of economic development impact studies have been reported by transportation planning agencies in a recent survey of state economic development practices (Weisbrod, 2000). One common complaint is that there are difficulties resulting from the inexperience of agency staff, inadequate data, and the complexity of the analysis. To date, new findings and techniques have not resulted in practical tools that are accessible and can be used effectively by stakeholders. In many ways, the stakeholders are not seeking for more complex analytic methods, but rather more complete and understandable analysis tools that are ap- 
plicable to practical policy issues (Apogee Research Inc. and Greenhorne \& O'Mara, 1998). These difficulties hamper effective analysis of the economic development impacts, because they call for increased research effort including additional data collection and special staff training (Weisbrod, 2000).

In this regard, research is needed to build upon previous work and address all the issues and limitations of the current state-of-the-practice on estimating the economic development effects of highway investment.

The research objectives formulated in accordance to INDOT's concerns are summarized in the next section.

\subsection{Research Objectives}

Three particular reasons, for which a study on estimating and documenting the economic development impacts of highway projects in Indiana is warranted, have been identified:

Improved information base: Transportation planners and decision makers continue to seek guidance on issues related to project selection and investment decisions. Policymakers must be equipped with the best information and analysis possible about the interactions among the factors that affect economic development. However, acquiring accurate and comprehensive data on a regular basis is a perennial problem for analysts and policy makers. As such, there is a need for an improved information base that addresses the specific nature of the various economic development effects that can be associated with highway investments. Recent empirical data needs to be collected to document when, and to what extent, a proposed highway investment will result in economic benefits to the communities and regions in Indiana that it serves. These data include transportation system characteristics, population, employment, and economic conditions of the regions included in the economic analysis. 
Justification of the value of highway investment: There is current interest in using investments in expanded highway capacity as a means of furthering economic development objective. There remains a clear need to develop a better understanding of how highway system enhancements can be used as a tool for expansion of job and income opportunities, especially in depressed areas. Information on how various factors, including highway investment, interact to stimulate economic development could be useful at the project development phase to justify the value of investment. The use of this information by Indiana Department of Transportation (INDOT) and regional planning organizations will help inform transportation program and project investments that are intended to advance economic development.

Easy-to-use quantitative tool: Even if an agency has determined that involvement in economic development issues is appropriate, it may lack the funding, staff resources, or technical skills to give the issue full consideration. There are various types of economic data and models in existence, but it can be a complex and expensive process to assemble and apply them in a comprehensive manner. As such, there is a need for more complete and understandable analysis tools that can be used effectively by stakeholders. In particular, there is a need for data collection and analysis approaches for assessing economic development impacts that: (1) INDOT staff can understand and feel confident, and that are sufficiently complete and comprehensive to be publicly credible; (2) can be shown to be consistent with generally recognized findings and methods being used elsewhere, and (3) can be obtained and used in-house at a reasonable cost (Weisbrod, 2000).

The contribution and anticipated benefits of this study are discussed next.

\subsection{Anticipated Results}

This study intends to provide a useful and easily usable quantitative tool that can be used at the project development phase to estimate the statewide long-term economic effects of highway investment in Indiana. The investment scenarios are based on improvements identified in the 2025 Statewide Transportation Plan (CSI and BLA, 2004). 
The improvement types that will be considered include: added travel lanes, median construction, new interchange construction or modification, new alignments and bypass projects. Some of the reasons why a statewide study was selected instead of regional ones include the following: transportation funding starts at the state level; even localized impacts can have statewide implications, and overall, a statewide study can provide a more comprehensive view of the economic benefits of transportation. Short-term impacts (which mainly include construction jobs and the secondary impacts of construction) will be also estimated. However, these impacts are viewed as not contributing to sustainable growth. As such, a quantitative valuation study on the short-term effects of highway investment cannot identify the most efficient allocation of resources

Traditionally the estimation of economic development impacts of highway construction spending has been conducted with the use of Input-Output models without distinguishing between different types of highway improvements. As such, output, income, and employment multipliers for different highway improvement categories have not been calculated that would facilitate a project-level economic impact analysis. Furthermore, other deficiencies in traditional economic multiplier approaches require other analytical forms to be devised. Notably, among these forms have been econometric models such as macroeconomic regression models. These models have been used extensively for analysis of national economies and have compiled credible forecasting records (Glickman, 1977). A more detailed multiplier analysis using rigorous econometric techniques will assist INDOT staff to have in-house capacity to conduct economic effects estimation of individual highway projects given data constraints, staffing expertise, available time, and other practical limitations.

The results of this research study can be used in a number of ways to inform studies of planned or proposed projects, as follows:

Measurements of highway-related economic impacts, in a range of highway improvements and using project-level data and econometric methods, will expand this existing knowledge base and provide a more credible foundation for making highway investment decisions based on sound economic development criteria. INDOT Pre-Engineering staff 
will be able to use the results as multipliers to estimate cumulative economic impacts of given types of highway projects.

The estimates of the potential economic development effects of different types of highway projects with different project and location attributes can provide the groundwork to develop a scoring system for ranking alternative highway projects. A highway project prioritization/ranking process could assist INDOT to make comparisons of benefits and costs and select projects that have a strong potential to support economic development, among other factors (i.e., safety, mobility, and sustainability).

This study will also help planners better understand how various factors, including highway investment, interact to stimulate economic development. The results can be used to improve the judgment of planners and decision-makers as to when, and to what extent, a proposed highway investment will result in economic benefits to the communities and regions that it serves. In this context, the final product of this study can demonstrate the value of investing in transportation corridors to support economic growth and identify the most efficient allocation of resources, given funding mechanisms in place.

This research will also make an important contribution to extend previous work and build upon the findings of previous work in Indiana (Lombard et al., 1992). That study was undertaken to investigate the relationship between highways and economic development in Indiana, using cross-sectional multiple regression analysis of data from 1980 through 1988. The present research will study the economic development effects of different types of highway projects programmed for the State of Indiana, in a bid to address the limitations of prior research that are summarized below:

i. The study (Lombard et al., 1992) investigated the relationship between highway investment and county-level economic development without distinguishing between different types of highway improvements.

ii. The models were based on the data for relatively short period and were subject to specific economic changes in Indiana's history. 
iii. That study was conducted more than 10 years ago. The models only provide estimates of previous trends; they may not necessarily hold for future years.

iv. Highway expenditures that were included in the models as an explanatory variable were related to both capital and major maintenance projects funded by the federal or state governments. Therefore, the effect of only capital project improvements on economic development cannot be isolated from the aggregate results of that study.

Finally, the present research can enhance the on-going work at INDOT by serving as a complement to the economic development analysis conducted with the use of the Major Corridor Investment Benefit Analysis System (MCIBAS). MCIBAS was developed for the Indiana Department of Transportation (INDOT) to help evaluate effects on the economy of the state and subregions by assessing the relative costs and benefits of proposed major highway corridor projects. It consists of a traffic impact simulation model, a user benefit/cost analysis processor and an integrated economic impact analysis system. This research can build upon the economic impact analysis component of MCIBAS. The available economic analysis software packages will be evaluated for use in the MCIBAS process, in terms of their usefulness (types of output, flexibility in use and data requirements) and associated cost.

\subsection{Report Organization}

The research starts with a comprehensive literature review to ascertain the nature of past methodologies used in similar past research, and key findings. The main research objective is to investigate the relationship between long-term economic development, project attributes and location attributes using data for highway projects programmed for the State of Indiana. The analysis involves three main stages: first, determining which factors are important and how they can be measured; second, obtaining data at a geographic scale consistent with the economic variables; third, estimating the long-term economic development effects of different types of highway projects; and last, developing the analytical methodology to include multiple variables so that it can be used effec- 
tively by stakeholders. As part of this research study, the available economic analysis software are evaluated for potential use in the MCIBAS process. The present research also addresses how economic development is addressed across states and describes the existing highway-related economic development programs or policies operated by state transportation agencies. The final step of this research study involves the documentation of the results and conclusions as to the relationship between different types of highway investment and long-term economic development, with specific reference to the State of Indiana. Directions for future research are also identified. 


\section{CHAPTER 2. LITERATURE REVIEW}

\subsection{Concepts}

\subsubsection{Economic Development}

Economic development encompasses a range of objectives and concerns centered on goals of enhancing an area's base of jobs, income and business activity (where desired). There is a critical (but sometimes missed) distinction between the study of economic development impacts and the broader economic analysis of a project or program (Weisbrod, 2000):

Economic development impacts relate specifically to development of the economy of an area and the flow of dollars (or number of jobs) in that economy. These are impacts on the level of economic activity in a given area, and include changes in jobs, wages, and business output resulting from monetary effects of transportation on income and costs for households and businesses. Economic analysis, in contrast, can encompass any elements of benefit and cost to society (or subsets of society). It can include the impacts on transportation system users, on the environment, and on the quality of life, as well as economic development or business-related impacts.

Therefore, economic development impacts are just one part of the broader subject of economic analysis. It is also important to point out the fundamental distinction between economic development and economic growth. Economic growth takes place when the quantity of output is increased, while economic development is the process through which the quality or nature of the output is also enhanced (CUBRC et al., 2001). 


\subsubsection{Measures of Economic Development Impacts}

According to Weisbrod and Weisbrod (1997), there is a wide variety of overlapping measures used to measure economic impacts. The following four categories are identified:

- User Impacts: Components of user impacts (such as money cost of travel, travel time, safety, and comfort/reliability) are used to determine the value of user impacts, and are combined to measure total user benefit.

- Economic Impacts: The following basic measures of potential economic impacts of transportation projects have been identified (Weisbrod, 2000; EDRG and CSI, 2001):

i. Regional output;

ii. Gross regional product (GRP) or value added;

iii. Jobs;

iv. Wages and other income;

v. Number of businesses;

vi. Business volume and sales;

vii. Population;

viii. Private investment in buildings, plant, and equipment; and

ix. Real estate values.

- Government Fiscal Impacts, including public revenue and public expenditures.

- Other Societal Impacts, including air quality, other environment conditions, and social conditions. 
It is worth mentioning that US DOT has identified a new economic indicator the Transportation Services Index (TSI) designed to measure the performance of the economy as reflected in the movement of freight and passenger traffic by land, water and air. TSI is a single seasonably adjusted index of the month-to-month changes in the output of services provided by for-hire transportation industries. Changes are measured against the base year 1996. This index can be examined together with other economic indicators to produce a better understanding of the current and future course of the economy in terms of transportation-related activities. The movement of this index over time can be compared with other economic measures to understand the relationship of changes in transportation output to changes in Gross Domestic Product (GDP) (US BTS, 2004).

\subsubsection{Measurement Issues}

\subsubsection{Types of Economic Development Impact Mechanisms}

All the above-referenced impact measures can reflect different types of economic impacts. The economic impacts of transportation projects can be broadly classified into direct, indirect, induced, and dynamic economic impacts, as follows (Forkenbrock and Weisbrod, 2001):

- Direct Economic Impacts: The user benefits offered by transportation projects such as reduction in travel time and operating costs typically lead to reduction in business costs and increased productivity. The businesses in the region also benefit from improved accessibility to suppliers, customers, labor and other markets. This can lead to business growth for both users and non-users in the region. New businesses may be attracted in the region giving rise to increased opportunities for job choices. These changes may also attract tourists in the region.

- Indirect Economic Impacts: Indirect benefits of transportation projects refer to the increased purchases by the direct beneficiaries of the investment. For example, a transportation investment may offer direct benefits to a manufacturing company in the region, but indirect benefits will be accrued to suppliers of the manufactur- 
ing company and also to the manufacturers' employees who would benefit from increased wages.

- Induced Economic Impacts: Increased wages of the people in a region may induce them to spend more. This would lead to induced benefits by the businesses that provide food, clothing, and other consumer services in the region.

- Dynamic Economic Impacts: These refer to long-term changes in population and business location patterns, and resulting land use changes. These changes will in turn affect income and wealth in the area.

The sum of all the aforementioned effects represents the total effect on economic growth. The ratio of the (total effect/direct effect) is commonly referred to as an "economic multiplier," and the various non-direct effects are sometimes grouped together and referred to as "multiplier effects". Typical economic multipliers include output, employment and income multipliers. Their magnitudes vary depending on the type of transportation investment in which spending occurs and the size of the area economy. As a rule of thumb, the output multiplier values for most transportation investments are in the range of 2.5-3.5 for national impacts, $2.0-2.5$ for state impacts and 1.5-2.0 for local area impacts (Weisbrod and Weisbrod, 1997). For example, if a $\$ 250$ million highway improvement takes place along a corridor it can be expected that the net impact on the total level of economic activity in the study area may be increased by $\$ 375-\$ 500$ million.

Guidance for estimating the indirect effects of proposed transportation projects is offered in NCHRP Report 403 (1998). Weisbrod (2000) cautions that the estimation of multiplier effects is most relevant, when the study area is a region with idle or underutilized workers and resources, or a region with a potential ability to attract more workers or resources. Figure 2.1 illustrates the functional interrelationships of these different types of economic development impacts. 


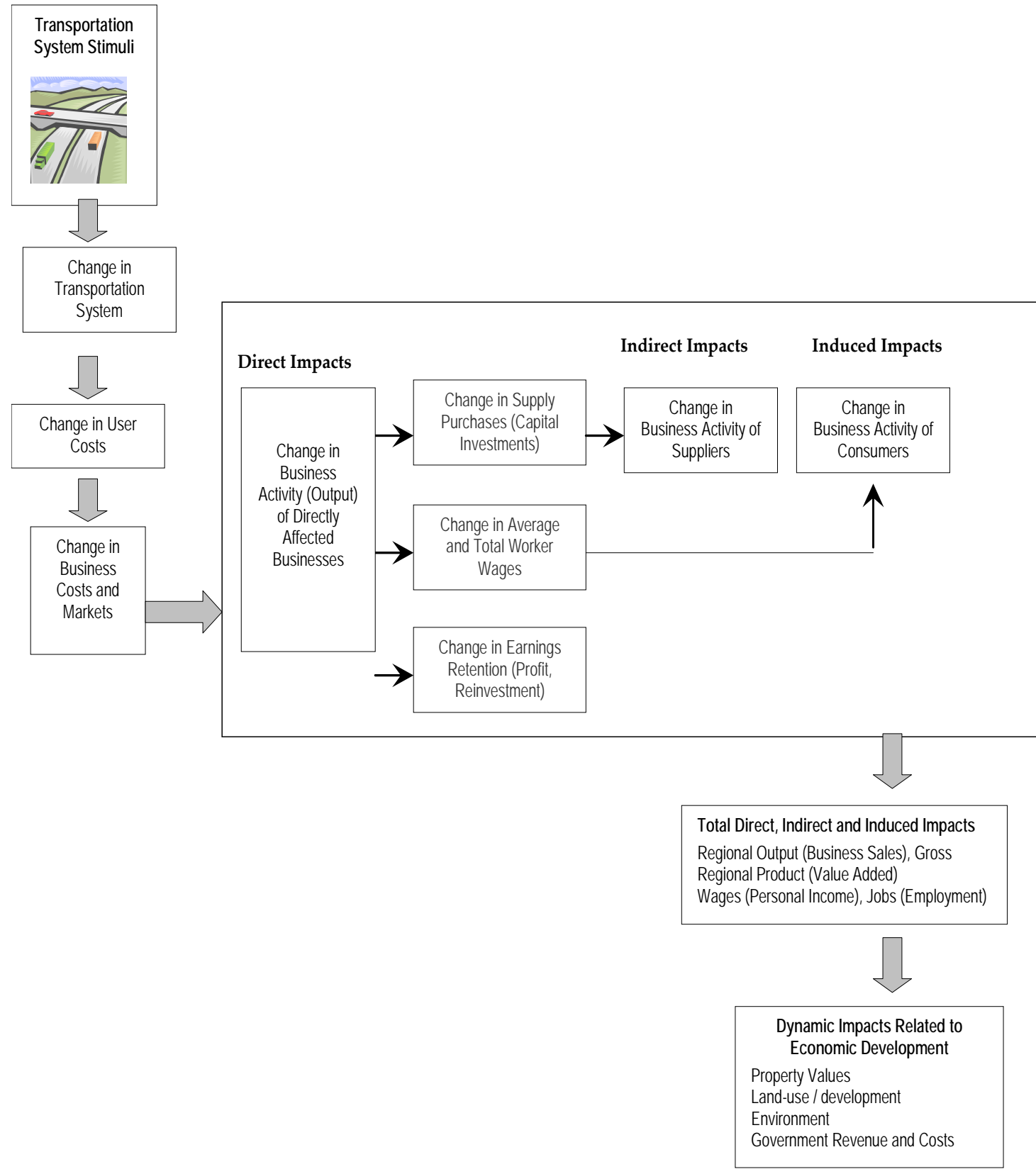

Figure 2.1 Types of Economic Development Impact Mechanisms (Adapted from: Weisbrod, 2000) 


\subsubsection{Selection of Appropriate Measures of Economic Development Impact}

Although there are several alternative measures of economic development impact, transportation planning agencies may not have to examine all of them, but may instead focus on one or more of such measures as to suit for their needs. In this regard, it is important to understand the advantages and disadvantages of the various indicators for measuring changes in economic activity. The use of multiple indicators provides for a more thorough and robust understanding of economic changes, and can help to identify any structural changes in the mix of economic activity. In the selection of an appropriate impact measure there are several factors to be considered, including: (1) information available, (2) usefulness for public information, and (3) usefulness for decision-making (Weisbrod, 2000). The selection of appropriate impact measures should also consider the purpose of the highway project (e.g., to promote economic development, reduce congestion, or address the special concerns of specific groups or areas) as well as the type of project and impact area (EDRG and CSI, 2001).

Furthermore, various types of economic impacts may occur at different geographic scales (Forkenbrock, 1990). For instance, employment markets are often described as regional, and employment impacts are most often measured at the county level. In contrast, real estate markets are often described as subregional, and property impacts are most often measured in terms of individual properties, blocks, or neighborhoods. As a result, the scale and nature of the highway project may very well affect the type of data that is most relevant or available, as well as the total impacts measured. The larger the area, the more likely that location movements of businesses will be seen as "internal retributions" of activity within the area rather that as "new" activity (Weisbrod, 2000).

Measuring economic impacts can be challenging and be subject to several sources of error. All the above-referenced measures of economic development impact are interrelated and basically represent different ways to view aspects of the same economic growth. For that reason, the different impact measures such as business output, wages, investment, and property values, cannot be added without double-counting that may lead to unrealistic estimate of the magnitude of overall effects. To avoid doublecounting, many researchers recommend that only one measure should be used to assess the total economic benefit (Weisbrod and Weisbrod, 1997). Some evaluations of 
particular transportation projects also cite jobs created, or the economic activity resulting from the construction of the project, as benefits of the project. A comprehensive discussion on measuring and avoid double-counting transportation improvement benefits, as well as on the nature of job creation is offered in Mohring (1993). However, experts argue that job creation from transportation spending would only be a true benefit if the person getting the job would otherwise be unemployed, and thus the reduction in unemployment benefits could be considered a benefit of the project. Nonetheless, local decision makers generally view such expenditures as producing benefits for their jurisdiction (GAO, 2005).

\subsection{Highway Infrastructure and Economic Development}

Early research on the relationship between highway transportation and economic development, which dates from the 1960s, focused largely on economic and demographic changes occurring after the construction of a section of interstate highway. Research since 1980 , on the other hand, has begun to explore the link between highway transportation and economic development, not simply economic change. However, the research in this field is often contradictory. From a position where transportation investment was often seen as an example of unproductive public sector investment likely to hinder growth by crowding out investment out of the more productive private sector, the 1990s introduced a number of studies which, by various methods, claimed substantial growth impacts (Quinet and Vickerman, 2004). Clearly, major highway system changes promote change in local and regional economies (Baird and Lipsman, 1990). Public infrastructure is also found to have a positive impact on investment and employment growth (Aschauer, 1989). Moreover, some of the recent studies argue that transportation investment has also raised the long-term rate of economic growth (Jacoby, 1999). Nevertheless, past research cautions that a highway project generates benefits only to the extent that it produces transportation cost savings in excess of its construction, operation, and maintenance costs (Forkenbrock et al., 1990).

This recognized link between transportation and economic development continues to justify significant public expenditures in transportation systems at the local, state, and federal levels. Nevertheless, not all the intuitive relationships are analytically estab- 
lished. In fact, it is difficult to quantitatively link such investments to national or regional growth, economic development, industry or national productivity, growth in economic welfare; or the nation's competitiveness in the international market (Smith, 1994). Some of the issues that have been identified and make the conceptualizing of infrastructure and economic development links difficult are discussed next.

\subsubsection{Issues on the Highway Investment/Economic Growth Relationship}

The relationship between highway investment and regional economic growth is a complex one, not easily summarized by appealing to one regional economic theory or another. A reason for this is that the complexity of most regional economic systems makes it difficult to isolate the influence of only one variable such as a new highway investment. While some economic models and techniques may do a better job of attribution than others, it is unlikely that any approach can establish the causal relationship between transportation investments and economic development with absolute certainty (Huddleston and Pangotra, 1990).

In addition, transportation infrastructure has both spatial and economic properties (Rephann and Isserman, 1994). Highways have effects on two spatial scales: the local and the regional. The linkages between physical infrastructure and those that use it are more direct when the analysis focuses on smaller geographical areas (Eberts, 1990). The larger the area (e.g., a state or nation as compared to a county) the more likely that impacts (such as the location movements of businesses) will be seen as an internal redistribution of activity within the area rather than a generative, new activity. Generative impacts occur when a transportation investment catalyzes regional economic growth that would not have occurred somewhere else in the state. Redistributive impacts occur when a transportation investment merely shifts economic activities from one region of the state to another. Basically, the business transactions would have occurred regardless of the transportation investment, but in a different location. In the latter case, although there may be growth at the subregional level, no net economic growth has occurred when measured at the state level. Nevertheless, distinct economic development impacts can be observed resulting from transportation projects at the firm, region (or state), and national levels (CUBRC et al., 2001). 
Another important consideration is an estimate of the potential for development in the area of a proposed project within a reasonable period of time. The estimate should recognize the potential both with and without the project. In areas experiencing little growth over time, an individual highway project will likely have a negligible contribution to a cumulative impact because of the absence of other activities occurring in the vicinity. Conversely in areas of moderate to rapid development, the contributions of a highway improvement can be a measurable element of the aggregated change leading to long-term impacts. In addition, new access into undeveloped locations can contribute to subsequent development activity (FHWA, 1992).

Because of the multifaceted nature of highway investment and its disparate causal links with economic growth, its influence is frequently broken down into components to facilitate analysis. Previous empirical studies tend to focus on three dimensions: (1) differences in highway effects occurring over time, (2) differences in highway effects by industry, and (3) differences in highway effects by region. Typically, in investigating the temporal effects of highway investment, researchers divide the study period into construction (short-term) and post-construction stages (medium- and long-term). During the construction stage, a region experiences an exogenous boost in construction expenditures, which is sustained over a few years until the project is completed. During the post-construction period, the construction stimulus is largely removed. Post-construction economic effects are more difficult to assess. Most studies have confined their evaluation periods to two decades after construction or less. One view is that the effects are immediate; another view is that they are realized after a lag of several years. Lags between four and seven years have been estimated empirically (Rephann and Isserman, 1994). In the long-run, what actually happens depends on the relative scarcity of land, labor and capital (Flyvbjerg et al., 2003).

Beyond the economic impacts of transportation investment associated with various phases of a project, the relative maturity of the transportation system also needs to be considered. The introduction of new transportation infrastructure into an area with a less developed transportation system will have a larger impact than a transportation project introduced into an area with a mature system. Impacts will be marginal in the latter scenario (CUBRC et al., 2001). Findings from the work (Nadiri and Mamuneas, 1998) that examined the development of the federal highway network corroborate that observation. 
The study estimated that highway infrastructure investments made during the 1950s through the 1970s had a larger economic impact than those made in the 1980s. It is suggested that this decrease may be attributable to the highway network becoming more comprehensive and dense in its coverage. In other words, post-1980 investments represent smaller or more incremental parts of a larger, mostly complete system. Follow-up research work also corroborates the notion that returns on highway investment have been declining over time (Mamuneas and Nadiri, 2003).

Furthermore, the distribution of highway effects varies by industry. Most industry research focuses on three sectors: manufacturing, retail trade, and services (Rephann and Isserman, 1994). Whereas most information is available on how location decisions work for the manufacturing sector, little is known about the other industries (Voytek and Ledebur, 1997).

Finally, the potential for secondary effects, and thus the need to conduct specific analyses to determine the possibility of impacts also depends upon the type of project being proposed. Capacity improvements, additional interchanges and construction on new location generally have a greater potential for indirect effects than projects to upgrade existing facilities (FHWA, 1992). As such, it is recognized that the economic impact of any particular project is still best evaluated on a case-by-case basis (McQuaid et al., 2004). However, questions remain as to how differing types of transportation investment affect economic development.

\subsubsection{Empirical Evidence}

Recent and past findings concerning the impact of investment in highway infrastructure and the overall effects of transportation on industries' output and location decisions, economic productivity, employment and income growth are summarized below.

\subsubsection{Public Infrastructure and Business Location Decisions}

The quantity and quality of public infrastructure may attract new businesses and induce existing businesses in an area to stay or to expand. Transportation can affect business 
location through: goods' transport financial costs; relative time costs and savings; certainty/reliability of travel time; the need to physically meet customers and suppliers; and finally, staff and customer travel costs (McQuaid et al., 2004). Transportation investment may help solidify an existing advantage or compensate for a disadvantage related to some other locational criteria, such as taxes or labor costs (Blair and Premus, 1987). Locations that can effectively lower business costs may develop a competitive advantage over regions unable to offer a similar savings in business costs (Arsen, 1997). From a macroeconomic perspective, state and metropolitan economies may be affected positively or negatively by shifts in production and warehousing facilities, depending on their competitive advantage.

Literature on business location decisions also reveals that business sensitivity to transportation differs by type of business. However, once a certain level of accessibility has been achieved, further transportation investments may have little or no additional value to a business (Weisbrod, 2000). Forkenbrock and Foster (1996) suggest that highway investment is most relevant "when all of the other critical factors already exist in an area (e.g., cost-effective labor, natural resources, other infrastructure), but transportation access is a problem. In such cases, a transportation investment amounts to adding the last critical ingredient needed to make the area viable." A recent study (Hodge et al., 2003) examining the potential of business attraction in the North County, New York region as a result of a new transportation facility corroborates previous findings that "while a new transportation facility alone will not guarantee economic success, it is a vital foundation to improve existing conditions." In this context, transportation appears as a necessary, but not sufficient condition for generating economic development (Huddleston and Pangotra, 1990).

Kriesel and McNamara (1990), using as case study 158 counties in Georgia from 1986 to 1988 , applied an ordered, multiple-category logit model to investigate the probability that a manufacturing plant would be attracted to a community. The miles of interstate in a county were found to be positively and significantly associated with decisions of plants to locate there. However, highway access was found not to be a primary factor in overall location decisions in many industries. To the extent that the highway system has reached a mature stage of development and provides good access to a large number of 
business locations, transportation access is a far less compelling argument in business location decisions.

Another example is the road link (A14) between the A1 and M1 motorways in the U.K that is reported to have saved 30-35 minutes on journeys accessing the motorway network. Since completion of this road link, industrial and commercial development within seven miles of the road increased by 470 percent, although this includes expansion of existing companies. However, it is not clear how much of this was influenced by changes in planning policies as well as increased demand (McQuaid et al., 2004),

Gillis and Cassavant (1994), cited in McQuaid et al. (2004), in a study in East Washington state, found that the availability of good road freight opportunities is the most significant factor in the development of a location. Specifically, they found that investment in highway infrastructure that facilitates increased or more efficient freight movements is a key in the location values to light industrial and commercial businesses. Also, they argue that airfreight has an increasing impact on the development of some areas of manufacturing.

Finally, econometric and survey studies of firms' location decisions suggest that firms have become much more "footloose" over the past 40 years (Hartgen et al., 1990; Forkenbrock and Foster, 1996). Case studies in AASHTO (1990) reveal that there is a clear interaction between high technology and transportation. Technological changes and their resulting effects on the number and organization of businesses and the number and kinds of products can generate major indirect or second-order effects on industry location and transportation choices. For example, new businesses associated with ecommerce have grown disproportionately in areas with strong existing industrial concentrations; a fact which provides evidence on the importance of increasing returns and access to skilled workers (Cortright, 2003).

\subsubsection{Public Infrastructure and Productivity/Output Gains}

Estimates at the national and state levels suggest a positive relationship between all public infrastructure investment and economic productivity gains. There is a chainreaction effect that links transportation improvements to a series of productivity gains 
that can affect the structure of how firms do business (AASHTO, 1990). In response to public infrastructure, businesses modify processes to increase labor and total factor productivity. As efficiency improves, unit costs decline and firm profits grow.

Since the late 1980s, a large number of production or cost functions studies have been carried out. Table 2.1 shows the elasticity of output with respect public capital from a range of prior studies conducted at the state or national level. Costa et al. (1987) employed a flexible production function and state level data to develop output elasticities for the public sector: 0.19 for manufacturing, 0.26 for non agriculture, and 0.2 for all sectors. This implies that, for instance, a one percent increase in spending on highway infrastructure led to 0.19 percent increase in manufacturing output. Eberts (1990) found that public capital stock makes a positive and significant contribution to manufacturing output; however, its output elasticity of 0.03 is small relative to the magnitude of the other inputs: 0.7 for labor and 0.3 for private capital.

An econometric analysis at the state level cited in Smith (1994), as part of a FHWA research program, indicated that for a one percent increase in highway capital stock, gross state product will increase by 0.121 to 0.127 percent. In a study conducted in Indiana (Smith, 1997) that examined the effect of public capital stock and its components on state output in Indiana, the output elasticity of public capital was found to be lower. An elasticity of 0.070 is reported, meaning that a 10 percent increase in the highway capital stock produces a 0.70 percent increase in gross state product.

A 1996 study by the Florida Transportation Commission and Floridians for Better Transportation examined the importance of transportation to the Florida economy. The report found that for every additional dollar invested in public capital, Florida's gross state product (GSP) grew by $\$ 0.35$, for a 35 percent return on investment. This analysis included all modes of transportation (plus non transportation public capital) and was performed using a production function, multiple regression methodology. In addition, in an analysis on highway performance, conducted using the Highway Economic Requirements System (HERS), it was found that investments to maintain current levels of highway conditions (e.g., level of service) result in $\$ 2.86$ in direct user benefits for every dollar invested. Another study at the state-level focuses on the economic impacts of highway spending in Maryland from 1982 to 1996 . The study found that highway invest- 
ments were responsible for almost 10 percent of Maryland's productivity growth between 1982 and 1996 (CSI and EDRG, 2005).

To this point, no model had included a method of finance for public infrastructure. Rudd (2000), cited in Baird (2005), estimated a general equilibrium model using public capital disaggregated into various components for a single cross section (1980) of 40 SMSAs. It was found that total SMSA capital stock was productive with an imputed output elasticity of 0.08 . Highways alone contributed significantly to output with an elasticity of 0.07 . The individual effect of road investment on productivity was estimated in a French study (Fritsch and Prud'Homme, 1997), cited in Quinet and Vickerman (2004), using crosssection data across the 21 regions in France. It was found an elasticity of regional GDP to highway infrastructure of the order of 0.08 to 0.10 . The productivity impacts of different types of infrastructure spending were investigated in Boarnet (1997), as cited in Baird (2005). Noting that if infrastructure is productive, it is so because of the service it provides (mobility, in the case of highways), Boarnet (1997) examined the differential impact of increasing the size of highway stock (i.e., expanding capacity) versus using the existing highway network more efficiently. Using California county data in a CobbDouglas production function that included a congestion variable, Boarnet (1997) determined that "transportation policies should focus at least as much on reducing congestion as on building more street and highway capital."

At the national level, studies on the economic effects of national transportation spending (sponsored by the federal government or national organizations) have focused largely on the national productivity impacts of transportation investment. Estimates of the impact of all public investment on national output, using production function methodology, have ranged from the extremes of highly positive to marginally negative. Although the majority of studies have indicated a positive relationship, the specific magnitude of that relationship is heavily debated. The high extreme suggests that a 10 percent increase in public investment will yield (roughly) a 4 percent increase in national output (Keane, 1996). In general, national-level productivity estimates of transportation investment tend to be higher than state-level estimates (Moomaw et al., 1995).

Using aggregate national data, Aschauer (1990) obtained an output elasticity of 0.39 for all non-military public capital, and 0.24 for "core" public capital (highways, airports, utili- 
ties, mass transit, and water and sewerage systems), implying that increased government intervention, through increased public capital, actually increased productivity in ways greater than previously thought. Munnell (1990a) used data extending from 1948 and 1987 and reported results similar to Aschauer's. Interestingly, using panel data Munnell (1990a) found that the output elasticity of public capital is less than one-half as large as the time series results ${ }^{2}$.

Other empirical evidence suggests that highway capital contributes significantly to the Nation's economic productivity (output elasticity of 0.08 ), though at about half the rate of private capital (elasticity of 0.16 ), and less than a quarter the rate of labor (elasticity of 0.37). The elasticity figure for transportation can be interpreted to mean that a one percent increase in highway investment triggers a 0.08 percent annual increase in national output (Jacoby, 1999). Another study (Fernald, 1999) found that when growth in highways (the largest component of infrastructure) changes, productivity growth changes disproportionately in US industries with more vehicles. The finding that vehicle-intensive industries benefit more from highway construction seems to suggest that highways are productive. The author also concluded that road-building explains much of the productivity slowdown through a one-time, unrepeatable productivity boost in the 1950s and 1960s, caused by the interstate system construction.

2 These two studies came under much criticism from observers who had earlier claimed that excessive government intervention in the past had lowered productivity. Objections to Aschauer's and Munnell's findings include the assertion that production inputs and outputs both tend to grow over time and analysis of such data may lead to spurious relationships. A comprehensive review of the debate and critique of the "macroeconomic approach" introduced by Aschauer is offered in Gramlich (1994), and Kulash (1997). 
Table 2.1 Evidence from Studies of Public Capital Elasticities

(Adapted from: Eberts, 2002; Hakfoot, 1996).

\begin{tabular}{|c|c|c|}
\hline Geographic Level & Elasticity Estimate & Study \\
\hline National & 0.06 & Ratner (1983) \\
\hline National & 0.39 & Aschauer (1989) \\
\hline National & 0.34 & Munnell (1990a) \\
\hline National & 0.40 & Keane (1996) \\
\hline National & $0.04-0.08$ & Nadiri and Mamuneas (1998) \\
\hline National & $0.08^{a}$ & Jacoby (1999) \\
\hline State & 0.20 & Costa et al. (1987) \\
\hline State & 0.17 & Eisner (1991) \\
\hline State & 0.15 & Smith (1990) \\
\hline State & $0.121-0.127^{a}$ & \multirow{2}{*}{ Duffy-Deno and Eberts (1991) } \\
\hline Metro areas & 0.08 & Eberts (1986) \\
\cline { 2 - 4 } & $0.037-0.11^{b}$ & \\
\hline Metro areas & 0.03 & \\
\hline \multicolumn{2}{c}{ anly highway investment is considered. } \\
bersonal income per capita elasticities.
\end{tabular}

Nadiri and Mamuneas (1996), under FHWA sponsorship, developed an econometric model of the influence of highway capital investment on firms' productivity and costs, and applied this model at both the detailed industry and economy-wide levels to estimate significant economic returns from highway investment. The results suggest that investments in highways have a strong effect on productivity. Using an extensive data set that included 35 sectors of the US economy over roughly four decades (1950 to 1989), Nadiri and Mamuneas (1996) calculated an overall output elasticity of 0.05 , and a 28 percent return per year for total highway capital. A subsequent FHWA-sponsored study (Nadiri and Mamuneas, 1998) expanded the previous model to include benefits from the reductions in product prices and increased consumption that result when lower production costs are passed through to consumers. Using this more comprehensive model of highway investment benefits, it was concluded that economic returns to highway investment were very high (perhaps exceeding 50 percent) during the 1960 s, but subsequently declined to approximately the average rate of return on private capital (16-17 percent) during the 1980s; a trend that may reflect the maturing of the US transportation system. Likewise, the productivity contribution of transportation investment has dropped steadily since the 1950s (elasticity slid from 0.15 in 1950 to 0.03 in 1991) (Jacoby, 1999). Recent research into the relationship between productivity, economic growth, and highway investment also supports the notion that returns on highway investment have been declining over time. The study shows average annual returns on investment of 13.6 per- 
cent between 1990 and 2000, slightly greater than the return on private capital investment (Mamuneas and Nadiri, 2003). Figure 2.2 offers a comparison of the estimates of the rates of return for private and public capital in US industries over time (1960-1991).



Figure 2.2 Rates of Return Trends US1960-1991 (Source: Eberts, 2002)

Much criticism have been leveled at productivity studies, particularly those using production and cost function frameworks. These studies typically do not take into account the intensity of use of transportation systems. Treating all transportation systems as if traffic flows are the same could potentially lead to biases in the estimates of the productivity of the transportation infrastructure. Moreover, it is argued that current production/cost function analyses do not incorporate the spatial correspondence, nor do they encompass system-wide effects (Eberts, 2000). In addition, there are problems of reliability of the data used and the method applied. For example, time series data analysis cannot separate the effects of supply and demand, and notably the effects of the short-run multiplier. As such, public investment is frequently the consequence rather than the cause of growth (Quinet and Vickerman, 2004). Therefore, Eberts (2000) suggests that the direction for the future is to build models that can provide this more comprehensive view while preserving the spatial correspondence between transportation infrastructure and economic activity. 


\subsubsection{Infrastructure Investment and Production Costs}

Infrastructure is found to be significant in reducing the cost of production, as transportation improvements lower distribution costs, allow the shrinking of inventory, and improve firms' access to labor. It was found that the rate of return for infrastructure investments for use in 12 US manufacturing industries for the years 1956 through 1986 ranges between 4.6 and 6.8 percent (Nadiri and Mamuneas, 1991). However, it is suggested that the rate would most likely be greater if all industries were included in the analysis (Bell and McGuire, 1997). A FHWA study "Industries Studies of the Relationship between Highway Transportation and Productivity" (1993), cited in Smith (1994), indicates that in the first year, a 6.6 percent rate of return accrues to the manufacturing sector as a whole, due to highway investment. Results for the economy as a whole may be even higher when other sectors of the economy are incorporated into the analysis since results for specific sectors of the economy will be additive.

A more recent study by Nadiri and Mamuneas (1998) on the impact of infrastructure investment on production costs for various industries showed that over the period 19471991, US industries realized production cost savings averaging 29 cents annually for every dollar invested in highways or alternatively, the costs of doing business decrease by approximately four percent for every one percent increase in highway capital stock. The reduction in production costs resulted in output expansion in the studied industries.

Highway investment is also a significant factor in long-term changes production technologies and processes. An increase in highway capital has been found to result in a drop in the demand for labor and materials (demand cross-elasticities of -0.02 and -0.01 , respectively) by enabling production reductions in locations where these inputs are less efficient. However, these increases in productive efficiency can also stimulate the demand for private capital (cross-elasticity of 0.06 ) as a substitute for labor. Increases in private capital investment can subsequently lead to business expansions and economic growth (Jacoby, 1999). 


\subsubsection{Private versus Public Sector Investment}

Several fundamental public policy questions were raised, most notably regarding the magnitude of the contribution of public infrastructure to the national economic output, and the relative productivity of private versus public capital investment (Costa et al., 1987; Eberts, 1990). The policy implications of this debate are as follows: if public infrastructure investment not only increases economic productivity significantly, but does so at a rate above that of private capital investment, public policy decision-makers would be well advised to maintain or increase infrastructure investment at a high level. In case the reverse holds true, the economy at large would be better off with less public investment and lower taxes, which would allow for more private capital investment. A study (Mehta et al., 1991) discussed in Bell and McGuire (1997), using two-stage least squares estimation to model growth in per capita personal income, private investment, and population argues that private and public sector investment rates are inversely and significantly related, which could imply that private and public sector investments are substitutes in production. It is estimated that a one percent increase in the rate of public investment leads to a 0.7 percent decline in the private investment rate.

More recently, Dalenberg and Partridge (1997) developed a firm/household spatial equilibrium model to investigate the impacts of highways as opposed to total infrastructure. Using state level data from 1972 to 1991, the authors estimated the model twice: once for the total private sector, and once for manufacturing firms only. Their results suggest that highways act more as a household amenity than as an unpaid input to firms. They also found that for the total private sector, highways reduce wages, although they tend to increase wages for manufacturing firms only. These results suggest that highways are productive for manufacturing firms but unproductive for non-manufacturing firms. This could imply that the manufacturing sector is somewhat more responsive to infrastructure investment, and frequently benefits when other sectors do not.

\subsubsection{Employment and Economic Growth}

Transportation investment is often called upon as a means to revive the economic competitiveness of a region, particularly when the economy is depressed. Unemployment, per capita income, and poverty levels relative to state (or broader regional) levels can be 
used to identify distressed regions and evaluate the progress of a region after a highway investment. Previous findings suggest that employment and income growth are positively related to the presence of highways, but the strength of the relationship is weaker for rural compared to urban areas, as well as for non-metropolitan areas compared to metropolitan areas (Brown, 1999).

Two studies in the 1970s, discussed in Weiss (2002), indicate the significant effect of the interstate system on employment. In 1970, a FHWA study compared, during a five year period (1958-1963), job growth in high density urban areas with topographic barriers of some kind (rivers, hills) served by freeways, to job growth in similar urban areas without freeway service. It was found that the job growth per thousand population for fast growing cities in Southeast, Midwest, and Northwest with freeway access was 43 compared to 23 for those cities without access. For other cities, the effect of the interstate on employment was more pronounced ( 27 for those cities with freeway access compared to only 2 for those without access). A follow-up report in 1974 noted that population had migrated to those high job growth areas and, in some cases, the population migration was faster than the job growth. By 1980, a report on the impact of the interstate system on non-metropolitan areas administered by University of Texas, which included analysis of 1960-1975 data, reported similar effects to those noted earlier for densely populated cities (Weiss, 2002).

A recent study conducted by FHWA focused on the economic development history of nine completed interstates and near interstate corridors. The research correlated county-level data on population, employment, and income with the time period before, during, and after completion of the interstates. In some counties, the changes in population, employment, and income were similar to changes in counties without interstates. In other counties, changes were dissimilar and imply that the influence of the interstate was positive from an economic development standpoint. The results of this study suggest that counties with partially successful employment expansion programs may have more successful programs if there is an interstate nearby. On the other hand, a new interstate in counties where economic development is inhibited by a lack of developable sites or other barriers, may result in little improvement in the economic development picture (Weiss, 2005). 
Some of the empirical evidence of previous work on infrastructure investment and income and/or employment growth are summarized in Table 2.2.

Table 2.2 US Case Studies Estimating Economic Growth Resulting from Highway Investments

\begin{tabular}{|c|c|c|}
\hline Study Area & Empirical Evidence/Projections & Study \\
\hline National & $\begin{array}{l}\$ 1 \text { billion (in } 1995 \text { dollars) of federal-aid highway } \\
\text { program spending would support approximately } 7,900 \\
\text { full-time, on-site highway construction jobs, } 19,700 \\
\text { indirect, and } 14,500 \text { induced jobs nationally. }\end{array}$ & Keane (1996) \\
\hline $\begin{array}{l}\text { Appalachian } \\
\text { Development } \\
\text { Highway Sys- } \\
\text { tem (ADHS) } \\
(1,400 \text { mile } \\
\text { network) }\end{array}$ & $\begin{array}{l}\text { Net increase of } 16,000 \text { jobs by } 1995 \text { and } 42,000 \text { Appa- } \\
\text { lachian jobs by } 2015 \text {. Five counties adjacent to the } \\
\text { ADHS had job growth exceeding } 15 \text { percent. }\end{array}$ & WSA (1998) \\
\hline Delta Region & $\begin{array}{l}\text { Job growth in seven non-metropolitan counties and } \\
\text { parishes in the range of } 7 \text { percent- } 80 \text { percent. }\end{array}$ & $\begin{array}{l}\text { http://www. } \\
\text { tfhrc.gov/pubr } \\
\text { ds/winter96/p } \\
\text { 96w19htm }\end{array}$ \\
\hline $\begin{array}{l}\text { Dallas/Fort } \\
\text { Worth area }\end{array}$ & $\begin{array}{l}\text { Undertaking } \$ 10 \text { million in interstate improvements } \\
\text { would stimulate } \$ 17.6 \text { million in regional output, } \$ 4.6 \\
\text { million in earnings, and } 203 \text { jobs. }\end{array}$ & $\begin{array}{l}\text { Politano, and } \\
\text { Roadifer } \\
(1989)\end{array}$ \\
\hline $\begin{array}{l}\text { Wisconsin } \\
\text { State Trunk } \\
\text { Highway } 29\end{array}$ & $\begin{array}{l}\text { Business growth of } 74 \text { percent within } 5 \text { miles of the } \\
\text { highway between } 1995 \text { and } 2002.4,871 \text { new jobs cre- } \\
\text { ated, more than twice the number of jobs created in the } \\
\text { previous six years. }\end{array}$ & $\begin{array}{l}\text { WisDOT } \\
(1998)\end{array}$ \\
\hline New York I-86 & $\begin{array}{l}\text { Upgrade to a 4-lane limited-access expressway would } \\
\text { result in } 676 \text { jobs for construction spending, } 2,358 \text { jobs } \\
\text { for enhanced competitive position, } 878 \text { jobs for in- } \\
\text { creased tourism, and } 176 \text { jobs for non-business operat- } \\
\text { ing cost reductions-from } 2000 \text { to } 2020 \text {. }\end{array}$ & $\begin{array}{l}\text { www.fhwa.do } \\
\text { t/planning/ec } \\
\text { ondev/i86ny. } \\
\text { htm }\end{array}$ \\
\hline $\begin{array}{l}\text { Mississippi } \\
\text { River Bridge } \\
\text { and Zachary } \\
\text { Taylor Parkway }\end{array}$ & $\begin{array}{l}\text { Construction period employment-9,121 job-years in the } \\
\text { corridor, } 9,598 \text { job-years in the rest of the state. } \\
\text { Construction period income- } \$ 176 \text { million in the corri- } \\
\text { dor, } \$ 342 \text { million in the rest of the state. } \\
\text { Post-project employment (year } 2035)-2,926 \text { in the cor- } \\
\text { ridor, } 194 \text { in the rest of the state. } \\
\text { Post-project income ( } 30 \text { years)- } \$ 120 \text { million in the cor- } \\
\text { ridor, } \$ 78 \text { million in the rest of the state. }\end{array}$ & $\begin{array}{l}\mathrm{N}-\mathrm{Y} \text { Associ- } \\
\text { ates and } \\
\text { Economic } \\
\text { Development } \\
\text { Research } \\
\text { Group (1999) }\end{array}$ \\
\hline $\begin{array}{l}\text { Minnesota } \\
\text { Counties }\end{array}$ & $\begin{array}{l}\text { A } 2.2 \text { percent decrease in total employment of counties } \\
\text { further away from major corridors as a result of a } 10 \\
\text { percent increase in highway construction expenditures. }\end{array}$ & $\begin{array}{l}\text { Zografos and } \\
\text { Stephanedes } \\
\text { (1992) }\end{array}$ \\
\hline
\end{tabular}


Table 2.2 (Continued)

\begin{tabular}{|l|l|l|}
\hline Study Area & Empirical Evidence/Projections & Study \\
\hline $\begin{array}{l}\text { Indiana } \\
\text { Counties }\end{array}$ & $\begin{array}{l}\text { Mean county employment increase by 1,220 jobs for } \\
\text { each unit increase in total highway mileage density. }\end{array}$ & $\begin{array}{l}\text { Lombard et } \\
\text { al. (1992) }\end{array}$ \\
\hline $\begin{array}{l}\text { Indiana SR26 \& } \\
\text { US 35 Corridor }\end{array}$ & $\begin{array}{l}\text { Projected employment impacts in the study area ranged } \\
\text { were expected to increase by } \$ 6 \text { to \$16 million (in 1997 } \\
\text { dollars), and personal income by } \$ 5 \text { to \$9 million over } \\
\text { the same years. Impacts at the state level were larger. }\end{array}$ & $\begin{array}{l}\text { CSI and BLA } \\
\text { (1998a) }\end{array}$ \\
\hline $\begin{array}{l}\text { Indiana US 31 } \\
\text { Corridor }\end{array}$ & $\begin{array}{l}\text { Projected employment impacts in the study area ranged } \\
\text { from } 610 \text { to } 1,870 \text { jobs from 2010 to 2030. Business } \\
\text { (in 1997 dollars), and personal income by \$29 to \$95 } \\
\text { over the same years. Impacts at the state level were } \\
\text { larger. }\end{array}$ & $\begin{array}{l}\text { CSI and BLA } \\
\text { (1998b) }\end{array}$ \\
\hline $\begin{array}{l}\text { Indiana I-69 } \\
\text { Evansville to } \\
\text { Indianapolis }\end{array}$ & $\begin{array}{l}\text { Preferred alternative will result in 4,600 additional per- } \\
\text { manent jobs, an additional \$173 million (in 2001 dollars) } \\
\text { in annual personal income by 2025 in Southwest Indi- } \\
\text { ana, and in \$3.5 billion (in 2001 dollars) in additional } \\
\text { personal income over 20 years. }\end{array}$ & $\begin{array}{l}\text { CSI and BLA } \\
\text { (2003) }\end{array}$ \\
\hline $\begin{array}{l}\text { Indiana SR 101 } \\
\text { Corridor }\end{array}$ & $\begin{array}{l}\text { Preferred alternative will result in 500 additional jobs, } \\
\text { and in \$22.7 million (in 2002 dollars) additional personal } \\
\text { income over 20 years. }\end{array}$ & $\begin{array}{l}\text { CSI et al. } \\
(2003)\end{array}$ \\
\hline
\end{tabular}

Duffy-Deno and Eberts (1991), using data for 28 metropolitan areas from 1980 through 1984, applied a simultaneous equation approach and found that public capital stock had positive and statistical significant effects on per capita personal income. The effects came through two channels: first, through, the actual construction of the public capital stock; and second, through public capital stock as an unpaid factor in the production process and a consumption good of households. This second effect was twice as large as the first effect using ordinary least squares (OLS) estimation, but the relative magnitudes of the two effects were roughly reversed using two-stage least squares (2SLS) estimation. It was found that a 10 percent increase in public outlays increases personal income per capita by 0.37 percent using ordinary least squares (OLS) estimates and by 1.1 percent using two-stage least squares (2SLS) estimates.

Lombard et al. (1992) used cross-sectional multiple regression analysis of data from 1980 through 1988 to investigate the relationship between highways and economic development in Indiana. Seven highway variables in the broad categories of road conditions, highway mileage, and highway expenditures were used in conjunction with several other variables that were hypothesized to be significantly related to economic growth. It 
was assumed that economic development can be modeled as either the change in employment over the time period under consideration, or as the change in wage-income over the same period. Results indicated that in most cases, highway mileage had a significant association with economic development. Evidence was also found that multilane highways had an especially high association with economic growth. The parameter values for highway infrastructure indicated that mean county employment had an average increase of 1,220 jobs associated with one unit increase in the total highway mileage density per county, all other variables being held constant. This translates into a mean employment increase of three jobs for the mean county with an area of $391 \mathrm{mi}^{2}$, over the nine-year period of the study.

In a study of all 87 Minnesota counties (Zografos and Stephanedes, 1992), the impact of highway investment on local economic health within highway corridors was examined. The analysis was based on highway construction expenditures and county employment data. The results suggested that, in counties traversed by major highway corridors, money spent on improving highways causes an increase in total employment (including manufacturing jobs) above the state average. Counties further away from major corridors showed little evidence that highway investment had leveraged any economic benefits.

Rephann and Isserman (1994), using a different approach-a quasi-experimental matching method-studied the effectiveness of highway investment as an economic development tool. This method was applied to examine the effects of interstate highways on counties which obtained links during the period 1963-1975 or are in close proximity to these newly linked counties. The results showed that the beneficiaries of the interstate links in terms of economic growth are interstate counties in close proximity to large cities or having some degree of prior urbanization, such as a city with more than 25,000 residents. Rural interstate and off-interstate counties exhibited few positive effects.

An earlier study (Politano and Roadifer, 1989) concluded that not addressing construction needs on a typical interstate highway in the Dallas/Fort Worth area results in a loss in motorist benefits for the area equivalent to $\$ 1.8$ million in regional output, $\$ 580,000$ in regional earnings, and 27 jobs. On the other hand, undertaking $\$ 10$ million in interstate improvements will stimulate $\$ 17.6$ million in regional output, $\$ 4.6$ million in earnings and 
203 jobs. These estimates were obtained with the use of the economic simulation model "Regional Economic Impact Model for Highway Systems" (REIMHS).

The French Ministry of Public Works and Transportation (SETRA) set up economic studies at the beginning of the 1980s, aimed at evaluating how regions in France traversed by large road infrastructures are affected. An analysis of jobs and the financial impact linked to the use of the A10 (Poitiers - Bordeaux) showed that the motorway is a large business on a regional level as it employs directly or indirectly 3 or 4 people per kilometer and leads to substantial payment of salaries and taxes. The author concluded that the motorway is considered an economic benefit to the region crossed and could bring about economic development (Orus, 1996).

At the national level, regression analysis was used to investigate the relationship between the level of highway capital and the growth rate of per capita output for the 48 contiguous states between 1960 and 1985. In general, states with better highway infrastructure with regard to highway capacity and quality showed a higher per capita income growth over the period (Aschauer, 1990). The impact of federal-aid spending on employment was investigated in a study sponsored by FHWA. Using FHWA highway program composition data from 1993 and the forecasts of highway construction costs based on the FHWA Highway Construction Price Index, it was estimated that \$1 billion (in 1995 dollars) of federal-aid highway program spending in 1996 would support approximately 7,900 full-time, on-site, highway construction jobs nationally. In addition, using a dynamic Input/Output model, it was estimated that approximately 19,700 indirect jobs and 14,500 induced jobs would be supported by an equal amount of federal-aid highway program spending in 1996 (Keane, 1996).

Other studies illustrate that during the 1969-1993 period, Appalachian counties with development highways were found to have grown significantly faster, in terms of income and earnings, than other Appalachian counties without a similar program. Based on the Appalachian Regional Commission Study, five counties adjacent to the Appalachian Development Highway System had job growth exceeding 15 percent, also indicating a benefit of two-to-four lane expansions (Isserman and Rephann, 1995; WSA, 1998). In a similar study conducted for the Delta region, it was concluded that public investment in highways in the Delta Region, is paying dividends in increased economic activity and 
resultant improvements in employment opportunity and quality of life throughout the region, increased human capital investment, interregional commerce, and international trade (FHWA, 1995).

\subsubsection{Land Use and Urban Development}

Literature on how highways are linked to metropolitan development suggests that highways influence land prices, population, and employment changes near the project, and that the land use effects are likely at the expense of losses elsewhere (Boarnet and Haughwout, 2000).

A review study on the growth of North Carolina's 1551 Census tracts during the 1990s compared with the locations of major road improvements-312 major road projects completed during the 1990s - concluded that nearness to the interstate system or to city centers was not a factor in most regions. Recent major road improvements, primarily urban and rural widenings, had a minor effect on growth, increasing growth by $50-550$ persons per decade per mile of investment, about 2-14 percentage points above the baseline growth. However, the relationships varied widely by region and were weak, generally explaining 10-25 percent of the variation in growth. This indicates that factors other than density or road investment (e.g., schools, sewer and water, taxes, community receptiveness) influence the location of growth significantly (John Locke Foundation, 2003).

After analyzing 2,500 census tracts and 138 separate major road projects in Ohio, it was concluded that, contrary to popular opinion, investing in road construction does not lead to sprawl; instead, population density appears to be the most important factor (The Buckeye Institute, 2003).

Finally, the influence of highway investments on population growth and land development was investigated using Virginia locations in three counties as case studies. Using three decades of data on highway investments, the authors compared what planners intended these transportation decisions to accomplish with what transpired. The results 
suggested that "transportation investments can affect short-term travel and longer-term location choices but it is difficult to use investments to manage growth precisely." Additionally, the case studies indicated that to some extent counties can influence the specific location of growth and what type is attracted-but if the market exists to support growth, eventually it will come (Ellington et al., 2005).

\subsubsection{Public Infrastructure and Negative Externalities}

Infrastructure investment aids businesses and increases productivity if it successfully reduces negative externalities (e.g., traffic congestion) that aggravate business costs, particularly logistics costs. By reducing congestion, increasing volume-to-capacity ratios, and removing conditions disrupting free flow of traffic, highway infrastructure investments generate benefits by reducing transit time and increasing reliability. In turn, the supply chain can be streamlined with lower in-transit inventory and safety stock inventory. More fundamentally, firms may respond by reorganizing their production and distribution activities (Allen et al., 1994; AASHTO, 1990). A recent study on firm inventory behavior and the returns from highway infrastructure investments argues that firms

are adversely affected by growing vehicle traffic; a 10 percent increase in vehicle-miles traveled produces roughly a one-billion-dollar increase in annual logistic costs. It was also found that annual returns from highway investments have fallen to less than 5 percent during the 1980s and 1990s and suggest that increasing highway spending appears to have become an inefficient way to offset congestion costs (Shirley and Winston, 2004).

Negative spillover effects have also been reported in the literature due to highways and other public infrastructure. Rephann and Isserman (1994) indicated negative spillover effects at the county level; adjacent counties to interstate counties were found to have many negative effects, the most significant of which was loss of retail activity. Boarnet (1998), cited in Baird (2005), used California county data from 1969 to 1988 to reach similar conclusions. This research first developed a theoretical model of two competing cities showing that if one city gets a productive (exogenous) increase in highway investment, then mobile factors such as capital and labor will migrate towards that city in response to wage and price changes. The net theoretical result is that output increases in the city receiving the highway come at the expense of the other city. Boarnet (1998) 
concluded that "street-and-highway capital is associated with higher output within the same county and with lower output in counties with similar population density, income, or employment shares in the fire sector."

Most recently, Chandra and Thompson (2000), also cited in Baird (2005), found negative spillover effects when studying the impacts of highways on rural US counties. Counties receiving highway investment showed statistically significant gains in total earnings roughly a decade after construction, with specific gains in fire, retail, and transportation and communication sectors. Adjacent counties were shown to receive a small boost in manufacturing earnings but a steady, consistent decline in retail and farming industries. The authors interpreted the evidence to indicate that "highways in non-metropolitan areas raise the level of economic activity in the counties that they pass directly through, but draw activity away from adjacent counties, thereby leaving the net level of economic activity unchanged."

\subsection{Motivations for Economic Impact Studies}

\subsubsection{Key Approaches}

There are four basic types of studies that assess the economic impacts of transportation investments, each with different motivations and methods. The key approaches and techniques used to assess economic development impacts are (Weisbrod, 2000):

- Studies to assess proposed investments: they are typically conducted to assist in decision-making among alternatives. They estimate the extent to which proposed transportation projects are likely to lead to positive economic development benefits for the regions in which they are located. A range of methods, from market studies to comprehensive economic simulation models, is used to forecast expected project impacts relative to base case forecasts to support investment decision-making. These impact forecasts could be improved if more information from post-project evaluation was available to provide a stronger basis for them. 
- Studies for planning and regulatory review: they are typically conducted in conjunction with a legally mandated environmental review process. Frequently, only a brief summary is made of land takings or impacts on the use of abutting property. For some regionally important or controversial projects though sophisticated models are sometimes used. The analysis methods used for these studies parallel those used to assess impacts of proposed investments, although the reporting of the results may differ depending on the nature of public concerns.

- Studies for public education; they are generally conducted to increase public understanding of the interrelationship of existing transportation facilities to the economy of the area they serve. These studies rely primarily on surveys or observations to document direct activity, and input-output models to estimate overall economic effects.

- Studies for post-project evaluation: they measure the actual impacts of transportation facilities or investments after they are finished and in use. These evaluations generally rely on times-series data to measure economic conditions in a study area before a transportation investment is made and after the same transportation investment has been in place for several years. Their findings can be quite useful for improving future investment decisions. However, relatively few studies have been done on such a rigorous basis. According to experts and transportation officials, once transportation investments are completed, they become a part of an entire transportation system and, therefore, the effects of the individual project become difficult to isolate, evaluate, and attribute to the individual project. Moreover, because state and local funding is limited and these studies can be costly and difficult, local officials indicated that studies of completed projects were not as high a priority as pursuing and conducting studies on future projects (GAO, 2005). 


\subsubsection{Highway-Related Impact Studies}

The empirical studies that focus on highways and highway-related impacts can be classified into the following general categories (EDRG and CSI, 2001):

- Studies of Rural Highway Systems: These studies look at county-level growth rates in earnings and/or employment in rural counties. Rates are compared for counties with and without interstate access (or, in some cases, other highways). The scope is usually national. Rates are usually compared over a 5-to 15-year period, at some point following the development of the highways. The implicit hypothesis is that highways should have a semi-permanent and relatively constant impact on growth rates. Some studies have controlled for other factors such as proximity to a metropolitan area. Examples, cited in EDRG and CSI (2001), include studies of interstate and rural highways across the US by Porterfield (1990), Broder (1992), and Kusmin (1996).

- Studies of Regional Development Program Impacts: These studies look at the impacts of specific regional infrastructure investment programs aimed at stimulating economic development. Impacts are usually measured in terms of countylevel employment, earnings, and/or population. There are two primary experimental measurements: 1) absolute levels before and after highway development in affected counties, and 2) growth rates after highway development in affected versus unaffected counties. As a set, the counties that benefit from the highway project may be compared to: 1) the remaining counties in the same region that do not benefit; 2) the state or US as a whole; or 3) a set of "matched" counties elsewhere. Examples include studies of the Appalachian Development Highway System by Rephann and Isserman (1994), and WSA (1998); the Delta Region studies by FHWA (1995); and (Hodge and Hand, 2004).

- Studies of Specific Highway Corridor Improvements: These studies focus on specific projects rather than highway systems. A combination of quantitative and qualitative assessment is generally used. The benefit of gathering qualitative data (e.g., through interviews) is that important local factors can be identified and 
their relative impacts can be assessed. The limitation of this approach is that findings on impacts may not automatically apply to other highway corridors, but the major advantage of this approach is that it provides a basis for identifying how differences in local context can affect the nature of resulting impacts (Forkenbrock and Weisbrod, 2001). Most of these studies of this type have been overseas. Good examples include studies of specific new motorways in France (Orus, 1996) and two other studies in Finland (Parantainen, 1999), and in Sweden (Anderstig, 1999), as cited in EDRG and CSI (2001).

- Bypass and Other Access Change Studies: These studies examine the impacts of highway bypasses around smaller cities and towns, or of other access restrictions that may affect businesses. Usually the focus is only on the city or town that is being bypassed, although some studies have tried to assess how bypassed locations may conversely benefit from bypasses elsewhere along the corridor. Impacts are generally measured in terms of employment, sales, and/or number of businesses at the city level or for another project-specific area for which data can be isolated. The focus is usually on retail/service businesses that are especially traffic-oriented businesses. Traffic volumes are also compared before and after construction on the bypassed and new routes. In contrast to other studies reviewed, levels of impacts are measured before and after the bypass rather than in terms of growth rates. The hypothesis is that a one-time "hit" occurs, although some studies have also looked at the longer-term evolution of impact levels. Bypass studies are frequently supplemented with local quantitative data gathering (windshield surveys, business surveys) as well as qualitative data from interviews. Bypass and other access restriction studies have generally found that net impacts to the community are neutral or positive in the long term. A summary of US statewide studies of the economic development impact of highway bypasses in small towns is provided in Leong and Weisbrod (2000). Examples of bypass studies in the report include highway bypasses in Wisconsin, Kansas, lowa, North Carolina, and Texas. Other studies, cited in EDRG and CSI (2001), include highway bypass studies in Washington (Gillis and Casavant, 1994), Australia (Bureau of Transport and Communications Economics, 1994) and a summary of US bypass studies in NCHRP Project 20-5. A more recent study was conducted in Kansas (Babcock and Davalos, 2004). 
- Interchange Studies: These studies utilize local business data (e.g., locations, sales) to evaluate the impacts of freeway interchanges on retail/service businesses. The scope is similar to bypass studies, although negative impacts are not hypothesized. Some creative work has been done in looking at spatial relationships among interchanges and with nearby cities/towns. Examples include Moon (1987), Hartgen and Kim (1998) and Aldrich and Kusmin (1997). In the latter study, it was found that access to interstate highway interchanges contributed to earnings growth in rural area; each interchange brought approximately 0.42 percent additional income growth during the period 1979-1989.

- Surveys on Factors Influencing Business Location: Forkenbrock and Foster (1996) summarized findings from recent surveys and studies of how proximity to highways affects subsequent business location decisions, although they did not evaluate impacts of any specific highway programs or projects. Nevertheless, such studies provide insight into the factors that should be considered in the empirical analysis of highway impacts. Good examples of this type of studies include: Blair and Premus (1987) and Lombard (1991). A more recent study examined the potential of business attraction in the North County, New York region as a result of a new transportation facility (Hodge et al., 2003). Finally, a study conducted overseas on the importance of transportation in business' location decisions is McQuaid et al. (2004).

Finally, there are studies that can be classified into more than one category. A good example is the study (Weisbrod and Treyz, 1998) that attempts to bridge two perspectives, describing how project-specific analysis methods can shed light on the overall macroeconomic effects of transportation infrastructure spending. 


\subsection{Review of Data Sources}

There are at least 24 different data sources that can be used to obtain information on the measures of potential economic impacts listed in Section 2.1.2. The data sources fall into four general categories (EDRG and CSI, 2001):

US Federal Data-These include data series published by the Census Bureau, Bureau of Labor Statistics, Bureau of Economic Analysis and Internal Revenue Service.

State and Local Data Sources-These include data on jobs and population published by the city, county, and state agencies. They include state data on population and employment, as well as local data on building permits and property assessments.

Private Data Sources-These include private companies providing market and real estate information. Some of these data are free on the web. Others are available only for a fee.

Interviews and Field Observations-Telephone or in-person interviews with local businesses, public officials, and private organizations in the project area are a source of information that cannot be obtained from public data sources. They can provide information regarding causal factors affecting observed changes. Additional field observations can also provide contextual insight into the nature of development impacts and factors affecting those impacts.

Detailed information on each recommended data source, including coverage, frequency, possible applications in economic analysis, and the advantages and disadvantages of each source is provided in Table 2.3. The ratings range from one (the best) to five (the worst) based on the following criteria (EDRG and CSI, 2001):

- How current and frequent the data are;

- Availability of data for small areas; 
- Level of industrial detail;

- Comprehensiveness;

- Quality of data collection and sampling methodology;

- Cost;

- Ease of accessibility via the Internet;

- Responsiveness of technical support; and

- Potential applications of data to analysis of economic impacts of transportation projects. 
Table 2.3 Evaluation of Data Sources for Economic Impact Analysis

(Source: EDRG and CSI, 2001)

\begin{tabular}{|c|c|c|c|c|c|c|c|c|c|c|c|c|c|c|c|c|}
\hline \multirow[t]{2}{*}{ Source } & \multirow[t]{2}{*}{ Data Series } & \multicolumn{7}{|c|}{ Data Measured } & \multicolumn{4}{|c|}{ Geography* } & \multicolumn{2}{|c|}{ SIC Level } & \multirow{2}{*}{$\begin{array}{c}\text { Most } \\
\text { Cumrent }\end{array}$} & \multirow{2}{*}{$\begin{array}{l}\text { Overall } \\
\text { Rating } \\
\end{array}$} \\
\hline & & Pop & Joba & Income, & Firms. & Sales. & Invest. & RE Val. & Metro & County. & City. & Small & Highest & Freq. & & \\
\hline BLS & LAUS (Unemployment) & & $x$ & & & & & & $x$ & $\mathrm{x}$ & $x$ & & 0 & Monthly & Jan-00 & 3 \\
\hline Census & Decennial Census & $x$ & $x$ & $x$ & & & & & $\mathrm{x}$ & $\mathrm{x}$ & $x$ & $x$ & NA & 10 Years & 1990 & 4 \\
\hline BLS & Covered Empl. \& Wages & & $x$ & $\mathrm{x}$ & $x$ & & & & $x$ & $x$ & $x$ & & 4 & Quarter & 1998-99 & 1 \\
\hline Census & County Biz Patterns & & $x$ & $x$ & $\mathrm{x}$ & & & & $x$ & $x$ & & $x$ & 4 & Annual & 1997 & 2 \\
\hline D \& B & Marketing Data & & $x$ & & $x$ & $x$ & & & $x$ & $x$ & $x$ & $x$ & 4 & Monthly & Jan-00 & 2 \\
\hline BEA & REIS Employ. Series & & $x$ & & & & & & $x$ & $x$ & & & 1 & Annual & 1997 & 3 \\
\hline BLS & Current Empl. Statistics & & $x$ & $x$ & & & & & $x$ & & & & $2 c$ & Monthly & Jan-00 & 3 \\
\hline BLS & Occupation. Empl. Stats & & & $\mathrm{x}$ & & & & & $\mathrm{x}$ & & & & $4^{4}$ & Annual & 1999 & 2 to 3 \\
\hline BLS & Natl. Compensa. Survey & & & $\mathrm{x}$ & & & & & $\mathrm{x}$ & & & & $4^{4}$ & Annual & 1998 & 4 \\
\hline BEA & REIS Income Series & & & $x$ & & & & & $x$ & $x$ & & & 2 & Annual & 1997 & 3 \\
\hline IRS & SOI County Income & & & $\mathrm{x}$ & & & & & $x$ & & & & 0 & Annual & 1997 & 3 \\
\hline Census & Small Area Income. Est. & & & $x$ & & & & & $x$ & & & $x$ & NA & 2 Years & 1995 & 5 \\
\hline Census & Economic Census & & $x$ & $\mathrm{x}$ & $\mathrm{x}$ & $\mathrm{x}$ & mfg. & & $x$ & $x$ & $x$ & $x$ & 4 & 5 Years & 1992 & 3 \\
\hline USCM & Gross Metro Product & & & & & $x$ & & & $x$ & & & & NA & Annual & 1998 & 4 \\
\hline Census & Res. Bldg. Permit Data & & & & & & $x$ & & $x$ & $x$ & $x$ & $x$ & NA & Monthly & Sep-99 & 3 \\
\hline Loc. Gov. & Building Permit Data & & & & & & $x$ & & & $x$ & $x$ & $x$ & NA & Monthly & $\operatorname{Tan}-00$ & 2 \\
\hline Loc. Gov. & Assessor's Data & & & & & & & $x$ & & $\mathrm{x}$ & $x$ & $x$ & NA & Varies & Varies & 3 \\
\hline Realtors & Local Com'1. RE Data & & & & & & & $x$ & $x$ & & $x$ & $x$ & NA & Quarter & Dec-99 & 2 \\
\hline Realtors & Res. Sales Transactions & & & & & & & $x$ & $x$ & & $x$ & $x$ & NA & Quarter & Jan-00 & 3 \\
\hline FW Dodge & Com'l. Prop. Mkt. Ind. & & & & & & & $x$ & $x$ & & & & & Annual & 1997 & 2 \\
\hline Census & Population Estimates & $x$ & & & & & & & $x$ & $x$ & & & NA & Annual & 1999 & 1 \\
\hline States & State Pop. Data & $x$ & & & & & & & $x$ & $x$ & $x$ & & NA & Annual & Varies & 2 \\
\hline Leaders & Interviews & $x$ & $x$ & $x$ & $x$ & $x$ & $x$ & $x$ & $x$ & $x$ & $x$ & $x$ & 2 & NA & Present & 1 \\
\hline- & Field Observations & & & & $x$ & & $x$ & & $x$ & $x$ & $x$ & $x$ & 1 & NA & Present & 1 \\
\hline
\end{tabular}

a "Small" area means by ZIP code, School District, Area Code, or address.

b Overall Rating: $1=$ best; $5=$ worst.

' Manufacturing sectors are reported for two-digit SIC's and a few three- and four-digit groups. Data are reported by one-digit SIC for non-manufacturing

d Employment data are reported for detailed occupations, not industry. 


\subsection{Evaluation of Economic Analysis Tools}

There are many tools available to analyze the economic development impact of transportation projects and programs. As stated in Chapter 1, there are multiple reasons why transportation agencies are interested in examining the economic benefits of projects, policies, and programs. Some of the reasons include: program development or project planning, environmental impact assessment to fulfill federal requirements (TEA-21), ranking of alternatives, and public information or discussion (Weisbrod, 2000). The key is to match the analytical tool to the purpose and level of desired sophistication of the analysis, and to available resources (Weisbrod and Weisbrod, 1997). A sample range of economic analysis approaches is depicted in Figure 2.2.

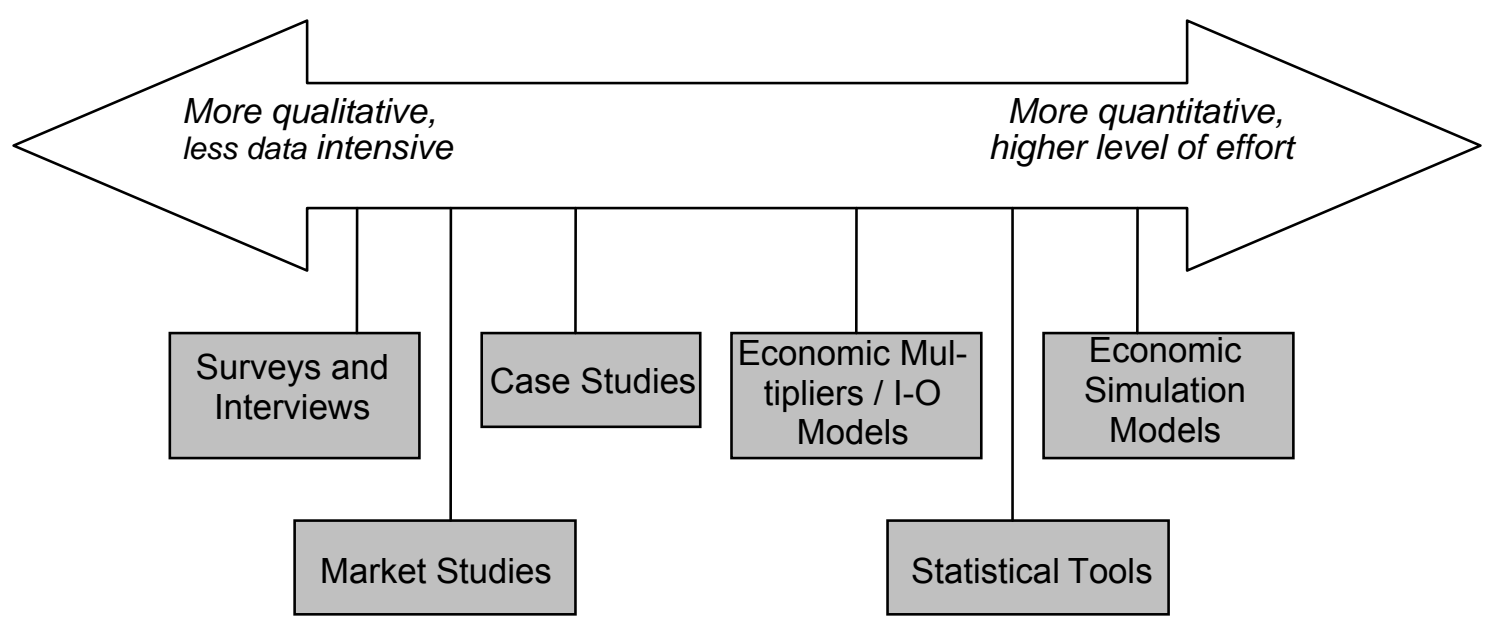

Figure 2.3 Approaches to the Analysis of Economic Development Impacts (Adapted from: CUBRC et al., 2001)

This research study will focus on the review of the more advanced approaches to economic analysis of transportation projects, policies, and programs. The approaches typically involve greater levels of effort, special staff training, specialized software, and more reliance on quantitative data. The payoff of implementation of such approaches in the planning process of an MPO or other agencies consists in impact estimates that are rea- 
sonably reliable, and often better than those produced by simpler approaches. Particularly, advanced approaches have the ability to capture system-wide impacts, which are particularly significant in the context of large and complex projects or entire multifaceted programs (CUBRC et al., 2001). The more advanced economic impact techniques that transportation agencies can apply to analyze the expected benefits of specific projects comprise:

- Economic multiplier approaches, such as input-output analysis;

- Statistical tools, which include regression and econometric modeling; and

- Economic simulation models.

\subsubsection{Economic Multiplier Approach/Input-Output Analysis}

The economic multiplier approach is most applicable to transportation projects that directly impact business attraction, expansion, retention, or tourism. Examples include a new highway access road that could be a catalyst for a business attraction to the region, or a transportation facility improvement that could produce increased tourism to the area. Economic multiplier approaches can also be used to analyze the expected impacts from the construction of transportation facilities and the purchase of transportation equipment. The economic multiplier approach is largely based on Input-Output (I-O) modeling. I-O modeling is a widely accepted methodology for tracking the economic impacts of major investments within a regional economy's industry sectors (CSI et al., 1998). Input-output models capture the inter-industry linkages of a regional economy and estimate economic multipliers. Standard economic multipliers estimate two kinds of secondary impacts from direct changes to an economy, namely indirect and induced (discussed in Section 2.1.3.1), both of which manifest them in the medium term. The total impacts are typically measured in terms of business sales, Gross Regional Product (GRP), wages, and jobs in the region (Weisbrod, 2000). 
I-O models are regional in scale. The regional scale of I-O models largely stems from the fact that many of the industry data that form the inputs to the models are regional (e.g., county-level or above) (CSI et al., 1998). Input-output models have the ability to capture the effects of changing transportation costs and accessibility on a region's economy. Input-output models will not forecast how jobs will be created directly or retained by a transportation improvement; rather, with some expectations on the number of jobs retained or created, an input-output model will estimate associated indirect and induced effects. Moreover, this approach can give detailed estimates of how various economic sectors will respond to an external impact. However, input-output analysis is unlikely to be useful as a stand-alone approach; it focuses only on the demand side of a regional economy and does not help to understand the supply side of a local economy. In addition, this methodology uses inter-industry relationships from national forecast, which is not necessarily applicable to smaller analysis levels. Therefore, localized input-output charts are difficult to develop (Lombard, 1991; Voytek and Ledebur, 1997). A major limitation of I-O models is that they are static. They do not account for long-term economic, industrial, and demographic changes or for changes in business costs over time. Consequently, I-O models produce results that are only valid for fixed points in time. Furthermore, many of the I-O models in use today were developed several years ago. Thus, they do not reflect up-to-date inter-industry relationships. Therefore, when multipliers from old models are applied to current projects, they may not provide accurate results (CSI et al., 1998). Finally, the use of economic multiplier tools is strictly expenditure driven and will only produce the effects of spending, regardless of what the dollars are spent on (CUBRC et al., 2001).

I-O models calibrated for specific counties or aggregations of counties are commercially available from the Minnesota IMPLAN Group (IMPLAN model), Regional Science Research Institute (PC I-O Model), and US Bureau of Economic Analysis (RIMS Regional Input Modeling System and a later enhanced model RIMS II). RIMS II provides tables of multipliers that analysts can apply to their own spreadsheets. IMPLAN and PC I-O, on the other hand, are programs that query users in order to provide a description of the direct effects, and then automatically generate estimates of the indirect, induced, and total effects of the facility (Weisbrod and Weisbrod, 1997). 
Input Output models have also been developed by state agencies. A 68 sector, surveybased input-output model was developed by the Economics Department at Kansas State University for the State of Kansas. The Kansas input-output model was adapted to include six additional sectors corresponding to six highway improvement types: 1) resurfacing; 2) restoration and rehabilitation; reconstruction and minor widening; 3) new bridges and bridge replacement; 4) major and minor bridge rehabilitation; 5) new construction; relocation; major widening; 6) safety/traffic operations/traffic system management; environmentally related. The input-output data for these six sectors was obtained by surveying highway contractors. Employment/output ratios for the industry sectors excluding the six highway improvement categories were computed from data in Minnesota IMPLAN Group. The estimated output, income, and employment multipliers for highway improvements such as new construction; relocation; or major widening were found 2.47 , 2.24, and 39.77 (jobs per million dollars), respectively. For restoration and rehabilitation, reconstruction and minor widening highway projects, the multipliers were slightly higher-2.59, 2.35, and 42.26 (jobs per million dollars) (Babcock, 2004).

Hybrid multiplier approaches for estimating economic impacts have also been applied. A good example is the hybrid approach using survey information on the direct output effects in conjunction with Regional Input-Output Modeling System (RIMS II) multipliers. A comparison of the impact estimates obtained by the two approaches indicated that the accuracy of the estimates can be improved when the hybrid approach is used. In addition, the comparison indicated that survey information need only be collected on the most important inputs (Beemiller, 1990).

A noticeable trend has been a shift from I-O models to applications of the Regional Economic Models, Inc. (Weiss and Figura, 2003). The REMI model is sometimes termed a dynamic input-output model but has enough additional functionality not to be considered a straight input-output model. It is discussed in detail in Section 2.5.3. A comparison of the most popular models available for analyzing the economic impact of transportation projects (RIMS II, IMPLAN and REMI) is also provided in Section 2.5.4. 


\subsubsection{Statistical Tools}

Another option to perform a more quantifiable economic development impact analysis is to use a statistical technique. This would typically be a more data-driven tool, relying on estimates of the relationship between highway investments and economic activity.

\subsubsection{Multiple regression models}

Multiple regression models are a frequently used statistical tool to infer causal relationships between a dependent variable representing some kind of economic activity, such as employment, land values, or building square footage, and various explanatory variables, including the existence of a new highway improvement, using local and non-local data. The elasticities (or impact factors or coefficients) can then be applied to estimate the expected future impact of highways on growth in the region (CUBRC et al., 2001).

Regression analyses, using either time series or cross-sectional data, have been used extensively in the past to estimate and forecast economic development effects of highway projects. Most of these studies argued that transportation characteristics such as proximity to an interstate highway are highly correlated with the locating of industries in an area. Some of the critiques of this line of research concern not the historical analysis or models, but rather how the findings are interpreted. One interpretation is that the research findings reflect the economic returns from transportation efficiency improvements in the past and do not necessarily conclude that continuing highway building will bring similar efficiency benefits or economic growth (Weisbrod, 2000). Another setback of this methodology is that although it determines correlations between infrastructure investment and economic growth variables, it does not necessarily indicate the causality between the two; that is whether highway investments caused the observed higher economic growth, or whether the highway investments were placed in areas with greater density and expected growth rates. Moreover, Arsen (1997) argues that economic development should not be treated as a linear function of infrastructure investment; as such, the infrastructure development link should not be implicitly assumed to conform to just a simple linear relationship. Furthermore, regression analyses using time-series data may not be very useful for examining the effects of public capital because there is 
insufficient variation in the value of capital stock from one year to the next; in addition, findings based on aggregate time-series analysis may represent unrelated trends in the data over time. Another line of criticism argues that there may be significant time lag between construction of public infrastructure and subsequent usage by producers, and therefore analysis without addressing such lags would lead to incorrect results (Bell and McGuire, 1997). ${ }^{3}$ These types of models however require much less data input in general than input-output models, and are less complicated to execute and calibrate (Lombard, 1991).

Studies that have applied regression analysis to measure the impacts of highway programs in the past, cited in EDRG and CSI (2001), include: Porterfield (1990); Kusmin, Redman, and Sears (1996); and Isserman and Rephann (1995). Multivariate regression techniques have also been used to look at bypasses and interchange development. There are also isolated examples of some more advanced regression techniques such as the simultaneous-equation approach applied by Duffy-Deno and Eberts (1991) to examine the relationship between metropolitan personal income and local public capital stock in 28 metropolitan areas from 1980 through 1984. Similar work to assess the relationship between levels of transportation investment and resulting changes in business location and regional development patterns was conducted in the Netherlands by Evers et al. (1988). However, these methods require data observations to be collected for a wider range of locations. That requirement for a large dataset, in turn, naturally leads researchers to rely on available aggregate county-level transportation data (EDRG and CSI, 2001). Finally, a random-effects approach was proposed by McHugh and Wilikinson (1988) to capture state-specific effects as an alternative to introducing regional dummies in the regression models.

\subsubsection{Other Econometric Models}

Recent research deploys other econometric techniques to gauge the contribution of transportation investment towards economic growth. An advantage of econometrics is

${ }^{3}$ Responses to these statistical data based criticisms have led to more sophisticated analytical reforms and reinterpretations of earlier findings. 
the ability to analyze the simultaneous effect of a large number of variables, lags and functional forms (Lombard et al., 1992). A summary of these techniques as provided in (EDRG and CSI, 2001), is provided next.

\subsubsection{Shift-Share Trend Analysis}

This approach is a variant on the time-series regression, in that it also compares economic pre/post trends between the project impact area and a broader surrounding area. However, it attempts to adjust for compositional changes between these areas. Shiftshare analysis decomposes the observed changes in regional economic growth into three components: 1) a trend effect, reflecting how the regional economy historically grows faster or slower than the national trend, 2) an industry mix effect, reflecting how the regional growth rate changes due to its mix of faster-growing and slower-growing industry sectors, and 3) an unexplained effect, reflecting remaining changes in the regional economy which cannot be correlated with either overall growth rates or industry mix differences. The logic of this approach is that it explicitly produces a profile of expected regional growth based on historical economic trends and current industry mix, and then represents the difference between that and the observed economic change as the "unexplained" effect which can be attributed to public or private interventions (such as a new highway). However, neither this method resolves the issue of causality, since there is no guarantee that the "unexplained" difference is due solely to highway investments during the pre/post period.

\subsection{Matched Comparison Areas}

This approach also compares trends over a pre/post time period for both the study area and a comparison area. However, this approach identifies the key socioeconomic characteristics of the local areas receiving highway improvements, and then seeks to identify outside areas which have not had such highway improvement but otherwise share similar socioeconomic characteristics. The matching factors may include income, population density, economic mix and ratings of baseline highway access availability. The process of paired matches among similar areas is presumed to control for all of these factors, leaving any observed differences attributable to the presence or lack of highway im- 
provements. In effect, this is a "quasi-experimental" design in which the matched areas lacking highway improvements represent the "control group," which is compared to the "experimental group" receiving the highway improvements. A quasi-experimental matching method was applied by Rephann and Isserman (1994) to study the effectiveness of highway investment as an economic development tool.

Regarding this approach, some researchers raise concerns about whether the selection of "twin" counties (control group) truly captures all of the necessary variables that can explain economic growth rates. In particular, there is the intractable problem that all control group areas are necessarily located in a different location than the project impact areas. That raises the issue of whether other regional factors, such as the different location of the study and control areas, may represent an unexplained factor affecting observed differences in economic growth rates. For instance, if the study and control areas are in different states, then there may also be differences in state tax or business policies, proximities to airports or seaports, or proximities to other growing market areas among those areas (EDRG and CSI, 2001).

\subsection{Cluster Analysis}

A typical application of cluster analysis is to identify variables for potential inclusion in a multiple regression model. Cluster analysis has been also used as a tool to shape state and regional economic development agendas. It may suggest the need for economic development activities, and also offers a rationale for setting priorities among competing economic development investments. For example, in a study (Hartgen et al., 1990) cluster analysis was used coupled with factor analysis to identify the characteristics of firms that express very high and very low satisfaction levels with transportation facilities and network investment. An enhancement of this approach involves a two-stage method to use quantitative analysis as a first cut, followed by qualitative analysis and additional quantitative analysis. The first stage of this analysis employs factor analysis and expert interviews to identify a set of clusters. The second stage applies input-output analysis, location quotients, shift-share analysis, and focus groups to assess each cluster. This approach examines the cluster as an entity in itself rather than a collection of industries to be studied individually (Held, 1996). 


\subsection{Other Methods}

Another analysis method adopted by Kriesel and McNamara (1990) is an ordered, multiple-category logit model applied for 158 counties in Georgia from 1986 to 1988 . This model investigated the probability that a manufacturing plant would be attracted to a community.

Finally, it is worth mentioning that a "meta analysis"-an approach widely used in medical and epidemiological studies-is not reported in the economic development literature. Under this approach, findings from multiple studies are pooled to derive greater statistical precision. Yet while this approach may have some promise, there is not yet any comparably large set of case studies for major highway corridor projects.

\subsubsection{Economic Simulation Models}

\subsubsection{Regional Economic Simulation Models}

Forecasting and simulation models primarily are used for predictive studies. It is particularly useful when the goal of the analysis is to compare alternatives, measure the regional economic (development) impacts of a project, or secure public financing (CSI et al., 1998). Many areas have used commercially produced economic simulation models to analyze the expected economic impacts of transportation investments. Perhaps the most widely used economic simulation model for transportation work is the Regional Economic Models, Inc. (REMI)-Policy Insight, dynamic input-output model. Other models include the Regional Economic Impact Model for Highway Systems (REIMHS) (Politano and Roadifer, 1989).

The REMI model has an input-output component to capture inter-industry linkages, but it is also a dynamic model, meaning that it estimates impacts over time; these impacts vary depending on relative costs, wages, etc. Second, unlike many input-output models, it readily handles impacts typical of transportation investments, such as changes to industry production costs and productivity, as well as direct job and sales impacts. Other 
key aspects of the REMI simulation model are its sensitivity to factors such as population migration, effects of business operating costs on the location of industry, detailed changes in wages by occupation, business mix shifts, and technological changes. It also allows for substitution between capital, labor, and fuel. It can assist in evaluating the economic merit of the whole spectrum of decisions made by transportation decisionmakers, from policies and regulations affecting the operation of the transportation systems, to individual transportation improvement projects of rather local significance and all the situations in between. The REMI model is preferred over input-output modeling for long-range planning owing to its dynamic nature and its ability to account for productivity changes that may develop as a result of transportation decisions over a 20- to 30year planning horizon (CUBRC et al., 2001; Forkenbrock and Weisbrod, 2001).

However, forecasting and simulation models rarely predict impacts below the county level, because much of the data used to construct the models is aggregated to the county-level. Moreover, these forecasting and simulation models tend to be very expensive and require substantial economic expertise on the part of the analyst in order to identify the appropriate inputs and interpret the results. Acquisition of data inputs can also be very time-consuming (Lombard, 1991; CSI et al., 1998). The high levels of complexity as well as the limited capabilities of these models to be used in-house at a reasonable cost hamper effective analysis of the economic development impactsby transportation agencies (Weisbrod, 2000). Case studies that rely on REMI as a forecasting and policy-analysis model to evaluate the economic effects of a wide range of policy initiatives are cited at: http://www.remi.com/support/articles.html

\subsubsection{2. $\underline{\text { Hybrid Modeling Systems }}$}

\subsection{Traffic and Economic Models}

A common approach for calculating the economic impacts of transportation investments is to use an economic simulation model in combination with a traffic network simulation model. For given projects, the traffic model calculates travel time savings by trip purpose. These time savings are translated into user benefits (in dollar terms) and are further translated into production cost savings and productivity enhancing benefits to enter 
into an economic simulation model, such as REMI. The REMI model then calculates the direct, indirect, and induced effects in terms of employment, income, population, and many other variables. If a transportation investment is likely to generate net business attraction/expansion impacts or tourism impacts, those can also be exogenously estimated and input into REMI (CUBRC et al., 2001).

The State of Indiana has developed an integrated modeling system that includes a macroeconomic simulation model to analyze investment alternatives. Indiana identified economic development as a key strategy with its 1986 statewide transportation plan, adding corridors in 1991 and has since designed sophisticated economic analysis tools to assess the impacts of major corridor improvements. The Major Corridor InvestmentBenefit Analysis System (MCIBAS) system was developed for the Indiana Department of Transportation to provide an integrated system of tools for assessing the relative costs and benefits, and economic impacts of proposed major highway corridor projects. MCIBAS can also be used to help evaluate regional economic disparities and analyze how these disparities are impacted by highway investments. It includes the following modules: Indiana Statewide Travel Model (ISTM), NET_BC, Economic Impact Analysis System (EIAS), and REMI Economic Forecasting and Simulation Model (CSI, 1998). Indiana uses data generated by these models in decision-making only after accounting for in-state transfers of jobs among corridors. While Indiana finds these tools useful for analyzing corridor alignment alternatives, the models are somewhat cumbersome and costly for the prioritization of multiple projects or project packages in the statewide plan (CUBRC et al., 2001). Case studies in Indiana using this approach include the US 31 corridor improvement, the SR 26 \& US 35 corridor improvements, the SR 37 environmental assessment / corridor study, and the I-69 construction.

An economic analysis procedure very similar to MCIBAS is the Highway Economic Analysis Tool (HEAT) developed for the Montana Department of Transportation (MDT). HEAT combines seven automated and linked modules into a software package that MDT operates in house to evaluate the economic benefits and costs of highway investments anywhere in the state. The HEAT analytical steps are as follows: (i) a GIS-based transportation and economic network is defined; (ii) the transportation and market access changes are calculated for alternative scenarios; (iii) impacts on market access and 
operating costs are calculated by industry; (iv) relative profitability and productivity of locations are then calculated; ( $v$ ) the REMI model is run and develop estimates of benefit, and $(\mathrm{vi})$ a cost estimation spreadsheet model is run and costs are compared to benefits (CSI and EDRG, 2005).

Other commercially available tools that can be applied for evaluating economic development impacts of highway projects include: the Local Economic Assessment Package (LEAP-Trans, formerly known as Hwy-Opps), the Regional Dynamics Economic Analysis Model (REDYN), REMI TRANSIGHT (transportation tool with REMI Policy Insight), and Transportation Economic Development Impact System (TREDIS). TREDIS, in particular, is designed to evaluate the full economic development of multimodal transportation investments (road, rail, air, and marine). Additional information on the use and past applications of these tools are offered at:

http://www.edrgroup.com/edr1/Products/index.shtml.

\subsection{Land-Use and Economic Models}

A more recent approach to predict future transportation demand is through the use of integrated transportation and land-use models. Three models that have been developed and attempt to include significant economic factors to better reflect how markets respond to changes in land use and transportation access, are: TELUS (Transportation, Economic, and Land-Use System), METROSIM, and MEPLAN models. The TELUS system was developed by the New Jersey Transportation Institute, Rutgers University, and the North New Jersey Transportation Planning Authority to help MPOs select projects for their TIPs (Transportation Improvement Plans). TELUS has three components: a) a data base with key information about projects; b) an I-O model for estimating jobs created and the income and tax impacts of projects; and c) a land use model for estimating property tax impacts. The research team used national inter-industry relationships as well as relationships developed from New Jersey bid sheets to develop impact factors and economic multipliers for the I-O model. Multipliers reflect the ratio of total/direct effects, and are expressed in terms of jobs (by industry), income, and GRP per million dollars of original investment. The METROSIM model is a custom model currently being tested in New York metro area. It combines a market-oriented economic (labor market) 
model with a transportation and land use model. The model takes into account how transportation projects are affected by the locational pattern of demand for land uses, and also allows basic and service employment to respond to transportation changes through labor market and businesses location decisions. The land use models MEPLAN has been applied in a number of metropolitan areas in the US and Europe. The MEPLAN model has been used to forecast impacts of local projects on urban areas, and broader regional impacts of larger projects. The local urban applications have typically featured small area zones and very limited industry detail, while the larger regional applications have typically featured broader zones and a greater level of industry detail. More information about these models is provided in Weisbrod (2000) and FHWA (2002).

\subsection{Link of Different Economic Models}

A recent study (Hodge and Hand, 2004) highlighted two recent state economic analyses of future program-level transportation investments in Florida and Wisconsin. Both analyses demonstrated the direct and dynamic effects of transportation on economic growth at the program-level. This study described the first efforts to link two established economic models - the Highway Economic Requirements System (HERS) model (Jack Faucett Associates, Inc., 1991), and the Regional Economic Models, Inc. (REMI) model (Fan et al., 2000). HERS was used to estimate the benefits to users of the highway system. REMI was used to convert these user benefits into macroeconomic benefits (in terms of real disposable personal income).

\subsubsection{Comparison of Input-Output and Economic Simulation Models}

As it can be inferred by the review of the current state-of-the-practice of analysis methods for estimating economic development effects, there are a wide range of commercially available input-output models that can be used to evaluate differing transportation projects. They range from the relatively inexpensive and fairly simple Regional InputOutput Modeling System (RIMS II) to the moderately priced and more complex Minnesota IMPLAN input-output model. A noticeable trend has been a shift to the most sophisticated and expensive integrated input-output-econometric model currently available 
for analysis of this type known as REMI. The benefits and drawbacks pertaining to the use of each model for economic analysis purpose, discussed in detail in the previous sections, make the choice of the appropriate analysis method a complex procedure. Table 2.3 provides a comparison of RIMS II, IMPLAN and REMI models, using information reported in FHWA (1994), Lynch (2000), and online at: http://www.bea.gov/bea/ regional/rims/; www.implan.com; www.remi.com.

Table 2.4 Comparison of the Different Models

\begin{tabular}{|c|c|c|c|}
\hline & REMI & RIMS II & IMPLAN \\
\hline \multicolumn{4}{|l|}{ Type } \\
\hline Regional Input-Output Model & & $\sqrt{ }$ & $\sqrt{ }$ \\
\hline Conjoined Input-Output and Behavior Model & $\sqrt{ }$ & & \\
\hline \multicolumn{4}{|l|}{ Inputs } \\
\hline Location & $\sqrt{ }$ & $\sqrt{ }$ & $\sqrt{ }$ \\
\hline Reference Year & $\sqrt{ }$ & $\sqrt{ }$ & $\sqrt{ }$ \\
\hline Analysis Period & $\sqrt{ }$ & & \\
\hline Expenditures per year & $\sqrt{ }$ & $\sqrt{ }$ & \\
\hline Total Sum of Expenditures & & & $\sqrt{ }$ \\
\hline Consumer Price Index & $\sqrt{ }$ & & $\sqrt{ }$ \\
\hline \multicolumn{4}{|l|}{ Sector Scheme } \\
\hline Disaggregated & 493 & 531 & 538 \\
\hline Aggregated & 53 & 39 & User Choice \\
\hline \multicolumn{4}{|l|}{ Outputs } \\
\hline Employment by industry & $\sqrt{ }$ & $\sqrt{ }$ & $\sqrt{ }$ \\
\hline Output by industry & $\sqrt{ }$ & $\sqrt{ }$ & $\sqrt{ }$ \\
\hline Earnings by industry & $\sqrt{ }$ & $\sqrt{ }$ & $\sqrt{ }$ \\
\hline Gross Regional Product (GRP) & $\sqrt{ }$ & & $\sqrt{ }$ \\
\hline Personal income & $\sqrt{ }$ & & $\sqrt{ }$ \\
\hline Personal Consumer Expenditures (PCE) index & $\sqrt{ }$ & & $\sqrt{ }$ \\
\hline Population by Demographic Group & $\sqrt{ }$ & & \\
\hline \multicolumn{4}{|l|}{ Applications on Transportation Projects } \\
\hline $\begin{array}{l}\text { Highway projects (highways, corridor improve- } \\
\text { ments) }\end{array}$ & $\sqrt{ }$ & $\sqrt{ }$ & $\sqrt{ }$ \\
\hline $\begin{array}{l}\text { Transit investments (high speed rail, urban } \\
\text { transportation, commuter rail) }\end{array}$ & $\sqrt{ }$ & & $\sqrt{ }$ \\
\hline Freight Projects (harbors, cargo facilities) & $\sqrt{ }$ & & $\sqrt{ }$ \\
\hline $\begin{array}{l}\text { Public infrastructure (military base, gas pipe- } \\
\text { lines, bridges, canals) }\end{array}$ & $\sqrt{ }$ & $\sqrt{ }$ & $\sqrt{ }$ \\
\hline Airports & $\sqrt{ }$ & $\sqrt{ }$ & $\sqrt{ }$ \\
\hline Industries (export industries, industry location) & $\sqrt{ }$ & & $\sqrt{ }$ \\
\hline Other (congestion, truck weight regulations) & $\sqrt{ }$ & & \\
\hline Costs for Statewide Analysis & & $\$ 275$ & $\$ 750$ \\
\hline Leasing models is available & $\sqrt{ }$ & & \\
\hline
\end{tabular}




\subsection{Explanatory Variables in Econometric Models}

A review of the economic development literature identified a number of factors hypothesized to affect economic development in a region. For industries considering location or expansion in a region, encouraging factors besides highway infrastructure were theorized to be (Blair and Premus, 1987; Lombard et al., 1992):

- Resource costs;

- Airport accessibility;

- Facilities that enhance the quality of life;

- Proximity to metropolitan areas;

- Relative wage rates and the presence of similar industries in the region;

- Tax rates; and

- Education levels.

Factors such as exogenous trends influencing local industries need also to be considered. Otherwise, causality may be incorrectly attributed (or not attributed) to the transportation project.

Other explanatory factors encountered in multiple regression analysis to estimate and forecast economic development effects of highway projects include (EDRG and CSI, 2001):

- Business/industry type;

- Experiment or control area; 
- Type of transportation improvement;

- Area type (urban, suburban, rural);

- Population of city for which impact is being measured;

- Region's industry base/economic type (tourism, coal, etc.);

- Median income of area; and

- Time-trend variable (applicable for time series data).

Additionally, county-level measures of road lane-miles (for different functional classes of roads can be also used as the explanatory variable to describe highway system changes. For example, the density of highway lane-miles can be used as independent variable to represent the extent and coverage of the highway network.

\subsection{Key Findings from the Literature Review}

The relationship between transportation and economic development is a subject that has occupied a good deal of attention over many years in both advanced and developing countries. Much of the research to date has been primarily providing a better understanding of the underlying factors that affect the interaction between highway investment and economic development. Research and practice tend to support the following conclusions (McQuaid et al., 2004; Flyvbjerg et al., 2003; EDRG and CSI, 2001; Weisbrod, 2000; Brown, 1999; Apogee Research Inc., and Greenhorne \& O'Mara, 1998; Eberts, 1990; and Drew, 1990):

- A good transportation system is a necessary but not a sufficient condition for development. Transportation investment alone will not result in economic development. 
- The existence of public infrastructure is a necessary precondition for economic growth. The consensus among economists is that public infrastructure stimulates economic activity, either by augmenting the productivity of private inputs or through its direct contribution to output, and it may also attract households and firms, which further contributes to an area's growth. However, the corresponding effect depends on the type of investment and on the economic conditions of the region.

- Accurately measuring the economic effects of highway investment is difficult because of the problems of isolating highway effects from the larger processes associated with regional economic growth. Studies that include specific causal factors have shown that other factors are often at least partially responsible for impacts correlated with transportation improvements.

- In determining business location, transport factors are more likely to influence intra-regional than interregional location decisions; that is, they influence the decision of where to locate within a region once that region has been chosen. Other factors such as a skilled and/or cost of workforce, the quality of the local environment, and cost of premises have been shown to be equally-if not more important—when considered in isolation.

- Economic development impacts of highway investment can vary considerably from project to project depending upon a variety of local circumstances. Important factors include the presence of other economic development programs or activities, area size and type (rural, urban, population, etc.), and proximity to a larger metropolitan area. Local economic characteristics are also important but have been more difficult to describe or quantify.

- Investments in transport infrastructure may be expected to result in significant development effects mainly in the following situations: (i) in regions where serious capacity problems exist in a network; (ii) in large urban areas where new capacity would result in significant savings in the cost of transport; and (iii) in situa- 
tions where investments in various types of infrastructure go together with investments in social capital.

- Economic development measures (e.g., income) are found to have a valid statistical connection with accessibility, but only explain a portion of the spatial variation of economic development. All other things being equal, there is a positive relationship between regional accessibility and levels of household income. The relationship is stronger in urban areas than in rural areas, but exists to some degree in both urban and rural settings. Past studies in Indiana have corroborated this finding (CSI and BLA, 2003).

- Rural counties in close proximity to metro areas and those with some prior degree of urbanization benefit economically, at least in the short term, by new highways, especially interstates. Less clear is whether these counties benefit in the long-run and what advantages more isolated rural counties derive from highway construction.

- Investment in higher-level facilities (interstate highways and other National Highway System routes) appears to have a closer relationship with economic growth than other types of highway investment.

- The relationship between interstate highway access and manufacturing is particularly strong. This is an important finding given the large role that manufacturing has in Indiana's economy.

Some of the limitations of the current state-of-the-practice that have been identified (EDRG and CSI, 2001) include:

- Study methodologies are driven by readily available data and budget limitations. Impacts are most commonly measured at the county level. Although disaggregate economic data are available they are rarely utilized due to the expense and level of effort required. Most importantly, research dealing with specific facility type improvements is limited. 
- Clear cause-and-effect relationships are not easy to establish. Quantitative methods such as multivariate regression are an effective way of introducing explanatory variables, measuring statistical significance, and considering time trends but have only shown correlation and not causation between transportation and economic growth. Qualitative evidence such as interviews with local officials and businesses provide equally important insights into local factors and considerations. The most recent informative studies use a combination of quantitative statistical techniques and qualitative assessments to identify causal factors and determine relationships.

- More attention is required to improve explanatory variables. Investigation is needed into how locality-specific factors and other explanatory variables play a role in the economic changes following completion of new highway investments. Moreover, more attention to intermediate variables could improve behavioral interpretations, particularly how changes in traffic volumes and patterns relate to business changes and economic impacts.

- More attention is required to explain the time-dynamics of impacts. Most studies to date have simply measure change over a single time period. In reality, some impacts may occur immediately, while others may take many years to occur.

- Finally, the ultimate objective of empirical studies should be to improve the judgment of planners and decision-makers as to when, and to what extent, a proposed highway investment will result in economic benefits to the communities and regions that it serves. A high level of complexity in data collection requirements as well as in the existing analytical methods is a common limitation in analyzing economic development impacts. 


\section{CHAPTER 3. STATE ECONOMIC DEVELOPMENT PRACTICES}

\subsection{Overview}

The previous chapter provided a basic overview of the types of economic impacts that might be expected from transportation investments, empirical findings, and common economic development impact modeling methodologies. This chapter focuses on how economic development is addressed across states in terms of existing highway-related economic development programs or policies operated by state transportation agencies. These programs support investments that are not justified by traffic or safety conditions, but are rather being done with the intention of spurring economic development.

A FHWA-funded research project developed a list of economic development highway programs as they existed in late 2002 and early 2003. This research was conducted by the Economic Development Research Group (Weisbrod and Gupta, 2003). The primary sources used were public information available online at state transportation agency websites, and telephone interviews with local government officials responsible for state transportation agencies economic development programs. According to this study, from a national perspective, counting both stand-alone state programs and state funding within the Appalachian Regional Commission's programs, there are 28 states that participate in some type of funding for economic development highway programs. Another 11 other states have existing policies recognizing economic development as a factor in project decision-making. The remaining 11 states have no formal funding programs or policies in place regarding economic development highway projects. However, even among them, three are currently considering setting up economic development highway policies: (1) California Department of Transportation; (2) Colorado Department of Transportation; and (3) Utah Department of Transportation. 
The state economic development programs and policies are summarized in Table A.1 (Appendix A) and discussed in more detail next.

\subsection{Formal Economic Development Highway Programs}

According to the study (Weisbrod and Gupta, 2003), state's economic development highway programs have four categories of objectives:

1. Provide public access to new, existing, or expanding industries with the intention to create jobs and spur private sector investment;

2. Provide public access to industrial zones;

3. Provide infrastructure investments associated with local or city government's economic development efforts; and

\section{Expand highway network to rural areas.}

The study (Weisbrod and Gupta, 2003) also indicates that the funding for economic development programs of state transportation agencies is sourced through various methods: 1) state capital funds (Alabama, North Carolina, Oregon, Virginia, West Virginia); 2) state road funds and local government funds (Illinois, Wisconsin); 3) state transportation revenue streams such as fuel sales tax, bonds, and other highway user revenue funds (Arizona, lowa, Georgia, Louisiana, Mississippi, South Carolina); 4) innovative finance programs (Michigan, Missouri, New York); 5) multi-year grant appropriations determined by the state legislature (Massachusetts, Washington); and 6) some portion of federal aid funds (Mississippi, Washington).

State transportation agencies differ in the way economic development programs are supported, the type of construction projects covered by these programs, and the way in which the economic development justification is defined. The profiles of the existing 
formal economic development road and highway programs are provided in detail in Weisbrod and Gupta (2003).

\subsection{Other State Policies and Activities}

Beyond programs that explicitly allocate funding for road and highway investment to address economic development goals, many states have policies that effectively promote the use of other program funds for these purposes. These policies can be classified into three groups (Weisbrod and Gupta, 2003):

- Set-aside of funds for discretionary economic development-related projects (Table A.2 in Appendix A).

- Inclusion of economic development as a factor in highway investment decisions (Table A.3 in Appendix A).

- Policies or programs in development (California, Colorado, and Utah DOTs).

\subsection{Distinguished State Practices in Project Prioritization/Ranking}

\subsection{1. lowa's RISE Program}

As part of the RISE program, lowa DOT uses five project rating criteria to select projects that have a strong potential to support economic development, but do not require an immediate commitment of funds. The five rating factors are as follows (lowa DOT, 1986):

1. Development potential (30 percent)-This factor captures the likelihood that development will take place at the site. Development includes business, industry, parks, and recreational or tourism activities. 
2. Economic impact (30 percent)—A series of cost effectiveness measures are used, including RISE dollars per direct and indirect job created or retained, the number of direct and indirect jobs created or retained per 1,000 people in the county, the number of visitors that will be attracted, and private capital investment leveraged per RISE dollar.

3. Local commitment and initiative (30 percent)_-This factor refers to the level of effort made to plan for and attract economic development at the site: whether arrangements have been made to put in place factors other than transportation (zoning, utilities, worker training program, etc.) to enhance the chance of success of the development; the amount of local participation in the roadway project; whether the applicant has used available marketing services such as the Community Economic Preparedness Program of the lowa Department of Economic Development.

4. Transportation needs (5 percent)—Consistency between the candidate project and area long-range plans is assessed (whether or not the roadway project has been identified as a transportation need), as well as the distance of the site from the state and interstate highway system.

5. Area economic need (5 percent) - For this factor, the level of unemployment and income relative to the state as a whole is measured, and the local tax effort is compared with the local tax capacity.

\subsubsection{Massachusetts PWED Program}

In 2004, the Massachusetts Public Works Economic Development (PWED) Program implemented a new process that provides for a formal scoring that allows projects to be categorized as "High", "Medium", or "Low" based upon the following scale (Weisbrod and Gupta, 2005): 
1. Employment and economic development opportunities (maximum 60 points), such as number of jobs to be created or retained, effect on area's unemployment rate, project wage average compared to state wage average, positive impact on local tax base, and significant public sector leverage of private sector investment.

2. Consistency with and support of other state and local smart growth and transportation goals (maximum 20 points).

3. Consistency with other state policies (maximum 20 points).

\subsubsection{Wisconsin's Programs}

\subsubsection{Wisconsin's TEA Program}

The Transportation Economic Assistance (TEA) program was created in Wisconsin to help communities attract employers and create more jobs through transportation improvements. Through TEA, local communities initiate funding requests which are reviewed four times a year. Eligible projects include all modes of transportation such as access roads, rail spurs, or intersection widening. After it has been determined that a local transportation improvement proposal meets all the eligibility conditions, as determined by a screening process, its funding priority is established by the following criteria and point system (maximum 14 points) (WisDOT, 1986):

1. Cost per job created or retained by the business directly benefiting from the improvement (maximum 10 points) - This weight is calculated from the following formula:

$$
10-\left(\frac{2(\cos t / j o b)}{1,000}\right)
$$

Projects with an infrastructure cost in excess of $\$ 5,000$ per job would receive zero points on this criterion, and would likely be disqualified for funding, while projects with costs per job less than $\$ 5,000$ receive a positive weight. 
2. County unemployment rate (maximum 1 point)-One point is earned for the unemployment criterion, that is if the county unemployment rate was above the 75th percentile rate for all Wisconsin counties during the previous calendar year; zero, otherwise.

3. Transportation efficiency (maximum 2 points), measured by the cost savings that would result from the infrastructure improvements.

4. Geographic diversity (maximum 1 point)_A project receives one point for geographic diversity if no TEA projects have been funded within 20 miles during the previous two fiscal years.

Furthermore, Wisconsin transportation department monitors the results of all grants, in terms of their achievement and retention of the promised number of jobs. The TEA program has had internal audits conducted twice, the most recent being in June 2003 . It was found that total job creation and retention was actually 16 percent above the level promised on applications, and the average time for achievement of the number of jobs was three years. The state average cost per job to date has been $\$ 2,356$ per direct job created or retained significantly better than the $\$ 5,000$ per job standard required for project funding (Weisbrod and Gupta, 2005).

\subsubsection{Project Prioritization Process}

Wisconsin Department of Transportation (WisDOT) employs a quantitative evaluation process to rank "major highway projects," which are defined as projects with a projected cost of over $\$ 5$ million, involving new construction of over 2.5 miles in length, or significant reconstruction and rehabilitation efforts (WisDOT, 1999). Wisconsin's Transportation Projects Commission (TPC), a 15-member commission, reviews candidate projects and recommends projects to the Governor and the Legislature for funding. WisDOT conducts preliminary environmental and engineering studies so all projects brought before the TPC will have undergone a draft Environmental Impact Statement or Environmental Assessment. This ensures that only projects likely to be future major project 
candidates are considered for funding. WisDOT ranks each candidate project on the basis of five categories of measures (with relative weights in parentheses):

1. Economic (40 percent), including benefits for existing businesses, potential for new business attraction and increased connectivity between economic centers.

2. Traffic flow (20 percent).

3. Safety (20 percent).

4. Environmental (10 percent).

5. Community input (10 percent).

In practice, Wisconsin uses an expert panel to assign scores to each economic measure, but the state is studying ways to implement more rigorous and objective forecasts of economic impacts in the future (CSI et al., 2004).

\subsubsection{Kansas's System Enhancement Program}

Kansas Department of Transportation uses a ranking/rating tool to assess the worthiness of highway projects in its program designed to fund state highway projects that improve safety, relieve congestion, improve access, or enhance economic development. To receive funding, projects must have the potential to accelerate the pace of development in their impact area. All applications are evaluated based on a 100-point scoring mechanism, excluding bonus points, based on the following scale (CUBRC et al., 2001):

1. Economic development enhancement (20 percent), ratings for each project assigned by an independent panel of experts.

2. Current volume/capacity ratio (25 percent).

3. Estimated future volume/capacity ratio (20 percent). 
4. Average trip length index (5 percent).

5. Accident rate (5 percent).

6. Fatal accident rate (5 percent).

7. Priority formula rating (10 percent).

8. Truck traffic (10 percent).

\subsubsection{Ohio's Economic Scoring Process}

Ohio Department of Transportation uses a ranking/rating tool that includes economic development criteria in its major new project selection process (ODOT, 2003). Ohio relies on an expert panel to assign points rather than a quantitative modeling approach. Factors related to economic development account for 30 percent of the maximum score that a project can receive (excluding points from bonus categories). The following are indicators for the economic development component of Ohio's project selection process with maximum possible scores in parentheses:

1. Job creation (maximum 10 points) - the level of non-retail jobs the project creates.

2. Job retention (maximum 5 points) —evidence that the project will retain existing jobs.

3. Economic distress (maximum 5 points) - awards points based on the severity of unemployment in the county. This measure directly estimates economic needs and regional economic equity.

4. Cost-effectiveness of investment (maximum 5 points) -a ratio of the number of jobs created and investment attracted. Determined by dividing the cost to Ohio for the transportation project by the number of jobs created. 
5. Level of investment (maximum 5 points) - the level of private sector, non-retail capital attracted to the state because of the project.

\subsection{Summary of State Funding Programs and Policies}

In a broad view, all transportation-related economic development programs operated by state agencies have formal application processes, eligibility criteria and project selection criteria. All of these state-funded economic development highway programs share common features: inner city or highway constructions, a local match requirement, and state capital funding. Project benefits are judged based on anticipated job growth, wage growth, and private investment (or local tax base growth) rather on need to expand capacity to meet projected demand. Some of the programs also have some form of benefit/cost standard, which may include the ratio of wages and property tax revenues generated per dollar of public investment, or the ratio of jobs created per dollar of public investment. Still, state agencies rely heavily on an expert panel to assign scores to each rating criterion rather than on a quantitative modeling approach.

While the economic development factors that are considered in judging project eligibility and priority may differ across programs, all of the states allow some flexibility and discretion, in order to be responsive to time-sensitive business growth and attraction opportunities. In addition, all of the programs involve a process of coordination between the state transportation department and the state economic development department to develop package offers of investment assistance to firms considering locations in the state. Some states, including Arizona, Massachusetts, and Pennsylvania, also collaborate with their local economic development agencies in project selection process, administration or cost sharing. The joint collaboration of state transportation agencies and local economic development offices creates a synergy of economic development efforts and provides scalability and flexibility in project selection and implementation. Finally, some programs have distinguishing elements that are indicative of best practices such as : the economic scoring process in Ohio, job tracking and auditing in Washington and Wisconsin, and the measuring of the impact of economic development programs in Georgia and lowa (Weisbrod and Gupta, 2005; Gupta et al., 2005). 


\section{CHAPTER 4. STUDY METHODOLOGY AND DATA COLLECTION}

\subsection{Overview}

The currently available base of information summarized in a previous chapter includes a wide assortment of studies ranging from extremely broad national studies (such as the literature on national productivity impacts of highway spending over time) to extremely narrow and not adequately controlled project assessments. While interesting, many of these studies are not sufficient by themselves to differentiate the advantages and disadvantages of alternative highway investments. For example, productivity studies, particularly those using production and cost function frameworks, typically do not take into account the intensity of highway system use nor do they encompass system-wide effects. Treating all transportation systems as though the resulting traffic flows are the same could potentially lead to biases in the estimates of the productivity of the transportation infrastructure (Eberts, 2000). Moreover, a high level of complexity in data collection requirements as well as in the existing analytical methods is a common limitation in analyzing economic development impacts. Traditionally the estimation of economic development impacts of highway construction spending has been conducted with the use of Input-Output methodology that produces economic multipliers. However, these models do not account for long-term economic, industrial, and demographic changes, or for changes in business costs over time, but rather produce results that are only valid for fixed points in time. As such, input-output analysis is unlikely to be useful as a standalone approach, or be applied at the project level to distinguish between different types of highway improvements.

This research study builds on the findings and general principles of prior research, and the limitations of past analytical methodologies to provide a more credible foundation for making highway investment decisions on the basis of sound economic development criteria. As such, this study expands the existing knowledge base by using rigorous ana- 
lytical tools (i.e., economic analysis, economic simulation models and econometric methods) to estimate the statewide economic development impacts associated with highway investment over time. The investment scenarios are based on improvements identified in the 2025 Statewide Transportation Plan (CSI and BLA, 2004). The improvement types that will be considered include: added travel lanes, median construction, new interchange construction or modification, new alignments and bypass projects. In summary, the paper provides a methodological approach and results concerning:

- What is the nature of economic development effects associated with individual highway projects?

- How location and project-specific factors interact to stimulate economic development?

- How highway investments can be used as a tool for expansion of job and income opportunities?

The end product of this research is an easy-to-use quantitative tool that can be used at the project development phase by INDOT staff to estimate the economic development effects of different types of highway investments, in a bid to identify the most efficient allocation of resources.

\subsubsection{Economic Development Measures}

In the present study, multiple indicators of economic development are used to ensure a thorough and robust understanding of economic development effects and to help identify any changes in the mix of economic activity. The economic development impact measures that are considered, are defined according to (Weisbrod and Weisbrod, 1997), and are consistent to those used in previous studies in Indiana (CSI and BLA, 2003):

i. Net change in employment: a standard factor that captures the net change in jobs (full-time and part-time) in the economy, and is easily understood. In a sur- 
vey of economic development practices across transportation agencies across the Nation, this measure was identified as the most useful for public information and decision-making (Weisbrod, 2000).

ii. Net change in real disposable income: this measure primarily reflects the net change in inflation-adjusted wage income earned by workers within the state. This is considered the most conservative measure of the total income impacts of a project.

iii. Net change in real output or business sales: it is the amount of production, including all intermediate goods purchased as well as value-added (compensation and profit). This measure indicates how the cost savings or productivity gains associated with the transportation improvement would affect business decisions to expand production or increase sales in the region. It can be also thought of as sales or supply. Output was the second measure after employment that was of most importance to agencies for communicating findings on economic impacts to decision-makers, as stated in the survey (Weisbrod, 2000).

iv. Net change in gross regional product (GRP): it is the sum of wage income and corporate profit generated in the region and reflects the overall economic activity in a region. A caveat in the use of this measure is that it could lead to overestimation of project benefits.

In terms of the direct nature (or otherwise) of their impacts, the aforementioned measures of economic development may be manifest in one of three ways (Weisbrod 2000): (1) as direct jobs from spending on construction and ongoing operations; (2) as indirect and induced impacts; and (3) as long-term project benefits (Weisbrod, 2000). For purposes of the present study, economic development impact measures refer to statewide long-term changes in economic development such as business location patterns, work force, labor costs, and prices.

Different measures were introduced as a proxy for general economic activity to correct the deficiencies inherent in each measure. For example, employment often does not 
detect general economic expansion caused by technical progress; income and output variables tend to rise relative to employment, especially if the innovations are, on balance, labor saving (Glickman, 1977). Also, real income from economic activity within a State can increase even if employment does not, and employment can be increased by measures and policies that could actually reduce real income (Forkenbrock et al., 1990). Additional measures that consider both project benefits (in terms of the above measures) and agency costs could be expressed as a ratio of benefit to costs, such as the ratio of wages or output generated per dollar of highway investment, or the ratio of jobs created per dollar of highway investment. These measures are typically used as indicators of economic development by state agencies when evaluating competing projects (Weisbrod and Gupta, 2003).

It should be pointed out that the economic development measures represent different perspectives for viewing the same effects of economic growth resulting from the same causes. Because of that relationship, care should be taken to avoid "double-counting" of benefits. Weisbrod and Beckwith (1990) suggested a method that avoids doublecounting; it focuses on the measurement of economic benefits on changes in real disposable income and separately estimating the value of other factors that are not represented in this measure of economic benefits (i.e., travel time and safety benefits for personal travel).

\subsubsection{Analysis Steps}

The final product of this study will be a useful and easy-to-use tool by which INDOT staff can estimate the economic effects of different types of highway improvements. The proposed analysis will assist INDOT staff to have in-house capacity to do economic effects estimation of individual highway projects given data constraints, staffing expertise, available time, and other practical limitations. The overall framework of the study applied for the estimation of regional economic development impacts for different highway improvement categories is illustrated in Figure 4.1. The analysis involves: (i) estimating 
user benefits of INDOT highway projects, (ii) estimating economic benefits ${ }^{4}$, in terms of overall (direct and secondary) long-term changes in business sales (output), employment, and income, with the use of a dynamic economic simulation model, and (iii) developing econometric models for investigating the relationship between the benefit measures of economic development (i.e., output, income and employment), project attributes (project type, size and costs), and location attributes (e.g., county, geographical region, accessibility).



(Econometric Models

Figure 4.1 Study Framework

The major data sources are discussed in the next section.

4 "Economic benefit analysis includes valuation of benefits that are broader than user benefits in that they may accrue to any business or resident in the region deriving additional income from business growth attributable to the highway improvements, even if they do not use the affected highway system, and can include multiplier effects" (Weisbrod and Grovak 2001). 


\subsection{Data Sources}

The present analysis includes an extensive data collection effort. The objectives of this data collection effort are to obtain the information required as inputs for the transportation and economic models, and to verify the findings and interpretation of model results.

Data collection involves gathering information on a number of factors hypothesized to affect economic development. Those factors can be classified into two categories: highway project-specific (project type, size, and associated construction costs), and location-specific factors, as illustrated in Table 4.1. The highway-project specific data, including project location, was obtained from the Indiana's Statewide Long-Range Transportation Plan; information only on the expansion projects was collected (as discussed in the next section). Information on the accessibility and land use indices was compiled with the assistance of INDOT Transportation Planning Personnel and Bernardin, Lochmueller \& Associates Inc. Data on the long-term economic benefits of the selected highway projects were generated with the use of the dynamic economic simulation model REMI (discussed in detail in Chapter 6). This information will be useful in a later part of the analysis to estimate long-term project-level economic multipliers.

Table 4.1 Data

\begin{tabular}{|c|c|c|}
\hline Highway Project-Specific Data & $\begin{array}{l}\text { Location/Accessibility/ } \\
\text { Land Use indices }\end{array}$ & $\begin{array}{l}\text { Statewide Long-Term } \\
\text { Economic Benefits }\end{array}$ \\
\hline $\begin{array}{l}\text { Project Type } \\
\text { Added Travel Lanes } \\
\text { New Construction/ Alignment } \\
\text { Median Construction } \\
\text { Interchange Construction/ } \\
\text { Modification } \\
\end{array}$ & \multirow{3}{*}{$\begin{array}{l}\text { Geographical Region } \\
\text { (North, Central, South } \\
\text { Indiana) } \\
\text { County } \\
\text { District } \\
\text { MPO } \\
\text { Type of Area (Urban/Rural) } \\
\text { Accessibility to Major Air- } \\
\text { ports } \\
\text { Accessibility to Universities } \\
\text { Accessibility to Employment }\end{array}$} & \multirow{3}{*}{$\begin{array}{l}\text { Net Change in Employment } \\
\text { Net Change in Real } \\
\text { Disposable Income } \\
\text { Net Change in Output } \\
\text { Net Change in Gross Re- } \\
\text { gional Product }\end{array}$} \\
\hline $\begin{array}{l}\text { Project Size } \\
\text { Project Length } \\
\text { Number of Lanes } \\
\text { Highway System }\end{array}$ & & \\
\hline $\begin{array}{l}\text { Project Costs } \\
\text { Construction Costs } \\
\text { ROW Costs } \\
\text { Engineering Costs } \\
\text { Duration of Construction } \\
\quad \text { (years) }\end{array}$ & & \\
\hline
\end{tabular}


The data collation efforts are discussed next.

\subsubsection{Indiana's 25-Year Long-Range Plan Highway Expansion Projects}

The Indiana Department of Transportation is in the process of updating its 25-year LongRange Plan. This plan provides a vision for the future development of the state transportation system with an emphasis on the state's highway network. A listing of state highway jurisdiction projects was developed for each of the state's twelve MPO's and each of the six INDOT districts. Projects were developed as one of the three categories: "committed projects" (listed in the first three fiscal years with federal funding be obligated); "proposed capacity expansion projects" (not programmed with traditional and federal funding and require special funding to advance towards implementation); "placeholder type of projects" (proposed for implementation but delayed outside the study's timeframe). Expansion projects include the following types: added travel lanes, new road construction, median construction, new interchange construction, new bridge construction and freeway upgrade. Non-expansion projects include: road rehabilitation (3R), road reconstruction (4R), and Transportation Systems Management (TSM) improvements. To determine the effectiveness of the plan in achieving economic development goals, the economic impacts of the projects included in the proposed 2003-2027 update of the Long-Range Plan (limited in scope to "capacity expansion" projectsapproximately 400 projects), were analyzed. This study was prepared by CSI and BLA (2004).

A representative sample of each highway improvement category (added travel lanes, new road construction, median construction, new interchange construction/modification) was selected. In total, 117 individual highway improvement projects were considered for analysis. The selected sample was further classified according to the area type, to urban and rural projects, as shown in Table 4.2. 
Table 4.2 Classification of Projects by Area and Highway Improvement Type

\begin{tabular}{|c|c|c|}
\hline & URBAN & RURAL \\
\hline Added Travel Lanes & 27 & 31 \\
\hline Median Construction & 20 & 4 \\
\hline New Road Construction & 8 & 18 \\
\hline Interchange Construction & 7 & 2 \\
\hline Total Number of Projects & 62 & 55 \\
\hline
\end{tabular}

Additional information provided for the LR Plan projects include: project ID, route, functional class, project length, start lanes, end lanes (after the improvement), project costs (in 2003 dollars ${ }^{5}$ ), district, MPO, and county. The summary statistics for the state highway jurisdiction projects included in the LR Plan are provided in Section 4.3.

\subsubsection{Highway Performing Monitoring System (HPMS) Database}

Necessary inputs for the travel demand and user benefit analysis such as information on highway geometrics, traffic operation data, and design parameters were obtained from the 2005 Highway Performance Monitoring System (HPMS) of Indiana (FHWA, 2000). In general, the HPMS is a national level highway information system that includes data on the extent, condition, performance, use, and operating characteristics of the Nation's highways. Likewise, the HPMS of Indiana is an inventory system that contains administrative and extent of system information on all public roads in Indiana.

The 2004 Statewide Reference Post Book (INDOT, 2005) was used to locate the projects on the state highway network and then, relate the data elements provided in HPMS to the location of these projects. Inventory information collected include: geometrics (e.g., lane, median and shoulder widths), traffic performance data and operation attributes (e.g., average annual daily traffic (AADT) for base year and a 20-year forecast

${ }^{5}$ The FHWA Highway Construction Price Index [online: http://www.fhwa.dot.gov/programadmin/ pricetrends.htm] was used to convert the 2003 dollar-values to 1996-dollar values, to be consistent with the units of the outputs (i.e., statewide long-term economic benefits of the selected highway projects) generated with the use of the regional economic model, REMI. 
AADT, facility capacity, percent single-unit trucks and percent combination trucks). Summary tables of the data reported in HPMS are provided in Appendix B (Tables B.1 and B.2).

\subsubsection{Indiana's Economic Profile and Transportation Statistics}

Information on Indiana's industries and business establishments by number of employees was obtained by the United States Bureau of Economic Analysis (US BEA). The service industries are primarily located on urbanized areas, while the heavy manufacturing, construction and wholesale industries are located in non-metropolitan areas. Separate tables were compiled for industries located in metropolitan and non-metropolitan areas in Indiana, as shown in Table B.3 (Appendix B).

Industrial specialization (or clustering) in Indiana was measured by conducting a location quotient analysis at the county level. A location quotient (LQ) is taken as a rough indicator of a region's competitiveness in that industry, measured in terms of employment. A LQ of one means an industry makes up the same share of a regional economy as it does of the national economy. The higher the LQ, the greater the competitive advantage a region appears to have (Glickman, 1977). LQ were calculated using the Location Quotient calculator-a tool produced by the United States Bureau of Labor Statistics (US BLS, 2005). The location quotients for selected industries in Indiana are provided at the county-level in Table B.4 (Appendix B).

Finally, the US Bureau of Transportation Statistics (US BTS) and the INDOT 1995 Survey served as the main sources of information main information sources for automobile travel in Indiana, including the percent of business-related automobile trips by area type (urban, rural), and automobile occupancy by trip purpose (business and non-business related trips) and by area type (urban, rural). The share of business-related automobile trips in rural areas in Indiana ranges from 3 to 5 percent, while the corresponding share in urban areas ranges from 4 to 6 percent. The average automobile occupancy for business-related trips in rural areas is 1.2 , while the average automobile occupancy for similar trips in urban areas is 1.1. 


\subsubsection{Regional Accessibility in Indiana}

The concept of personal accessibility relates to the ease with which residents of a particular region can travel to population and employment centers, and other types of attractions such as health facilities, educational institutions, airports, and cultural events. Accessibility is typically measured by calculating an index. Such index provides a quantitative measure of the attractiveness of destinations of a particular kind, and how quickly travelers can get there. Mathematical calculations are typical used to generate these indices which take into account both travel time and the size of the attraction to which people travel. Generally, a region which is well-connected internally and externally to common travel destinations has a high degree of accessibility. In contrast, a region that has a less-well developed highway network will generally have a low degree of accessibility.

Information on accessibility in Indiana was compiled based on the methodology established as part of the Indiana Statewide Travel Demand Model. Given below are some key concepts involved in using the model to calculate accessibility indices to airports, employment and universities, as described in CSI and BLA (2003):

Traffic Analysis Zone (TAZ): The entire state is divided into traffic analysis zones (TAZs). Each TAZ represents a portion of a county. Generally, the area within each TAZ is characterized by a relatively consistent type of land use. For example, urban and rural areas generally would not be included within the same TAZ.

Attractive Force (AF): For the purposes of each accessibility index, each TAZ was assigned an "Attractive Force" (AF). This AF measures the amount of a particular attraction contained in each zone. For each of the accessibility measures, the AF was defined as follows:

- Access to Employment: For each TAZ, AF was defined as the employment in that zone. 
- Access to Airports: If a TAZ contains an airport with scheduled commercial passenger service, $A F$ is the annual number of air passenger enplanements. Otherwise, $A F$ is equal to 0 .

- Access to Universities: If a TAZ contains a college or university with an enrollment of at least 2,500 students, AF is the number of students enrolled. Otherwise, $A F$ is equal to 0 .

Network Travel Time (t): For each TAZ, the model calculates the average congested travel time (for 24 hours) between that TAZ and each of the other TAZs in the entire model. The travel time between the TAZs is adjusted by an impedance exponent to reflect the fact that people do not respond to variations in travel time in a purely linear fashion. This impedance exponent is used to reflect people's actual behavior, in that drivers' willingness to travel to destinations drops.

Accessibility Index (AI): This index is determined by calculating the ratio of the attractive force to travel time between that TAZ and each other TAZ, and then calculating the sum of those ratios. If the value of this index is high for a TAZ, that TAZ has high accessibility to that attraction. If the value of this index is low for a TAZ, that TAZ has low accessibility to that attraction. The mathematical formula is expressed as follows:

$$
A I=\sum_{j} \frac{A F_{j}}{t_{i j}^{x}}
$$

where, $A I$ is the accessibility index; $A F_{j}$ is the attractive force at zone $j ; t_{i j}$ is the network travel time between $i$ and $j$, and $x$ is the impedance exponent.

For the purposes of this statewide study, the accessibility indices to airports, employment and universities are assigned at the county-level and take values from 1 (low degree of accessibility) to 5 (high degree of accessibility). The accessibility indices to airports, employment and universities for Indiana counties are provided in Appendix B (Figures B.1, B.2 and B.3, respectively). 


\subsection{Data Collection Summary Statistics}

The database compiled for the purposed of this study includes 117 highway improvement projects programmed for future implementation in 48 out of 92 counties in Indiana, as part of the Long-Range Transportation Plan. Urban and rural areas are represented in the sample (53 versus 47 percent), as well as areas in Northern, Central and South Indiana (19 versus 47 versus 34 percent). Almost 13 percent of projects are programmed for Marion County, 10 percent for Lake County, while smaller percentage corresponds to the rest 46 counties. Projects are also classified by highway functional class, i.e., whether the improvement is programmed for an interstate corridor, or a US or a state road. The projects are approximately equally distributed on the three aforementioned classes. The average project involves a 7.6-mile highway improvement, costs around \$42 million (in 1996 dollars), has a two-year duration of construction, and medium degree of accessibility to airports, employment and universities (values of 3, 3.5 and 3.2 , respectively).

The summary statistics for the variables collected are presented in Table 4.3 and are grouped as highway project-specific and location-specific variables. When statistically justified, location-specific variables were interacted with other location-specific or highway project-specific variables (indicator or continuous variables). The variables created as a result of that interaction are also presented in Table 4.3. For instance, the summary statistics for ACCAIRPNS, ACCUNIVNS, and ACCEMPNS show that the degree of accessibility to airports, employment and universities of North or South Indiana is significantly lower to that of Central Indiana. This could be of importance when comparing the economic development potential of similar projects in different geographical locations. 
Table 4.3 Summary Statistics for Highway Project-Specific, and Location-Specific Variables

\begin{tabular}{|c|c|c|}
\hline & Variable Code & $\begin{array}{r}\text { Percentage or Mean } \\
\text { (standard deviation) }\end{array}$ \\
\hline \multicolumn{3}{|l|}{ Project-Specific Variables } \\
\hline $\begin{array}{l}\text { Distribution of Projects by Project Type } \\
\text { (Added Travel Lanes/Median Construc- } \\
\text { tion/New Road Construc- } \\
\text { tion/Interchange Construction) } \\
\end{array}$ & ATL/MC/NRC/IC & $\begin{array}{r}49.6 / 20.5 / \\
22.2 / 7.7\end{array}$ \\
\hline $\begin{array}{l}\text { Distribution of Projects by Highway Sys- } \\
\text { tem (Interstate/US/State Highway) }\end{array}$ & I/US/ST & $\begin{array}{c}30.8 / 35.0 / \\
34.2\end{array}$ \\
\hline Project Length (miles) & PRLENGTH & $7.60(7.16)$ \\
\hline $\begin{array}{l}\text { Number of Travel Lanes before the } \\
\text { Improvement }\end{array}$ & STARTLN & $3.37(1.47)$ \\
\hline $\begin{array}{l}\text { Number of Travel Lanes after the } \\
\text { Improvement }\end{array}$ & ENDLN & $4.96(1.85)$ \\
\hline Number of Added Travel Lanes & ADDEDLN & $1.58(0.89)$ \\
\hline Start Lane-miles & STARLNMI & $24.75(24.64)$ \\
\hline End Lane-miles & ENDLNMI & $38.00(37.49)$ \\
\hline Added Lane-miles & NEWLNMI & $13.25(15.01)$ \\
\hline Project Costs (million 1996 dollars) & PRCOSTMI & $42.11(40.41)$ \\
\hline Duration of Construction (years) & CONSTDUR & $1.99(1.26)$ \\
\hline \multicolumn{3}{|l|}{ Location-Specific Variables } \\
\hline $\begin{array}{l}\text { Distribution of Projects by Geographical } \\
\text { Region (North/Central/South Indiana) }\end{array}$ & $\begin{array}{l}\text { NORTH/CENTRAL/ } \\
\text { SOUTH }\end{array}$ & $19.7 / 47.1 / 34.2$ \\
\hline $\begin{array}{l}\text { Distribution of Projects by District } \\
\text { (Crawfordsville/Fort Wayne } \\
\text { /Greenfield/LaPorte/Seymour } \\
\text { /Vincennes) }\end{array}$ & $\begin{array}{l}\text { CRAWFLLE/ } \\
\text { FORWAYNE/GREENF } \\
\text { LD/LAPORTE/SEYMO } \\
\text { UR/VINCENNS }\end{array}$ & $\begin{array}{c}12.8 / 3.4 / 29.1 / 15.4 / \\
21.4 / 17.9\end{array}$ \\
\hline $\begin{array}{l}\text { Distribution of Projects by Area Type } \\
\text { (Urban/Rural) }\end{array}$ & URBAN & $53.0 / 47.0$ \\
\hline
\end{tabular}


Table 4.3 (Continued)

\begin{tabular}{|c|c|c|}
\hline & Variable Code & $\begin{array}{l}\text { Percentage or Mean } \\
\text { (standard deviation) }\end{array}$ \\
\hline $\begin{array}{l}\text { Percentage of Projects Programmed for } \\
\text { Urban Areas excluding Marion County }\end{array}$ & RESTURBAN & 40.2 \\
\hline $\begin{array}{l}\text { Percentage of Projects Programmed for } \\
\text { Marion County }\end{array}$ & MARION & 12.8 \\
\hline $\begin{array}{l}\text { Percentage of Projects Programmed for } \\
\text { Lake County }\end{array}$ & LAKE & 10.3 \\
\hline $\begin{array}{l}\text { Percentage of Counties Designated as } \\
\text { Economic Center }{ }^{a}\end{array}$ & ECONCENT & 59.0 \\
\hline $\begin{array}{l}\text { Degree of Accessibility to Major Airports } \\
\text { (1-low to 5-high) }\end{array}$ & ACCAIRP & $2.96(1.56)$ \\
\hline $\begin{array}{l}\text { Medium to High Degree of Accessibility } \\
\text { to Airports ( } 1 \text {, if ACCAIRP>2, } 0 \text { other- } \\
\text { wise)/ } \\
\text { High Degree of Accessibility to Airports } \\
(1, \text { if ACCAIRP }>3,0 \text { otherwise) }\end{array}$ & $\begin{array}{l}\text { ACCAIR345/ } \\
\text { ACCAIR45 }\end{array}$ & $52.1 / 41.0$ \\
\hline $\begin{array}{l}\text { Degree of Accessibility to Universities }{ }^{b} \\
\text { (1-low to 5-high) }\end{array}$ & ACCUNIV & $3.47(1.34)$ \\
\hline $\begin{array}{l}\text { Medium to High Degree of Accessibility } \\
\text { to Universities ( } 1 \text {, if ACCUNIV> } 2,0 \\
\text { otherwise)/ } \\
\text { High Degree of Accessibility to Univer- } \\
\text { sities ( } 1 \text {, if ACCUNIV }>3,0 \text { otherwise) }\end{array}$ & $\begin{array}{l}\text { ACCUNIV345/ } \\
\text { ACCUNIV45 }\end{array}$ & $72.6 / 51.3$ \\
\hline $\begin{array}{l}\text { Degree of Accessibility to Employment }{ }^{b} \\
\text { (1-low to 5-high) }\end{array}$ & ACCEMP & $3.21(1.51)$ \\
\hline $\begin{array}{l}\text { Medium to High Degree of Accessibility } \\
\text { to Employment ( } 1 \text {, if ACCEMP>2, } 0 \\
\text { otherwise)/ } \\
\text { High Degree of Accessibility to Em- } \\
\text { ployment ( } 1 \text {, if ACCEMP>3, } 0 \text { other- } \\
\text { wise) }\end{array}$ & $\begin{array}{l}\text { ACCEMP345/ } \\
\text { ACCEMP45 }\end{array}$ & $62.4 / 48.7$ \\
\hline \multicolumn{3}{|l|}{ Additional Variables } \\
\hline $\begin{array}{l}\text { Distribution of Projects in Urban Areas by } \\
\text { Highway System }\end{array}$ & URBI/URBU/URBST & 20.5/14.5/18.0 \\
\hline $\begin{array}{l}\text { Distribution of Projects in Rural Areas by } \\
\text { Highway System }\end{array}$ & RURI/RURU/RURST & $10.3 / 20.5 / 16.2$ \\
\hline
\end{tabular}


Table 4.3 (Continued)

\begin{tabular}{|l|l|c|}
\hline & Variable Code & $\begin{array}{c}\text { Percentage or Mean } \\
\text { (standard deviation) }\end{array}$ \\
\hline $\begin{array}{c}\text { Distribution of Projects in Urban Areas by } \\
\text { Geographical Region }\end{array}$ & $\begin{array}{l}\text { URBNORTH/URBCEN } \\
\text { TR/URBSOUTH }\end{array}$ & $15.4 / 29.9 / 8.5$ \\
\hline $\begin{array}{l}\text { Distribution of Projects in Rural Areas by } \\
\text { Geographical Region }\end{array}$ & $\begin{array}{l}\text { RURNORTH/RURCEN } \\
\text { TR/RURSOUTH }\end{array}$ & $4.3 / 17.1 / 25.6$ \\
\hline $\begin{array}{l}\text { Degree of Accessibility to Major Airports } \\
\text { in North or South Indiana }{ }^{b} \\
(1-\text {-low to 5-high) }\end{array}$ & ACCAIRPNS & $1.32(1.70)$ \\
\hline $\begin{array}{l}\text { Degree of Accessibility to Universities in } \\
\text { North or South Indiana }{ }^{b} \\
\text { (1-low to 5-high) }\end{array}$ & ACCUNIVNS & $1.38(1.52)$ \\
\hline $\begin{array}{l}\text { Degree of Accessibility to Employment in } \\
\text { North or South Indiana }{ }^{b} \\
\text { (1-low to 5-high) }\end{array}$ & ACCEMPNS & $1.36(1.71)$ \\
\hline
\end{tabular}

a for transportation planning purposes.

${ }^{\mathrm{b}}$ value assigned at the county-level.

Table 4.4 offers a comparison of the summary statistics across the four highway improvement types under consideration. Some of the general observations that can be made as a result of the comparison include:

- The majority of ATL projects considered in this study are programmed for highways in rural areas in Central Indiana. The majority of ATL projects in urban areas are programmed for interstate highways.

- The majority of NRC projects considered in this study are programmed for US highways in rural areas in South Indiana.

- The majority of MC projects considered in this study are programmed for US or state highways in urban areas in North or Central Indiana.

- The majority of IC projects considered in this study are programmed for interstate or state highways in urban areas in Central Indiana. 
- On average, NRC projects are programmed for areas with low degree of connectivity, as it can be inferred by the low values of accessibility indices to airports, employment and universities. This does not necessarily apply to the other project types considered.

Table 4.4 Summary Statistics for Highway Project-Specific, and Location-Specific Variables by Highway Improvement Type

\begin{tabular}{|c|c|c|c|c|}
\hline \multirow{2}{*}{ Variable Code } & \multicolumn{4}{|c|}{$\begin{array}{l}\text { Percentage or Mean } \\
\text { (standard deviation) }\end{array}$} \\
\hline & ATL & NRC & MC & IC \\
\hline I/US/ST & $51.7 / 20.7 / 27.6$ & $3.8 / 73.1 / 23.1$ & $0.0 / 37.5 / 62.5$ & $55.6 / 11.1 / 33.3$ \\
\hline PRLENGTH & $11.6(6.9)$ & $6.5(6.3)$ & $1.8(0.9)$ & $0.7(0.8)$ \\
\hline STARTLN & $3.7(1.7)$ & - & - & - \\
\hline ENDLN & $5.9(2.0)$ & $3.8(0.9)$ & - & - \\
\hline ADDEDLN & $2.2(0.6)$ & - & - & - \\
\hline STARLNMI & $38.4(25.2)$ & - & - & - \\
\hline ENDLNMI & $62.4(36.9)$ & $23.8(21.5)$ & - & - \\
\hline NEWLNMI & $24.0(13.4)$ & - & - & - \\
\hline PRCOSTMI & $62.6(38.6)$ & $37.0(42.1)$ & $8.1(4.7)$ & $15.4(6.9)$ \\
\hline CONSTDUR & $2.6(1.3)$ & $1.8(1.2)$ & $1(0)$ & $1(0)$ \\
\hline $\begin{array}{c}\text { NORTH/ } \\
\text { CENTRAL/ SOUTH }\end{array}$ & 8.6/58.6/32.8 & 19.2/19.2/61.5 & $41.7 / 50.0 / 8.3$ & 33.3/44.4/33.3 \\
\hline $\begin{array}{c}\text { CRAWFLLE/ } \\
\text { FORWAYNE/GREE } \\
\text { NFLD/LAPORTE/S } \\
\text { EYMOUR/ } \\
\text { VINCENNS } \\
\end{array}$ & \begin{tabular}{|c|}
$17.2 / 31.0 / 32.8 /$ \\
$1.7 / 10.3 / 6.9$
\end{tabular} & $\begin{array}{c}11.5 / 15.4 / 7.7 / 3.8 / \\
46.2 / 15.4\end{array}$ & $\begin{array}{c}4.2 / 8.3 / 41.7 / 8.3 / \\
4.2 / 33.3\end{array}$ & $\begin{array}{c}4.2 / 8.3 / 41.7 / 8.3 / \\
4.2 / 33.3\end{array}$ \\
\hline URBAN & $46.6 / 53.4$ & $30.8 / 69.2$ & $83.3 / 16.7$ & $77.8 / 22.2$ \\
\hline RESTURBAN & 24.1 & 30.8 & 79.2 & 66.7 \\
\hline
\end{tabular}


Table 4.4 (Continued)

\begin{tabular}{|c|c|c|c|c|}
\hline \multirow{2}{*}{ Variable Code } & \multicolumn{2}{|c|}{$\begin{array}{l}\text { Percentage } \\
\text { (standard deviation) }\end{array}$} & or & \multirow[t]{2}{*}{ Mean } \\
\hline & ATL & NRC & MC & \\
\hline MARION & 22.4 & 0.0 & 4.2 & 11.1 \\
\hline LAKE & 6.9 & 0.0 & 33.3 & 0.0 \\
\hline ECONCENT & 58.6 & 42.3 & 70.8 & 77.8 \\
\hline ACCAIRP & $3.3(1.4)$ & $1.4(0.8)$ & $3.5(1.4)$ & $3.6(1.9)$ \\
\hline $\begin{array}{l}\text { ACCAIR345/ } \\
\text { ACCAIR45 }\end{array}$ & $62.1 / 50.0$ & 7.7/3.8 & $70.8 / 50.0$ & $66.7 / 66.7$ \\
\hline ACCUNIV & 3.8 (1.3) & $2.8(1.3)$ & $3.4(1.1)$ & $3.4(1.7)$ \\
\hline $\begin{array}{l}\text { ACCUNIV345/ } \\
\text { ACCUNIV45 }\end{array}$ & 79.3/63.8 & $50.0 / 30.8$ & $83.3 / 41.7$ & $66.7 / 55.6$ \\
\hline ACCEMP & $3.3(1.4)$ & $2.3(1.5)$ & $3.8(1.3)$ & $3.4(1.9)$ \\
\hline $\begin{array}{l}\text { ACCEMP345/ } \\
\text { ACCEMP45 }\end{array}$ & $63.8 / 51.7$ & $42.3 / 19.2$ & 79.2/66.7 & $66.7 / 66.7$ \\
\hline $\begin{array}{l}\text { URBI/URBU/ } \\
\text { URBST }\end{array}$ & $34.5 / 3.5 / 8.6$ & $3.8 / 19.2 / 7.7$ & $0.0 / 37.5 / 45.8$ & 33.3/11.1/33.3 \\
\hline $\begin{array}{l}\text { RURI/RURU/ } \\
\text { RURST }\end{array}$ & 17.2/17.2/19.0 & $0.0 / 53.9 / 15.4$ & $0.0 / 0.0 / 16.7$ & 22.3/0.0/0.0 \\
\hline $\begin{array}{l}\text { URBNORTH/ } \\
\text { URBCENTR/ } \\
\text { URBSOUTH }\end{array}$ & 8.6/31.0/6.9 & 7.7/7.7/15.4 & $37.5 / 45.8 / 0.0$ & 22.2/44.4/22.2 \\
\hline $\begin{array}{l}\text { RURNORTH/ } \\
\text { RURCENTR/ } \\
\text { RURSOUTH } \\
\end{array}$ & $0.0 / 27.6 / 25.9$ & $11.5 / 11.5 / 46.2$ & $4.2 / 4.2 / 8.3$ & $11.1 / 0.0 / 11.1$ \\
\hline ACCAIRPNS & $1.03(1.50)$ & $1.15(0.93)$ & $2.13(2.36)$ & $1.44(2.07)$ \\
\hline ACCUNIVNS & 1.05 (1.39) & $2.08(1.60)$ & $1.46(1.59)$ & $1.22(1.48)$ \\
\hline ACCEMPNS & $1.03(1.52)$ & $1.38(1.06)$ & $2.08(2.34)$ & $1.44(2.07)$ \\
\hline
\end{tabular}




\section{CHAPTER 5. SHORT-TERM EFFECTS OF HIGHWAY INVESTMENT AND LONG- TERM EFFECTS OF MAJOR CORRIDOR STUDIES IN INDIANA}

\subsection{Estimation of Short-Term Economic Development Effects of Highway Investment}

This section presents the analysis procedure for estimating the economic effects of construction spending for the different types of highway improvements programmed as part of the Statewide Long-Range Transportation Plan (CSI and BLA, 2004). These effects include construction jobs and the secondary impacts of construction that are short-term in nature. As such, they are viewed as not contributing to sustainable economic growth as opposed to the long-term effects of highway investment (which will be the focus of the next chapter). Typically, the short-term effects of construction spending are estimated with the use of input-output analysis (discussed in Section 2.5.1.).

Two input-output models are considered for this purpose: the RIMS II (Regional Input Modeling System II) that is commercially available from the US Bureau of Economic Analysis (US BEA), and the IMPLAN model that is commercially available from the Minnesota IMPLAN Group. Both models are calibrated for the State of Indiana. RIMS II is essential a spreadsheet analysis based on US BEA's National I-O Table and Regional Economic Accounts. RIMS II provides tables of final demand multipliers and direct effect multipliers for output, earnings, and jobs that analysts can apply to their own spreadsheets. The level of industrial detail in RIMS II helps avoid aggregation errors, which often occur when industries are combined. RIMS II multipliers can also be compared across areas because they are based on a consistent set of estimating procedures nationwide. IMPLAN, on the other hand, is exclusively an I-O model that queries users in order to provide a description of the direct effects, and then automatically generates estimates of the indirect, induced, and total effects of the facility. IMPLAN is a user-friendly software package; however, it is more complex than RIMS II. The software package limits the user to entering the expenditure data in term of certain years. This means that if 
the data is expressed in current year dollars, then it must be deflated before being entered into the program. Likewise, the results must be inflated to be expressed in current year dollars. A limitation of both models is that they are static with no specific time dimension; it is assumed that impacts occur in one year. Table 2.3 in Section 2.5.4 provided a summary of the major components of RIMS II and IMPLAN I-O models.

The sectors in the National I-O matrix affected by highway construction spending are: Construction, Real Estate and Architectural and Engineering Services (Lynch, 2000). The output, income, and employment multipliers for these sectors considered in RIMS II and IMPLAN I-O models are presented in Table 5.1. As it can be observed, RIMS II output and employment multipliers are higher than the corresponding ones provided by IMPLAN, while RIMS II income multipliers are lower than the corresponding IMPLAN ones. It should be noted that IMPLAN model generates different types of multipliers: Type I, Type II, Type III and Type SAM multipliers. The Type II multipliers are the default multipliers that can be used in most circumstances, and are also comparable to the RIMS II multipliers. As such, the Type II multipliers are presented in Table 5.1. Likewise, RIMS II provides users with different types of multipliers: final-demand and directeffect multipliers. Because construction is a final good, the final demand multipliers for output, income, and employment are considered.

Table 5.1 Input-Output Economic Multipliers

\begin{tabular}{|c|c|c|c|c|}
\hline & Multipliers $\backslash$ Sectors & Construction & Real estate & $\begin{array}{c}\text { Engineering } \\
\text { services }\end{array}$ \\
\hline \multirow{3}{*}{ RIMS II } & Output (2001\$) & 2.3657 & 1.5429 & 1.9087 \\
\cline { 2 - 5 } & Earnings (2001\$) & 0.7181 & 0.2462 & 0.6916 \\
\cline { 2 - 5 } & $\begin{array}{c}\text { Employment (number of jobs/million } \\
2001 \$)\end{array}$ & 23.1793 & 13.4465 & 20.5118 \\
\hline \multirow{3}{*}{ IMPLAN } & Output (2001\$) & 1.9060 & 1.4095 & 1.7435 \\
\cline { 2 - 5 } & Earnings (2001\$) & 0.8827 & 0.9392 & 1.1806 \\
\cline { 2 - 5 } & $\begin{array}{c}\text { Employment (number of jobs/million } \\
2001 \$)\end{array}$ & 20.1912 & 13.3939 & 22.9039 \\
\hline
\end{tabular}

The summary statistics for the short-term economic development effects of highway construction spending using input-output analysis are presented in Table 5.2. Some additional calculated benefit/cost measures, such as the ratio of wages or output generated 
per dollar of highway investment, and the ratio of jobs created per dollar of highway investment are also presented. On average, the projects programmed for Indiana could generate 20-23 jobs, 0.7-0.9 million earnings and 1.9-2.3 million additional output per million 2001 dollars of construction spending. These effects include construction jobs and the secondary impacts of construction. In the long-run, when the construction stimulus is removed, the magnitude of these effects will depend on the availability of land, labor and capital (Flyvbjerg et al., 2003). Some insights on the long-term economic development effects of past highway investment in Indiana are provided next.

Table 5.2 Summary Statistics for the Short-Term Economic Development Effects of Highway Construction Spending

\begin{tabular}{|c|c|c|}
\hline & Variable Code & $\begin{array}{c}\text { Mean } \\
\text { (standard deviation) }\end{array}$ \\
\hline \multicolumn{3}{|l|}{ RIMSII Outputs } \\
\hline Net Change in Employment (jobs) & RIMSEMP & $1,055(1,013)$ \\
\hline Net Change in Earnings (million 2001 dollars) & RIMSINCMI & $32.7(31.4)$ \\
\hline Net Change in Output ${ }^{c}$ (million 2001 dollars) & RIMSOUTMI & $108(103)$ \\
\hline $\begin{array}{l}\text { Jobs Created per million } 2001 \text { dollars of Con- } \\
\text { struction Spending (jobs per million } 2001 \text { dollars) }\end{array}$ & JOBPER01\$1 & $22.9(7.7)$ \\
\hline $\begin{array}{l}\text { Net Change in Earnings per million } 2001 \text { dollars } \\
\text { of Construction Spending (million } 2001 \text { dollars) }\end{array}$ & INCPER01\$1 & $0.7(0.2)$ \\
\hline $\begin{array}{l}\text { Net Change in Output per million } 2001 \text { dollars of } \\
\text { Construction Spending (million } 2001 \text { dollars) }\end{array}$ & OUTPER01\$1 & $2.3(0.8)$ \\
\hline \multicolumn{3}{|l|}{ IMPLAN Outputs } \\
\hline Net Change in Employment (jobs) & IMPLEMP & $919(882)$ \\
\hline Net Change in Earnings (million 2001 dollars) & IMPLINCMI & $40.2(38.6)$ \\
\hline Net Change in Output (million 2001 dollars) & IMPLOUTMI & $86.8(83.3)$ \\
\hline $\begin{array}{l}\text { Jobs Created per million } 2001 \text { dollars of Con- } \\
\text { struction Spending (jobs per million } 2001 \text { dollars) }\end{array}$ & JOBPER01\$2 & $19.9(6.7)$ \\
\hline $\begin{array}{l}\text { Net Change in Earnings per million } 2001 \text { dollars } \\
\text { of Construction Spending (million } 2001 \text { dollars) }\end{array}$ & INCPER01\$2 & $0.9(0.3)$ \\
\hline $\begin{array}{l}\text { Net Change in Output per million } 2001 \text { dollars of } \\
\text { Construction Spending (million } 2001 \text { dollars) }\end{array}$ & OUTPER01\$2 & $1.9(0.6)$ \\
\hline
\end{tabular}

5.2. Long-Term Economic Development Effects of Major Corridor Studies in Indiana 


\subsubsection{Data}

Data on long-term economic development effects of major highway corridor projects in Indiana were collected to shed light into the complex causal situation analyzed. In total, there were five major studies conducted in Indiana where long-term economic development impacts have been estimated to fulfill the requirements of an environmental impact study. Most of these studies examined the impacts of different highway improvements along different segments of a corridor (traversing a number of counties) and considered various alternatives. The economic impacts of the candidate alternatives were evaluated using the dynamic regional economic simulation model REMI (discussed in Section 2.5.3.1.). The data collected are summarized in Table 5.3. Details for each study under consideration are provided below.

\subsubsection{On-going Corridor Studies}

\subsection{I-69 Evansville to Indianapolis Environmental Assessment/Corridor Study}

The proposed action involves the completion of an interstate highway connecting Evansville and Indianapolis, Indiana. The northern terminus of the project is I-465 on the south side of Indianapolis and southern terminus is I-64 just north of Evansville. The study area includes 26 counties, over one quarter of the State of Indiana. Within the study area, there are major cities, midsize cities, small towns, and rural communities. The purpose of the Evansville to Indianapolis section of I-69 is to provide an improved transportation link between the two cities, which strengthens the transportation network and supports economic development in Southwest Indiana. There were a total of 12 distinct alternatives considered in the Environmental Impact Statement (EIS). The alternatives considered are spread across a broad area. While they all connect the same termini, they serve different cities and pass through different counties. The long-term economic growth in the study area in the year 2025 is forecasted with the use for the REMI model, separately for each alternative under consideration. The EIS study is prepared by CSI and BLA (2003). 
5.2.1.1.2. S.R. 37 Environmental Assessment/Corridor Study from Noblesville to Marion

The four-county (Grant, Hamilton, Madison, and Tipton counties) study area consists of a diverse economic formulation, with a strong emphasis on agricultural services, construction, wholesale and retail trade, services, finance, insurance and real estate. This study includes reviews of alignment options, road standards, traffic demands, conceptual design, costs, economic benefits, and environmental issues as well as other implications. Along with the "No-Build", ten alternatives/combinations are considered and several types of facilities are evaluated for the SR 37 corridor: a 4-lane divided expressway (non-freeway/partial access, at-grade intersections), a 4-lane freeway (fully limited access, over/underpasses, interchanges), and 2-lane improved (passing lanes, two-way left turn lanes, etc). The primary focus, however, is on economics, and what level of investment is warranted in the SR 37 corridor. The proper level of investment is calculated in terms of travel efficiency and economic development benefits, compared with the highway's costs. The methodology utilized in the economic analysis closely matches the MCIBAS (discussed in Section 2.5.3.2.1.). The REMI model was run only for four alternatives that met the purpose and need statement, and were not excessive. The base year for the impacts is 2006 and the study period extends to 2025 . Woolpert LLP prepared the study. Wilbur Smith Associates assisted with economic impact analysis (http://www.sr37study.com/).

\subsection{SR 101 Corridor Improvement Feasibility Study}

The Indiana Department of Transportation has initiated a study of transportation needs and opportunities in the State Route 101 corridor in Southeastern Indiana. The objectives of this study are to assess the feasibility of improvements to the Indiana State Route 101 corridor between US 50 and Markland Dam, as well as other alternatives for improving safety and mobility in Southeastern Indiana. SR 101 is a rural two-lane roadway that runs north-south in disconnected segments along the eastern border of Indiana, from Dekalb County in Northern Indiana to Switzerland County in the south, approximately the entire length of the state. Because of its lack of continuity, its ability to effectively serve north-south vehicular movement in eastern Indiana is limited. This is a particular problem affecting accessibility for counties located in the southeastern part of the 
state, south of I-74. These counties include Dearborn, Ohio, Switzerland, Ripley, and Jefferson. Two key transportation needs were identified for the study area: improve roadway safety and reduce accident frequency; and improve regional accessibility and connectivity. This study was prepared by CSI, BLA and Dyer Environmental Services (2003).

\subsubsection{Past Corridor Studies}

\subsection{Economic Impacts of SR 26 and US 35 Corridor Improvements}

This study was completed in 1998 and demonstrates the use of MCIBAS (and REMI) to assess the economic development impacts of corridor improvements in Indiana. The corridor runs east-west roughly from Marion to Lafayette (north of Indianapolis). The corridor is 77 miles in length, with SR 26 and US 35 each making up about one-half of the length. The study area was defined as Tippecanoe, Carroll, Clinton, Howard, Tipton and Grant counties. SR 26/US 35 passes through all of these counties except Carroll and Tipton, which were included due to their proximity to the corridor and economic linkages with the other counties in the study corridor. The economic impact analysis focused on the potential transportation and economic impacts of major improvements to the entire corridor between I-65 and I-69. The analysis period was from 2005, the year construction begins, until 2034. Economic impacts were forecasted for both the study area and the rest of the state. The study suggested that the SR 26/ US 35 route be upgraded to a high level two lane roadway. This study was prepared by CSI and BLA (1998a).

\subsubsection{US 31 Corridor Study}

This study is an application of the model MCIBAS (and REMI) to analyze the transportation and economic impacts of the upgrade of US 31 between Indianapolis and South Bend to interstate level of service. The interstate design standard is characterized by total access control; two (or more) travel lanes in each direction; and posted speeds of 55 miles per hour in urban areas and 65 miles per hour in rural areas. The study esti- 
mated the transportation and economic impacts of major improvements to the entire 124-mile corridor between I-465 in Indianapolis and the US 20 bypass in South Bend. The study area was defined as Hamilton, Tipton, Howard, Miami, Cass, Fulton, Marshall, St. Joseph, and Elkhart counties. The objectives of the study were to evaluate the regional economic impacts of transportation improvements to the US 31 corridor; ensure cost-effective public sector investment by comparing economic benefits to implementation costs; and enhance previous and ongoing US 31 studies with information on a broader range of potential impacts. The analysis period was from 2005, the year construction begins, until 2034. Economic impacts were forecasted for both the study area and the rest of the state. This study suggested that the project would create a net benefit for the regional economy. This study was prepared by CSI and BLA (1998b). 
Table 5.3 Summary Statistics for Long-Term Effects of Major Corridor Studies in Indiana

\begin{tabular}{|c|c|c|}
\hline Variables & $\begin{array}{c}\text { Percentage or } \\
\text { Mean (standard } \\
\text { deviation) }\end{array}$ & $\begin{array}{l}\text { Number of Ob- } \\
\text { servations }\end{array}$ \\
\hline System (I/US/SR) & $55 / 9 / 36$ & $12 / 2 / 8$ \\
\hline Route (I-69/SR37/US31/US35\&SR26/SR101) & $57 / 19 / 5 / 5 / 14$ & $12 / 4 / 1 / 1 / 3$ \\
\hline $\begin{array}{l}\text { Geographic. Region (South- } \\
\text { east/Southwest/North/Central Indiana) }\end{array}$ & $57 / 24 / 24 / 5$ & $12 / 5 / 5 / 1$ \\
\hline $\begin{array}{l}\text { Percentage of Counties in Study Area designated as } \\
\text { Economic Centers }^{a}\end{array}$ & 37 & 21 \\
\hline $\begin{array}{l}\text { Distribution of Projects by District } \\
\text { (Crawfordsville/Seymour/Greenfield/Fort } \\
\text { Wayne/Vincennes/LaPorte) }\end{array}$ & $\begin{array}{c}67 / 81 / 81 / 24 / \\
57 / 10\end{array}$ & $\begin{array}{c}14 / 17 / 17 / 5 / \\
12 / 2\end{array}$ \\
\hline Project Length & $106.64(49.17)$ & 21 \\
\hline Length of New Construction (miles) & $97.78(47.91)$ & 21 \\
\hline Potential Bridges over Water & $39.8(20.2)$ & 15 \\
\hline Potential Interchanges & $21(11.8)$ & 15 \\
\hline Potential Grade Separations for Roads/Railroads & $58.3(7.8)$ & 12 \\
\hline Construction Costs (million 2001 dollars) & $790(551)$ & 21 \\
\hline Engineering Costs (million 2001 dollars) & $53(37)$ & 21 \\
\hline Total Cost (million 2001 dollars) & $960(674)$ & 21 \\
\hline Business Cost Savings (million 2001 dollars) & $170(602)$ & 17 \\
\hline $\begin{array}{l}\text { Business Attraction Impacts (in business sales) by } \\
2025\end{array}$ & $470(122)$ & 12 \\
\hline $\begin{array}{l}\text { Business Attraction Impacts (in number of jobs) by } \\
2025\end{array}$ & $137(99)$ & 5 \\
\hline Change in Annual Visitor-Days (thousand) by 2025 & $107.6(47.2)$ & 17 \\
\hline Net Short-Term ${ }^{c}$ Change in Employment & $616.3(1293.5)$ & 6 \\
\hline $\begin{array}{l}\text { Net Short-Term }{ }^{c} \text { Change in Roadside Business Sales } \\
\text { (million } 2001 \text { dollars) }\end{array}$ & $61(129.5)$ & 6 \\
\hline $\begin{array}{l}\text { Net Short-Term }{ }^{c} \text { Change in Real Disposable Income } \\
\text { (million } 2001 \text { dollars) }\end{array}$ & $15(32.2)$ & 6 \\
\hline Net Long-Term ${ }^{\mathrm{d}}$ Change in Employment & $1970(1664)$ & 21 \\
\hline $\begin{array}{l}\text { Net Long-Term }{ }^{\mathrm{d}} \text { Change in Roadside Business Sales } \\
\text { (million } 2001 \text { dollars) }\end{array}$ & $78(77.5)$ & 21 \\
\hline $\begin{array}{l}\text { Net Long-Term }{ }^{\mathrm{d}} \text { Change in Real Disposable Income } \\
\text { (million } 2001 \text { dollars) }\end{array}$ & $77(63.1)$ & 21 \\
\hline
\end{tabular}

${ }^{a}$ For transportation planning purposes.

${ }^{\mathrm{b}}$ The sum does not add to 100 percent as most of the projects under study were under the jurisdiction of two or more districts.

${ }^{c}$ Year 2006.

${ }^{\mathrm{d}}$ Year 2025. 


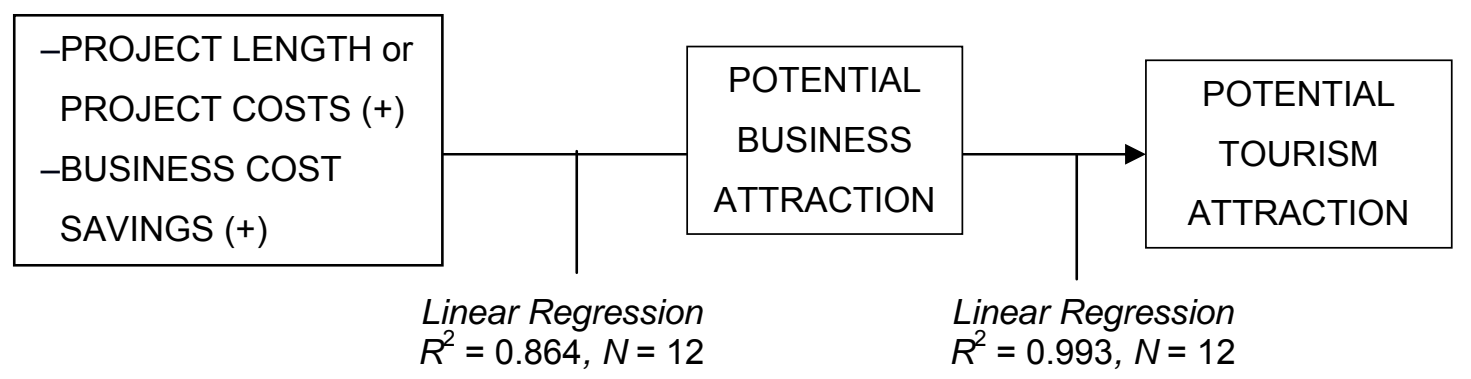

Figure 5.2 Regression Analysis Estimates of Potential Business and Tourism Attraction

The results suggest that the size of highway investment, measured by either the length or cost of the highway project, is a major factor among the multitude of factors that can influence development; the larger the project, the greater the economic development benefits measured in terms of changes in output, income and employment. Project location was also found to be a significant determinant of whether a major highway corridor project will produce economic development benefits. In particular, highway improvements on corridors traversing counties that are designated as economic centers for transportation planning purposes seem to have a greater impact on the Indiana economy compared to the same type of improvements elsewhere in the state. Finally, highway functional class was significant in explaining the long-term changes in employment. It was found that investments on interstate highways could be used as a tool for expansion of job opportunities in Indiana.

It was also of interest to investigate how location and project-specific factors interact to stimulate business and tourism attraction. The results suggest that the potential of business attraction seems to be driven by the size of highway investment (project length or costs) and the business cost savings that derive from the highway improvements. These savings are essentially production cost savings and productivity enhancing benefits that are based on the user benefits (in dollar terms) that accrue to trucks and automobiles on business trips, estimated for each highway project. It was also found that for a given project, the potential for tourism attraction is explained almost perfectly by the potential business attraction. These models can be also viewed to suggest a chain rela- 
tionship among direct cost savings for businesses, business attraction impacts and tourism attraction impacts, as shown in Figure 5.2.

The results of the regression analysis of the data collected on major highway corridor projects in Indiana provided some insights on the relationship between major highway improvements and the state's economic development potential. However, these models do not suffice to distinguish between different types of highway improvements and differentiate the advantages and disadvantages of alternative highway investments, such as capacity improvements, additional interchanges or new road construction. The next chapter presents a methodology that can be applied at the project level in a bid to address how differing types of highway investment can affect the Indiana economy, and estimate statewide long-term economic development impact factors in a range of highway improvements. 


\section{CHAPTER 6. FRAMEWORK FOR LONG-TERM REGIONAL ECONOMIC DEVELOPMENT IMPACT ANALYSIS}

\subsection{Overview}

This chapter describes the framework and methodology for estimating the statewide long-term changes in economic development associated with highway investments. The framework builds on findings from prior research (discussed in Chapter 2), and on the available resources for statewide analysis. It is based on a five-step process, with the use of the dynamic economic simulation model REMI (Fan et. al., 2000), as follows:

i. Estimating direct impacts of the highway system improvement on traffic patterns, levels and speeds;

ii. Estimating user benefits, in terms of reductions in travel time, safety costs, and vehicle operating costs for trucks, and automobiles used for business purposes;

iii. Translating user benefits to economic consequences (direct impacts);

iv. Estimating potential business attraction by industry; and last,

v. Estimating long-term secondary (indirect and induced) economic impacts in terms of business sales (output), employment and income, that result from the direct economic impacts estimated in the previous step.

The next sections discuss each step in greater detail. Information about the REMI model is provided below. 


\subsubsection{REMI Model}

As discussed in Section 2.5.3.1., the REMI Policy Insight model is perhaps the most widely used economic simulation model for transportation-related applications. The REMI model is dynamic; it accounts for long-term economic, industrial, and demographic changes or changes in business costs over time. REMI incorporates aspects of four major modeling approaches: input-output, general equilibrium, econometric, and economic geography. Input-output analysis was discussed in Section 2.5.1. General equilibrium analysis considers simultaneous equilibrium in all markets; equilibrium is reached when supply and demand are balanced. This tends to occur in the long run as prices, production, consumption, imports, exports, and other changes occur to stabilize the economic system. The econometric specifications are derived from economic theories that are generally neoclassical in nature. ${ }^{6}$ The new economic geography features represent the spatial dimension of the economy. Detailed documentation of the model is available in Treyz and Treyz (2002).

Conceptually, the model consists of five basic blocks: (1) output, (2) labor and capital demands, (3) population and labor supply, (4) wages, prices, and profits, and (5) market shares. The output block contains the input-output component of the model. The inputoutput component is non-survey based, using national technical coefficients. The detailed structure of the REMI model requires an extensive amount of data. Of particular importance are data on employment, income, and output. REMI uses three sources of employment, and wage and salary (income) data: employment, wage, and personal income series by the US Bureau of Economic Analysis (US BEA); ES-202 establishment employment and wage and salary data by the US Bureau of Labor Statistics (US BLS); and county business patterns (CBP) data published by the US Bureau of the Census. Output measures are based on regional employment data, the US BEA gross state product series, and national output-to-employment ratios. The REMI model can be configured into any number of regions based on county definitions. For the purposes of his

\footnotetext{
${ }^{6}$ Neoclassical economics rely on the idea that prices adjust to restore equilibrium to various markets, in spite of temporary demand shocks. In the long run, when prices adjust fully to macroeconomic shocks, aggregate demand is not the critical factor determining the level of total output (Barron et al., 2003).
} 
study, the REMI Policy Insight model (version 6.0) was configured for a single region, the State of Indiana.

The use of the REMI model for the analysis of policy effects is a two-step process. First, a baseline forecast is generated using a national forecast as one of its inputs. This forecast estimates employment, income, and output levels in the economy assuming no major changes in policy. Second, the direct effects of the policy change are input to the REMI model through a large set of policy variables. These variables include sales, employment, production costs or productivity, by industry; construction projects, by type; consumer or government spending, by category; energy costs; transportation costs; and similar measures. These policy variable changes are run through the model to produce an alternative forecast. The difference between the baseline and alternative forecasts indicates the total expected effect of the policy change. Outputs of the model that may be compared between the baseline and alternative forecasts include employment by industry or occupation; sales or output by industry; and income by industry.

\subsection{Analysis Framework}

The five steps involved in the analysis procedure for estimating the statewide long-term changes in economic development associated with highway investments are discussed next.

\subsubsection{User Benefit Analysis}

User benefit analysis is conducted to measure the benefits resulting from the different types of highway improvements in terms of the improvement in travel time, travel expense and safety for users (i.e., truck and automobiles) on different trip purposes (business and non-business) over a 20 -year period; all expressed in terms of money value. It 
is assumed that benefits will begin to accrue in the first year of highway operation. ${ }^{7}$ The construction period is estimated according to project length and project complexity (Table 6.1). Finally, the benefit streams are discounted at a 5 percent rate to reflect the present worth. The analysis steps are discussed in detail in the next sections, based on the guidelines provided by AASHTO (2003) and HERS manual (Jack Faucett Associates, Inc., 1991).

Table 6.1 Duration of Construction by Project Type

\begin{tabular}{|l|l|}
\hline Project Type & Duration of Construction \\
\hline Added travel lanes & 1 year per 5-mile construction \\
\hline Median Construction & 1 year \\
\hline New Road Construction & 1 year per 5-mile construction \\
\hline Interchange Construction & 1 year \\
\hline
\end{tabular}

\subsubsection{Estimation of Travel Time Changes}

Travel time value represents a significant factor in the overall benefit estimation process. Separate values of travel time were assigned for different types of vehicles. Table 6.2 shows the travel time values included in the analysis. The values were adapted from the NET_BC module of MCIBAS (CSI, 1998) by adjusting to the base year of 2003 with appropriate price indices. The Consumer Price Index (CPI) was used to adjust the indices for automobiles, while the Producer Price Index (PPI) was utilized for single-unit trucks and combination trucks. Several $\mathrm{CPI}$ and PPI equations were developed in Choocharukul (2000) by performing the regression analysis using 20 years of historical price data. The regression equations used for adjusting the indices for travel time values, classified by index category, are shown in Table 6.3.

${ }^{7}$ In general, the construction period benefits are not included in the economic analysis as additional project benefits. Weisbrod and Beckwith (1992) caution that construction expenditures are typically considered to be short-term temporary impacts and are assumed to be funds that would have been spent anyway by state and local governments-if not on this project, then on other transportation or public works investments with comparable capital expenditure benefits. 
Table 6.2 Unit Values of Travel Time (2003 dollars)

(Adapted from CSI, 1998)

\begin{tabular}{|l|l|c|c|}
\hline Item & Index & $2003 \$$ Value & Unit \\
\hline Automobile Travel Time & CPI (All items) & 20.57 & $\$ /$ person/hour \\
\hline $\begin{array}{l}\text { Single-Unit Truck Time } \\
\text { Value }\end{array}$ & PPI (All commodities) & 24.46 & $\$ /$ vehicle/hour \\
\hline $\begin{array}{c}\text { Combination Truck } \\
\text { Travel Time }\end{array}$ & PPI (All commodities) & 29.55 & $\$ /$ vehicle/hour \\
\hline
\end{tabular}

Table 6.3 Equations for $\mathrm{CPI}$ and PPI

(Source: Choocharukul, 2000)

\begin{tabular}{|l|l|c|}
\hline Index & Equations & $R^{2}$ \\
\hline CPI (All items) & CPI $=4.4117 \times($ Year -1979$)+80.963$ & 0.9952 \\
\hline CPI (Fuel and Utilities) & $\mathrm{CPI}=2.2849 \times($ Year -1979$)+88.014$ & 0.9182 \\
\hline $\begin{array}{l}\text { PPI (All commodities) } \\
\begin{array}{l}\text { PPI (Highway and Street Con- } \\
\text { struction) }\end{array}\end{array}$ & $\mathrm{PPI}=1.8841 \times($ Year -1979$)+92.082$ & 0.9389 \\
\hline
\end{tabular}

* used for adjusting highway project construction costs.

For each highway project, the HPMS data includes average annual daily traffic (AADT) for the data year and also for a future data year, 20 years beyond the data year. A constant rate of growth throughout the analysis period is applied throughout the period. Because the volume of additional traffic each year is based upon the previous year's volume, more vehicles are added each year. In the case that additional traffic is expected to use the improved highway, the rule-of-half from conventional economic theory is applied. The rule-of-half states that the benefit of new traffic is approximately equal to one half of the change in travel time multiplied by the number of new trips. Estimation of induced demand for the different highway improvements is based on elasticity of travel demand relationships, as reported in reviews of empirical studies of induced traffic (TRB, 1995; Dowling et al., 2005). These relationships show the percent change in the quantity of travel, which results from a one percent change in the perceived unit cost of travel. Short-term elasticity of demand values are applied to estimate induced demand on year 
1 (first year of highway operation), while long-term elasticity of demand values are applied to estimate induced demand on year 20 (future year).

Before and after improvement speeds can be obtained from the look-up tables provided in Choocharukul (2000). This method provides an overall measure of the effect of volume changes and capacity improvements on travel time without requiring detailed profile of volumes by time of day. These tables are based on the average weekday daily traffic to capacity ratio (AWDT/C) for estimating the values of average daily speed, average peak speed, and average off-peak speed. Look-up tables are presented in Appendix B (Table B.5). To use the look-up tables, the average annual daily traffic (AADT) and roadway capacity $(C)$ will be first calculated. Average weekday daily traffic (AWDT) is determined by applying a conversion factor of 1.0991 to the AADT. The factor was computed from hourly volume data for I-465 in Indiana. The AWDT/C ratios before and after improvement can be calculated from the following equations:

AWDT/C $($ before $)=($ AADT $\times 1.0991) /$ Capacity per Lane $($ before $) \times$ Number of Lanes (before)]

AWDT/C $($ after $)=($ AADT $\times 1.0991) /[$ Capacity per Lane $($ after $) \times$ Number of Lanes (after)]

Yearly travel time costs before and after improvement can be computed as given below:

Per VMT Travel Time Cost $=$ Number of Days per Year $\times$ (Length of Roadway/ Average Speed $) \times[(\%$ Automobile/100 $\times$ Automobile Time Value $\times$ Automobile Occupancy $)+(\%$ SU Truck/100 $\times$ SU Truck Time Value $)+(\%$ Combination Truck/ $100 \times$ Combination Truck Time Value)]

\subsubsection{Estimation of Vehicle Operating Cost Changes}

Vehicle operating costs include fuel, tires, lubricants, maintenance, and depreciation. Vehicle operating cost changes are based on fuel and oil consumption and primarily reflect changes in average operating speed. Once the average daily speed and vehiclemiles traveled (VMT) are known, fuel and oil consumption can be computed by substituting these parameters into the appropriate equations (shown in Table 6.4) that were developed by McFarland et al. (1993). The calculation takes fuel and oil consumption for 
each type of vehicle (automobiles, single-unit trucks, and combination trucks) as a function of speed. Fuel consumption for trucks is also based on gross vehicle weight (GVW). Average estimates of weights of (single-unit and combination) trucks for all major functional classes of highways in Northern, Central, and Southern Indiana are shown in Table 6.5, based on a past study conducted in Indiana (Islam, 2003). Total fuel and oil consumption costs are then computed by multiplying the calculated fuel and oil consumption rates with the corresponding vehicle-miles of travel and unit fuel and oil costs. Default values for unit fuel and oil prices are presented in Table 6.6. The values represent approximate fuel and oil prices in Indiana in the year 2003. For future years, the Consumer Price Index (CPI) under the "fuel and other utilities" category (shown in Table 6.3) was used to adjust the prices. Fuel and oil costs are typically about 70 percent of total vehicle operating costs. Therefore, total vehicle operating costs were computed by adjusting fuel and oil costs by a factor of 1.43 . The difference between vehicle operating costs before and after improvement represents the vehicle operating cost changes.

Table 6.4 Equations for Fuel and Oil Consumption

(Source: McFarland et al., 1993)

\begin{tabular}{|c|c|c|c|}
\hline Index & Unit & Vehicle Type & Equations \\
\hline Fuel & gal/ 1,000 miles & Automobiles & $\begin{array}{l}\text { Fuel }=65.46896-1.47217 \times \text { Speed }+ \\
0.02127 \times \text { Speed }^{2}\end{array}$ \\
\hline Fuel & gal/ 1,000 miles & Single-Unit Trucks & $\begin{array}{l}\log (\text { Fuel })=5.57605+0.00012 \times \text { Speed }^{2}- \\
0.4656 \times \text { Log }(\text { Speed })+0.29271 \times \text { Log } \\
\left(\mathrm{GVW}^{*}\right)\end{array}$ \\
\hline Fuel & gal/ 1,000 miles & $\begin{array}{l}\text { Combination } \\
\text { Trucks }\end{array}$ & $\begin{array}{l}\log (\text { Fuel })=5.57605+0.00012 \times \text { Speed }^{2}- \\
0.4656 \times \log (\text { Speed })+0.29271 \times \text { Log }^{-} \\
\left(\text {GVW }^{*}\right)\end{array}$ \\
\hline Oil & qrt/1,000 miles & Automobiles & $\begin{array}{l}\log (\text { Oil })=2.57939+0.01924 \times \text { Speed }- \\
\quad 0.83012 \times \log (\text { Speed })\end{array}$ \\
\hline Oil & qrt/1,000 miles & Single-Unit Trucks & $\begin{array}{l}\log (\text { Oil })=1.99570-0.05372 \times \text { Speed }+ \\
0.00058 \times \text { Speed }^{2}\end{array}$ \\
\hline Oil & qrt/1,000 miles & $\begin{array}{l}\text { Combination } \\
\text { Trucks }\end{array}$ & $\begin{array}{l}\log (\text { Oil })=3.12838-0.05509 \times \text { Speed }+ \\
0.00054 \times \text { Speed }^{2}\end{array}$ \\
\hline
\end{tabular}

* GVW= Gross Vehicle Weight in thousands Ibs. (estimates from Table 6.5). 
Table 6.5 Average Estimates of Truck Weights by Functional Class in Indiana (in thousands lbs.) (Source: Islam, 2003)

\begin{tabular}{|l|c|c|}
\hline \multicolumn{3}{|c|}{ NORTHERN INDIANA } \\
\hline Facility Type & Single-Unit Trucks & Combination Trucks \\
\hline Rural Interstates & 12.6 & 50.6 \\
\hline Rural Other Principal & 11.8 & 56.0 \\
\hline Rural Minor Arterial & 11.8 & 56.0 \\
\hline Urban Interstates & 9.7 & 46.0 \\
\hline Urban Other Freeways \& Expressways & 9.7 & 46.0 \\
\hline Urban Other Principal & 9.7 & 46.0 \\
\hline \multicolumn{1}{|c|}{ CENTRAL INDIANA } \\
\hline Facility Type & Single-Unit Trucks & Combination Trucks \\
\hline Rural Interstates & 10.5 & 56.5 \\
\hline Rural Other Principal & 12.4 & 59.8 \\
\hline Rural Minor Arterial & 12.0 & 49.7 \\
\hline Urban Interstates & 10.8 & 85.8 \\
\hline Urban Other Freeways \& Expressways & 10.8 & 85.8 \\
\hline Urban Other Principal & 14.3 & 49.1 \\
\hline \multicolumn{2}{|c|}{} \\
\hline Facility Type & 22.5 & Single-Unit Trucks \\
\hline Rural Interstates & 12.3 & 58.5 \\
\hline Rural Other Principal & 9.9 & 50.1 \\
\hline Rural Minor Arterial & 11.2 & 45.7 \\
\hline Urban Interstates & 11.2 & 47.8 \\
\hline Urban Other Freeways \& Expressways & 11.2 & 47.8 \\
\hline Urban Other Principal & Combination Trucks \\
\hline
\end{tabular}

Table 6.6 Unit Values of Fuel and Oil Costs (2003 dollars) (Adapted from: Choocharukul, 2000)

\begin{tabular}{|l|c|c|}
\hline Vehicle Type & Fuel $(\$ / \mathrm{gal})$ & Oil $(\$ / \mathrm{qrt})$ \\
\hline Automobiles & 1.47 & 4.2 \\
\hline Single-Unit Trucks & 1.49 & 2.1 \\
\hline Combination Trucks & 1.57 & 2.1 \\
\hline
\end{tabular}

\subsubsection{Estimation of Crash Cost Changes}

Total crash cost is computed by multiplying unit crash cost with the crash rate and the corresponding vehicle-miles of travel (VMT), as shown in Equation (6.4). Crash rates are computed based on the safety performance functions including crash severity, presented in Table 6.7. These functions were developed in Tarko and Kanodia (2003) for 
all major functional classes of highways in Indiana. Unit crash cost estimates by highway functional class are shown in Table 6.8.

$$
\text { Per VMT Crash Cost }=\text { Crash Rate per VMT } \times \text { Cost per Crash }
$$

Reduction in the number of crashes after project improvement is estimated from the appropriate crash reduction factors. A crash reduction factor (CRF) is defined as the percentage reduction in number of crashes after an improvement is made to the road section, considering that all other parameters remain unchanged. Crash reduction factors for various types of highway improvement projects are presented in Table 6.9. With the use of CRF, crash costs after improvement can be computed as shown in Equation (6.5). Crash cost savings are then calculated from the difference in crash costs before and after the improvement, as follows:

Per VMT Crash Costs Improvement $=(1-$ CRF $) \times$ Crash Rate per VMT $\times$ Cost per Crash

Table 6.7 Safety Performance Functions including Severity for Highway Facilities in Indiana (Source: Tarko and Kanodia, 2003)

\begin{tabular}{|l|l|c|}
\hline \multirow{2}{*}{ Facility } & Safety Performance Functions & $\begin{array}{c}\text { Overdispersion } \\
\text { parameter }\end{array}$ \\
\hline \multirow{2}{*}{ Rural two-lane segment } & $a_{I F}=0.208 \times L \times Q^{0.604}$ & 0.420 \\
\cline { 2 - 3 } & $a_{P D}=0.712 \times L \times Q^{0.592}$ & 0.430 \\
\hline \multirow{2}{*}{ Rural multilane segment } & $a_{I F}=0.107 \times L \times Q^{0.814}$ & 0.451 \\
\cline { 2 - 3 } & $a_{P D}=0.634 \times L \times Q^{0.615}$ & 0.484 \\
\hline \multirow{2}{*}{ Urban two-lane segment } & $a_{I F}=0.105 \times L \times Q^{1.080}$ & 1.253 \\
\cline { 2 - 3 } & $a_{P D}=0.603 \times L \times Q^{0.896}$ & 1.349 \\
\hline \multirow{2}{*}{ Urban multilane segment } & $a_{I F}=0.674 \times L \times Q^{0.435}$ & 1.588 \\
\cline { 2 - 3 } & $a_{P D}=2.028 \times L \times Q^{0.460}$ & 1.946 \\
\hline \multirow{2}{*}{ Rural interstate } & $a_{I F}=0.044 \times L \times Q^{0.917}$ & 1.053 \\
\cline { 2 - 3 } & $a_{P D}=0.169 \times L \times Q^{0.943}$ & 2.604 \\
\hline \multirow{2}{*}{ Urban interstate } & $a_{I F}=0.00048 \times L \times Q^{2.238}$ & 2.704 \\
\cline { 2 - 3 } & $a_{P D}=0.0057 \times L \times Q^{1.954}$ & \\
\hline
\end{tabular}

where, a ${ }_{P D}$-typical PDO crash frequency, in PDO crashes per year; a ${ }_{I F}$-typical injury/fatality crash frequency, in injury/fatality crashes per year; $L$-road segment length, in miles; and Q-AADT entering an intersection or along the road segment, in thousand veh/day. 
Table 6.8 Crash Costs for Indiana, in 2003 dollars

(Source: Tarko and Kanodia, 2003)

\begin{tabular}{|l|c|c|}
\hline Facility Type & Injury/Fatal (I/F) crash (\$) & $\begin{array}{c}\text { Property Damage Only } \\
(\text { PDO) crash (\$) }\end{array}$ \\
\hline Rural Interstates & 78,717 & 6,822 \\
\hline Rural Other Principal & 81,866 & 6,822 \\
\hline Rural Minor Arterial & 81,866 & 6,822 \\
\hline Rural Major Collector & 81,866 & 6,822 \\
\hline Rural Minor Collector & 81,866 & 6,822 \\
\hline Rural Local & 59,300 & 6,822 \\
\hline Urban Interstates & 54,577 & 6,822 \\
\hline Urban Other Freeways \& & 50,379 & 6,822 \\
\hline Expressways & 50,379 & 6,822 \\
\hline Urban Other Principal & 50,379 & 6,822 \\
\hline Urban Minor Arterial & 50,379 & 6,822 \\
\hline Urban Minor Collector & 44,606 & 6,822 \\
\hline Urban Local & & \\
\hline
\end{tabular}

Table 6.9 Crash Reduction Factors for Highway Improvements in Indiana (Source: Lamptey et al., 2004; Tarko et al., 2000)

\begin{tabular}{|l|l|c|c|c|}
\hline Improvement & Facility & CRF total & CRF I/F & CRF PDO \\
\hline Road widening & Rural interstate & 0.74 & 0.75 & 0.7 \\
\hline Road widening & Urban interstate & 0.7 & 0.75 & 0.74 \\
\hline Road widening & Rural multilane/two-lane & 0.4 & 0.5 & 0.3 \\
\hline Road widening & Urban multilane/two-lane & 0.3 & 0.5 & 0.4 \\
\hline Median construction & Rural facilities & $\mathrm{n} / \mathrm{a}$ & 0.13 & 0 \\
\hline Median construction & Urban facilities & $\mathrm{n} / \mathrm{a}$ & 0.11 & 0 \\
\hline Interchange Construction $^{\text {a }}$ & Rural/Urban facilities & $\mathrm{n} / \mathrm{a}$ & 0.87 & 0.74 \\
\hline New road construction & Rural interstate & 0.34 & 0.52 & 0.3 \\
\hline New road construction & Urban interstate & 0.24 & 0.13 & 0.25 \\
\hline New road construction & Rural multilane/two-lane & 0.13 & 0.10 & 0.15 \\
\hline New road construction & Urban multilane/two-lane & 0.33 & 0.18 & 0.34 \\
\hline
\end{tabular} $\begin{aligned} & \text { applicable to upgrades of signalized at-grade intersections to interchanges on non-interstate } \\
& \text { facilities. }\end{aligned}$

\subsubsection{Estimation of User Benefits}

The basic user benefit calculation recognizes the three, major sources of user benefits discussed in the previous sections: the savings in travel time, vehicle operating costs, and crash costs, as well as the consumer surplus that such savings generates. The 
user benefit calculation also incorporates induced traffic demand by incorporating traffic volumes with and without the project. The basic computational element of user benefit analysis is shown in the equation below:

$$
B=\Delta U \cdot\left(\frac{V_{0}+V_{1}}{2}\right) \cdot L=(\Delta H+\Delta O C+\Delta C C) \cdot\left(\frac{V_{0}+V_{1}}{2}\right) \cdot L
$$

where, $B$ is the user benefit to vehicle or user class at travel hour on link in project year $\mathrm{t}$; $\Delta U$ is the change in per VMT-user cost; $\Delta H=H_{0}-H_{1}$ is the change in per VMT (or per user) travel time costs; $\triangle O C=\triangle O C_{0}-\triangle O C_{1}$ is the change in per VMT (or per user) vehicle operating costs; $\triangle C C=\triangle C C_{0}-\triangle C C_{1}$ is the change in per VMT (or per user) crash costs; $V_{0}$ is the number of vehicles (or users) of class in hour without the improvement; $V_{1}$ is the number of vehicles (or users) of class in hour with the improvement; and $L$ is the segment or corridor length, in miles.

\subsubsection{Present Worth of Benefits}

All benefits are estimated on an annual basis. The analysis period was taken as 20 years after the benefits begin (i.e., first year after the construction is over). For example, if construction lasts five years, project benefits are estimated for the next twenty years of project life (twenty-five years after the implementation of project). For an accurate comparison, it is necessary to convert yearly benefits to present value equivalents. Based on available economic analysis methodologies (Jack Faucett Associates, Inc., 1991; AASHTO, 2003) and state current practices, a discount rate of 5 percent was assumed. The present worth of the benefit stream was computed by Equation (6.7), as follows:

$$
P W \text { benefit }=\sum_{t=1}^{20} B(t) \frac{1}{(1+d)^{t}}
$$

where, $P W$ benefit is the present worth of benefits; $t$ is the number of years since the year a project is completed; $B(t)=$ total benefits in year $t$; and $d=$ discount rate.

Present worth of benefits resulting from Equation (6.7) represents the value at the year a project is completed and made available to users. Because all projects do not start in 
the analysis year-the duration of construction differs by project, as previously shown in Table 6.1-the present worth of benefits is transferred to the analysis year, using the appropriate present worth factor.

\subsubsection{Issues Specific to User Benefit Analysis of Highway Improvements}

This section provides additional project-specific considerations that need to be taken into account in the user benefit analysis procedure presented previously. The major highway improvements considered in this study include adding capacity projects, new road construction, median construction, and interchange construction or modification. The primary effect of adding lanes is to add additional capacity to one or more road segments in a highway network. Consequently, the primary benefits from additional lanes derive from changes in travel time, changes in vehicle operating costs and changes in crash costs in the highway network. Analyzing the benefits of additional lanes fits easily into the general framework of the user benefit formula (6.6) and the associated measurement guidelines.

Evaluation of a completely new highway is analogous to the addition of new-lane capacity on an existing facility. That is, the primary benefits from a new highway derive from the changes in the same components of total user cost that are involved in evaluating new-lane capacity. As with the analysis of new-lane capacity, the analysis of the user benefits of new highways involves comparison of total user costs with and without the improvement. In the case of new highways, however, the affected highway segments did not exist without the improvement (by definition), and thus, there is not an immediately obvious base case against which to measure the effects of the new highway segments. The solution to this base case measurement problem can be simple, or complex, depending upon the circumstances. In this study, the new highway projects are to connect two nodes (i.e., cities) that are already connected by another road; as such, the performance of the existing road provides the base-case conditions for the analysis. Information on travel times, volumes, and costs on the existing facility is used to measure base case user costs for travelers on both the existing and proposed facility. Speeds are estimated using the standard Bureau of Public Roads (BPR) speed-flow equation contained in the Highway Capacity Manual (HCM, 2000), shown in Equation (6.8). 
Static User Equilibrium (SUE) assignment is applied to assign traffic to both routes (existing and proposed), using Wardrop's first principle (Wardrop, 1952). User costs are then measured with the new highway in place, and the analysis is essentially a study of the changes in corridor user costs.

$$
s=\frac{s_{f}}{1+a(v / c)^{b}}
$$

where, $s$ is the predicted mean speed; $s_{f}$ is the free flow speed; $v$ is the volume; $c$ is the practical capacity; $\alpha=0.15$, and $b=4$.

One of other improvement type considered is the addition of a median to help direct traffic and to separate turning vehicles from vehicles continuing through the lane. The addition of medians has been shown to reduce delays and reduce accident rates relative to segments that do not utilize medians to control traffic flows (AASHTO, 2003). The Highway Capacity Manual (HCM, 2000) provides guidelines for calculating the change in capacity and travel speeds as a result of the addition of a median.

Finally, interchange projects pose a special set of issues for user benefit evaluation. Such projects include new interchange construction on interstate facilities, as well as upgrades from at-grade signalized intersections to grade-separated interchanges on non-interstate facilities. The benefit calculations mainly stem from travel time savings associated with improved access to a limited-access facility, among other factors. For the purpose of the present analysis, it is assumed that the benefit of a new interchange, translated in terms of travel time savings, is approximately equal to one half of the travel time before the interchange construction multiplied by the number of trips. In addition, improving an at-grade intersection to an interchange is likely to provide benefits in terms of both travel time and safety. In such cases, the reduction in crashes is estimated using the crash reduction factors shown in Table 6.9. 


\subsubsection{Economic Benefit Analysis}

Economic benefit analysis is conducted for the valuation of broader benefits than the traditional measures of user benefits. These benefits typically include: business savings from market economies of scale, productivity benefits, logistic opportunities for just-intime production economies, shift in business growth and locational factors, etc. In general, highway investments can affect productivity in three ways: (i) by decreasing business costs of current delivery operations; (ii) by expanding or increasing business sales through an increase in effective market size; and (iii) by decreasing unit costs through gain of opportunities for scale economies in production and delivery processes (Weisbrod et al., 2001). These additional benefits may accrue to any business or resident in the region deriving additional income from business growth attributable to the highway improvements, even if they do not use the affected highway system (Weisbrod and Grovak, 2001). These benefits may be interrelated and can also include multiplier effects. This approach measures impacts in terms of effects on employment, income, output and gross regional product (value added).

\subsubsection{Estimation of Direct Business Cost Savings by Industry}

This section discusses the estimation of direct cost savings on existing businesses in the study area (the State of Indiana) that result from the highway user benefits. User benefits associated with non-business trips are excluded from the economic benefit analysis as they do not directly impact the cost or productivity of doing business and cannot produce any secondary economic impact. The estimated business automobile and truckrelated travel efficiency benefits (i.e., reduced direct user travel costs for existing trips) over the analysis period (20 years) are first translated into monetary consequences (i.e., effects on flows of dollars) and then, allocated to various types of existing businesses located in the state. These business expansion impacts by business sector (industry) are used as direct impacts for entry in into the REMI dynamic economic simulation model.

The portion of benefits accruing to automobiles on business travel are allocated primarily to service industries (transportation, professional, personal, finance, insurance and real 
estate, etc.), while the portion of truck-related benefits are allocated primarily to all other industries (durable and non-durable manufacturing, mining, construction, transportation and public utilities, retail trade, wholesale trade, agriculture, forestry and fishery services). ${ }^{8}$ These direct business cost savings are allocated among industries based on the relative sensitivity of each industry to highway-related costs, weighted by each industry's share of the state's economic activity. Highway-related costs are measured as the sum of the portion of business costs associated with purchases of trucking services, and the portion of business cost spent on drivers' and mechanics' wages, vehicle purchases and maintenance. The state's economic activity is measured by employment levels. This methodology is discussed in detail in Weisbrod and Grovak (2001) and CSI (1998). It should be noted that different industry distribution applies for metropolitan and nonmetropolitan areas in Indiana. The service industries are primarily located on urbanized areas, while the heavy manufacturing, construction and wholesale industries are located in rural areas.

Next, these benefits are totaled by industry and distributed between intermediate inputs and value-added (i.e., industry's gross output minus its intermediate inputs) based on the national input-output matrix. The benefits related to intermediate inputs are entered into the REMI model as a reduction in operating costs, while the benefits related to value-added are entered as an increase in total factor productivity. ${ }^{9}$ The net increase in productivity is calculated by comparing the cost savings to the total value added by industry. The general approach for entering project benefits into REMI model is outlined in the Interstate 5 (I-5) Portland, OR-Vancouver, WA case study available at: http://www.fhwa.dot.gov/planning/toolbox/portland_methodology_economic.htm

${ }^{8}$ Ideally, at a smaller level of analysis, the Transportation Satellite Accounts (TSAs)-available from the US Bureau of Transportation Statistics (US BTS) - would be used to allocate truck benefits to each industry. A more simplified approach was deemed appropriate at the statelevel analysis; truck benefits were assigned to those industries that (on average) rely mostly on trucks for their freight shipments. Similar assumption was made for the allocation of business automobile-related benefits.

${ }^{9}$ Economic texts define productivity as the ratio of total business output over weighted average cost of business inputs, where business output is defined in terms of dollars of business sales and business inputs are defined to include costs of obtaining labor, equipment, supplies, transportation, and other services (Weisbrod et al., 2001). 


\subsubsection{Estimation of Potential Business Attraction and Tourism}

In addition to the direct cost savings for businesses, highway projects have the potential of enhancing strategic connections between specific locations and activities, and expanding the size of market reach to customers and labor, which can further attract outof-state business activity and investment. Business attraction impacts associated with a highway project are typically estimated as changes in employment by industry. Industries that are best served by highway modes, appear to be underrepresented or lagging in growth within the study area compared to the neighboring areas, and/or export their goods to the rest of the country have the potential for business attraction benefits (CSI, 1998). In the Long-Range Transportation Plan and subsequent study (CSI and BLA, 2004), such industries were identified in the manufacturing, wholesale trade, and transportation and warehousing sectors. Potential business attraction benefits were distributed among those industries at proportions identified in CSI and BLA (2004), as follows: durable manufacturing — 67.4 percent, non-durable manufacturing -23.3 percent, wholesale trade-7.3 percent, and transportation and warehousing -2 percent. Business attraction impacts that represent net transfers among counties within the state were not taken into account. This eliminates the potential for "double-counting" that could also occur if local and retail services were included in this calculation.

Typically, the net business attraction impacts at small levels of analysis (i.e., corridor or local)are exogenously estimated, that is using market estimation models surveys of area firms, and/or interviews with business, economic development and tourism professionals (Weisbrod and Beckwith, 1990). However, at greater level of analysis (i.e., county, state, or nation), the method of location quotients (LQ) is preferred as a fast and inexpensive alternative classification method compared to conducting business surveys or interviews. The method of location quotients takes account of indirect as well as direct exports and is useful for identifying industries that appear are underrepresented or lagging in growth within the study area compared to the neighboring areas, or the rest of the state or nation. LQ was discussed in detail Section 4.2.3.

Past studies have applied LQ analysis to estimate potential business attraction associated with highway investments (CSI, 1998a; 1998b). It was assumed that if the location 
has experienced strong growth (indicated by LQ greater than 1) without the transportation improvement, new business attraction would be limited since the existing highway system has not been a barrier to business growth. However, a counterargument can also be made; the potential for business attraction might be higher in a region with competitive advantages such as skilled labor force, agglomeration economies, etc. (indicated by LQ greater than 1).

Prior studies of business attraction impacts of highway projects in rural areas in Indiana (CSI, 1996a; CSI, 1996b) provided a broad overview of the types of industries that might be attracted to rural areas, as well as the magnitude of the expected job changes based on the functional class and lane-mileage of the highway improvement. It was estimated that the magnitude of the direct business attraction (expressed as additional jobs) of a 100-mile four-lane modified highway is up to 556 jobs over a 15-year period, while the magnitude of the direct business attraction of a 100-mile four-lane modified freeway with limited access is up to 1,241 jobs over the same period. CSI (1996b) also suggested that the impact of urban highway projects on business attraction would be on a par with, or perhaps lower, than that on business expansion; however, no quantitative assessment was provided.

In the present study, the method of location quotients (LQ) is applied to quantify the magnitude of potential business attraction. LQ were calculated for the manufacturing industry $^{10}$ at the county-level for the year 2004, using the Location Quotient calculator (US BLS, 2005). The share of manufacturing industry in each county within Indiana was compared to the corresponding share in the rest of the study area to compute the location quotient. Based on the conclusions of prior research (CSI, 1998a; 1998b), the potential for business attraction of highway projects would be proportional to that of business expansion by a factor of $1 / L Q$. If the reverse argument is true, potential for business attraction of highway projects would be proportional to that of business expansion by a factor of $L Q$. This study investigates both assumptions and provides a range of

\footnotetext{
${ }^{10}$ The manufacturing industry was selected since it has the most competitive advantage among the wholesale trade, transportation and warehousing sectors in Indiana (LQ = 1.77), compared to the rest of the nation. Also, prior research has argued that manufacturing firms seem to benefit more from highways (Dalenberg and Partridge, 1997; Fernald, 1999).
} 
business attraction impacts for each highway improvement. It was also of interest to compare the business attraction estimates made available from prior studies of business attraction impacts of highway projects in rural areas in Indiana with those estimated using LQ analysis (both scenarios). The results of the comparison of the different assumptions in estimating business attraction impacts are reflected in the econometric models presented in the next chapter.

Some additional assumption inherent in the estimation of potential business attraction and tourism are provided below:

- The additional jobs are assumed to be created in equal increments over a 15year period after the improvement is completed, consistent with the state-of-thepractice (CSI and BLA, 2004; CSI, 1998a; CSI, 1998b).

- It is also assumed that additional jobs will not be attracted in the state as a result of median construction projects. Estimates about the types and sizes of businesses that may be attracted to a region as a result of the other highway improvements were based on the methodology and scenarios described above.

- Finally, given that a reasonable assessment of tourism attraction impacts can be made only a through analysis of the specific area economy, it is assumed that the highway projects under study will have a limited impact on out-of-state tourism attraction. As such, tourism attraction impacts associated with individual highway projects are not considered in the economic benefit analysis presented herein.

\subsubsection{Estimation of Long-Term Secondary Economic Development Effects}

The final step of the analysis procedure includes entering the results of the previous steps into the regional economic simulation model (REMI), running a long-term simulation, and evaluating the results. The REMI simulation model is run for each highway improvement project to develop a long-term forecast of the total statewide economic de- 
velopment effects, including business expansion, business attraction, and their associated multiplier effect. The simulation results (i.e., direct, indirect, and induced economic effects) are compared to the baseline to estimate project impacts in terms of changes in employment, business sales, real disposable income and gross regional product (in 1996 dollars) on an annual basis over the 20-year analysis period.

In this study, the additional economic development effects resulting from potential business attraction were estimated separately from the direct business expansion effects. This allowed for alternative scenarios to be examined. In total, the REMI model was run four times to calculate the total (direct, indirect, and induced) effects associated with the highway improvements on a year-by-year basis over the analysis period: once without business attraction, and subsequently for the three different scenarios of business attraction (discussed in 6.2.3.).

Table 6.10 presents the summary statistics for the economic development variables estimated under different assumptions of business attraction, as well as some additional calculated benefit/cost measures, such as the ratio of wages or output generated per dollar of highway investment, or the ratio of jobs created per dollar of highway investment. $^{11}$

${ }^{11}$ REMI outputs are expressed in 1996 dollars. The PPI (all)—shown in Table 6.3—can be used to convert the benefit values to current dollar values (i.e., 2006), except for the benefit measure "net change in real disposable income" where the CPI (all)-also, shown in Table 6.3-is recommended. 
Table 6.10 Summary Statistics for Economic Development Impacts of Highway Improvements Predicted by REMI

\begin{tabular}{|c|c|c|}
\hline $\begin{array}{l}\text { Statewide Economic Development-Specific } \\
\text { Variables }\end{array}$ & Variable Code & $\begin{array}{l}\text { Mean (standard } \\
\text { deviation) }\end{array}$ \\
\hline $\begin{array}{l}\text { Net Change in Employment } \\
\text { (jobs) }\end{array}$ & REMIEMP & $\begin{array}{c}34.52(75.91)^{\mathrm{b}} \\
91.16(191.67)^{\mathrm{c}} \\
84.04(187.51)^{\mathrm{d}} \\
178.93(277.07)^{\mathrm{e}}\end{array}$ \\
\hline $\begin{array}{l}\text { Net Change in Real Disposable Income } \\
\text { (million } 1996 \text { dollars) }\end{array}$ & REMIINCMI & $\begin{array}{l}5.01(8.55)^{b} \\
7.74(12.46)^{c} \\
7.08(11.64)^{d} \\
11.25(15.17)^{e}\end{array}$ \\
\hline $\begin{array}{l}\text { Net Change in Output } \\
\text { (million } 1996 \text { dollars) }\end{array}$ & REMIOUTMI & $\begin{array}{l}18.74(40.46)^{b} \\
32.95(62.28)^{c} \\
30.20(59.50)^{d} \\
50.94(17.60)^{e}\end{array}$ \\
\hline $\begin{array}{l}\text { Net Change in Gross Regional Product } \\
\text { (million } 1996 \text { dollars) }\end{array}$ & REMIGRPMI & $\begin{array}{l}9.10(19.21)^{b} \\
15.77(28.99)^{c} \\
14.43(27.67)^{d} \\
26.98(45.38)^{e}\end{array}$ \\
\hline \multicolumn{3}{|l|}{ Benefit/Cost Specific Variables } \\
\hline $\begin{array}{l}\text { Jobs Created per million } 1996 \text { dollars of Con- } \\
\text { struction Spending (jobs per million } 1996 \text { dol- } \\
\text { lars) }\end{array}$ & JOBPER96\$ & $\begin{array}{l}1.74(4.72)^{b} \\
3.20(6.44)^{c} \\
2.40(5.68)^{d} \\
4.76(6.67)^{e}\end{array}$ \\
\hline $\begin{array}{l}\text { Net Change in Earnings per million } 1996 \text { dollars } \\
\text { of Construction Spending (million } 1996 \text { dollars) }\end{array}$ & INCPER96\$ & $\begin{array}{l}0.25(0.60)^{b} \\
0.33(0.68)^{c} \\
0.27(0.58)^{d} \\
0.40(0.67)^{e}\end{array}$ \\
\hline $\begin{array}{l}\text { Net Change in Output per million } 1996 \text { dollars of } \\
\text { Construction Spending (million } 1996 \text { dollars) }\end{array}$ & OUTPER96\$ & $\begin{array}{l}0.87(2.67)^{b} \\
1.28(2.97)^{c} \\
0.98(2.56)^{d} \\
1.60(2.97)^{e}\end{array}$ \\
\hline $\begin{array}{l}\text { Net Change in Gross Regional Product per mil- } \\
\text { lion } 1996 \text { dollars of Construction Spending } \\
\text { (million } 1996 \text { dollars) }\end{array}$ & GRPPER96\$ & $\begin{array}{l}0.42(1.27)^{b} \\
0.61(1.41)^{c} \\
0.47(1.20)^{d} \\
0.79(1.44)^{e}\end{array}$ \\
\hline
\end{tabular}

a cumulative change over the 20-year analysis period, estimated by REMI.

${ }^{\mathrm{b}}$ assuming no business attraction (Scenario 1 ).

${ }^{c}$ potential of business attraction proportional to that of business expansion by a factor of $1 / L Q$ (Scenario 2).

d potential of business attraction proportional to that of business expansion by a factor of $L Q$ (Scenario 3).

${ }^{\mathrm{e}}$ potential of business attraction for rural projects based on (CSI, 1996b) (Scenario 4).

In general, it can be observed that economic development estimates range depending on the assumption inherent in each scenario. They are lower when no additional bene- 
fits are expected because of business attraction and higher under the fourth scenario where the magnitude of the expected business attraction (in number of jobs) for rural projects was based on highway functional class and lane-mileage. A comparison of the summary statistics of the variables obtained using the location quotient analysis shows that overall, scenario 3 yielded lower estimates than scenario 2 . This is probably attributed to the fact that the majority of the improvements under study were programmed for areas with lower competitive advantage (LQ lower than 1) compared to other regions in the state. As such, the potential of business attraction for the given highway projects is greater when it is assumed proportional to that of business expansion by a factor of $1 / L Q$, than under the alternative assumption.

Subsequent $t$-tests for testing differences between two means (i.e., comparing the means of two populations) showed there are no significant differences between the means of the variables estimated under scenario 2 and 3 . However, the results obtained based on business attraction estimates of prior research (scenario 4) were found to be statistically different than the results generated using the method of location quotients to estimate potential business attraction. Based on the statistical evidence, this study will develop separate econometric models to investigate the relationship between economic development effects estimated under different assumptions of business attraction (scenario 2 or 3, and scenario 4) and different types of highway investments. The hypotheses and results of the econometric analysis are presented in the next chapter.

\subsection{Demonstration of Analysis Procedure}

To illustrate how the analytical framework presented in the previous sections could be used in practice the case of a highway expansion project, with the geometric and operational characteristics presented in Table 6.10., is considered. The project is scheduled for construction in 2006. We are interested in estimating the statewide economic development effects of this project in 20 years after the completion of its construction (20082027). It is assumed that benefits will begin to accrue in the first year of highway operation. A discount rate of 5 percent is used. 
Table 6.11 Summary of Project Characteristics

\begin{tabular}{|l|c|l|c|}
\hline Type of Project & $\begin{array}{c}\text { Added Travel } \\
\text { Lanes }\end{array}$ & $\begin{array}{l}\text { Base Case-Average Daily Traffic } \\
\text { in 2005 }\end{array}$ & 81,742 \\
\hline Functional Class & Urban Interstate & $\begin{array}{l}\text { Base Case-Average Daily Traffic } \\
\text { in 2025 }\end{array}$ & 162,736 \\
\hline $\begin{array}{c}\text { Length of Construction } \\
\text { Period (years) }\end{array}$ & 2 & $\begin{array}{c}\text { Proposed System-Average Daily } \\
\text { Traffic in Year 1 }\end{array}$ & 89,456 \\
\hline Project Costs (\$2003) & $165,000,000$ & $\begin{array}{l}\text { Proposed System-Average Daily } \\
\text { Traffic in Year 20 }\end{array}$ & 178,093 \\
\hline Start Lanes & 6 & Base Case-Capacity (veh/hr) & 6,224 \\
\hline End Lanes & 8 & $\begin{array}{l}\text { Proposed System-Capacity } \\
\text { (veh/hr) }\end{array}$ & 8,299 \\
\hline Project Length (miles) & 8 & Percent of SU/Comb. Trucks (\%) & $15.9 / 4.9$ \\
\hline
\end{tabular}

First, we estimate the user benefits attributable to the proposed project. They fall into three categories: travel time savings, vehicle operating cost changes, and safety cost savings. To assess the broader economic impact of these benefits, estimates were developed regarding the distribution of two categories of vehicle trips: truck trips and automobile business-related trips. The estimation results for the first and last year of the 20year analysis period are shown in Figure 6.1.

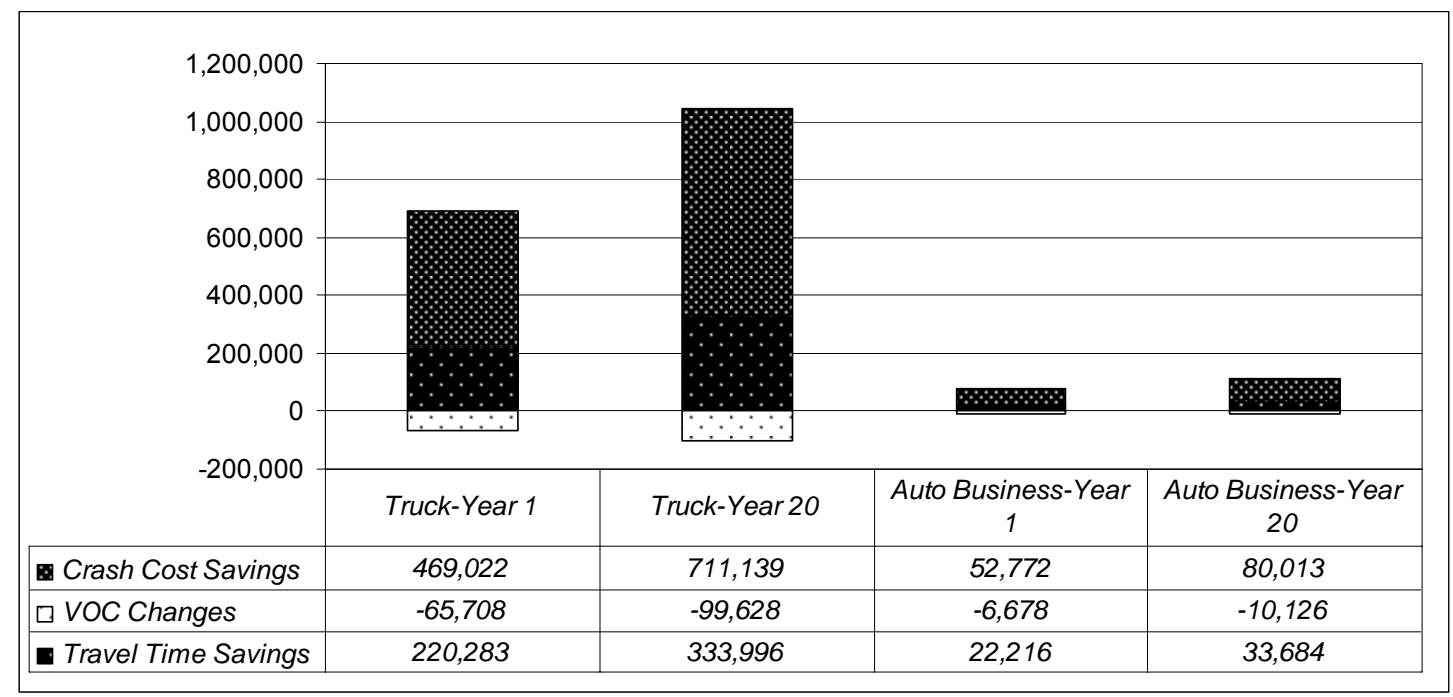

Figure 6.1 User Benefits by Mode, Trip Purpose and Analysis Year (in 2003 dollars) 
The cumulative user benefits for truck trips over the 20 -year analysis period is $\$ 17.5$ million in 2003 dollars, while the cumulative user benefits for auto business trips over the same period is $\$ 4.1$ million in 2003 dollars. ${ }^{12}$ These benefits are further translated into production cost savings and productivity enhancing benefits to enter into the economic simulation model REMI. The REMI model is then run and the simulation results are compared to the baseline to determine the total (including direct, indirect and induced) economic effects associated with business cost savings resulting from the proposed highway project (Table 6.11).

Table 6.12 REMI Estimation Results Associated with Business Expansion

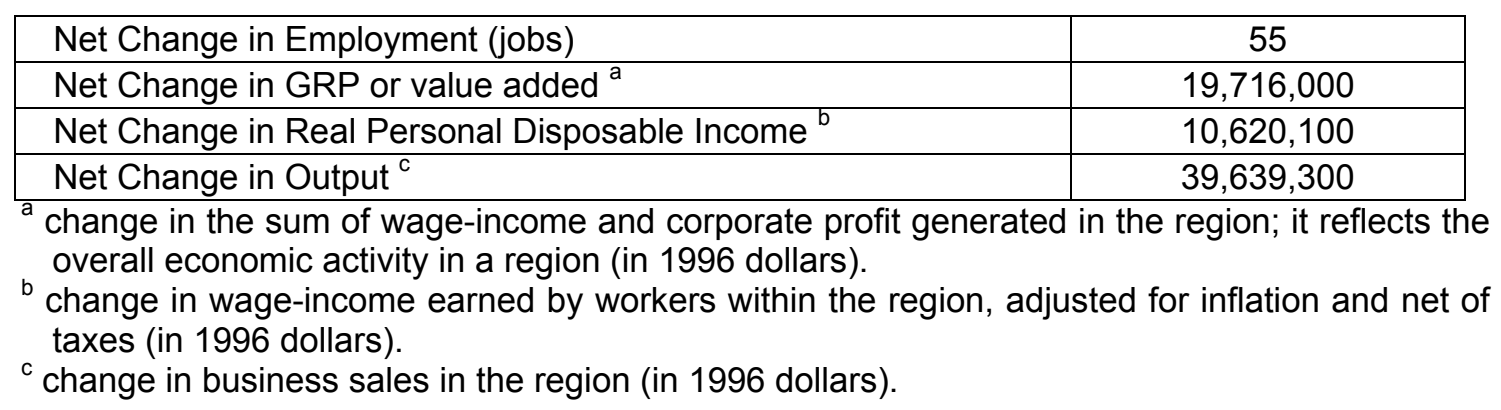

In addition to the direct cost savings for businesses, highway projects have the potential of attracting out-of-state business activity and investment. It is assumed that the significant increases in accessibility resulting from the urban highway would benefit manufacturers most, since manufacturers are particularly dependent on reliable truck transportation. Other industries that export their goods to the rest of the country and are projected to produce statewide attraction benefits include: wholesale trade, transportation and warehousing industries. The method of location quotients (LQ) is applied to quantify the magnitude of business attraction. The LQ for the manufacturing industry located in the urban area where the highway improvement takes place, calculated using the Location Quotient calculator (US BLS, 2005), was found 0.61. The magnitude of business attrac-

\footnotetext{
${ }^{12}$ Increases in highway speeds-that result in speeds higher than the operating speeds at which the cost of operation is optimal-can result in a decline in operating efficiency and higher operating costs incurred by both automobiles and trucks (Weisbrod and Beckwith, 1990). In this case, the savings resulting from vehicle operating costs changes are negative (dissavings).
} 
tion is assumed to be proportional to that of business expansion by a factor of $1 / \mathrm{LQ}=$ $1 / 0.61=1.64$, or $55^{\star} 1.64=90$ jobs are estimated to be attracted as a result of the highway improvement. For analytical purposes, it is assumed that the additional jobs will be created will be in equal increments over a 15-year period after the improvement is completed. Finally, tourism attraction impacts associated with the highway project are anticipated to be limited at the state level.

The REMI model is then run and the simulation results are compared to the baseline to determine the total economic development impacts resulting from both cost savings for businesses and business attraction impacts associated with the highway project. The project is predicted to generate 296 (direct, indirect and induced) jobs that would accrue to the industries that benefit most from increased access to buyer and supplier markets, and accrue multiplier effects from increased business and consumer spending, such as: manufacturing, retail trade and services industries. The results of the simulation performed for the proposed highway project over a 20-year period are summarized below.

Table 6.13 REMI Estimation Results, Including Business Attraction

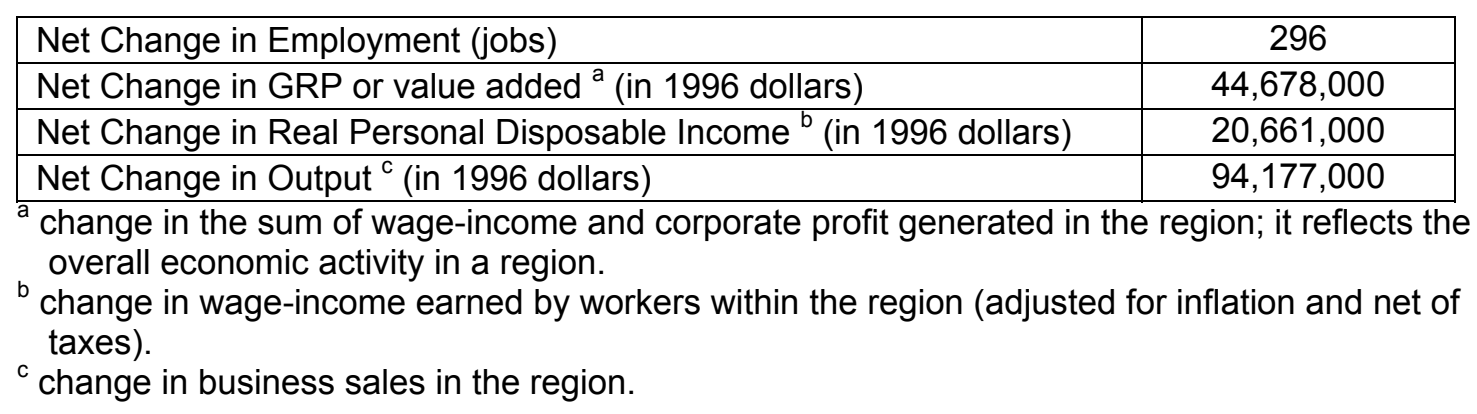

In summary, the employment benefits of the urban interstate highway improvement would be in the range of 55 (low) to 256 (high) new jobs created. The "high" value is fairly sensitive to the magnitude of the potential business attraction. To accommodate this concern, this study estimates a range of statewide long-term economic development benefits estimated for different types of highway improvements-under different scenarios of business attraction-which can be used by decision-makers to evaluate alternative highway investments based on sound economic development criteria. 


\section{CHAPTER 7. STATEWIDE LONG-TERM ECONOMIC DEVELOPMENT BY HIGHWAY IMPROVEMENT TYPE AND LOCATION}

\subsection{Overview}

This research study investigates the relationship between long-term economic development and different types of highway investments programmed for the State of Indiana. Temporal, spatial, and project characteristics are included. To achieve this, the analysis involves three main steps: first, determining which factors are important and how they can be measured in the long-run; second, obtaining data at a geographic scale consistent with the economic variables; and third, developing the analytical methodology (econometric models) to include multiple variables so that it can be used effectively by stakeholders. The first two steps were discussed in previous chapters. This chapter presents the econometric models developed in a bid to investigate the relationship between the benefit measures of economic development (i.e., output, income, employment, and gross regional product), project attributes (project type, size and costs), and location attributes (e.g., county, geographical region, accessibility), that is statistically shown to hold for Indiana. The analysis procedure and the variables (dependent and independent) considered in the econometric models are shown in Figure 7.1.

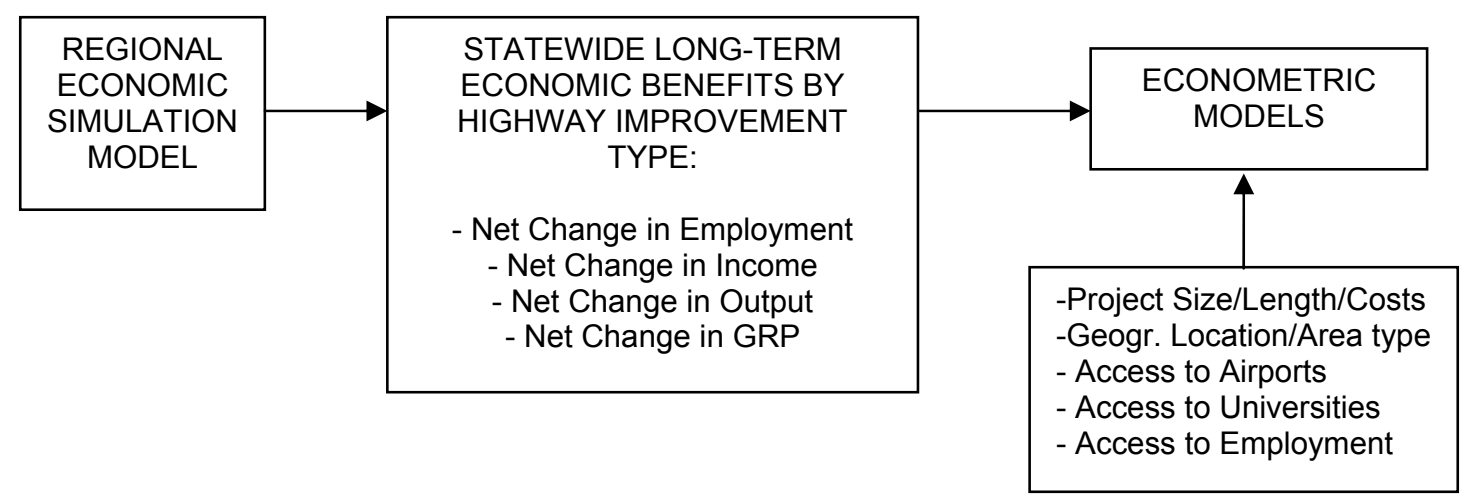

Figure 7.1 Econometric Analysis Procedure 


\subsection{Methodological Approach}

\subsubsection{Econometric Model Specification}

In econometric analyses of regional systems, two classes of models may be distinguished: simple and simultaneous. Viewing regional models from a perspective of a simultaneous system of equations provides in general more efficient results than those resulting from simple single-equation estimation (Glickman, 1977). The simultaneous models express causal relationships among the various equations and the endogenous variables in the model, and are far morel elegant in their formulation and sophisticated in their use of statistical techniques than are the simple models. Moreover, in a system of equations, it is possible to have a series of dependent variables that may be considered as a group, yet may not have direct interaction as they would in common simultaneous equation models. For example, the economic development impact measures considered in this study (i.e., net change in employment, real disposable income, output and gross regional product) may be examined by estimating four separate equations with each measure as the dependent variable. However, treating the level of output and the level of employment independently would be unrealistic since employment and output are simultaneously determined. Furthermore, since all four dependent variables are indicators of the same underlying process (i.e., change in economic activity) resulting from a specific highway project, the four equations are likely to share unobserved characteristics. The equations are thus seemingly unrelated, but they have contemporaneous (cross-equation) correlation of their error terms. If the equations are estimated separately by ordinary least squares (OLS), the parameter estimates are consistent but not efficient. Efficient parameter estimates are obtained by considering the contemporaneous correlation of the disturbances (Washington et al., 2003; Pindyck and Rubinfeld, 1998). Considering contemporaneous correlation in seemingly unrelated regression equations is referred to as SURE.

As noted, the equations are related through the correlation in their errors. Therefore, instead of considering one equation at a time, the equations are aggregated and their coefficients $(\beta)$ are estimated according to the following procedure. Consider a set of $M$ 
seemingly uncorrelated equations, each with $p_{i}$ independent variables and $T$ observations, with the $i^{\text {th }}$ equation given by:

$$
y_{i}=X_{i} \cdot \beta_{i}+\varepsilon_{i}, i=1, \ldots, M
$$

where, $y_{i}$ is a $T \times 1$ vector of observed values on the $i^{\text {th }}$ dependent variable, $X_{i}$ is a $T \times p_{i}$ matrix with rank $p_{i}$ of observations on $p_{i}$ independent variables, $\beta_{i}$ is a $p_{i} \times 1$ vector of unknown regression coefficients, and $\varepsilon_{i}$ is a $T \times 1$ vector of error terms. It is assumed that $\varepsilon=\left(\varepsilon_{1}, \varepsilon_{2}, \ldots, \varepsilon_{M}\right)$ has a multivariate normal density with mean $E(\varepsilon)=0$ and covariance $E(\varepsilon \varepsilon)=\sum \otimes I_{T}=V$, where $\sum=\left(\sigma_{i j}\right)$ is a positive symmetric matrix, $I_{T}$ is a $T \times T$ identity matrix and $\otimes$ is the Kronecker product. The generic equation can be written, similar to a linear regression model, as:

$$
Y=X \beta+\varepsilon
$$

where, $Y=\left(y_{1}, y_{2}, \ldots, y_{M}\right), \beta=\left(\beta_{1}, \beta_{2}, \ldots, \beta_{M}\right)$ and $X=I_{T} \otimes X_{i}$. Using Generalized Least Squares (GLS), a best linear unbiased estimator is obtained as follows:

$$
\hat{\beta}=\left\{X^{\prime}\left(\Sigma \otimes I_{T}\right)^{-1} \cdot X\right\}^{-1} \cdot X^{\prime}\left(\Sigma \otimes I_{T}\right)^{-1} \cdot Y
$$

The estimator $\hat{\beta}$, known as seemingly unrelated Ordinary Least Squares (OLS) method restricted residuals estimator, is at least as efficient as the estimator of $\beta$ obtained by using the OLS method on each of the $M$ equations given in Equation (7.1). The $t$ Student statistic is used at the 90 percent confidence level for testing the significance of the independent variables.

Elasticities are calculated to characterize the sensitivity of the dependent variables $Y=\left(y_{1}, y_{2}, \ldots, y_{M}\right)$, due to changes in explanatory variables $X=I_{T} \otimes X_{i}$. The elasticity is computed for each project as:

$$
E_{X}=\beta \cdot \frac{X}{Y}
$$


where, $Y=\left(y_{1}, y_{2}, \ldots, y_{M}\right), \beta=\left(\beta_{1}, \beta_{2}, \ldots, \beta_{M}\right)$ and $X=I_{T} \otimes X_{i}$.

Note that elasticities are not applicable to indicator variables (those variables taking on values of 0 or 1$){ }^{13}$ Instead, impact factors are estimated as the change in statewide economic development measures (i.e., output, income, employment, and gross regional product) caused by a change in indicator variables. It is also important to note that these factors are dynamic; they measure the statewide effect of a given type of highway improvement twenty years after implementation. The short-term effects in close vicinity to the project's location (i.e., county and/or adjacent counties) could be higher than the corresponding statewide long-term effects when the construction stimulus is removed. In the long-run, what actually happens depends on the relative scarcity of land, labor and capital (Flyvbjerg et al., 2003).

\subsubsection{Statistical Tests}

In a wide variety of economic applications a critical question arises as to whether the same model is appropriate for two potentially different subsamples. In this study, it was of interest to examine whether the same seemingly unrelated regression equation holds for different highway improvement types, or separate models are statistically warranted to develop. The Chow test (Chow, 1960) can be used to test the stability of model parameters across project types. For two different project types (e.g., added travel lanes and new road construction), three models must be estimated: a model using the complete data; a model using data for project type 1; and a model using data for project type 2. The test statistic for equality of the coefficients across subsamples follows an $F$ distribution with $\left(N_{1}+N_{2}-2 k\right)$ degrees of freedom as follows:

${ }^{13}$ Due to the nature of the data (with a preponderance of indicator variables), many of the statistically significant explanatory variables were indicator variables. This does not present a problem for estimation or interpretation of findings. Also, when statistically justified, indicator variables were interacted with continuous variables (such as the project length for new road construction projects). 


$$
F_{k, N_{1}+N_{2}-2 k}=\frac{\frac{R S S_{r}-R S S_{u r}}{k}}{\frac{R S S_{u r}}{N_{1}+N_{2}-2 k}}
$$

where, $R S S r$ is the residual sum of squares for the all-data model (restricted); RSSur is the residual sum of squares for the unrestricted model, estimated as the sum of squares from each of the subsample model results $\left(R S S_{1}\right.$ and $\left.R S S_{2}\right) ; N_{1}$ and $N_{2}$ are the number of observations in each subsample; and $k$ is the number of restrictions to be tested.

If the $F$ statistic is larger than the critical value of the $F$ distribution with $k$ and $\left(N_{1}+N_{2}-\right.$ $2 k$ ) degrees of freedom, the equality of coefficients across subsamples can be rejected. That is, treatment of the data as two different subsamples is more appropriate than assuming that the same model parameters apply equally to both groups. In this case, the data cannot be pooled; instead, separate models by project type must be estimated.

For the purposes of this research, the Chow test was conducted to test the stability of model parameters across the four project types. The test results are shown in Table 7.1. It can be observed that it is statistically justified-with 99 percent confidence-that ATL (added travel lanes) projects and construction-related projects (i.e., new road, median, and interchange construction) are treated separately. This might indicate that there are some inherent differences in these two groups (added-capacity to existing facilities vs. new construction projects) and therefore, the same model parameters cannot apply equally to both groups. The econometric models presented in the next section are expected to shed light into the differences in these two separate project groups identified in this analysis step. 
Table 7.1 Chow Test Results

\begin{tabular}{|c|c|c|c|c|c|}
\hline & \multicolumn{4}{|c|}{ Residual Sum of Squares (SSR) } & \multirow{2}{*}{$\mathrm{N}$} \\
\hline & REMIEMP & REMIINCMI & REMIOUTMIIREMIGRPMI & \\
\hline ATL & 2340166.0 & 6205.8 & 191564.1 & 80029.1 & 58 \\
\hline NRC/MC/IC & 509188.3 & 3596.0 & 74560.1 & 15924.3 & 59 \\
\hline ALL & 3857968.0 & 13099.7 & 334823.1 & 135345.9 & 117 \\
\hline $\mathrm{k}$ & & & & & \\
\hline $\mathrm{N}_{1}+\mathrm{N}_{2}-2 \mathrm{k}$ & 111 & 110 & 112 & 110 & \\
\hline $\mathrm{F}$ & & & & & \\
\hline$F_{k, N_{1}+N_{2}-2 k, 0.01}$ & 6.19 & 4.95 & 5.52 & 6.04 & \\
\hline & 2.96 & 2.79 & 3.17 & 2.79 & \\
\hline
\end{tabular}

where, REMIEMP—net change in employment (jobs); REMIINCMI—net change in real disposable income (million 1996 dollars); REMIOUTMI-net change in output (million 1996 dollars); REMIGRPMI-net change in gross regional product (million 1996 dollars); ATL-added travel lanes; NRC—new road construction; MC—-median construction; IC—-interchange construction; and ALL-all data.

\subsection{Estimation Results}

Based on the statistical evidence presented in the previous section, separate econometric models were developed for added capacity projects (58 observations) and construction type projects-new road, median, and interchange construction (59 observations). Table 7.2 presents the summary statistics for the statewide long-term economic development effects estimated by each highway improvement category. Furthermore, as discussed in Section 6.2.4., there was statistical evidence to develop separate models according to the inherent assumption of business attraction. It was found that the longterm economic development effects that were predicted based on business attraction estimates of prior research (CSI, 1996b) are statistically different than the ones estimated using the method of location quotients. The final product of this analysis will be order-of-magnitude estimates of long-term economic development effects of highway investment in Indiana by project type and location attributes. 
Table 7.2 Summary Statistics for Economic Development Variables Classified by Group of Projects

\begin{tabular}{|c|c|c|c|c|c|}
\hline \multirow{2}{*}{$\begin{array}{l}\text { VARIABLE } \\
\text { CODE }\end{array}$} & \multicolumn{5}{|c|}{ Mean (standard deviation) ${ }^{a}$} \\
\hline & ATL & NRC & MC & IC & NRC/MC/IC \\
\hline REMIEMP & $\begin{array}{l}122.16(235.36)^{b} \\
292.14(332.05)^{c}\end{array}$ & $\begin{array}{l}36.57(79.31)^{b} \\
54.91(66.73)^{c}\end{array}$ & $1.56(2.77)^{d}$ & $\begin{array}{l}195.47(207.92)^{b} \\
280.66(254.31)^{\mathrm{c}}\end{array}$ & $\begin{array}{l}46.57 \underset{b}{(114.02)} \\
67.64 \underset{c}{(140.58)}\end{array}$ \\
\hline REMIINCMI & $\begin{array}{l}8.88(12.11)^{b} \\
15.86(16.16)^{c}\end{array}$ & $\begin{array}{l}3.89(5.92)^{b} \\
4.63(5.45)^{c}\end{array}$ & $0.69(0.57)^{d}$ & $\begin{array}{l}21.73(19.71)^{b} \\
28.86(20.05)^{\mathrm{c}}\end{array}$ & $\begin{array}{l}5.31(10.97)^{b} \\
6.72(12.71)^{c}\end{array}$ \\
\hline REMIOUTMI & $\begin{array}{l}39.29(64.32)^{b} \\
74.42(86.00)^{c}\end{array}$ & $\begin{array}{l}12.90(24.27)^{b} \\
17.23(20.94)^{c}\end{array}$ & $0.24(0.33)^{d}$ & $\begin{array}{l}101.48(100.17)^{b} \\
132.27(101.99)^{c}\end{array}$ & $\begin{array}{l}21.26(53.39)^{b} \\
27.87(60.68)^{b}\end{array}$ \\
\hline REMIGRPMI & $\begin{array}{l}19.32(29.74)^{\mathrm{b}} \\
41.03(54.50)^{\mathrm{c}}\end{array}$ & $\begin{array}{c}5.06(10.62)^{b} \\
8.04(9.89)^{c}\end{array}$ & $0.17(0.18)^{d}$ & $\begin{array}{l}48.05(45.90)^{b} \\
62.66(47.02)^{\mathrm{c}}\end{array}$ & $\begin{array}{c}9.63(24.80)^{b} \\
13.17(28.44)^{c}\end{array}$ \\
\hline JOBPER96\$ & $\begin{array}{l}1.62(1.77)^{b} \\
4.54(3.96)^{c}\end{array}$ & $\begin{array}{l}2.71(7.74)^{b} \\
4.85(6.80)^{c}\end{array}$ & $0.22(0.40)^{d}$ & $\begin{array}{l}12.36(11.25)^{b} \\
18.01(12.32)^{c}\end{array}$ & $\begin{array}{l}3.17(7.76)^{b} \\
4.98(8.57)^{c}\end{array}$ \\
\hline INCPER96\$ & $\begin{array}{l}0.15(0.19)^{b} \\
0.27(0.24)^{c}\end{array}$ & $\begin{array}{l}0.28(0.60)^{b} \\
0.38(0.52)^{c}\end{array}$ & $0.09(0.11)^{d}$ & $\begin{array}{l}1.51(1.26)^{b} \\
2.07(1.30)^{c}\end{array}$ & $\begin{array}{l}0.39(0.78) b \\
0.52(0.90) \mathrm{c}\end{array}$ \\
\hline OUTPER96\$ & $\begin{array}{l}0.55(0.55)^{b} \\
1.16(1.02)^{c}\end{array}$ & $\begin{array}{l}0.78(0.22)^{b} \\
1.39(2.00)^{c}\end{array}$ & $0.04(0.07)^{d}$ & $\begin{array}{l}6.85(5.88)^{b} \\
9.22(5.80)^{c}\end{array}$ & $\begin{array}{l}1.41(3.52)^{b} \\
2.03(4.03)^{c}\end{array}$ \\
\hline GRPPER96\$ & $\begin{array}{l}0.28(0.26)^{b} \\
0.62(0.66)^{c}\end{array}$ & $\begin{array}{l}0.36(1.04)^{b} \\
0.64(0.94)^{c}\end{array}$ & $0.03(0.04)^{d}$ & $\begin{array}{l}3.26(2.72)^{b} \\
4.40(2.72)^{c}\end{array}$ & $\begin{array}{l}0.67(1.66)^{b} \\
0.97(1.91)^{c}\end{array}$ \\
\hline
\end{tabular}

${ }^{a}$ cumulative change over the 20 -year analysis period, estimated by REMI.

${ }^{b}$ potential of business attraction proportional to that of business expansion by a factor of $L Q$ (Scenario 3).

${ }^{c}$ potential of business attraction for rural projects based on (CSI, 1996b) (Scenario 4).

${ }^{d}$ assuming no business attraction potential.

where, ATL—added travel lanes; NRC—new road construction; MC—-median construction; IC— interchange construction; REMIEMP—net change in employment (jobs); REMIINCMI-net change in real disposable Income (million 1996 dollars); REMIOUTMI-net change in output (million 1996 dollars); REMIGRPMI-net change in gross regional product (million 1996 dollars); JOBPER96\$-jobs created per million 1996 dollars of highway construction spending (jobs per million 1996 dollars) ; INCPER96\$-net change in earnings per million 1996 dollars of highway construction spending (million 1996 dollars); OUTPER96\$—net change in output per million 1996 dollars of highway construction spending (million 1996 dollars); and GRPPER96\$-net change in gross regional product per million 1996 dollars of highway construction spending (million 1996 dollars).

Table 7.2 shows that the statewide long-term economic development benefits of adding travel lanes are, on average, greater than those of constructing new roads, medians or interchanges. However, the economic development benefits compared to the associated costs of those investments are lower, mainly because of the large capital outlays required for added capacity projects compared to the other type of projects considered in 
this study (average projects costs by project type were reported in Table 4.4). This preliminary finding could be of importance to identify the most efficient allocation of future resources on investments related to improvements in highway capacity.

\subsubsection{Added-Capacity Projects}

The first group of projects identified by the Chow test involves highway improvements in expanding capacity on an existing highway, such as adding travel lanes in both directions of a highway. Added-capacity highway projects are of particular interest as they require relatively large capital outlays. Typically, the requirement for such an investment is justified on the need for expanding capacity to meet current unsatisfied or future demand, or improve the level of service (i.e., reduce congestion and delays) at a facility or highway network. Given the typically large scale of these investments, it was of great interest to ascertain their impacts on statewide economic development over a 20 -year period so that their overall benefits can be assessed to justify their costs. A system of seemingly unrelated regression equations (SURE) was developed to investigate the relationship between this type of highway investment and statewide long-term changes in economic development in Indiana, under the two different scenarios of business attraction (Scenario 3 and 4). The SURE equations are shown in Table 7.3 and 7.4. Twotailed $t$-test results suggested that all parameter coefficients were significantly different from zero at more than 90 percent confidence. Details of the SURE models developed are provided in Appendix D (Tables D.1 and D.2). 
Table 7.3 SURE Estimation Results for Highway Investments Involving Adding Travel Lanes (Scenario $4^{*}$ )

\begin{tabular}{|l|c|}
\hline $\begin{array}{l}\text { REMIEMP }=-156.00+10.56 \times N E W L N M I-168.40 \times U R B A N+347.21 \times I \\
+43.75 \times A C C A I R P-90.86 \times C E N T R A L\end{array}$ & $\begin{array}{c}\text { (Adjusted } R^{2}= \\
0.55)\end{array}$ \\
\hline$R E M I N C M I=-8.71+0.51 \times N E W L N M I-4.51 \times R E S T U R B A N+14.08 \times I$ & $\left(\right.$ Adjusted $R^{2}=$ \\
$+2.04 \times A C C A I R P-3.78 \times C E N T R A L+0.022 \times P R C O S T M I$ & $0.47)$ \\
\hline$R E M I O U T M I=-77.01+3.01 \times N E W L N M I-17.93 \times U R B A N+65.85 \times I$ & $\left(\right.$ Adjusted $R^{2}=$ \\
$+15.97 \times A C C A I R P$ & $0.47)$ \\
\hline$R E M I G R P M I=-27.21+2.18 \times N E W L N M I-16.16 \times R E S T U R B A N$ & (Adjusted $R^{2}=$ \\
$+21.43 \times I-19.25 \times S T+8.13 \times A C C A I R P-22.44 \times C E N T R A L$ & $0.40)$ \\
\hline
\end{tabular}

* potential of business attraction for rural projects based on (CSI, 1996b).

where, REMIEMP — net change in employment (jobs); REMINCMI-net change in real disposable income (million 1996 dollars); REMIOUTMI —net change in output (million 1996 dollars); REMIGRPMI-net change in gross regional product (million 1996 dollars); NEWLNMI-new (added) lane-miles; URBAN-(1, if project located in urban areas; 0, for rural projects); RESTURBAN-(1, if project located in urban areas excluding Marion county; 0 , otherwise); $I-(1$, for interstate highway improvements; 0 , otherwise); $S T-(1$, for state highway improvements; 0 , otherwise); ACCAIRP_degree of accessibility to major airports (1-low to 5-high); CENTRAL-(1, if project located in Central Indiana; 0, otherwise); and PRCOSTMI-project costs (million 1996 dollars).

Table 7.4 SURE Estimation Results for Highway Investments Involving Adding Travel Lanes (Scenario $3^{*}$ )

\begin{tabular}{|c|c|}
\hline $\begin{array}{l}\text { REMIEMP }=-205.57+6.92 \times N E W L N M I-36.04 \times U R B A N+150.43 \times I \\
+33.83 \times A C C A I R P-21.90 \times C E N T R A L\end{array}$ & (Adjusted $R^{2}=0.25$ ) \\
\hline $\begin{array}{l}\text { REMINCMI }=-10.87+0.31 \times N E W L N M I+2.16 \times U R B C E N T R+8.20 \times I \\
+2.10 \times A C C A I R P+0.44 \times A C U N I V N S\end{array}$ & $(\mathrm{Ad}$ \\
\hline REMIOUTMI $=-67.35+1.97 \times N E W L N M I+40.98 \times I+11.41 \times A C C A I R P$ & (Adjusted $R^{2}=0.31$ ) \\
\hline $\begin{array}{l}\text { REMIGRPMI }=-29.14+0.93 \times N E W L N M I-2.03 \times R E S T U R B A N \\
+22.04 \times I-5.15 \times A C C A I R P-3.26 \times C E N T R A L\end{array}$ & (Adjusted $R$ \\
\hline
\end{tabular}

" potential of business attraction proportional to that of business expansion by a factor of LQ.

where, REMIEMP — net change in employment (jobs); REMINCMI-net change in real disposable income (million 1996 dollars); REMIOUTMI - net change in output (million 1996 dollars); REMIGRPMI-net change in gross regional product (million 1996 dollars); NEWLNMI-new (added) lane-miles; URBAN-(1, if project located in urban areas; 0 , for rural projects); I-(1, for interstate highway improvements; 0, otherwise); ACCAIRP—-degree of accessibility to major airports (1-low to 5-high); CENTRAL-(1, if project located in Central Indiana; 0, otherwise); URBCENTR-(1, if project located in urban areas in Central Indiana; 0 , for rural projects); ACUNIVNS-degree of accessibility to universities in North and South Indiana (1 to 5); and RESTURBAN-(1, if project located in urban areas excluding Marion county; 0 otherwise). 
The estimation results, presented in Table 7.3 and Table 7.4 , suggest that statewide economic development in Indiana appears to be enhanced with highway investments in added capacity. The number of lane-miles—used as a proxy for project size-is a significant factor in the estimated regional econometric system of equations; all other factors being equal, the larger the project the greater its impact on economic activity, measured in terms of employment, income, output and gross regional product (GRP). For example, consider two projects that involve adding a lane in each direction but differ in project length by one mile. In this hypothetical case, the models would predict that the larger project would produce greater economic development benefits of the following magnitude: 14-21 more jobs, \$0.6-\$1 additional million in real disposable income, \$4$\$ 6$ million additional output, and \$2-\$4 million additional GRP. The net economic impacts on the Indiana economy, however, could be higher or lower than those values depending on the magnitude and direction of the effects of the other factors included in the multivariate econometric specification. These factors are discussed next.

The size of highway investment can also be measured by project cost. The results presented in Table 7.3 suggest that, ceteris paribus, an additional million in highway investment (in 1996 dollars) could increase real disposable income by a factor of 0.022 (or $\$ 22,000$ ). An elasticity value of 0.16 was estimated, which suggests that one percent increase in highway spending on investments in new-lane capacity results in 0.16 percent increase in real disposable income (in 1996 dollars) over a 20-year period after construction. This value may seem lower compared to the economic multipliers estimated using the input-output methodology (shown in Table 5.2). A direct comparison of the results generated by the two different methods could only lead to erroneous conclusions, since the input-output economic multipliers reflect only the unique effects of construction spending on the economy at one point in time, while the results of the econometric model reflect the effects of a multitude of factors that can influence development—including a highway investment-over time.

Highway improvements such as adding travel lanes (ATL) can generate benefits by increasing volume-to-capacity ratios, reducing transit time and logistic costs for businesses, which in turn can result in greater business cost savings. These business cost savings were allocated among industries based on each industry's sensitivity to high- 
way-related costs and weighted by each industry's share of economic activity (measured by employment) in Indiana (as discussed in Section 6.2.2.1). The results suggest that interstate highway improvements, in particular, appear to have a stronger potential for economic development compared to investments on other highway functional classes. This could be possibly attributed to the higher dependence (demonstrated by higher truck volumes) of some industries such as manufacturing on interstates for their freight movements coupled with those industries' greater share of economic activity in Indiana. This is consistent with past research that has claimed significant regional economic benefits of undertaking interstate improvements on population, employment and income growth (Politano and Roadifer, 1989; Weiss, 2002; Weiss, 2005).

The estimation results also suggest that the location of the project is a significant determinant of whether a highway project will generate economic development benefits. Adding travel lanes into a highway in rural areas - in particular, in North or South Indianawith a less developed transportation system will have a larger impact than a similar project introduced into an urban area with a mature system. This finding seems to be in line with prior research that argued that highway improvements into undeveloped locations or areas of moderate to rapid development can have a measurable contribution of aggregate change leading to long-term impacts (FHWA, 1992). In addition, in general, rural areas are in less than full employment, and as such, the potential for business attraction and employment benefits would be greater compared to urban areas in full employment. Furthermore, rural areas could be gaining improved access to urban markets.

Given that 47 percent of ATL projects in urban areas were programmed for Marion County (where Indianapolis is located), data on urban projects could share common attributes. To test this hypothesis, an alternate variable was considered as indicator of projects programmed for urban areas besides Marion County (RESTURBAN). The Durbin-Watson (DW) test that detects for serial or spatial correlation was used. ${ }^{14}$ It was found that introducing separate variables as indicators of urban projects in Marion County and of similar projects in other urban areas in the system of equations resulted in

${ }^{14}$ A value of DW close to 2 is indicative of independence across observations, while lower (higher) values suggest a positive (negative) correlation (Washington et al., 2003). 
a DW statistic-value closer to the desirable value. Besides the gain in efficiency, treating projects in Marion County differently than the other urban projects in the econometric specification allowed for the following conclusion to be reached; that is, the statewide economic development benefits of adding travel lanes would be greater if the project is located in Marion County compared to the other urban areas. The results shown in Table 7.4 show that, all other factors being equal, economic activity and, in particular, real disposable income increases with added capacity investments in urban areas in Central Indiana, where Marion County is located. This could be probably reflecting the effect of factors other than highway density or highway investment (e.g., education, labor, other infrastructure) that can influence the location of economic growth, as it has been pointed out in prior research (John Locke Foundation, 2003). For example, there are greater employment opportunities available around Indianapolis than in the rest urban areas in Indiana. Further, economic activity and, in particular, personal income can increase as new economic migrants move to a region in search of employment.

By definition, accessibility index is a measurable factor of how well-connected internally and externally a region is to common travel destinations (i.e., to airports, universities and employment centers). Past study (CSI and BLA, 2003) showed that, all other factors being equal, there is a positive relationship between regional accessibility and levels of household income in Indiana. This study found that accessibility to airports is another condition for generating economic development associated with highway investments in expanded capacity. For example, all other factors being equal, a project in a region with high accessibility (value of 5 ) to airports may increase statewide employment by 136176 more jobs, output by $\$ 44-64$ million more, gross regional product by $\$ 20-32$ million more, and real disposable income by $\$ 8$ million more, compared to a project in a region with low accessibility (value of 1 ) to airports. Moreover, it was found that regional disposable income can increase with highway investments in regions North or South Indiana that are well-connected to universities in by up to $\$ 2$ million, all other factors being equal. It is important to note economic development measures may have a valid statistical connection with accessibility indices, but these indices only explain a part of the spatial variation of economic development. 
In summary, the econometric analysis for the economic development effect of added capacity projects yielded the following:

- Clearly, adding travel lanes on an Interstate in rural North or South Indiana with high degree of accessibility to airports would generate greater economic development benefits compared to a similar investment on a lower functional class highway in a different regional setting.

- The statewide economic development benefits of highway investment decisions in new-lane capacity would be greater if the project is located in Marion County compared to the other urban areas.

\subsubsection{Economic Development Benefit/Cost Ratios of Highway Investments in Added \\ Capacity}

The equations shown in Tables 7.3 and 7.4 provide a broad view of the expected statewide economic development effects of investments in new-lane capacity. However, they are not sufficient to identify the most cost-effective investments. To achieve this, economic development benefit/cost measures were introduced as dependent variables in the models, such as the ratio of wages or output generated per dollar of highway investment or the ratio of jobs created per dollar of highway investment. These measures are typically used as indicators of economic development by state agencies when evaluating competing projects (Weisbrod and Gupta, 2003). Moreover, these econometric equations can provide the groundwork to develop a point system (i.e., weights)—similar to the ones used in Wisconsin's TEA Program (Section 3.4.1.3) -to quantify a project's economic development potential. The estimation results under the two different scenarios are presented in Tables 7.5 and 7.6. Two-tailed $t$-test results suggested that all parameter coefficients were significantly different from zero at more than 90 percent confidence. The Durbin-Watson (DW) test that detects for serial or spatial correlation was indicative of independence across observations (DW values close to 2). Details of the SURE models developed are provided in Appendix D (Table D.3 and D.4). 
Table 7.5 SURE Estimation Results on Economic Development Benefit/Cost Ratios of Added-Capacity Projects (Scenario $4^{*}$ )

\begin{tabular}{|l|c|}
\hline JOBPER96\$ $=1.42+0.07 \times N E W L N M I-4.26 \times U R B A N+1.30 \times I$ & (Adjusted $R^{2}=$ \\
$+0.72 \times A C C A I R P+1.01 \times R U R S O U T H$ & $0.37)$ \\
\hline INCPER96\$ $=0.13-0.19 \times U R B A N+0.06 \times A C C A I R P+0.04 \times A C U N I V N S$ & (Adjusted $R^{2}=$ \\
$-0.07 \times R U R S T$ & $0.12)$ \\
\hline OUTPER96 $\$=0.07+0.02 \times N E W L N M I-0.77 \times U R B A N+0.25 \times A C C A I R P$ & (Adjusted $R^{2}=$ \\
$+0.31 \times A C E M P 345$ & $0.25)$ \\
\hline GRPPER96\$ $=0.08+0.02 \times N E W L N M I-0.49 \times U R B A N+0.16 \times A C C A I R P$ & (Adjusted $R^{2}=$ \\
$-0.21 \times C E N T R A L-0.34 \times R U R S T$ & $0.28)$ \\
\hline
\end{tabular}

* potential of business attraction for rural projects based on (CSI, 1996b).

where, JOBPER96\$-jobs created per million 1996 dollars of highway construction spending (jobs per million 1996 dollars); INCPER96\$-net change in earnings per million 1996 dollars of highway construction spending (million 1996 dollars); OUTPER96\$-net change in output per million 1996 dollars of highway construction spending (million 1996 dollars); GRPPER96\$-net change in gross regional product per million 1996 dollars of highway construction spending (million 1996 dollars); NEWLNMI-new (added) lane-miles; URBAN( 1 , if project located in urban areas; 0 , for rural projects); $I-(1$, for interstate highway improvements; 0, otherwise); ACCAIRP-degree of accessibility to major airports (1-low to 5high); RURSOUTH-(1, if project located in South rural Indiana; 0, otherwise); ACUNIVNSdegree of accessibility to major education institutions in North or South Indiana (1-low to 5high); RURST-(1, for projects on rural state highways; 0, otherwise); ACEMP345-degree of accessibility to employment (3 to 5); and CENTRAL-(1, if project located in Central Indiana; 0, otherwise).

Table 7.6 SURE Estimation Results on Economic Development Benefit/Cost Ratios of Added-Capacity Projects (Scenario $3^{*}$ )

\begin{tabular}{|l|c|}
\hline JOBPER96 $\$=-0.92+0.06 \times N E W L N M I+0.37 \times A C C A I R P$ & $\left(\begin{array}{c}\text { Adjusted } R^{2}= \\
0.11)\end{array}\right.$ \\
\hline INCPER96 $\$=-0.02+0.05 \times A C C A I R P+0.01 \times A C U N I V N S$ & $\begin{array}{c}\text { Adjusted } R^{2}= \\
0.10)\end{array}$ \\
\hline $\begin{array}{l}\text { OUTPER96 } \$=-0.39+0.01 \times N E W L N M I+0.18 \times A C C A I R P \\
+0.07 \times A C E M P 345\end{array}$ & $\begin{array}{c}\text { Adjusted } R^{2}= \\
0.15)\end{array}$ \\
\hline $\begin{array}{l}\text { GRPPER96\$ }=-0.15+0.01 \times N E W L N M I+0.09 \times A C C A I R P \\
-0.02 \times R U R S T\end{array}$ & $\begin{array}{c}\text { Adjusted } R^{2}= \\
0.13)\end{array}$ \\
\hline
\end{tabular}

* potential of business attraction proportional to that of business expansion by a factor of LQ.

where, JOBPER96\$-jobs created per million 1996 dollars of highway construction spending (jobs per million 1996 dollars); INCPER96\$-net change in earnings per million 1996 dollars of highway construction spending (million 1996 dollars); OUTPER96\$-net change in output per million 1996 dollars of highway construction spending (million 1996 dollars); GRPPER96\$-net change in gross regional product per million 1996 dollars of highway construction spending (million 1996 dollars); NEWLNMI-new (added) lane-miles; ACCAIRP-degree of accessibility to major airports (1-low to 5-high); ACUNIVNS-degree of accessibility to major education institutions in North or South Indiana (1-low to 5-high); ACEMP345-degree of accessibility to employment (3 to 5); and RURST-(1, for projects on rural state highways; 0 , otherwise). 
The estimation results are consistent with the analysis results presented in the previous section. In summary, the economic development benefit/cost ratios of added capacity projects are higher for investments on interstate highways in rural South Indiana with a high degree of accessibility to airports, universities and employment, compared to similar investments on state highways in a different regional setting (i.e., rural areas in Central Indiana, or urban areas with low connectivity to airports, universities or employment).

\subsubsection{New Road, Median and Interchange Construction Projects}

The second group of projects identified by the Chow test involves new constructionrelated projects such as new road, median and interchanges. The need for such investments may be driven by different factors than in the case of adding travel lanes to meet unsatisfied demand or improve the operating level of service. For example, new road construction investments may be justified by the need to provide access to lessconnected regions, while typically, median construction projects are justified on safety grounds, that is in a bid to reduce crashes (in particular, fatalities and injuries) usually on two-lane highway segments. Interchange construction projects include new interchange construction on interstate facilities, as well as upgrades from at-grade signalized intersections to grade-separated interchanges on non-interstate facilities. As previously, a system of seemingly unrelated regression equations was developed to investigate the relationship between these types of investments and statewide long-term changes in economic development in Indiana for each scenario of business attraction (Table 7.7 and 7.8). The econometric analysis may not be able to capture the factors that impose the implementation of such projects, but may indicate some factors that could be linked to such factors. Two-tailed $t$-test results suggested that all parameter coefficients were significantly different from zero at more than 90 percent confidence. The Durbin-Watson (DW) test that detects for serial or spatial correlation was indicative of independence across observations (DW values close to 2). Details of the SURE models developed are provided in Appendix D (Tables D.5 and D.6). 
Table 7.7 SURE Estimation Results for Highway Investments Involving New Construction-Related Projects (Scenario $4^{*}$ )

\begin{tabular}{|l|c|}
\hline $\begin{array}{l}\text { REMIEMP }=10.42+4.02 \times P R L E N N R C+225.24 \times I+175.44 \times A C E M P I 45 \\
+18.41 \times \text { SOUTHNRC }\end{array}$ & $\begin{array}{c}\text { Adjusted } R^{2}= \\
0.56)\end{array}$ \\
\hline $\begin{array}{l}\text { REMINCMI }=2.14+0.28 \times P R L E N N R C+19.37 \times I+19.34 \times A C E M P I 45 \\
+0.65 \times U R B U-0.60 \times M C-0.67 \times S T N R C\end{array}$ & $\begin{array}{c}\text { Adjusted } R^{2}= \\
0.66)\end{array}$ \\
\hline REMIOUTMI $=4.96+1.35 \times P R L E N N R C+106.62 \times I+80.68 \times A C E M P I 45$ & $\begin{array}{c}\text { Adjusted } R^{2}= \\
0.69)\end{array}$ \\
\hline REMIGRPMI $=2.32+0.64 \times P R L E N N R C+48.48 \times I+40.32 \times A C E M P I 45$ & $\begin{array}{c}\text { Adjusted } R^{2}= \\
0.70)\end{array}$ \\
\hline
\end{tabular}

" potential of business attraction for rural projects based on (CSI, 1996b).

where, REMIEMP-net change in employment (jobs); REMINCMI-net change in real disposable income (million 1996 dollars); REMIOUTMI — net change in output (million 1996 dollars); REMIGRPMI—net change in gross regional product (million 1996 dollars); PRLENNRC — project length in miles for new road construction projects; I-(1, for interstate highway improvements; 0, otherwise); ACEMPI45-high degree of accessibility of interchange construction projects to employment (4 to 5); SOUTHNRC-(1, for new road construction projects in South Indiana, 0 otherwise); URBU-(1, if project located on urban US highway; 0 , otherwise); $M C$ - 1 , for median construction projects; 0 , otherwise); and STNRC-(1, for new road construction projects on state highways; 0 , otherwise).

Table 7.8 SURE Estimation Results for Highway Investments Involving New Construction-Related Projects (Scenario $3^{*}$ )

\begin{tabular}{|c|c|}
\hline REMIEMP $=16.59+1.40 \times P R L E N N R C+172.84 \times I+82.49 \times A C E M P I 45$ & $\begin{array}{c}\text { (Adjusted } R^{2}= \\
0.36)\end{array}$ \\
\hline$R E M I N C M I=3.08+14.25 \times I+11.35 \times A C E M P I 45+0.66 \times U R B U-1.32 \times M C$ & $\begin{array}{c}\text { (Adjusted } R^{2}= \\
0.41)\end{array}$ \\
\hline $\begin{array}{l}\text { REMIOUTMI }=8.26+0.27 \times P R L E N N R C+82.18 \times I+50.60 \times A C E M P I 45 \\
-2.12 \times U R B A N\end{array}$ & $\begin{array}{c}\text { (Adjusted } R^{2}= \\
0.44)\end{array}$ \\
\hline$R E M I G R P M I=3.25+37.14 \times I+25.60 \times A C E M P I 45$ & $\begin{array}{c}\text { (Adjusted } R^{2}= \\
0.47)\end{array}$ \\
\hline
\end{tabular}

" potential of business attraction proportional to that of business expansion by a factor of LQ.

where, REMIEMP—net change in employment (jobs); REMINCMI-net change in real disposable income (million 1996 dollars); REMIOUTMI - net change in output (million 1996 dollars); REMIGRPMI-net change in gross regional product (million 1996 dollars); $P R L E N N R C$ - project length in miles for new road construction projects; I- (1, for interstate highway improvements; 0, otherwise); ACEMPI45-high degree of accessibility of interchange construction projects to employment (4 to 5); URBU-(1, if project located on urban US highway; 0 , otherwise); $M C$ - $(1$, for median construction projects; 0 , otherwise); and URBAN-(1, if project located in urban areas; 0 , for rural projects). 
Overall, the estimation results indicate significantly higher economic development effects generated by interchange construction projects, compared to median construction projects. This might have been anticipated since interstate highway interchanges provide access to a limited-access facility and it has been argued that they can generate economic benefits, in terms of commercial development growth (Hartgen and Kim, 1998) or earnings growth (Aldrich and Kusmin, 1997). On the other hand, the addition of medians has been shown to reduce delays and reduce accident rates relative to segments that do not utilize medians to control traffic flows (AASHTO, 2003), but these benefits might not be a measurable element of economic development potential that could lead to statewide long-term effects.

The magnitude of the economic development potential of interchange projects depends on the number of employment opportunities available in the location where the project is programmed for. For example, all other factors being equal, constructing new interchanges in areas with a high degree of accessibility to employment (values 4 or 5 ) may increase statewide employment by $83-175$ jobs, output by $\$ 51-81$ million, gross regional product $\$ 25-40$ million and real disposable income by $\$ 11-19$ million, compared to areas with lower degrees of accessibility (values 1 to 3 ).

New road construction projects seem to have potential for statewide long-term economic development effects that are a function of both project and location attributes. For example, consider two new road projects that differ in project length by one mile. In this hypothetical case, the models would predict that the larger project would produce greater economic development benefits of the following magnitude: 2-4 more jobs, \$0.3-\$1.4 million additional output, $\$ 0.3$ million additional in real disposable income, and $\$ 0.6$ million additional GRP. The net impacts on the Indiana economy, however, could be higher or lower than those values depending on the magnitude and direction of the effects of the other factors, such as highway functional class and project location, which are included in the multivariate econometric specification.

The construction of state highways appears to generate lower economic development benefits than similar investments on US highways. It was found that projects programmed for urban US highways can generate around $\$ 0.7$ million in additional real dis- 
posable income. This might be possibly attributed to the smaller dependence (demonstrated by higher truck volumes) of some industries such as manufacturing on state roads for their freight movements. Finally, new road construction projects programmed for South Indiana seem to have a greater potential for economic development-18 more jobs - compared to similar investments in North or Central Indiana. In general, new road construction projects are programmed for regions with low access to employment, airports and universities compared to the other types of projects, as it was indicated in Table 4.4. South Indiana in particular is less well connected to the rest of the state compared to other regions in the North or Central part of the state. Therefore, this finding might reveal the beneficial effects of providing new access to locations with a lower level of system-wide connectivity, consistent with past research (FHWA, 1992).

In summary, the econometric analysis for the economic development effect of new construction projects yielded the following:

- Clearly, interstate highway interchanges with a high degree of accessibility to employment would generate greater economic development benefits compared to median construction projects or new road construction projects on state roads in North or Central Indiana.

- The statewide economic development benefits of new road construction projects would be greater for larger projects (i.e., more miles constructed) programmed for US highways in South Indiana compared to similar investments on state roads in North or Central Indiana.

\subsubsection{Economic Development Benefit/Cost Ratios of Investments New Road, Median and Interchange Construction Projects}

As previously, the models shown in Tables 7.7 and 7.8 were modified to predict economic benefit/cost ratios of highway investments. The estimation results are presented in Table 7.9 and Table 7.10, respectively. Two-tailed $t$-test results suggested that all parameter coefficients were significantly different from zero at more than 90 percent confidence. The Durbin-Watson (DW) test that detects for serial or spatial correlation was 
indicative of independence across observations (DW values close to 2). Details of the SURE models developed are provided in Appendix D (Tables D.7 and D.8).

Table 7.9 SURE Estimation Results on Economic Benefit/Cost Ratios of New Construction-Related Projects (Scenario $4^{*}$ )

\begin{tabular}{|l|c|}
\hline $\begin{array}{l}\text { JOBPER96 }=3.47+10.01 \times I+13.12 \times A C E M P I 45-2.75 \times U R B A N \\
+2.90 \times \text { SOUTHNRC }\end{array}$ & $\begin{array}{c}\text { Adjusted } R^{2}= \\
0.54)\end{array}$ \\
\hline INCPER96 $\$=0.41+0.84 \times I+1.72 \times A C E M P I 45-0.26 \times U R B A N$ & $\begin{array}{c}\text { Adjusted } R^{2}= \\
0.60)\end{array}$ \\
\hline OUTPER96 $\$=1.62+5.29 \times I+6.84 \times A C E M P I 45-1.38 \times$ URBAN & $\begin{array}{c}\text { Adjusted } R^{2}= \\
0.67)\end{array}$ \\
\hline GRPPER96 $\$=0.74+2.37 \times I+3.42 \times$ ACEMPI45 $-0.61 \times$ URBAN & $\begin{array}{c}\text { Adjusted } R^{2}= \\
0.68)\end{array}$ \\
\hline
\end{tabular}

potential of business attraction for rural projects based on (CSI, 1996b).

where, JOBPER96\$-jobs created per million 1996 dollars of highway construction spending (jobs per million 1996 dollars); INCPER96\$-net change in earnings per million 1996 dollars of highway construction spending (million 1996 dollars); OUTPER96\$-net change in output per million 1996 dollars of highway construction spending (million 1996 dollars); GRPPER96\$-net change in gross regional product per million 1996 dollars of highway construction spending (million 1996 dollars); I-(1, for interstate highway improvements; 0 , otherwise); ACEMPI45-high degree of accessibility of interchange construction projects to employment (4 to 5); URBAN-(1, if project located in urban areas; 0 , for rural projects); and SOUTHNRC - (1, for new road construction projects in South Indiana; 0, otherwise).

Table 7.10 SURE Estimation Results on Economic Development Benefit/Cost Ratios of New Construction-Related Projects (Scenario 3*)

\begin{tabular}{|l|c|}
\hline JOBPER96 $\$=3.97+7.84 \times I+6.77 \times$ ACEMPI45 $-3.85 \times$ URBAN & $\begin{array}{c}\left(\text { Adjusted } R^{2}=\right. \\
0.26)\end{array}$ \\
\hline INCPER96 $\$=0.40+0.47 \times 1+1.17 \times A C E M P I 45-0.30 \times$ URBAN & $\begin{array}{c}\left(\text { Adjusted } R^{2}=\right. \\
0.32)\end{array}$ \\
\hline OUTPER96 $\$ 1.42+3.69 \times 1+4.68 \times A C E M P I 45-1.46 \times$ URBAN & $\begin{array}{c}\left(\text { Adjusted } R^{2}=\right. \\
0.41)\end{array}$ \\
\hline GRPPER96 $\$=0.65+1.59 \times I+2.38 \times A C E M P I 45-0.64 \times$ URBAN & $\begin{array}{c}\text { Adjusted } R^{2}= \\
0.41)\end{array}$ \\
\hline
\end{tabular}

potential of business attraction proportional to that of business expansion by a factor of LQ.

where, JOBPER96\$-jobs created per million 1996 dollars of highway construction spending (jobs per million 1996 dollars); INCPER96\$-net change in earnings per million 1996 dollars of highway construction spending (million 1996 dollars); OUTPER96\$—net change in output per million 1996 dollars of highway construction spending (million 1996 dollars); GRPPER96\$-net change in gross regional product per million 1996 dollars of highway construction spending (million 1996 dollars); I-(1, for interstate highway improvements; 0 , otherwise); ACEMPI45-high degree of accessibility of interchange construction projects to employment (4 to 5); and URBAN-(1, if project located in urban areas; 0 , for rural projects). 
The estimation results, presented in Tables 7.9 and 7.10, indicate that the economic development benefit/cost ratios of new construction projects are a function of highway functional class (i.e., interstate), type of area (i.e., urban), and degree of accessibility to employment opportunities (only for interchange construction). For example, all other factors being equal, highway interstate interchanges or new interstate highways could produce greater economic development benefits, per million dollars of highway construction spending, of the following magnitude: 8-10 jobs, \$0.5-\$0.8 million additional earnings, \$3.7-\$5.3 million additional output, and \$1.6-\$2.4 million additional GRP, compared to median construction projects or new road construction projects on lower class highways.

The magnitude of the economic development benefit/cost ratios of new interchange projects depends on the number of employment opportunities available in the location where the project is programmed for. For example, all other factors being equal, the economic development benefit/cost ratios of constructing new interchanges in areas with a high degree of accessibility to employment (values 4 or 5) would be of the following order of magnitude: 7-13 jobs per million dollars of highway construction spending, \$1.2-\$1.7 million additional earnings per million dollars of highway construction spending, \$4.7-\$6.8 million additional output per million dollars of highway construction spending, and \$2.4-\$3.4 million additional GRP per million dollars of highway construction spending, compared to areas with a lower accessibility index (values 1 to 3 ).

Finally, the greater statewide long-term economic development potential of new road construction projects programmed for South Indiana was also confirmed in this analysis (Table 7.10). It seems that such investments could yield up to 3 more jobs per million dollars of highway construction spending, compared to similar investments in North or Central Indiana. 


\subsection{Comparison of Alternative Parameter Estimators}

The decision to use systems estimation involved a trade-off between the added expense borne of estimating a simultaneous system of regression equations (SURE) and the gain in efficiency that is suggested by econometric theory (Washington et al., 2003; Pindyck and Rubinfeld, 1998). It was of interest to compare alternative estimation techniques in a bid to support-using empirical data-the choice of estimation procedure made in this study. The comparison involved single-equation regression models and simultaneous SURE models. In single-equation regression models, parameter estimates were obtained by using the Ordinary Least Squares (OLS) method on each of the individual equations that comprise each of the system of equations. Under the SURE specification, the parameter estimates were obtained by using the Generalized Least Squares (GLS) method on each of the system of equations (presented in Tables 7.3 through 7.9).

The comparison revealed that SURE parameter estimates were found to be more efficient than the OLS counterparts. In general, single regression equations yielded higher variance parameter estimates (i.e., wider confidence intervals) compared to simultaneous regression equations. The values of $t$-statistic for individual variables were also superior in the compared to the single-equation estimation. Moreover, the SURE models yielded more significant variables at the selected level of confidence than the singleequation estimation permitted. For example, in the model presented in Table 7.3 the variable indicating the cost of a highway project (PRCOSTMI) was not significant under single-equation estimation for the net change in real disposable income (REMINCMI). Therefore, the comparison results justify the decision to estimate a simultaneous system of equations over a single equation, in a bid to increase the efficiency of parameter estimates. 


\subsection{Validation of Analysis Results}

The final step of the analysis involved model validation. To achieve this, the economic impacts of Indiana's Long-Range Transportation Plan investments were estimated using the proposed analysis procedure (presented in Figure 4.1) and then compared with the results reported in CSI and BLA (2004). In that study, the MCIBAS model ${ }^{15}$ (discussed in Section 2.5.3.2.1) was used to determine the effectiveness of the plan in achieving statewide economic development goals over time (i.e., 20, 25 and 30 years after the long-range plan investments are implemented). Table 7.11 offers a comparison of the estimates obtained under the two approaches over 20 years after the plan implementation.

Table 7.11 Comparison of Results

\begin{tabular}{l|l|l|}
\hline Statewide Long-term Cumulative Net Change in: & MCIBAS $^{\text {a }}$ & Study Framework $^{\text {D }}$ \\
\hline Employment (jobs) & 15,050 & $9,850-20,950$ \\
\hline Income (billions of 2000 dollars) & 1.1 & $1.8-3.4$ \\
\hline Output (billions of 2000 dollars) & 4.0 & $3.8-6.3$ \\
\hline \\
a Source: CSI and BLA (2004). \\
${ }^{\mathrm{b}}$ Range of estimates (low-high).
\end{tabular}

Table 7.11 shows that the estimation results obtained under the two approaches are very comparable. The MCIBAS estimates of employment and output are within the range estimated under the proposed framework. The estimates of income, though, seem to be more conservative under the MCIBAS approach. Based on this comparison, it can be inferred that the use of sophisticated economic analysis tools such as the MCIBAS model to analyze investment alternatives could be redundant, especially for statewide economic impact analysis. This research developed a quantitative tool that is sufficiently complete and comprehensive to be publicly credible and further, as the validation revealed, it is consistent with widely acceptable findings and methods.

\footnotetext{
${ }^{15}$ For that application, MCIBAS was modified to consider a statewide program of projects rather than a single corridor.
} 


\section{CHAPTER 8. QUESTIONNAIRE SURVEY ON ECONOMIC DEVELOPMENT PRACTICES IN INDIANA}

\subsection{Survey Description and Results}

The main objective of this research study is to develop a tool capable of incorporating economic evaluation measures more explicitly into INDOT's transportation decision making process. One of the tasks in this project was to collect information from transportation agencies and organizations across Indiana that may have interests in economic development aspects. A questionnaire survey was conducted upon approval of the "Committee on the Use of Human Research Subjects" at Purdue University ${ }^{16}$. The survey was intended to address the following questions:

Under what circumstances do or should economic developers and transportation agencies in Indiana conduct economic development impact assessments?

1. What measures for economic development impacts are or should typically be used?

2. What strategies/tools are or should be used among economic developers and transportation agencies in Indiana?

This survey was targeted towards researchers and development practitioners, public organization staff, economic development organization staff, and private sector consultants and market analysts who are engaged in promoting the economic welfare of Indiana. The survey participants were provided information on how transportation projects

${ }^{16} 610$ Purdue Mall, Hovde Hall Room 307, West Lafayette, IN 47907-2040; phone: (765) 4945942; email address is: <irb@purdue.edu>. 
can affect economic development, and how economic development impacts can be assessed. It was anticipated that survey participants would benefit from participation by acquiring a better understanding of how various factors, including highway investment, interact to stimulate economic development; the nature of economic development effects; and the level of use of a series of general categories of measures, tools and techniques. The survey was voluntary. The risk to subjects was minimal; no greater than everyday experiences. All responses were kept confidential.

The design of this survey was largely based on previous nationwide surveys sponsored by NCHRP (Weisbrod, 2000; Forkenbrock et al., 2001) and GAO (2005), as well as on a recent statewide survey in Utah conducted by Brigham Young University in conjunction with the Utah Department of Transportation (BYU, 2006). These surveys are discussed in Appendix E.

The questionnaire consisted of five parts (shown in Appendix F). The first part dealt with the profile of the economic development organization (i.e., agency, consultant, university or other). The second part included a number of questions referring to the participants' views about the circumstances, motivations, criteria and measures encountered in economic development impact assessments. The third and fourth part referred to participants' views about the existing methods, tools, and techniques, and the frequency and adequacy of their use to assess economic development impacts. The final part dealt with Indiana's economic development profile (i.e., industry targeting, economic development programs, infrastructure). The questionnaire was pilot tested prior to its distribution for this study.

The following sections summarize the responses to the questions posed as part of this survey accompanied by a discussion on the key findings ${ }^{17}$.

\footnotetext{
${ }^{17}$ Menna Noureldin, JTRP 2006 Summer Intern, assisted the research team in recording, analyzing and presenting the responses to the questionnaire survey.
} 


\subsubsection{Organization Profile (Part 1)}

\subsubsection{What best describes your organization?}

In total, there were 18 responses to the survey. The survey participants included: 8 transportation agencies and consultants; 5 economic development agencies and consultants; and 5 planning agencies and others (i.e., university or electric and gas utility).

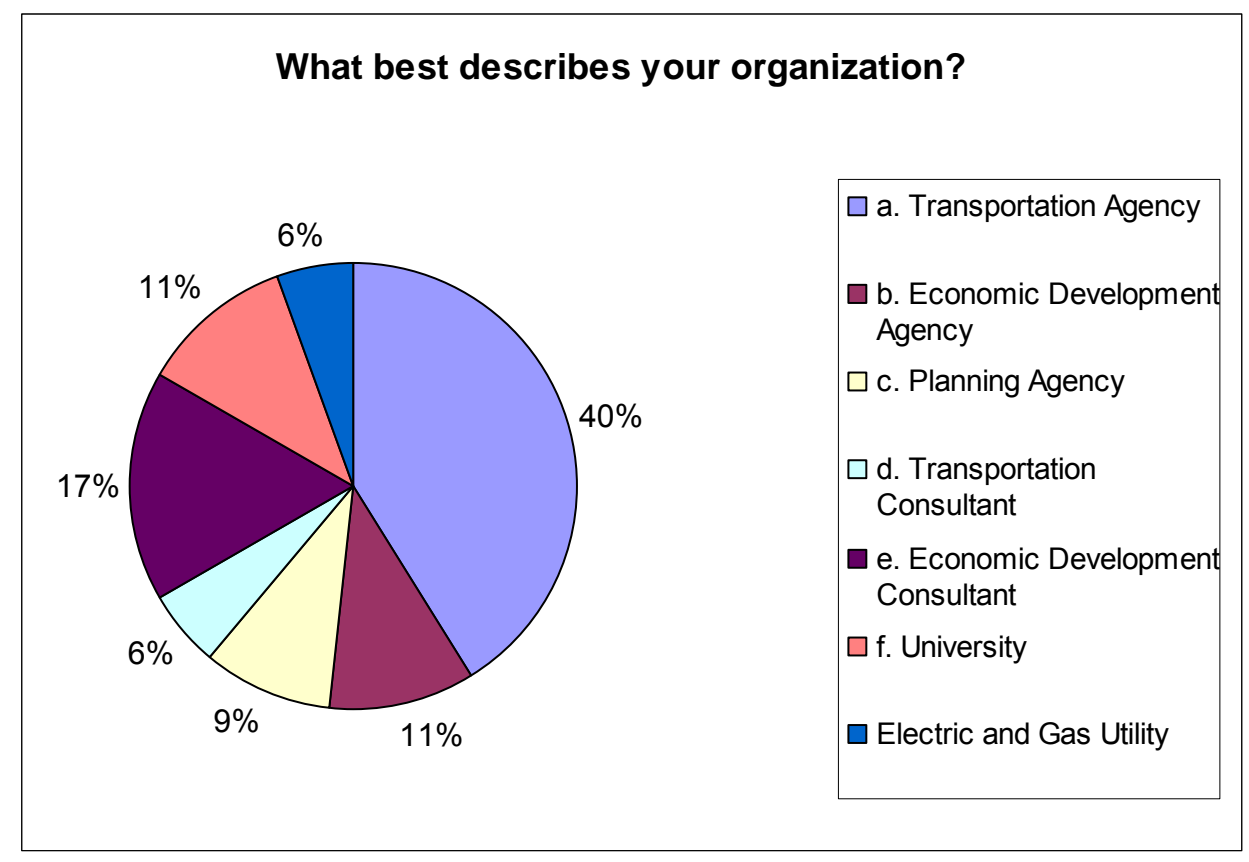

8.1.1.2. Does your organization get involved in evaluating economic development impacts of transportation projects?

Two-thirds of the survey participants (67\%) stated that they get involved in evaluating economic development impacts of transportation projects. 


\subsubsection{Economic Development Practices (Part 2)}

8.1.2.1. What evaluation criteria should be considered when choosing one transportation project to fund over another, and what weight (\%) do you think each factor should carry? (Please check all that apply)

When choosing which transportation project to fund over another: transportation agencies and consultants place the greatest value on safety $(27 \%)$ and mobility $(23 \%)$, followed by economic development (14\%) and accessibility (14\%). On the other hand, all the other agencies and consultants place the greatest value on economic development, followed by safety and environmental protection.

According to the majority of transportation agencies and consultants, the associated weight for the economic development criterion should be less than $20 \%$, while most economic development agencies and consultants stated that it should be equal to or greater than $20 \%$.

\begin{tabular}{|c|c|c|c|c|}
\hline & \multicolumn{4}{|c|}{ Weight of Economic Development in Analysis of Funding Transportation } \\
Projects
\end{tabular}




\section{Transportation agencies and consultants}
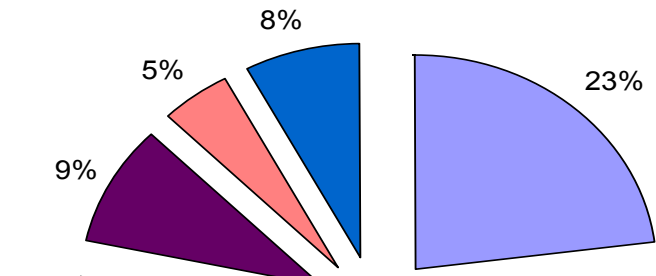

$\square$ Mobility

$\square$ Accessibility

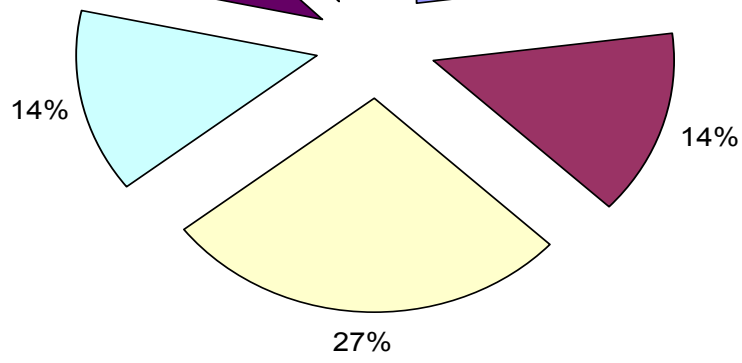

$\square$ Safety

$\square$ Economic Development

$\square$ Environmental Protection

$\square$ Quality of Life

$\square$ Others

\section{Economic development agencies and consultants}

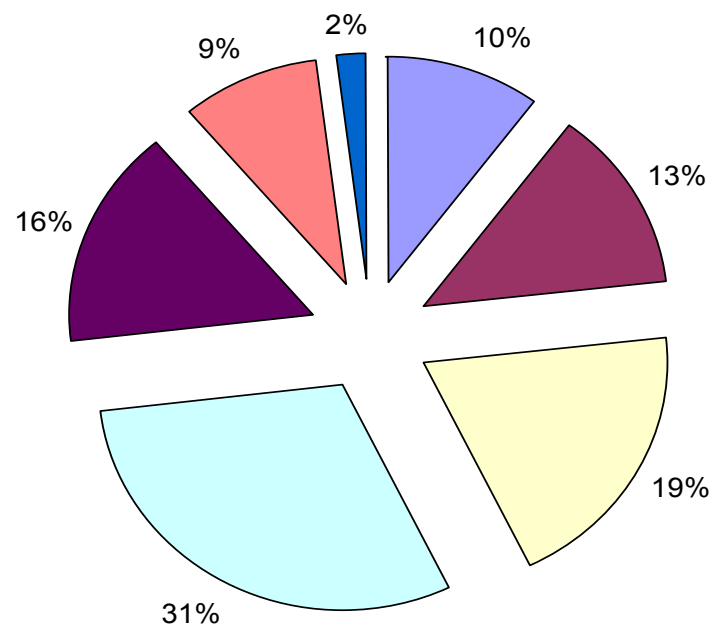

$\square$ Mobility

$\square$ Accessibility

$\square$ Safety

$\square$ Economic Development

$\square$ Environmental Protection

$\square$ Quality of Life

$\square$ Others 


\section{Planning agencies and others}

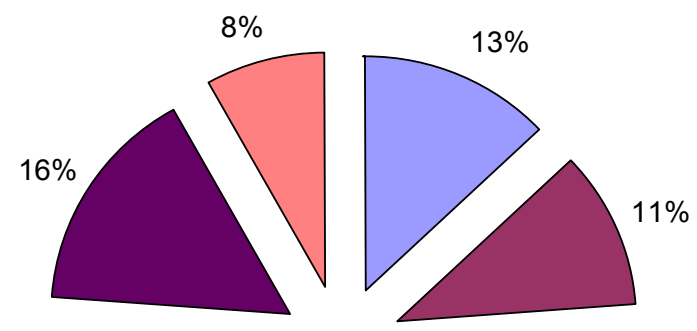

$\square$ Mobility

$\square$ Accessibility

$\square$ Safety

$\square$ Economic Development

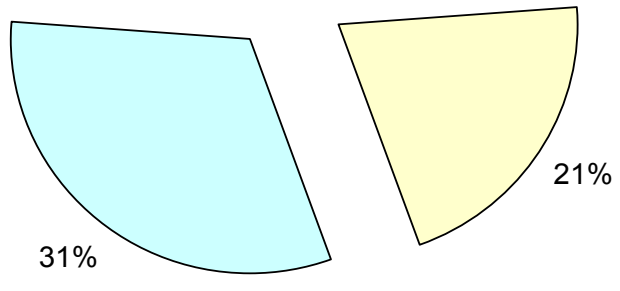

Environmental Protection

$\square$ Quality of Life

\subsubsection{Under which of the following circumstances, should economic development im-}

\section{pacts of transportation projects to be estimated?}

More than $50 \%$ of participants agreed that all transportation projects should always have the associated economic development impacts estimated. Almost all participants $(89 \%)$ agreed that economic development impacts should always be estimated for projects intended to promote economic development. 


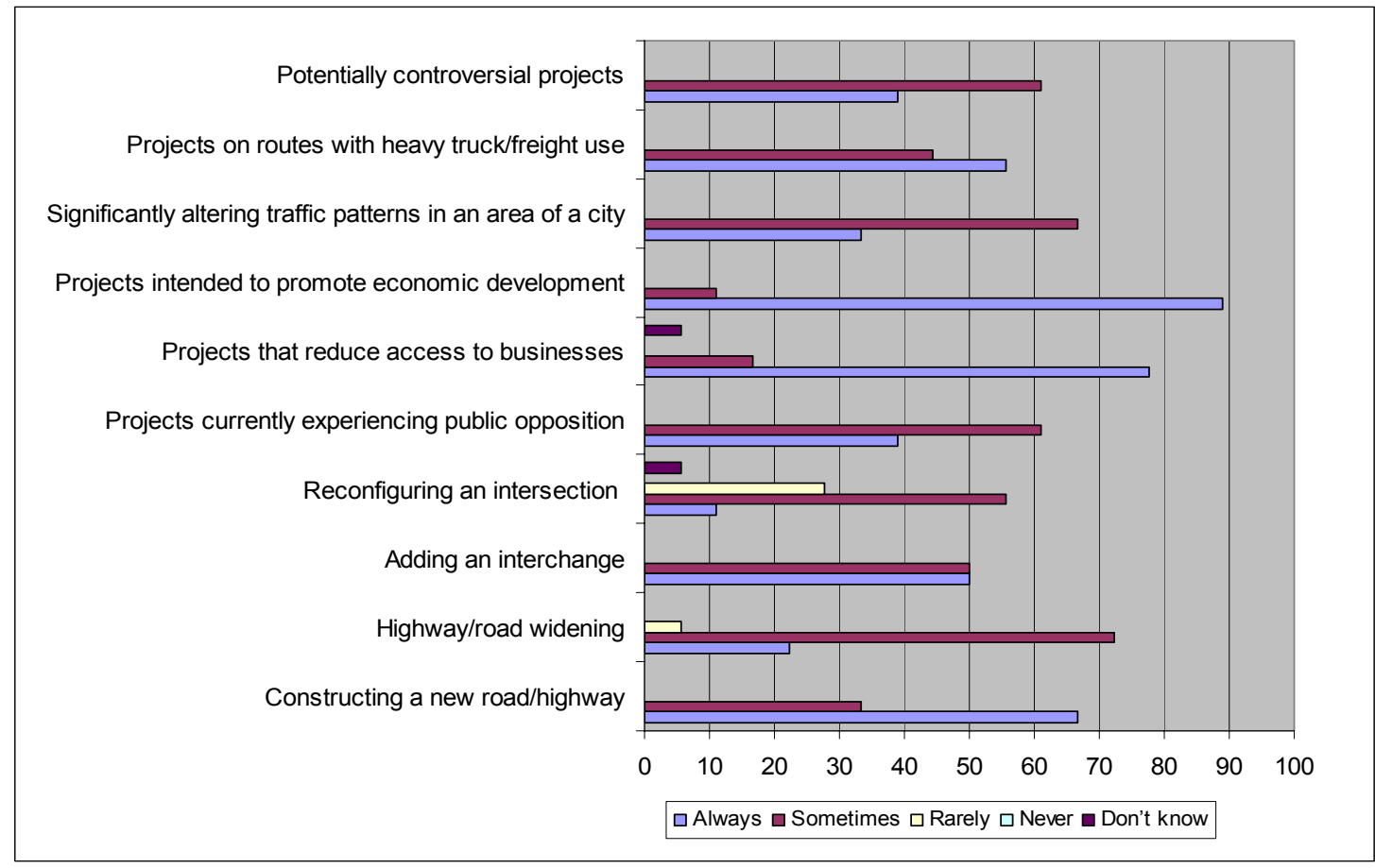

8.1.2.3. What should be the primary motivation for analyzing the economic development impacts of transportation projects? (Please check all that apply)

$94 \%$ of survey participants agreed that ranking projects in terms of their desirability should be a primary motivation. Over $80 \%$ of transportation agencies and consultants think that better project planning should be a primary motivation. $60 \%$ of transportation agencies and consultants and $60 \%$ of planning and other agencies think public information or discussion should be a primary motivation. 


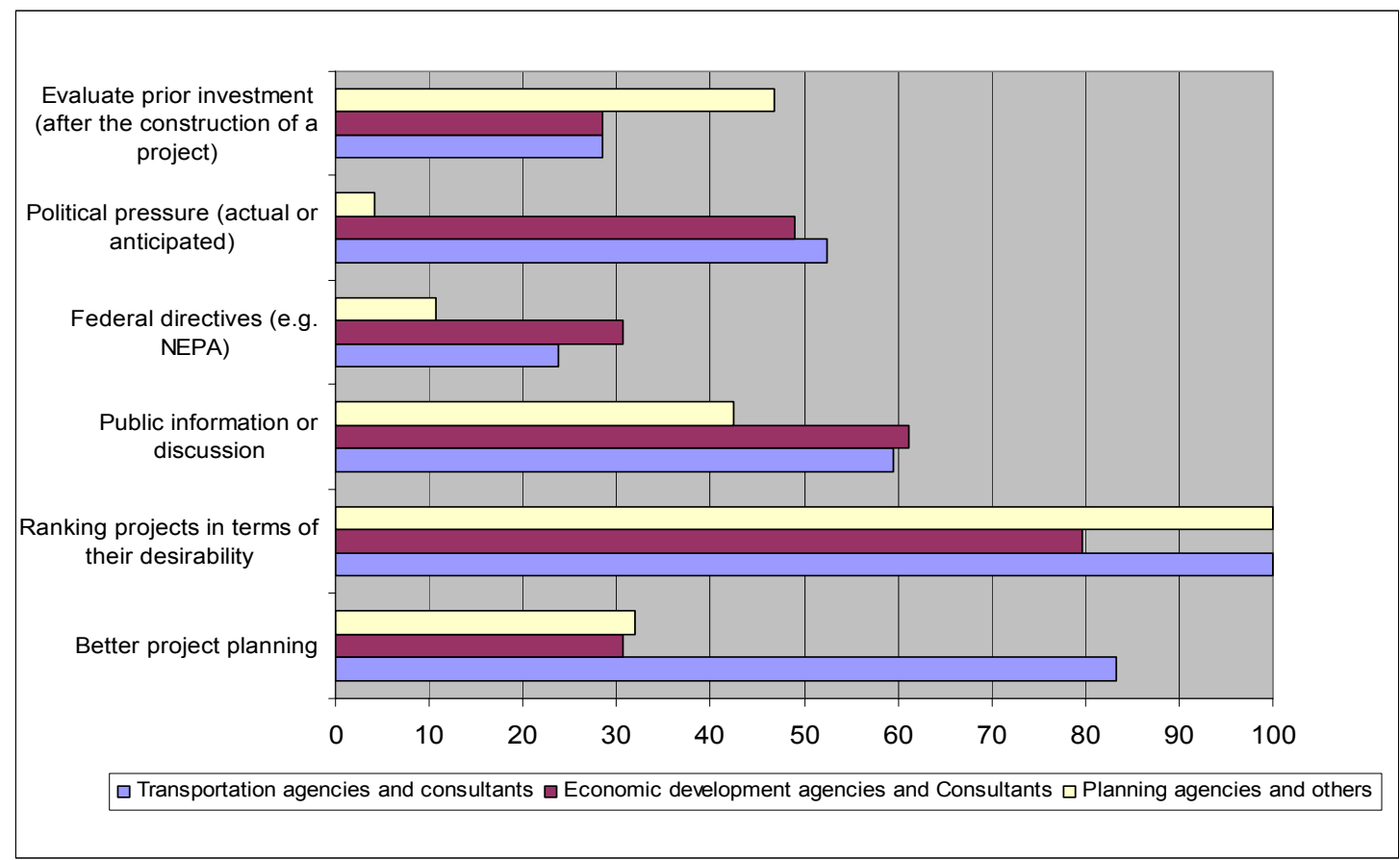

8.1.2.4. Which of the following statements best describe the role of economic development impacts in project evaluations? (Please check all that apply)

$60 \%$ of transportation agencies and consultants agree that economic development impacts should be considered in project evaluations, but they would not significantly influence a project's fate. Nearly the same percentage of economic development agencies and consultants agree that a project would be redesigned to address the economic impacts of that project. 


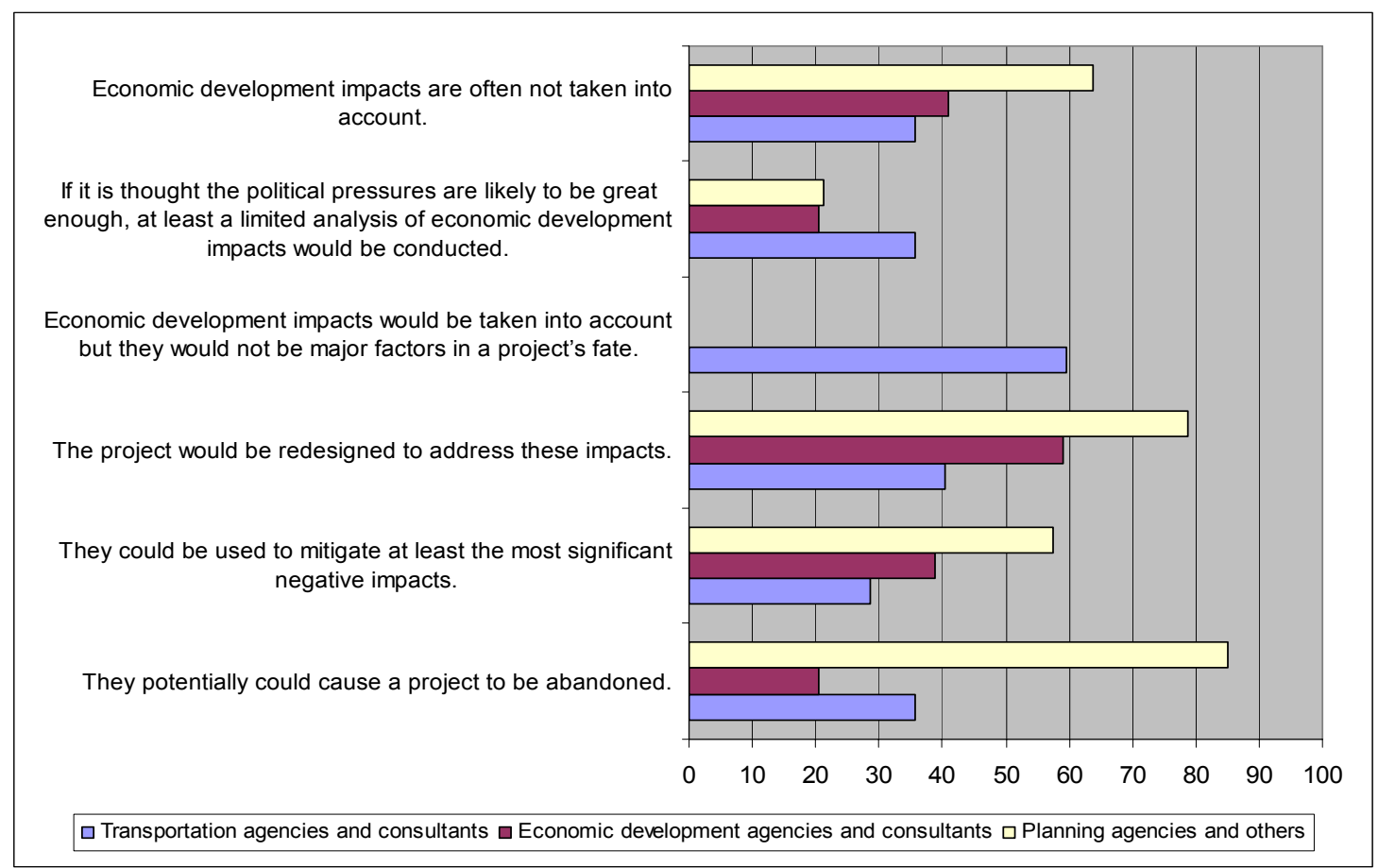

\subsubsection{What should be the primary criteria to evaluate a transportation project's impact on economic development? (Please check all that apply)}

The criteria given to survey participants and their responses are shown graphically below. 


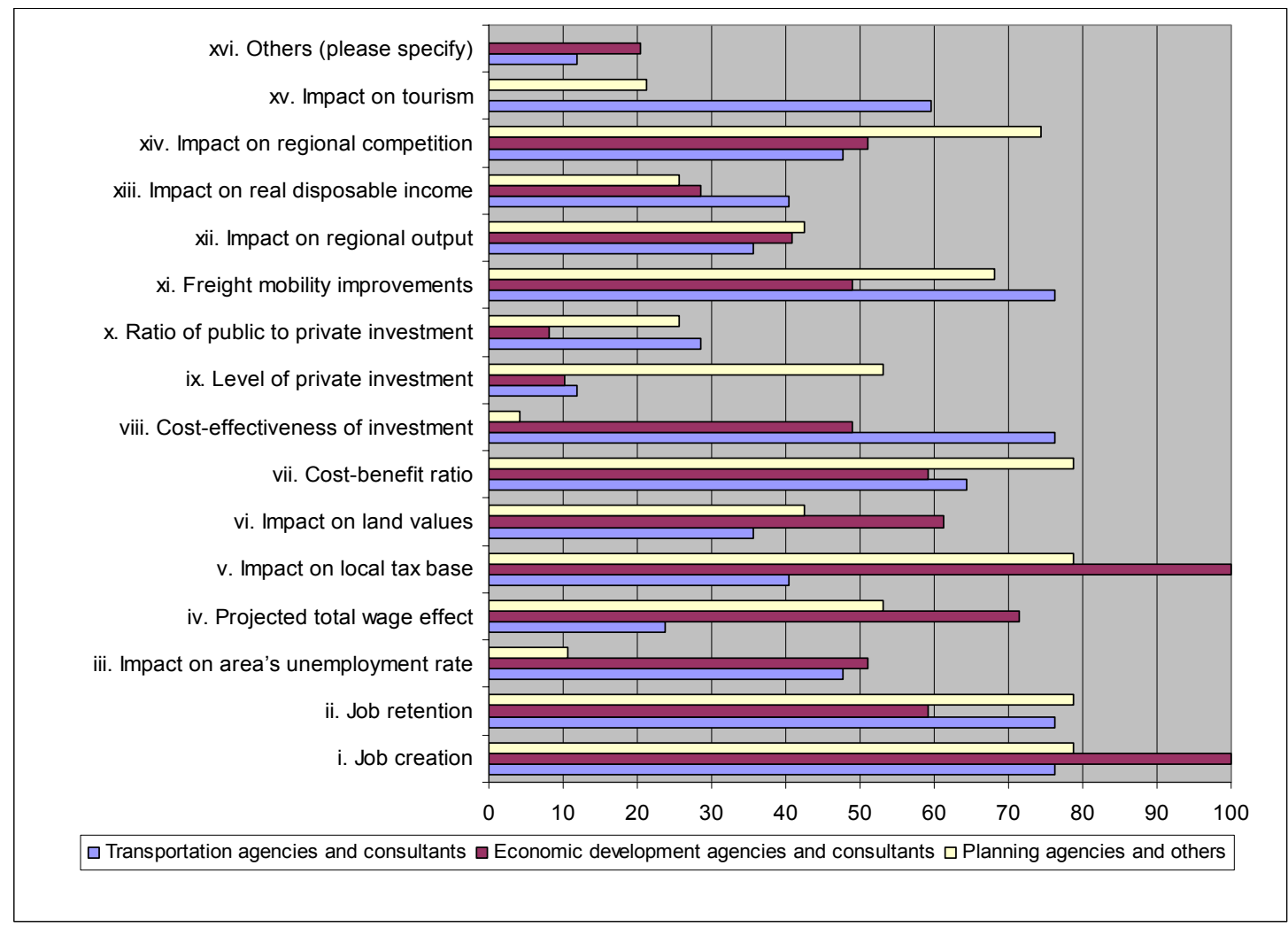

8.1.2.6. Which measures appear to be of most importance for communicating findings to the public?

All participants agreed that job creation and job retention are the most important measures to be communicated to the public. For transportation agencies and consultants, job creation (69\%) is viewed more important for public information than job retention (14\%). This is also true for most of the other survey participants. 


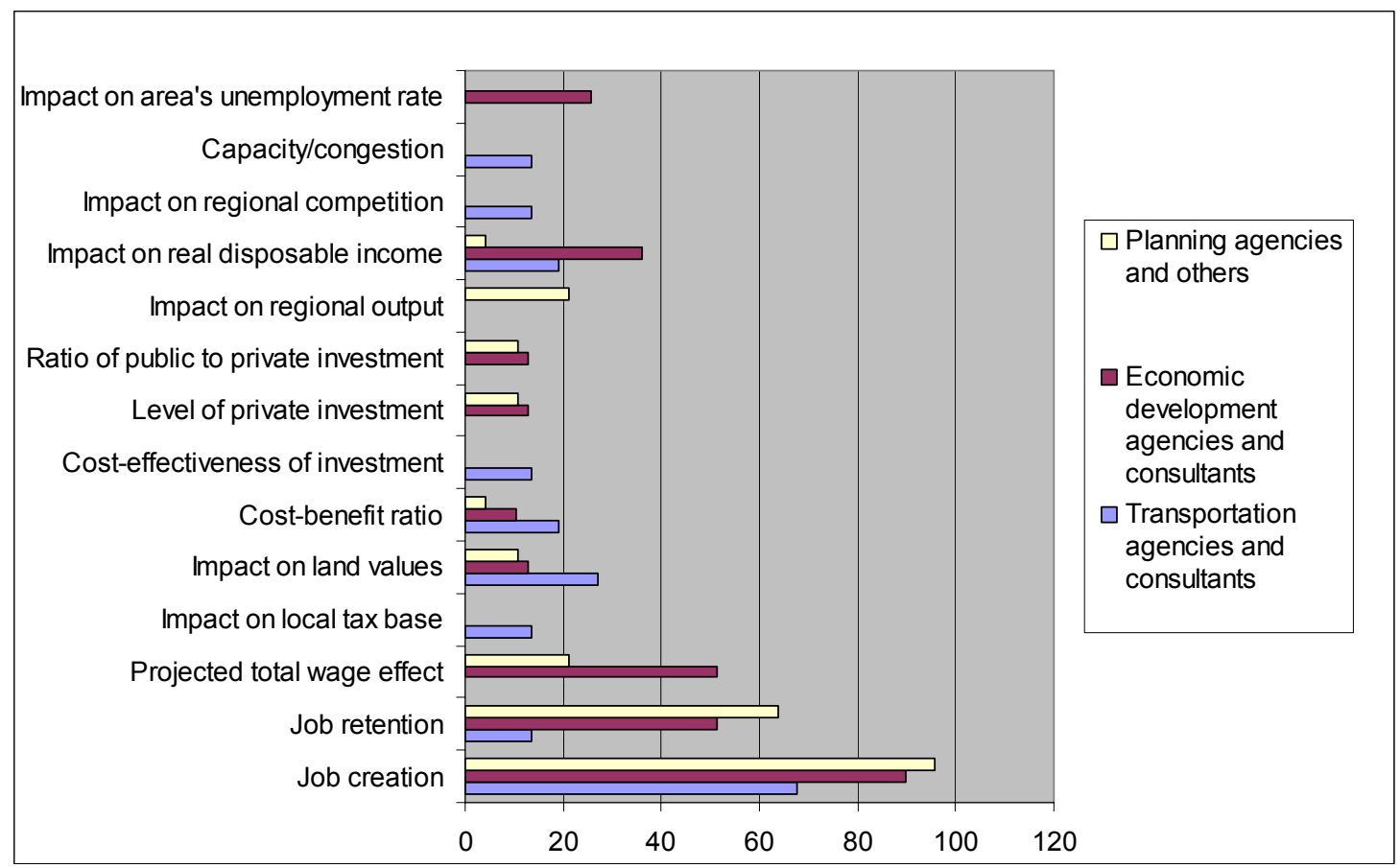

8.1.2.7. Which measures (listed in Q2.5) appear to be of most importance for communicating findings to decision-makers?

For transportation agencies and consultants, the four most important measures to communicate to decision-makers are cost-benefit ratio (60\%), cost-effectiveness of investment (46\%), job creation (60\%), and job retention (46\%). For economic development agencies and consultants, job creation (100\%), job retention $(74 \%)$, cost-benefit ratio (74\%), and impact on local tax base $(64 \%)$ are the most important measures to communicate to decision-makers. For planning agencies and others, job creation (79\%), job retention (57\%), and impact on the local tax base (53\%) are the most important to report to decision-makers. 


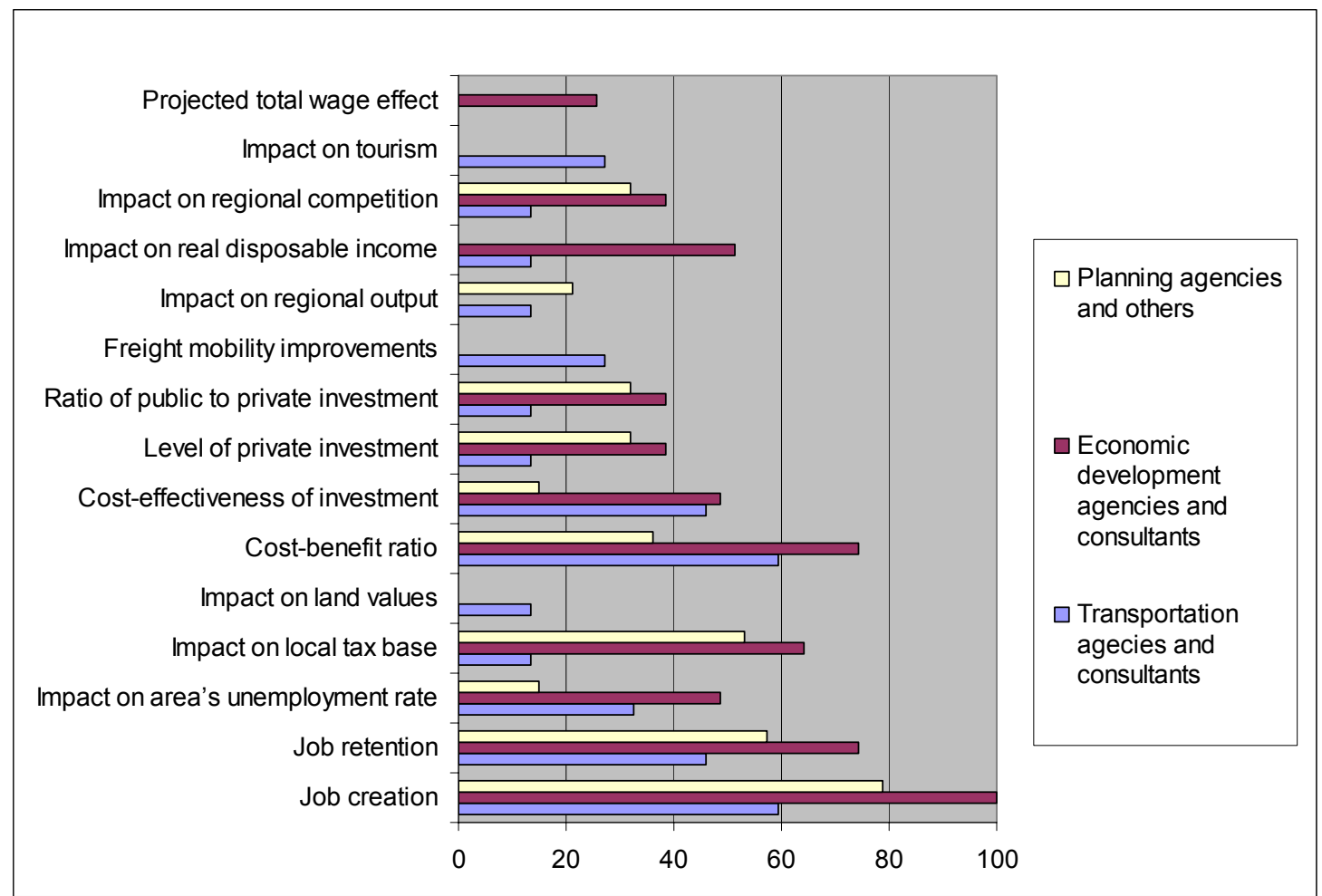

8.1.2.8. Please list factors that are important to consider as part of the economic development score from Q2.5, and the weight (\%) that each factor should be expected to carry. (All weights should add to 100\%)

Participants were provided the same criteria of Question 2.5a (Section 2.1.2.5) to choose from. Transportation agencies and consultants viewed job creation (13\%), costeffectiveness of investment (13\%), and freight mobility improvements (11\%) as the most important. Economic development agencies and consultants viewed job creation (17\%), impact on local tax base $(12 \%)$, cost-benefit ratio $(12 \%)$, and freight mobility improvements $(12 \%)$ as most important. Planning and other agencies viewed cost-benefit ratio $(27 \%)$ and job creation (12\%) as most important. 


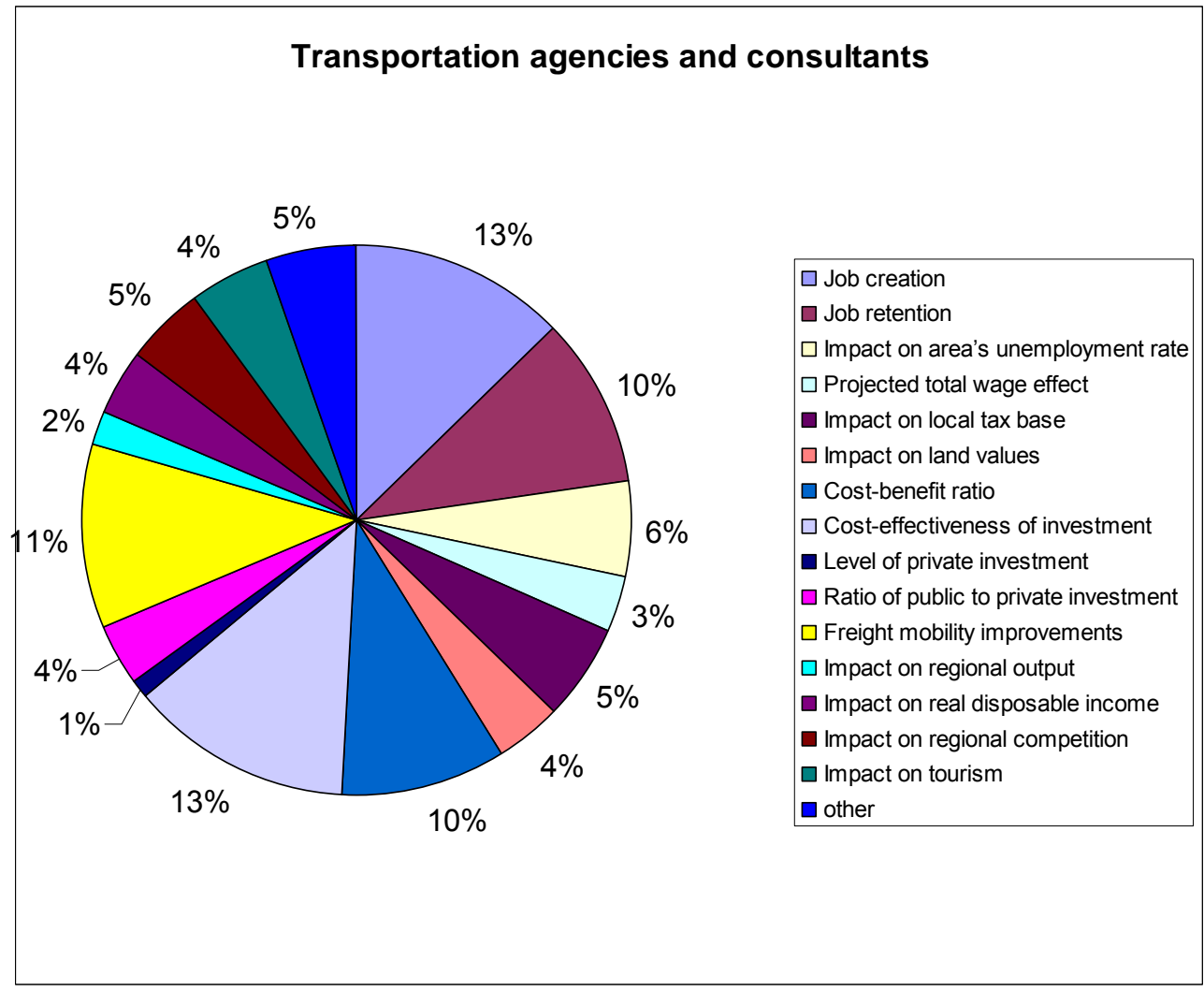




\section{Economic development agencies and consultants}

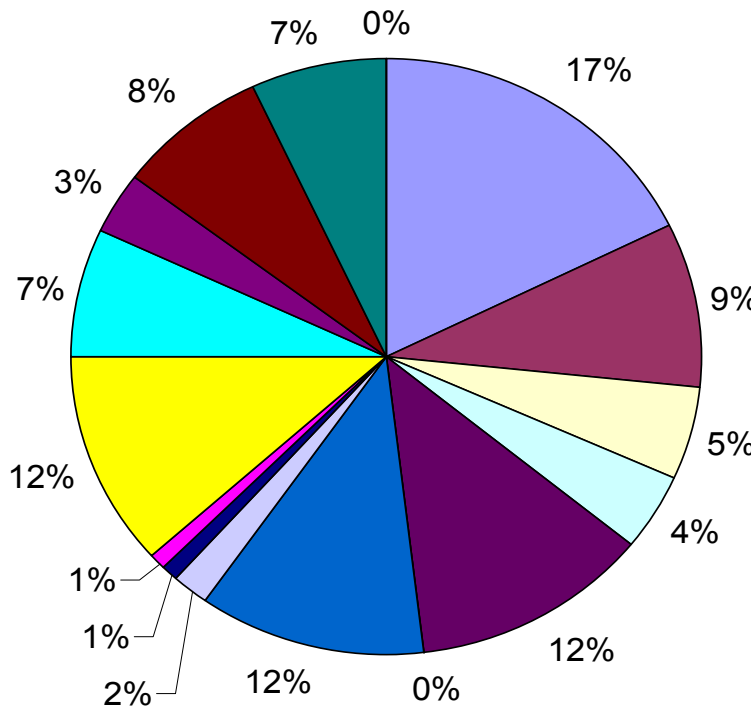

$\square$ Job creation

$\square$ Job retention

$\square$ Impact on area's unemployment rate

$\square$ Projected total wage effect

$\square$ Impact on local tax base

$\square$ Impact on land values

$\square$ Cost-benefit ratio

$\square$ Cost-effectiveness of investment

- Level of private investment

$\square$ Ratio of public to private investment

$\square$ Freight mobility improvements

$\square$ Impact on regional output

- Impact on real disposable income

- Impact on regional competition

$\square$ Impact on tourism

ather

\section{Planning and other agencies}

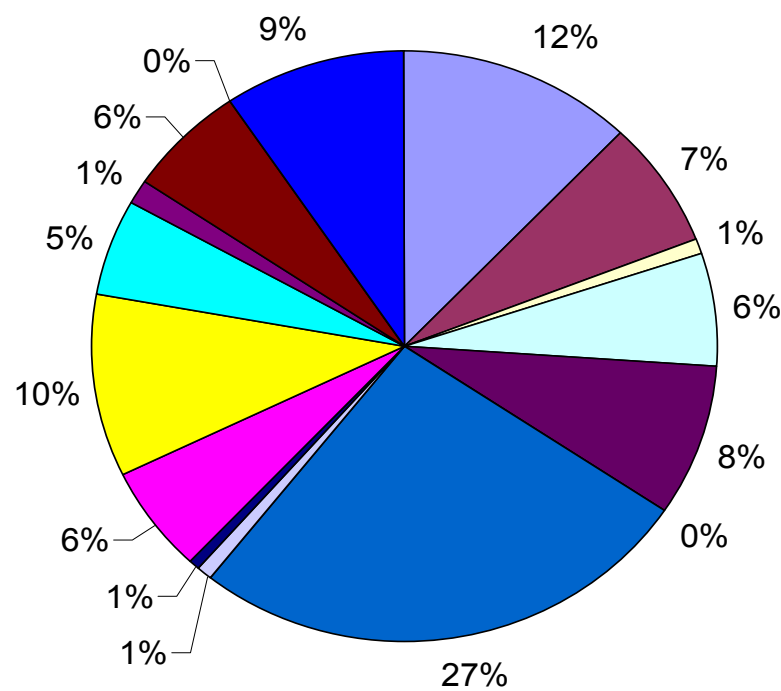

$\square$ Job creation

$\square$ Job retention

$\square$ Impact on area's unemployment rate

$\square$ Projected total wage effect

- Impact on local tax base

$\square$ Impact on land values

$\square$ Cost-benefit ratio

$\square$ Cost-effectiveness of investment

- Level of private investment

$\square$ Ratio of public to private investment

$\square$ Freight mobility improvements

$\square$ Impact on regional output

u Impact on real disposable income

- Impact on regional competition

$\square$ Impact on tourism

$\square$ other 
8.1.2.9. If your organization were to carry out an analysis of the likely economic development impacts of a potential highway improvement, which of the following would best describe your practices? (Please check all that apply)

$50 \%$ of economic development agencies and consultants would conduct the analysis of the economic development impacts of a potential highway improvement in-house, and over $40 \%$ of them would retain the services of a consultant and seek the assistance of a college or university. Over $75 \%$ of transportation agencies and consultants would retain the services of a consultant. All planning agencies and other agencies would seek the assistance of a college or university and over $70 \%$ of them would also retain the services of a consultant.

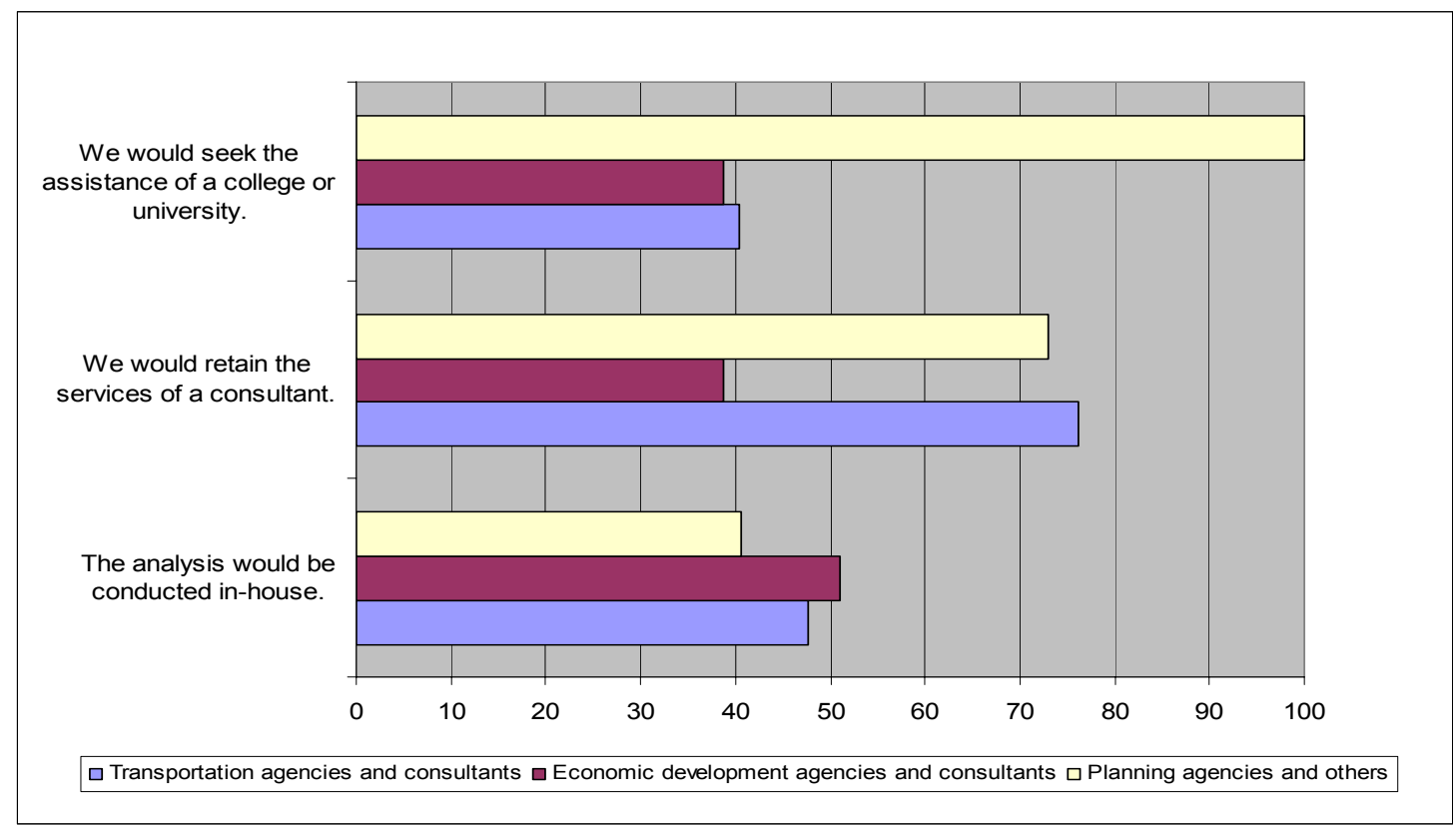

8.1.2.10. Over the past 5 years, how has your organization's involvement in the analysis of the economic development impacts of transportation projects changed? (Check one)

Over $60 \%$ of transportation agencies and consultants are doing a lot more in-depth analysis or a little more analysis. Over $70 \%$ planning agencies and others are doing the same amount of analysis or a little more analysis. $60 \%$ of economic development agen- 
cies and consultants do not do any analysis or are doing less analysis of the economic development impacts of transportation projects.

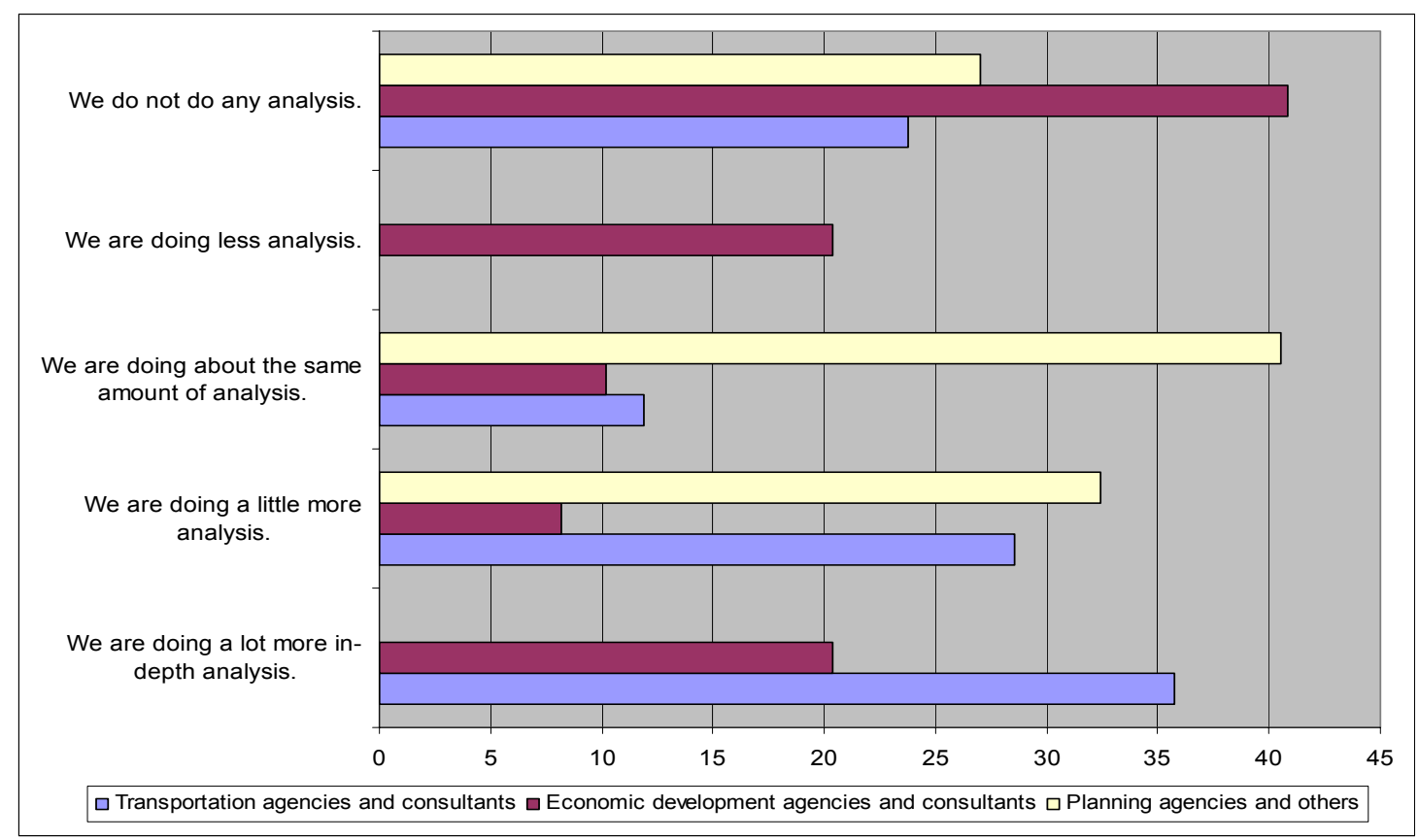

8.1.2.11. In circumstances when your organization does not analyze the economic development impacts of a transportation project, which of the following best describe the reasons why? (Please check all that apply)

The most common reasons why transportation agencies and consultants sometimes do not analyze the economic development impacts of a transportation project are that the size and scope of the investment do not justify such analysis (64\%) and/or simple methods/tools are not available (48\%). With economic agencies and consultants, the most important reasons why they do not conduct analysis of economic development impacts of a transportation project is that the size and scope of the investment do not justify such analysis and that there is no demand or audience for it (39\%). Planning agencies and others face the circumstances of the lack of demand/audience and the fact that the scope and size of the investment do not justify such analysis (both $46 \%$ ) 


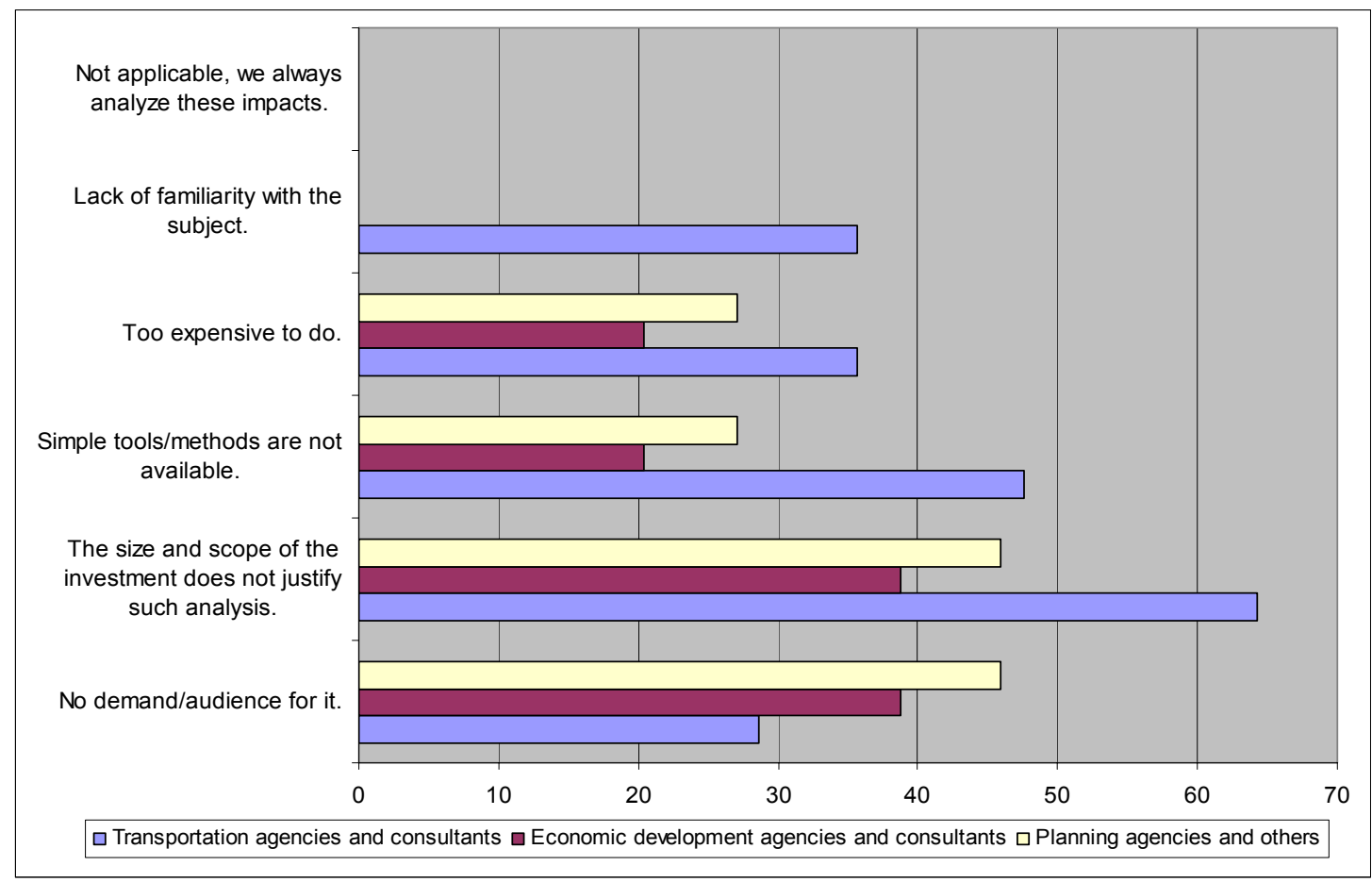

8.1.2.12. How many full-time professional staff members are engaged solely in economic development in your organization?

On average, two full-time professional staff members in economic development agencies and consultants, and planning agencies and others are engaged solely in economic development, while there is no such full-time staff in most transportation agencies or transportation consulting firms.

\subsubsection{Use of Specific Methods for Assessing Economic Development Impacts (Part 3)}

8.1.3.1. How often does your organization use the following economic impact analysis tools?

Traditional benefit/cost analysis and computer-economic models are most often used by transportation agencies and economic development consultants. Economic development consultants also use multiplier analysis/ input-output analysis. Business interviews 
or surveys are rarely used by transportation consultants. Business dislocation analysis and integrated travel demand-economic models are techniques that are used the least.

\subsubsection{What criteria determine the use of one tool over the other? (Check all that apply)}

Transportation agencies and consultants stated that project size $(100 \%)$, size of impact area $(87 \%)$, and local concerns $(87 \%)$ determined the use of one tool over another. Economic development agencies and consultants stated that staff expertise $(71 \%)$, cost of specific tool (61\%), and available time for analysis (49\%) determined the use of one tool over another. Nearly $60 \%$ of planning and other agencies argued that all criteria mattered except for duration of construction and other organizations' experience.






\subsubsection{Adequacy of Available Methods, Tools, and Techniques (Part 4)}

8.1.4.1. What is your opinion as to the adequacy of current methods, tools, and techniques summarized in the following statements?

About $80 \%$ of survey participants are interested in learning more about the methods, tools, and techniques that would help their organization conduct economic impact analyses of proposed transportation projects. About $60 \%$ of survey participants agree that there has been significant progress in the past decade or so in the ability of organizations to estimate the economic development impacts of highway projects.

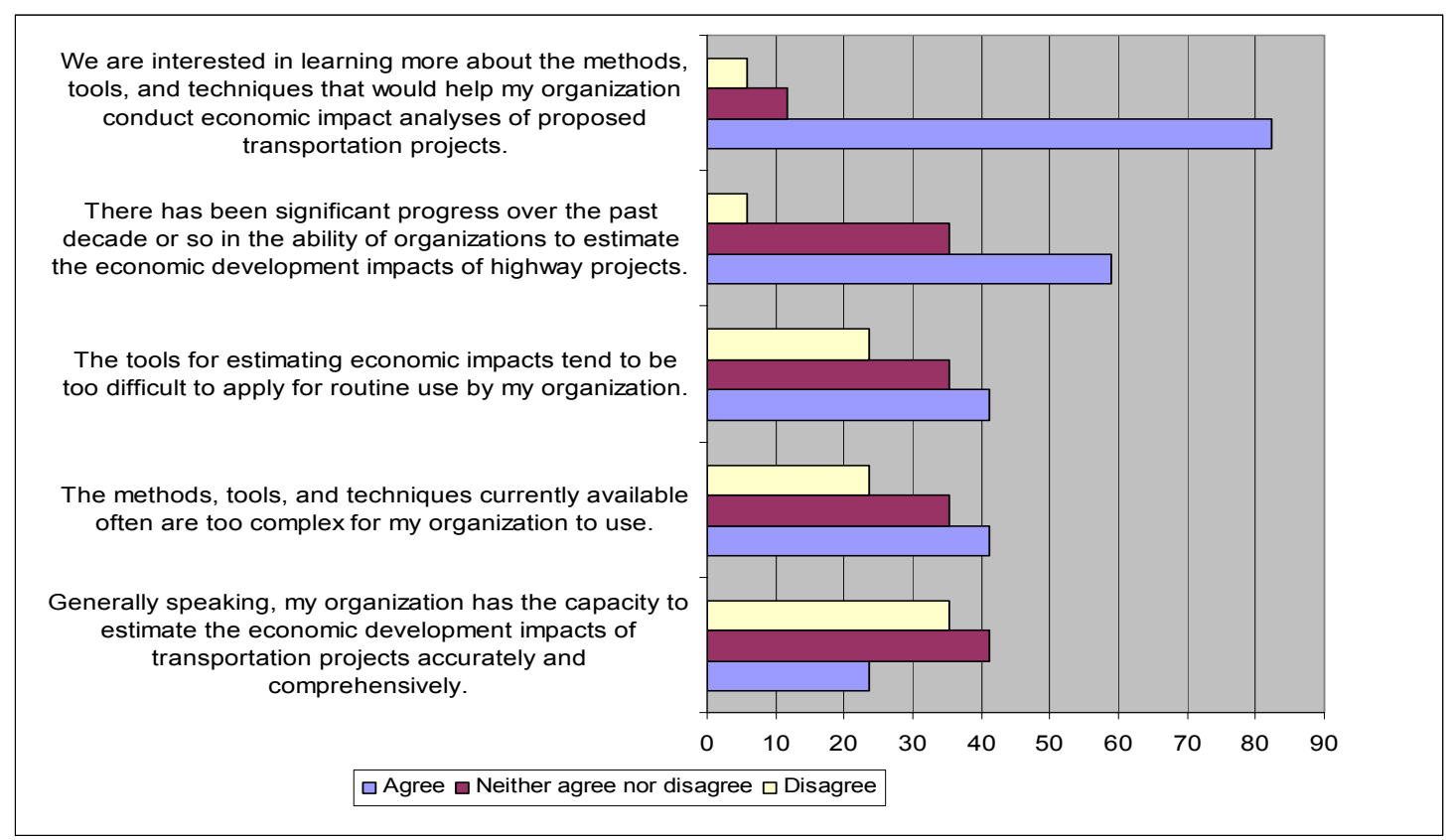

\subsubsection{To enhance your organization's ability to evaluate the economic development} impacts of transportation system changes, which of the following are needed?

Survey participants agree that more useful guidelines in applying impact methods, tools, or techniques $(47 \%)$, and that more resources for the organization in terms of staff, time or equipment are badly needed to enhance their ability to evaluate the economic development impacts of transportation system changes (59\%). Over $80 \%$ of survey partici- 
pants agree that better data relevant to analysis of these impacts would help or are badly needed in the analysis of these impacts.

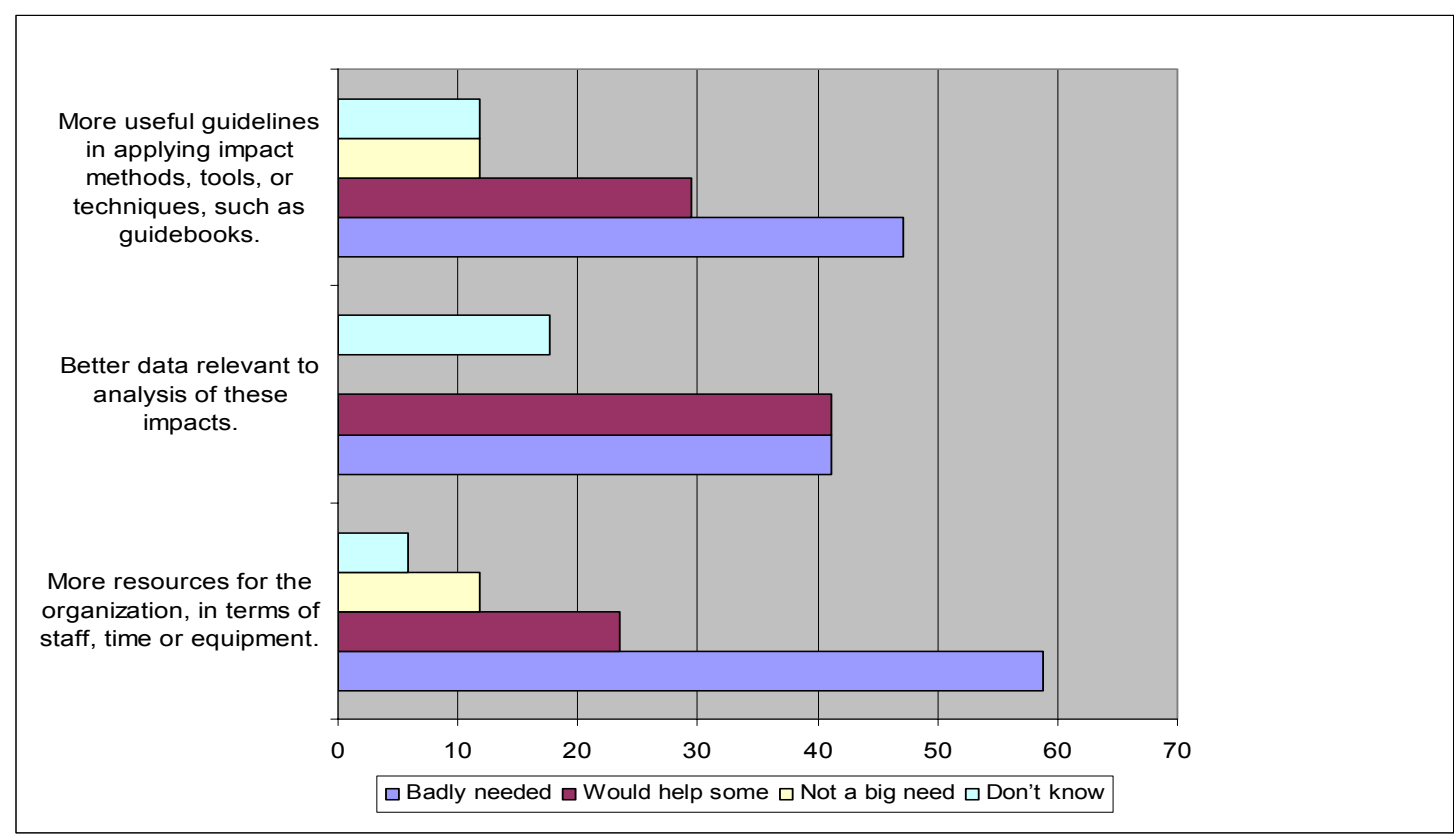

8.1.5. Indiana's Economic Development Profile (Part 5)

8.1.5.1. What are the features that you believe make your jurisdiction (state, county or city) most attractive to an outside firm seeking a business location? (Check all that ap-

ply)

Almost all survey participants agreed that the convenient location for shipping and access to markets or suppliers would make their jurisdiction most attractive to an outside firm seeking a business location. Existing infrastructure, including telecommunications capacity was also considered important. 


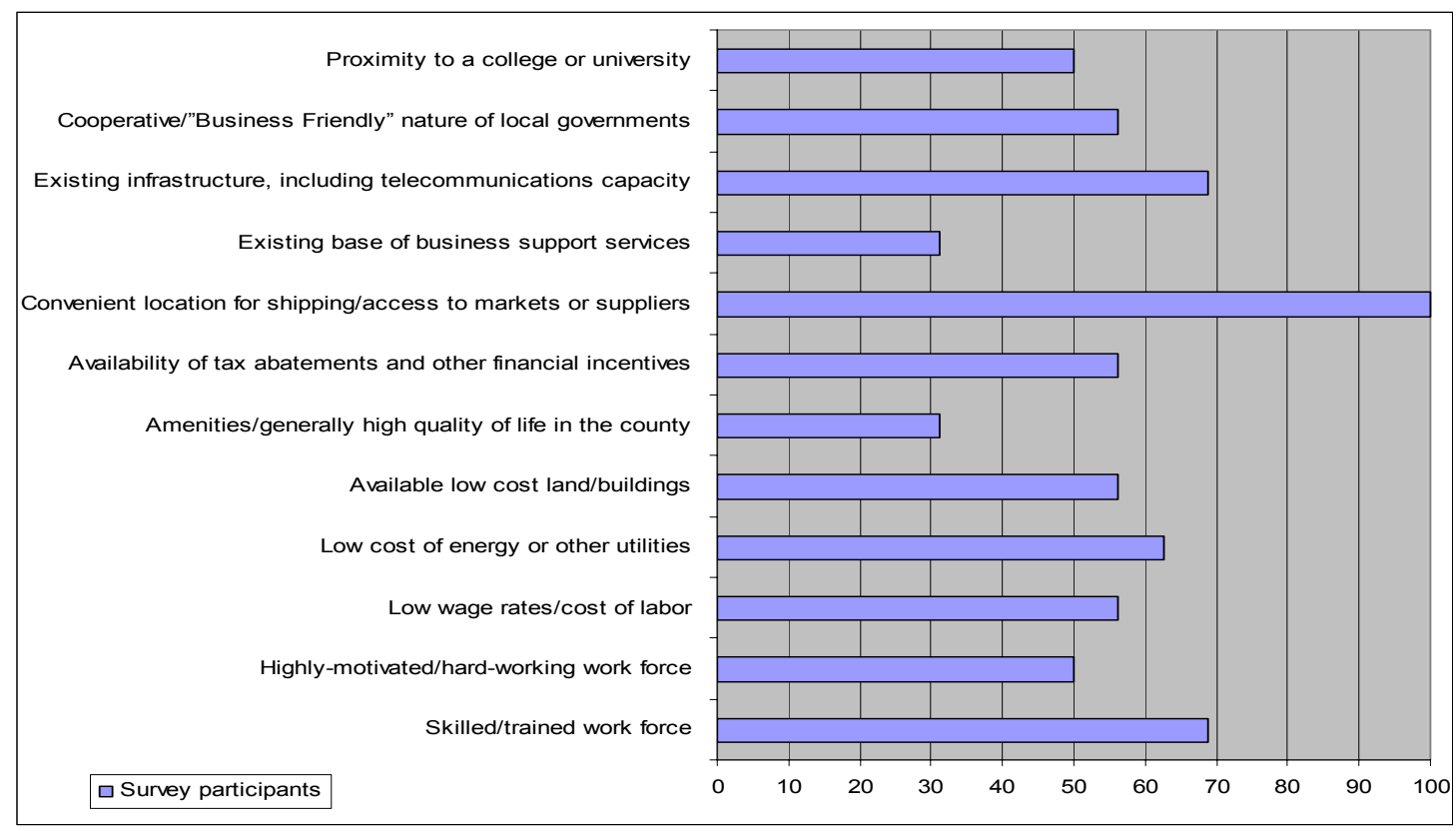

8.1.5.2. What are the features that you believe make your jurisdiction (state, county or city) least attractive to an outside firm seeking a business location? (Check all that apply)

Survey participants agreed on three features that would make their jurisdiction least attractive to an outside firm seeking a business location. These features are: lack of skill/trained workforce (53\%), lack of amenities/generally low quality of life in the area (53\%), and lack of existing base of business support services (40\%). 


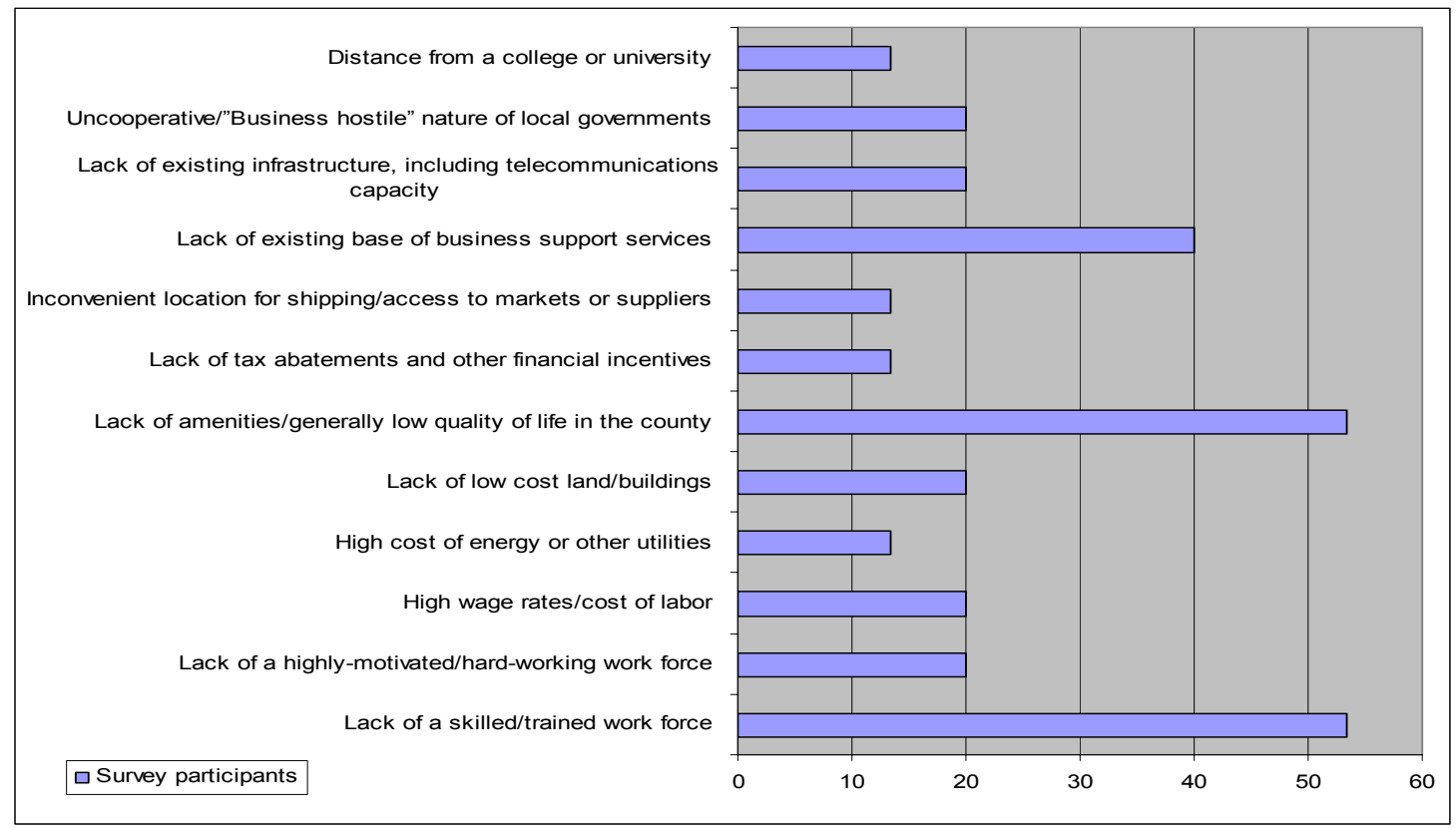

8.1.5.3. Which of the following have been built in your jurisdiction (state, county or city) in the last five years? (Please check all that apply)

More than $55 \%$ of participants stated that in the last five years, all of the structures listed in the questionnaire (i.e., new highway infrastructure/ highway improvements, industrial park, new industrial infrastructure, and business incubator facility) except for a visitor/convention center have been built in their jurisdiction.

8.1.5.4. In the last ten years, which of the following has generated the most job growth in your jurisdiction (state, county or city)? (Please check one)

$75 \%$ of participants believe that the expansion of existing businesses has generated the most job growth in their jurisdiction in the last ten years. 
8.1.5.5. In the next ten years, which of the following do you expect to generate the most job growth in your jurisdiction (state, county or city)? (Please check one)

More than $60 \%$ of economic development agencies and consultants that participated in this survey believe that the most job growth in their jurisdiction will be generated from the creation of new businesses and/or the expansion of existing businesses in the next ten years. Over $70 \%$ of planning and other agencies that participated in this survey believe that the most job growth in their jurisdiction will be generated from the expansion of existing businesses in the next ten years.

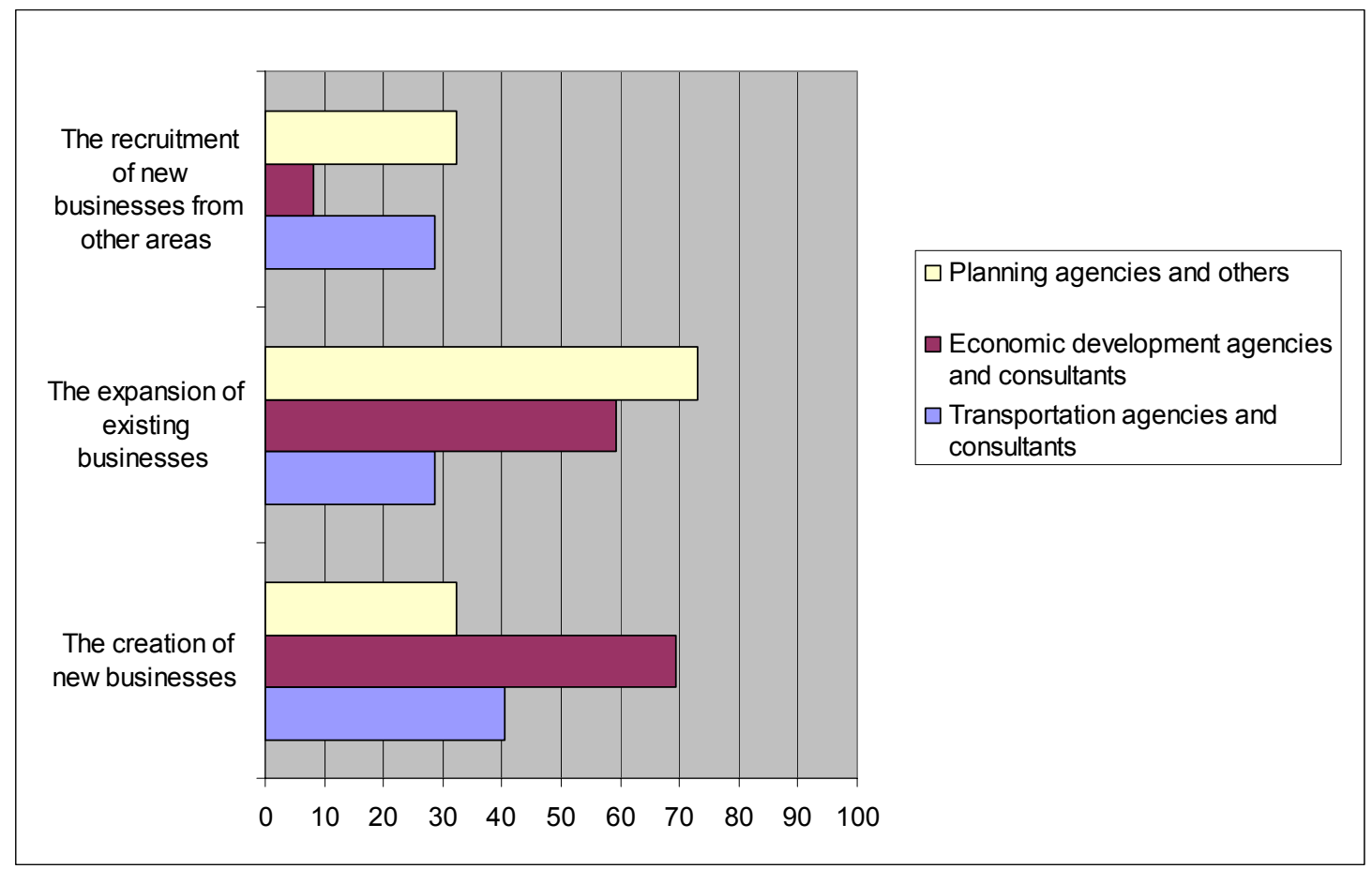

8.1.5.6. If your organization has an economic development program, does it target any specific industries (e.g., high technology, manufacturing) or infrastructure projects for the $\underline{\text { next five years? }}$

Nearly $70 \%$ of economic development agencies and consultants and $45 \%$ of planning and other agencies do target specific industries or infrastructure projects in their eco- 
nomic development programs. However, $60 \%$ of transportation agencies and consultants found this question "not applicable" to their practices.

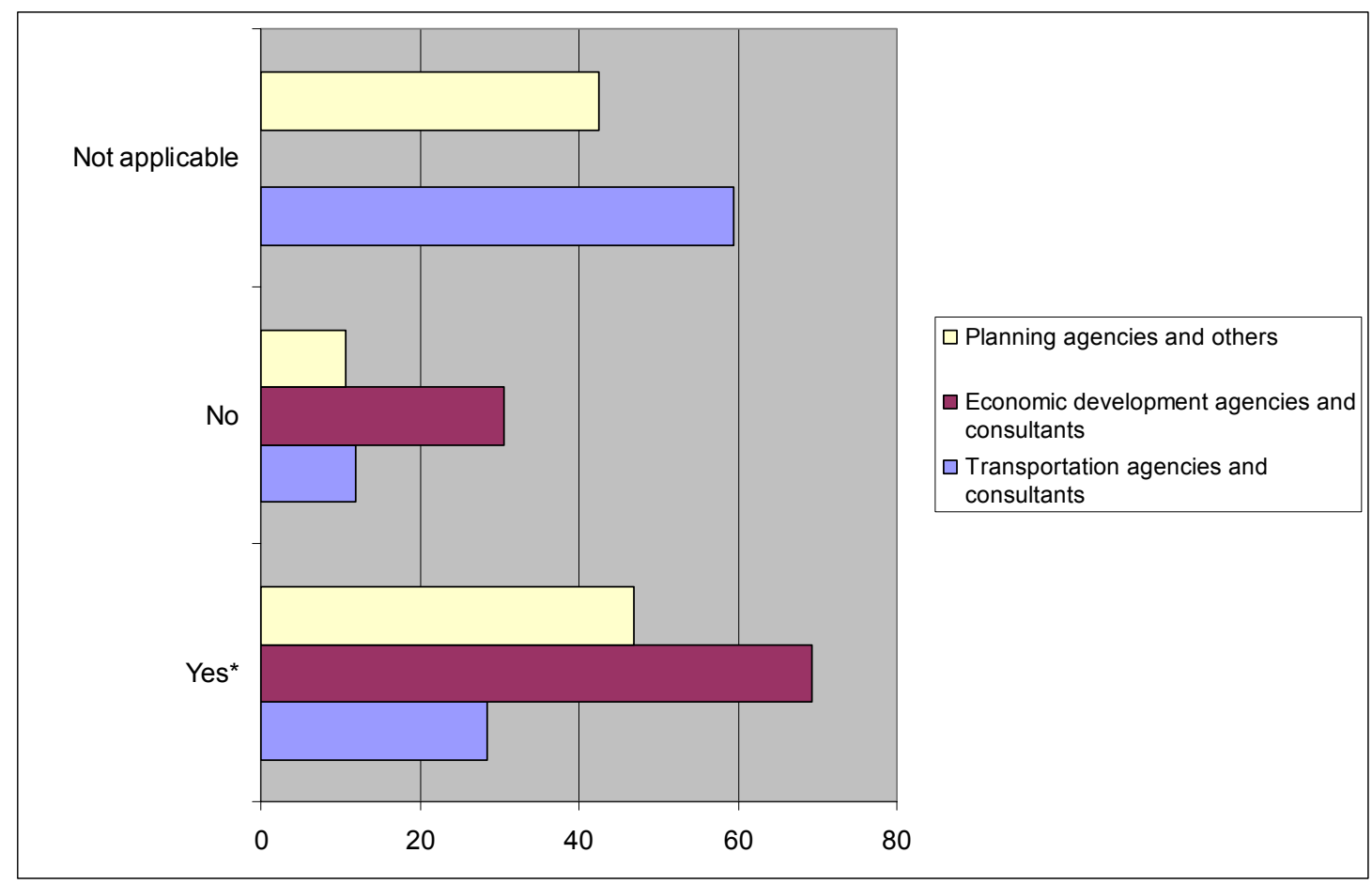




\section{CHAPTER 9. CONCLUSIONS AND RECOMMENDATIONS}

\subsection{Contribution of this Research and Implementation}

This study was initiated by INDOT preliminary engineering personnel who are engaged with assessing the economic development potential of highway investments at the project development phase. The intent of this research effort was to extend the traditional transportation impact framework by examining how different types of highway improvements can affect the Indiana economy and how project- and location-specific factors interact to stimulate economic development. Past attempts to assess the economic development impacts of highway investments have found that this is a difficult relationship to document. Given the complexity of the problem and the limitations of available data, this study should be viewed as an incremental step toward a broader analysis of the economic development effects of highway projects. The analysis went beyond accounting for user benefits and travel efficiency improvements and included additional economic development benefits in terms of business cost savings and productivity benefits. A major contribution of this study is the demonstration of a general approach that can be applied for broad analysis of highway projects' economic effects at the state level, while taking into account the intensity of highway system use. In addition, this study illustrated the types of data necessary to document these effects, and demonstrated how analysis can be carried out and ultimately improved.

The end product is a quantitative tool that can be used at the project development phase to estimate the statewide long-term economic development effects of different types of highway investments and evaluate such investments based on sound economic development criteria. This tool can assist INDOT to make better decisions regarding highway investment and increase the efficiency of investment. To date, Indiana includes economic development as decision criterion on project-to-project basis and has developed sophisticated economic analysis tools (i.e., MCIBAS model) to analyze investment alter- 
natives. However, these models are somewhat cumbersome and costly for the prioritization of multiple projects. Notably, the state has not established an alternative method to rank or prioritize projects similar to the scoring method adopted by Wisconsin (Section 3.4.1.3) and Ohio (Section 3.4.5). Though both states use a ranking tool that includes economic development criteria in project selection, they rely on an expert panel to assign scores to each criterion.

The econometric equations developed-in particular those that include economic development benefit/cost ratios such as the ratio of jobs created per dollar of highway investment—can provide the groundwork to develop a scoring system and associated weights to quantify a project's economic development potential, based on more rigorous and objective forecasts (than the subjective scores assigned by experts). The proposed highway project prioritization/ranking process could assist INDOT to make order-ofmagnitude comparisons of benefits and costs and select projects that have a strong potential to support statewide economic development, among other factors (i.e., safety, mobility, and sustainability). To avoid "double-counting" of benefits, care should be taken to measure economic development benefits as changes in real disposable income or gross regional product and separately estimate the value of other factors that are not represented in these measure s (i.e., user benefits for non-business or equivalently personal travel), as suggested in Weisbrod and Beckwith (1990).

\subsection{Research Findings}

This research involved extensive data assembly and econometric model analysis. Econometric models were developed to examine the degree of sensitivity of economic development effects to factors such as type of highway project, functional class and geographic location, all with a reference to the State of Indiana. The econometric analysis yielded order-of-magnitude estimates of potential economic development effects of future highway projects as a function of the above factors, under different scenarios of business attraction. The estimation and use of these models (and factor parameters) were the subject of considerable discussion in this study. 
Overall, highway investments can have a positive impact on state economy. The econometric models developed revealed that the corresponding impact depends on a multitude of factors associated with statewide economic growth. Project-specific factors and the economic conditions of the region are both partially responsible for impacts correlated with the highway improvements under study. Those factors could explain up to 70 percent of the variation in the economic development variables, which suggests a fairly good fit given the complex causal situation analyzed. The major research findings that can assist state agencies in making better decisions regarding highway investment, in terms of identifying the most efficient allocation of resources, are summarized below:

1. Capacity improvements (i.e., added travel lanes), additional interchanges and highway construction on new location generally have a greater potential for longterm secondary economic development effects than projects to upgrade existing facilities (median construction), consistent with prior research (FHWA, 1992).

2. On average, the statewide long-term economic development benefits of adding travel lanes are greater than those of constructing new roads or interchanges. However, the economic development benefits compared to the associated costs of added capacity projects are lower, mainly because of the large capital outlays required for those investments compared to the other type of projects considered in this study. This finding could assist decision-makers to identify the most efficient allocation of resources on investments related to improvements in highway capacity.

3. The size of highway investment measured by either project length or costs is another factor among the multitude of significant factors identified in the econometric analysis. However, it was found that the size of highway investment is not the single and most significant determinant of economic development. Note that prior research (Huddleston and Pangotra, 1990; Forkenbrock and Foster, 1996; John Locke Foundation, 2003; Ellington et al., 2005) has argued that highway investment alone cannot result in economic development or influence the location of growth. There are factors other than highway density or spending such as re- 
gional economic conditions (i.e., labor, education, resources) that influence economic development.

4. Highway functional class and degree of accessibility (especially to airports and employment) were found to be significant determinants of whether a highway project will produce economic development benefits. It was found that there are statewide long-term economic development benefits by constructing new interstate highway interchanges as well as expanding highway capacity, especially of rural interstates, in close proximity to airports. On the other hand, investments on state roads with low degree of connectivity to the existing highway network would generally generate lower economic development benefits compared to similar investments on interstates or US highways.

5. Overall, the statewide long-term economic development benefits of highway investments in Indiana would be greater if the project is located in rural areas in North or South Indiana, or in urban areas in Central Indiana (especially, in Marion County) compared to investments in other geographical regions.

\subsection{Questionnaire Survey Findings}

The results of the survey conducted for Indiana shed light into the circumstances under which economic developers and transportation agencies in Indiana conduct economic development impact assessments, the measures that are or should typically be used, their associated weights, and the strategies/tools that are often used among economic developers and transportation agencies in Indiana. The survey also provided some insights on Indiana's economic development profile, in terms of job growth in the past and potential for job growth in the future, as it was perceived by the survey participants. In summary, the survey on economic development practices across Indiana indicated the following:

1. When choosing one transportation project to fund over another, transportation agencies and consultants, placed a greater value on evaluation criteria such as 
safety and mobility compared to the economic development criterion for which they assigned on average a less than $20 \%$-weight. On the other hand, economic development practitioners and planning agencies placed the greatest value on economic development and assigned a weight that is greater than or equal to $20 \%$.

2. Most participants agreed that economic development impacts of transportation projects should be estimated for ranking projects in terms of their desirability, and especially for those intended to promote economic development. However, transportation agencies and consultants stated that the economic development impacts would not significantly influence a project's fate.

3. The most common reason why agencies and consultants sometimes do not analyze the economic development impacts of a transportation project are that the size and scope of the investment do not justify such analysis. Other reasons include that that there is no demand or audience for it and/or simple methods/tools are not available.

4. Job creation and job retention appear to be the most important measures when communicating findings to the public. This was also indicated in previous surveys in Utah (BYU, 2006) and nation-wide (Weisbrod, 2000). In addition to these measures, cost-benefit ratio, cost-effectiveness of investment and impact on local tax base are of most importance for communicating findings to decisionmakers. Besides these factors, freight mobility improvements were also important to consider as part of a economic development score.

5. Transportation agencies and consultants select economic impact analysis tools based on the size of project, size of impact area, and local concerns; while for economic development professionals the selection is based on staff expertise, cost of tool and available time of analysis. The tools most often used by transportation agencies and economic development consultants are traditional benefit/cost analysis and computer-economic models, while business dislocation analysis and integrated travel demand-economic models are techniques that are 
used the least. Economic development consultants also use multiplier analysis/ input-output analysis. Transportation consultants stated that they rarely use business interviews or surveys.

6. On average, two full-time professional staff members in economic development agencies and consultants, and planning agencies and others are engaged solely in economic development, while there is no such full-time staff in most transportation agencies or transportation consulting firms. All planning agencies and most of transportation agencies would retain the assistance of a consultant or seek the assistance of a college or university. Only half of the economic development agencies have in-house capabilities of carrying out economic development impact analysis.

7. Most participants stated that the expansion of existing businesses has generated the most job growth in their jurisdiction in the last ten years. The expansion of existing businesses as well as the creation of new businesses is expected to generate most job growth in the next ten years.

\subsection{Lessons Learned}

Additional considerations and lessons learned from the present research that may be of interest to INDOT preliminary engineering personnel engaged with economic development impact analysis include:

1. Comparing the economic development impacts associated with highway facility investments must be conducted with caution and in the context of the overall motivations and objectives of projects, since economic development is only one dimension for evaluating the benefits of highway investments. INDOT policymakers screen highway investments based also on economic efficiency grounds, including changes in traffic volumes and patterns. This research took into account the intensity of highway system use and showed how changes in transportation performance measures relate to business changes and economic impacts 
for different types of highway investments. These need to be carefully assessed by INDOT staff to make informed investment decisions.

2. Business attraction benefits are difficult to predict with accuracy since highway investments are only one factor in the complexity of business location decisions. This study made broad estimates about the types and sizes of businesses that may be attracted to a region as a result of a major highway project. Estimating business attraction should be done with caution not to include impacts that represent net transfers among regions within the study area, or industries that in general, do not export their goods to the rest of the state.

3. The econometric analysis framework was developed to capture different aspects of overall economic activity or growth. As such, it considered the (indirect) interaction of four economic development measures rather than a single-equation estimation that could only capture one aspect of economic development. This allowed for more sophisticated use of statistical techniques that yielded consistent, efficient and lower variance parameter estimates, when compared to singleequation parameter estimates. Moreover, the simultaneous estimation identified more significant variables at the selected level of confidence than the singleequation estimation permitted.

4. Finally, it became apparent that input-output analysis, which has been used extensively in the past to estimate economic development impacts, would only produce the effects of highway construction spending, regardless of what the dollars are spent on, the analysis period, and who are the beneficiaries. This study showed that the corresponding long-term effects would be significantly lower than those predicted by input-output analysis. This is mostly because in the long-run, the construction stimulus is removed and what actually happens depends on the relative scarcity of land, labor and capital (Flyvbjerg et al., 2003). 


\subsection{Recommendations}

The data collected and generated for the purpose of this study reported herein have produced a better understanding of the interrelationships among economic development, type of highway improvement and geographical location. This study has also shown how investments in highway infrastructure can be ranked and prioritized based on their economic development potential in a bid to identify the most efficient allocation of resources. However, these results are subject to some limitations inherent in the economic software used, and data availability considerations. These limitations underscore the need for careful market research and additional data and analysis before any improvements are considered to ensure that planned improvements ensure the most efficient allocation of resources. With these considerations in mind, the following recommendations are suggested:

1. This study involved substantial effort to credibly estimate economic development effects of future investments, using the regional economic simulation model (REMI). The models presented in this study could have benefited considerably by having information on the actual economic effects of comparably large set of case studies for major highway investments in Indiana. INDOT should consider developing a database to record the types of data that this study demonstrated are necessary to document economic development effects of highway projects (e.g., data on project attributes, regional economic conditions, degree of accessibility/ connectivity and changes in accessibility resulting from the transportation improvement). This information would be essential for future research to conduct an ex-post evaluation of highway investments to validate the results presented herein.

2. The estimates of the potential economic development effects of different types of highway projects with different project and location attributes can provide the groundwork to develop a scoring system for ranking alternative projects. INDOT could consider validating the proposed scoring method. This could be achieved by convening a panel of experts (i.e.., stakeholders and targeted audiences throughout the state) to solicit their scores based on their perception of economic 
development potential for different highway investment scenarios in Indiana. A follow-up statistical analysis will enable comparison of the scores assigned by the panelists, and the scores estimated as a function of project and location attributes with the use of econometric models presented herein.

3. This study considered different types of highway projects as part of Indiana's Statewide Long-Range Transportation Plan, given funding mechanisms now in place, but did not took into account the effect of public financing mechanism on regional economic development. The role of project funding sources (public/fiscal spending or private capital) on the regional economic development potential of a highway investment in Indiana needs to be further investigated.

4. This research demonstrated of a general approach that can be applied for broad analysis of statewide economic effects of highway projects, while taking into account the intensity of use of highway systems. A useful extension of this study would be to investigate whether the study framework holds for additional project types or strategies at different spatial scale and if not, what modifications (e.g., types of data) are necessary to document these effects. INDOT might be interested in examining the economic development effects associated with local access management strategies, or quantifying the effects of smart infrastructure system technologies (i.e. intelligent transportation systems) on the Indiana economy. 


\section{LIST OF ABBREVIATIONS}

$\begin{array}{ll}\text { 2SLS } & \text { Two-Stage Least Squares } \\ \text { AADT } & \text { Annual Average Daily Traffic } \\ \text { AASHTO } & \text { American Association of State Highway and Transportation Officials } \\ \text { ADHS } & \text { Appalachian Development Highway System } \\ \text { AF } & \text { Attractive Force } \\ \text { AI } & \text { Accessibility Index } \\ \text { ARC } & \text { Appalachian Regional Commission } \\ \text { ATL } & \text { Added Travel Lanes } \\ \text { AWDT } & \text { Average Weekday Daily Traffic } \\ \text { BLA } & \text { Bernardin Lochmueller \& Associates, Inc. } \\ \text { BPR } & \text { Bureau of Public Roads } \\ \text { CBP } & \text { County Business Patterns } \\ \text { CPI } & \text { Consumer Price Index } \\ \text { CRF } & \text { Crash Reduction Factor } \\ \text { CSI } & \text { Cambridge Systematics, Inc. } \\ \text { CUBRC } & \text { Calspan-University at Buffalo Research Center, Inc. } \\ \text { DW } & \text { Durbin-Watson Statistic } \\ \text { EDRG } & \text { Economic Development Research Group } \\ \text { EIAS } & \text { Economic Impact Analysis System } \\ \text { EIS } & \text { Environmental Impact Statement } \\ \text { FHWA } & \text { Federal Highway Administration } \\ \text { GIS } & \text { Geographic Information Systems } \\ \text { GLS } & \text { Generalized Least Squares } \\ \text { GDP } & \text { Gross Domestic Product } \\ \text { GRP } & \text { Gross Regional Product } \\ \text { GSP } & \text { Gross State Product } \\ \text { GVW } & \text { Gross Vehicle Weight } \\ \text { HCM } & \text { Highway Capacity Manual } \\ \end{array}$




\begin{tabular}{|c|c|}
\hline HEAT & Highway Economic Analysis Tool \\
\hline HERS & Highway Economics Requirements System \\
\hline HPMS & Highway Performance Monitoring System \\
\hline IC & Interchange Construction \\
\hline INDOT & Indiana Department of Transportation \\
\hline $\mathrm{I}-\mathrm{O}$ & Input-Output \\
\hline ISTDM & Indiana Statewide Travel Demand Model \\
\hline ITS & Intelligent Transportation Systems \\
\hline LEAP & Local Economic Assessment Package \\
\hline LQ & Location Quotient \\
\hline $\mathrm{MC}$ & Median Construction \\
\hline MCIBAS & Major Corridor Investment Benefit Analysis System \\
\hline MDT & Montana Department of Transportation \\
\hline MPO & Metropolitan Planning Organization \\
\hline MSA & Metropolitan Statistical Area \\
\hline NAICS & North American Industry Classification System \\
\hline NEPA & National Environmental Policy Act \\
\hline NRC & New Road Construction \\
\hline OLS & Ordinary Least Squares \\
\hline PPI & Producer Price Index \\
\hline PW & Present Worth \\
\hline PWED & Public Works Economic Development \\
\hline REDYN & Regional Dynamics Economic Analysis Model \\
\hline REIMHS & Regional Economic Impact Model for Highway Systems \\
\hline REMI & Regional Economic Models, Inc. \\
\hline RIMS & Regional Input-Output Modeling System \\
\hline RISE & Revitalize lowa's Sound Economy \\
\hline SAFETEA-LU & Safe, Affordable, Flexible and Efficient Equity Act-A Legacy for Users \\
\hline SAM & Social Accounting Matrix \\
\hline SR & State Route \\
\hline SUE & Stochastic User Equilibrium \\
\hline SURE & Seemingly Unrelated Regression Equations \\
\hline TAZ & Traffic Analysis Zone \\
\hline
\end{tabular}




$\begin{array}{ll}\text { TEA } & \text { Transportation Assistance Program } \\ \text { TEA-21 } & \text { Transportation Equity Act of } 21^{\text {st }} \text { Century } \\ \text { TELUS } & \text { Transportation, Economic, and Land-Use System } \\ \text { TIP } & \text { Transportation Improvement Plan } \\ \text { TPC } & \text { Transportation Projects Commission } \\ \text { TRB } & \text { Transportation Research Board } \\ \text { TREDIS } & \text { Transportation Economic Development Impact System } \\ \text { TSA } & \text { Transportation Satellite Account } \\ \text { TSI } & \text { Transportation Services Index } \\ \text { TSM } & \text { Transportation System Management } \\ \text { US BEA } & \text { United States Bureau of Economic Analysis } \\ \text { US BLS } & \text { United States Bureau of Labor Statistics } \\ \text { US BTS } & \text { United States Bureau of Transportation Statistics } \\ \text { VMT } & \text { Vehicle-Miles Traveled } \\ \text { WIsDOT } & \text { Wisconsin Department of Transportation } \\ \text { WSA } & \text { Wilbur Smith \& Associates, Inc. }\end{array}$




\section{LIST OF REFERENCES}

Aldrich, L., and L. Kusmin. "Rural Economic Development: What Makes Rural Communities Grow?" Agriculture Information Bulletin, No. 737, US Department of Agriculture, September 1997.

Allen, B.J., C.P. Baumel, and D.J. Forkenbrock. "Expanding the Set of Efficiency Gains of a Highway Investment: Conceptual, Methodological, and Practical Issues." Transportation Journal, Vol. 34, No. 1, 1994, pp. 39-47.

American Association of State Highway and Transportation Officials (AASHTO). "Transportation: Key to a Better Future." Washington, D.C., 1990.

American Association of State Highway and Transportation Officials (AASHTO). "User Benefit Analysis for Highways." Washington, D.C., 2003.

Apogee Research Inc., and Greenhorne \& O'Mara. "Research on the Relationship between Economic Development and Transportation Investment." NCHRP Report 418, Transportation Research Board, National Research Council, Washington, D.C., 1998.

Arsen, D. "Is There Really an Infrastructure/Economic Development Link?" In Dilemmas of Urban Economic Development: Issues in Theory and Practice, edited by Richard D. Bingham and Robert Mier, Sage, Newbury Park, CA, 1997.

Aschauer, D.A., "Is Public Expenditure Productive?" Journal of Monetary Economics, Vol. 23, 1989, pp. 177-200.

Aschauer, D.A. "Highway Capacity and Economic Growth." Economic Perspectives, Federal Reserve Bank of Chicago, Vol. 14, No. 5, Sept/Oct 1990. 
Babcock, M.W. "Approximation of the Economic Impacts of the Kansas Comprehensive Transportation Program." Prepared for the Kansas Department of Transportation, December 2004.

Babcock, M.W., and J.A. Davalos. "Case Studies of the Economic Impact of Highway Bypasses in Kansas." Journal of the Transportation Research Forum, Vol. 43, No. 1, Spring 2004, pp. 55-75.

Baird, B. "Public Infrastructure and Economic Productivity: A Transportation-Focused Review". Presented at the 84th TRB Annual Meeting, Washington, D.C., January 2005.

Baird, E.A., and M.A. Lipsman. "Role of Non-Interstate Highway Transportation in Enhancing Economic Development in lowa." Transportation Research Record 1274, Transportation Research Board, National Research Council, Washington, D.C., 1990, pp. 255-269.

Barron, J.M., G.J. Lynch, and K.H. Blanchard. Economics: A Survey. Purdue University. Lakeshore Publishers, Euclid, OH, 2003.

Beemiller, R.M. "Hybrid Approach to Estimating Economic Impacts Using the Regional Input-Output Modeling System (RIMS II)." Transportation Research Record 1274, Transportation Research Board, National Research Council, Washington, D.C., 1990, pp. 89-96.

Bell, M.E., and T.J. McGuire. "Macroeconomic Analysis of the Linkages between Transportation Investments and Economic Performance." NCHRP Report 389, Transportation Research Board, National Research Council, Washington, D.C., 1997.

Blair, J.P., and R. Premus. "Major Factors in Industrial Location: A Review." Economic Development Quarterly, Vol. 1, No. 1, 1987, pp. 72-85. 
Boarnet, M., and A. Haughwout. "Do Highways Matter? Evidence and Policy Implications of Highways' Influence on Metropolitan Development." Prepared for the Brookings Institution Center on Urban and Metropolitan Policy, August 2000.

Boarnet, M. G., and S. Chalermpong. "New Highways, House Prices, and Urban Development: A Case Study of Toll Roads in Orange County, CA." Housing Policy Debate, Vol. 12, No. 3, 2001, pp. 575-605.

Brigham Young University (BYU). “Assessing the Economic Impacts of Transportation Improvement Projects." Prepared For Utah Department of Transportation Research and Development Division/Planning Division, March 2006.

Brown, D.M. "Highway Investment and Rural Economic Development: An Annotated Bibliography." Bibliographies and Literature of Agriculture, No. 133, Food and Rural Economics Division, Economic Research Service, US Department of Agriculture,1999.

Calspan-UB Research Center, Inc. (CUBRC), University at Buffalo, The State University of New York, and Cambridge Systematics, Inc. "Handbook of Economic Development." Prepared for the New York State Department of Transportation, September 2001.

Cambridge Systematics, Inc. (CSI) "Economic Impacts of the Southwest Indiana Highway Corridor." Prepared for Indiana Department of Transportation, (INDOT), 1996a.

Cambridge Systematics, Inc. (CSI) "Impacts of Transportation Investments on the Indiana Economy." Prepared for Indiana Department of Transportation (INDOT), 1996b.

Cambridge Systematics, Inc. (CSI) "Economic Impact Analysis System: Major Corridor Investment-Benefit Analysis System." Prepared for Indiana Department of Transportation (INDOT), 1998.

Cambridge Systematics, Inc. (CSI), and Bernardin, Lochmueller and Associates (BLA), Inc. "Economic Impacts of SR 26 and US 35 Corridor Improvements." Prepared for Indiana Department of Transportation (INDOT), 1998a. 
Cambridge Systematics, Inc. (CSI), and Bernardin, Lochmueller and Associates (BLA) "Economic Impacts of US 31 Corridor Improvements." Prepared for Indiana Department of Transportation (INDOT), 1998b.

Cambridge Systematics, Inc. (CSI), and Bernardin, Lochmueller and Associates (BLA) “I-69 Evansville to Indianapolis, Indiana Final Environmental Impact Statement." Prepared for Indiana Department of Transportation and Federal Highway Administration. 2003. [online: http://www.deis.i69indyevn.org/FEIS/ Accessed January 20, 2006.]

Cambridge Systematics, Inc. (CSI), and Bernardin, Lochmueller and Associates (BLA) “Economic Impacts of Indiana's Statewide Long-Range Transportation Plan." Prepared for Indiana Department of Transportation (INDOT), 2004.

Cambridge Systematics, Inc. (CSI), Bernardin, Lochmueller and Associates (BLA), and Dyer Environmental Services. "SR 101 Corridor Improvement Feasibility/ NEPA Study." Prepared for Indiana Department of Transportation (INDOT), 2003.

Cambridge Systematics, Inc. (CSI), and Economic Development Research Group (EDRG). "Montana Highway Reconfiguration Study". Prepared for Montana Department of Transportation (MDT), 2005.

Cambridge Systematics, Inc. (CSI), R. Cervero, and D. Aschauer. "Economic Impact Analysis of Transit Investments: Guidebook for Practitioners." TCRP Report 35, Transportation Research Board, National Research Council, Washington, D.C., 1998.

Cambridge Systematics, Inc. (CSI), Mathis and Associates, and Kittelson \& Associates, Inc. "State of the Practice in Project Prioritization." Prepared for Florida Department of Transportation (FDOT), 2004.

Choocharukul, K. "The Development of a Congestion Management System Methodology for Indiana." Master of Science Thesis, Civil Engineering, Purdue University, West Lafayette, Indiana, 2000. 
Chow, G.C. "Tests of Equality between Sets of Coefficients in Two Linear Regressions." Econometrica, 1960.

Cortright, J. "Transportation, Industrial Location and the New Economy." Transportation Research Circular E-C050, Transportation Research Board, National Research Council, Washington, D.C., 2003.

Costa, J., Da Silva, R. Ellson, and R.C. Martin. "Public Capital, Regional Output, and Development: Some Empirical Evidence." Journal of Regional Science, Vol. 27, No.3, August 1987, pp. 419-437.

Dalenberg, D., and M. Partridge. "Public Infrastructure and Wages: Public Capital's Role as a Productive Input and Household Amenity." Land Economics, Vol. 73, No. 2, 1997, pp. 268-284.

Dowling, R., R. Ireson, A. Skabardonis, D. Gillen, and P. Stopher. "Predicting Air Quality Effects of Traffic-Flow Improvements: Final Report and User's Guide." NCHRP Report 535, Transportation Research Board, National Research Council, Washington, D.C., 2005.

Drew, D.R. “Conference Summary." Transportation Research Record 1274, Transportation Research Board, National Research Council, Washington, D.C., 1990, pp. 285-290.

Duffy-Deno,. K.T., and R.W. Eberts. "Public Infrastructure and Regional Economic Development: A Simultaneous Equations Approach." Journal of Urban Economics, Vol. 30, 1991, pp. 329-343.

Eberts, R.W. "Public Infrastructure and Regional Economic Development." Economic Review, Federal Reserve Bank of Cleveland, Vol. 26, No. 1, 1990, pp. 15-27.

Eberts, R.W. "Understanding the Impact of Transportation in Economic Development." Transportation in the New Millennium, TRB Committee on Transportation and Economic Development, 2000. 
Eberts, R.W. "Highway Infrastructure: Policy Issues for Regions." Presented at "Maintaining and Financing Public Infrastructure in Tough Budgetary Times" Conference sponsored by the Federal Reserve Bank of Chicago and the National Association of State Budget Officers, September 25, 2002. [online: http://www.chicagofed.org/ news_and_conferences/conferences_and_events/maintaining_and_financing_public_inf rastructure_agenda.cfm. Accessed June 15, 2005.]

Economic Development Research Group, Inc. (EDRG), and Cambridge Systematics, Inc. (CSI) "Using Empirical Information to Measure the Economic Impact of Highway Investments." Prepared for Federal Highway Administration (FHWA), Washington, D.C., 2001.

Ellington, D.B., A.H. Lester, and J.S. Miller. "A Tale of Three Regions: Influence of Highway Investments on Population and Traffic Growth in Virginia." FHWA/VTRC 05R23. Prepared for Virginia Department of Transportation and Federal Highway Administration, Virginia Transportation Research Council, Richmond, Virginia, 2005.

Evers, G.H.M., P.H. Van Der Meer, J. Oosterhaven, and J.B. Polak. "Regional Impacts of New Transport Infrastructure: A Multi-Sectoral Potentials Approach." Transportation, Vol. 14, 1988, pp. 113-126.

Fan, W., F. Treyz, and G. Treyz. "An Evolutionary New Economic Geography Model." Journal of Regional Science, Vol. 40, No. 4, 2000, pp. 671-695.

Federal Highway Administration, (FHWA). "Secondary and Cumulative Impact Assessment in the Highway Project Development Process." Prepared by Federal Highway Administration Project Development Branch, HEP-31, Washington, D.C., 1992.

Federal Highway Administration, (FHWA). "An Assessment of Input-Output Models". US Department of Transportation, Transportation Studies Division, by DRI/McGraw-Hill, Contract Number DTFH61-93-C-00055, January 1994. 
Federal Highway Administration, (FHWA). "Linking the Delta with the Nation and the World." Report FHWA-PD-96-007, Washington, D.C., 1995.

Federal Highway Administration, (FHWA). "Highway Performance Monitoring System (HPMS) Field Manual." Washington, D.C., December 2000. [online: http:// www.fhwa.dot.gov/policy/ohpi/hpms/hpmspubs.htm. Accessed July 10, 2005.]

Federal Highway Administration, (FHWA). "Toolbox for Regional Policy Analysis." Washington, D.C., 2002. [online: http://www.fhwa.dot.gov/planning/toolbox/index.htm. Accessed June 6, 2004.]

Fernald, J.G. "Roads to Prosperity? Assessing the Link between Public Capital and Productivity." American Economic Review, American Economic Association, Vol. 89, No. 3, 1999, pp. 619-638.

Flyvbjerg, B., N. Bruzelius, and W. Rothengatter. Megaprojects and Risk: An Anatomy of Ambition. Cambridge University Press, Cambridge, U.K., 2003.

Forkenbrock, D.J. "Putting Transportation and Economic Development into Perspective." Transportation Research Record 1274, Transportation Research Board, National Research Council, Washington, D.C., 1990, pp. 3-11.

Forkenbrock, D.J., and N.S.J. Foster. "Highways and Business Location Decisions." Economic Development Quarterly, Vol. 10, No. 3, 1996, pp. 239-248.

Forkenbrock, D.J., and G. Weisbrod. "Guidebook for Assessing the Social and Economic Effects of Transportation Projects." NCHRP Report 456, Transportation Research Board, National Research Council, Washington, D.C., 2001.

Forkenbrock, D.J., T.F. Pogue, N.S.J. Foster, and D.J. Finnegan. "Road Investment to Foster Local Economic Development." The Public Policy Center, University of lowa, lowa City, lowa, 1990. 
Forkenbrock D. J., S. Benshoff, and G. Weisbrod. "Assessing the Social and Economic Effects of Transportation Projects" NCHRP Project B25-19. Prepared for Transportation Research Board, National Research Council, Washington, D.C., 2001.

Glickman, N.J. Econometric Analysis of Regional Systems: Explorations in Model Building and Policy Analysis. Academic Press Inc., New York, 1977.

Gramlich, E.M. “Infrastructure Investment: A Review Essay.” Journal of Economic Literature, Vol. 32, September 1994, pp. 1176-1196.

Gupta, M., G. Weisbrod, and M.Weiss. "Transportation Programs Linking to Economic Development: A Microanalysis of Different Practices." Presented at the 84th TRB Annual Meeting, Washington, D.C., January 2005.

Hakfoot, J. "Public Capital, Private Sector Productivity and Economic Growth: A Macroeconomic Perspective." 1996. In Principles of Transport Economics by E. Quinet, and R. Vickerman, Edward Elgar Publishing, Inc., Massachusetts, 2004.

Hartgen, D.T., and J.Y. Kim. "Commercial Development at Rural and Small-Town Interstate Exits." Transportation Research Record 1649, Transportation Research Board, National Research Council, Washington, D.C., 1998, pp.95-104.

Hartgen, D.T., A.W. Stuart, W.A. Walcott, and J. Clay. "Role of Transportation in Manufacturers' Satisfaction with Locations." Transportation Research Record 1274, Transportation Research Board, National Research Council, Washington, D.C., 1990, pp. 12-23.

Held, J.R. "Clusters as an Economic Development Tool: Beyond the Pitfalls." Economic Development Quarterly, Vol. 10, No. 3, 1996, pp. 249-261.

Highway Capacity Manual (HCM). Transportation Research Board, National Research Council, Washington, D.C., 2000. 
Hodge, D.J., and C. Hand. "Macroeconomic Impacts of Program-level Transportation Investments." Presented at the 83rd TRB Annual Meeting, Washington, D.C., January 2004.

Hodge, D.J., G. Weisbrod, and A. Hart. "Do New Highways Attract Businesses? Case Study for North County, New York." Transportation Research Record 1839, Transportation Research Board, National Research Council, Washington, D.C., 2003, pp. 150-158.

Huddleston, J.R., and P.P. Pangotra. "Regional and Local Economic Impacts of Transportation Investments." Transportation Quarterly, Vol. 44, No. 4, October 1990, pp. 579_ 594.

Indiana Department of Transportation (INDOT). "2004 Statewide Reference Post Book." [online: http://www.in.gov/dot/div/development/pavement/StateWide_2004.pdf. Accessed July $5,2005$.

lowa Department of Transportation (lowa DOT). "RISE Program: Administrative Rules." Ames; IA, 1986.

Isserman, A., and T. Rephann. "The Economic Effects of the Appalachian Regional Commission: An Empirical Assessment of 26 Years of Regional Development Planning." Journal of the American Planning Association, Vol. 61, No. 3, Summer 1995, pp. 345366.

Islam, M.S. "An Analysis of Truck Travel Characteristics in Indiana." Master of Science Thesis, Civil Engineering, Purdue University, West Lafayette, Indiana, 2003.

Jack Faucett Associates, Inc. "The Highway Economics Requirements System (HERS)." Federal Highway Administration, Washington, D.C., July 1991.

Jacoby, A.C. "Recent Advances in Understanding the Effects of Highway Investment on the US Economy." Transportation Quarterly, Vol. 53, No. 3, 1999, pp. 27-34. 
John Locke Foundation. "Highways and Urban Sprawl in North Carolina." Policy Report. September 25, 2003. [online: http://www.johnlocke.org/policy_reports/2003092541.html. Accessed June 10, 2004.]

Keane, T.F. "The Economic Importance of the National Highway System." Public Roads Magazine, Vol. 59, No. 4, Spring 1996.

Kriesel, W., and K. McNamara. "Improved Measures of Manufacturing Attraction: The Role of Industrial Site Hedonic Prices." Presented at the Annual Meeting of American Agricultural Economics Association, Vancouver, B.C., Canada, 1990.

Kulash, D.J. "Economic Returns from Transportation Investment." Transportation Quarterly, Vol. 51, No. 3, Summer 1997, pp. 8-19.

Lamptey, G., S. Labi and K.C. Sinha. "SMSS, Safety Management System Software v1.0 User Manual." Prepared for Indiana Department of Transportation (INDOT). Purdue University, West Lafayette, Indiana, November 2004.

Leong, D., and G. Weisbrod. "Summary of Highway Bypass Studies." Economic Development Research Group, Boston, Massachusetts, December 2000.

Lombard, P.C. "The Relationship between Highway Infrastructure and Regional Economic Development." PhD Dissertation, Civil Engineering, Purdue University, West Lafayette, Indiana, 1991.

Lombard, P.C., K.C Sinha., and D. Brown. "Investigation of the Relationship between Highway Infrastructure and Economic Development in Indiana." Transportation Research Record 1359, Transportation Research Board, National Research Council, Washington, D.C., 1992, pp. 76-81.

Lynch, T. "Analyzing the Economic Impact of Transportation Projects Using RIMS II, IMPLAN AND REMI." Prepared for Office of Research and Special Programs, US Department of Transportation. Florida State University, Institute for Science and Public Affairs, Florida, October 2000. 
Mamuneas, T.P., and M.I. Nadiri. "Production, Consumption, and the Rates of Return to Highway Infrastructure Capital." Prepared for the Federal Highway Administration (FHWA), Preliminary Draft, 2003.

McFarland, W.F., J.L. Memmott, and M.L. Chui. "Microcomputer Evaluation of Highway User Benefits." Final Report for NCHRP Project 7-12, Texas Transportation Institute, College Station, TX., 1993.

McHugh, R.J., and J.T. Wilikinson. "A Random-Effects Approach to Substate Growth Models: A Comment on the Determinants of County Growth". Journal of Regional Science, Volume 28, No. 2, 1998, pp. 271-273.

McQuaid, R.W., M.Greig, A. Smyth, and J. Cooper. "The Importance of Transport in Business' Location Decisions." Napier University, Edinburgh, U.K., January 2004.

Mohring, $H$. "Maximizing, Measuring, and Not Double-Counting TransportationImprovement Benefits: A Primer on Closed-and Open-Economy Cost-Benefit Analysis." Transportation Research Part B, Vol. 27B, No. 6, 1993, pp. 413-424.

Moomaw, L., J.K. Mullen, and M. Williams. "The Interregional Impact of Infrastructure Capital." Southern Economic Journal, Vol. 61, No. 3, 1995, pp. 830-846.

Moon, H.E. Jr. "Interstate Highway Interchanges as Instigators of Non-metropolitan Development." Transportation Research Record 1125, Transportation Research Board, National Research Council, Washington, D.C., 1987, pp. 8-14.

Munnell, A.H. "Why Has Productivity Growth Declined? Productivity and Public Investment." New England Economic Review, 1990a, pp. 3-22.

Munnell, A.H. "How Does Public Infrastructure Affect Regional Economic Performance? Is There a Shortfall in Public Capital Investment?" Federal Reserve Bank of Boston, 1990b. 
N-Y Associates, and Economic Development Research Group. "Economic Impact Study (Phase II) of the Proposed Mississippi River Bridge at St. Francisville, Louisiana and the Zachary Taylor Parkway Alexandria, Louisiana to Poplaville, Mississippi." Prepared for the Louisiana Department of Transportation and Development, Baton Rouge, Louisiana, May 1999.

Nadiri, M.I., and T.P. Mamuneas. "The Effects of Public Infrastructure and R\&D Capital on the Cost Structure and Performance of US Industries." Working Paper No. 3887, National Bureau of Economic Research, October 1991.

Nadiri, M.I., and T.P. Mamuneas. "Contribution of Highway Capital to Industry and National Productivity Growth." Prepared for the US DOT, Federal Highway Administration (FHWA), Office of Policy Development, September 1996.

Nadiri, M.I., and T.P. Mamuneas. "Contribution of Highway Capital to Output and Productivity Growth in the US Economy and Industries." Prepared for the Federal Highway Administration (FHWA), 1998.

Ohio Department of Transportation (ODOT). "Transportation Review Advisory Council Policies and Procedures." January 2003.

Orus, J.-P., "The Economic Impacts of Major Motorways Infrastructures: Main Lessons of Ex Post Studies." SETRA-Ministere de I'Equipement, du Logement, des Transports et du Tourisme, Banneux, France, 1996.

Pindyck, R.S., and D.L. Rubinfeld. Econometric Models and Economic Forecasts. $4^{\text {th }}$ edition, Irwin / McGraw-Hill, 1998.

Politano, A.L., and C.J. Roadifer. "Regional Economic Impact Model for Highway Systems (REIMHS)." Transportation Research Record 1229, Transportation Research Board, National Research Council, Washington, D.C., 1989, pp. 43-52. 
Quinet, E., and R. Vickerman. Principles of Transport Economics. Edward Elgar Publishing, Inc.,2004.

Rephann, T., and A. Isserman. "New Highways as Economic Development Tools: An Evaluation Using Quasi-Experimental Matching Methods." Regional Science and Urban Economics, Volume 24, No. 6, December 1994, pp. 723-751.

Siethoff, B. T. and K.M. Kockelman. "Property Values and Highway Expansion: Timing, Size, Location, and Use Effects." Transportation Research Record 1812, Transportation Research Board, National Research Council, Washington, D.C., 2002, pp. 191-200.

Shirley, C., and C. Winston. "Firm Inventory Behavior and the Returns from Highway Infrastructure Investments." Journal of Urban Economics, Vol. 55, No. 2, 2004, pp. 398415.

Smith, T.M., "The Impact of Highway Infrastructure on Economic Performance." Public Roads Magazine, Vol. 57, No.3, Spring 1994.

Smith, J.A. "A Study of the Influence of Public Capital Stock on State Output." Master of Science in Civil Engineering, Purdue University, Indiana, May 1997.

Tarko, A.P., K.C. Sinha, S. Eranky, H. Brown, E. Roberts, R. Scinteie, and S. Islam. "Crash Reduction Factors for Improvement Activities in Indiana." FHWA/IN/JTRP Final Report, Purdue University, West Lafayette, Indiana, May 2000.

Tarko, A., and M. Kanodia. "Hazard Elimination Program: Volume 1-Research Report, Volume 2-Guidelines for Highway Safety Improvements in Indiana." FHWA/IN/JTRP. 2003/19, Purdue University, West Lafayette, Indiana, December 2003. [online: http://rebar.ecn.purdue.edu/JTRP_Completed_Project_Documents/SPR_2485/FinalRep ort/spr_2485_form1700.pdf. Accessed September 6, 2005.]

The Buckeye Institute for Public Policy Solutions. "The Impact of Highways and Other Major Road Improvements on Urban Growth in Ohio." Policy Report, January 2003. 
Transportation Research Board (TRB), "Expanding Metropolitan Highways. Implications for Air Quality and Energy Use." Special Report 245, Committee for Study of Impacts of Highway Capacity Improvements on Air Quality and Energy Consumption, Transportation Research Board, National Research Council, Washington, D.C. 1995.

Treyz, F., and G. Treyz. "REMI Policy Insight Model Documentation Version 6.0." Regional Economic Models, Inc., Amherst, Massachusetts, August 2002.

United States Bureau of Labor Statistics (US BLS). Location Quotient Calculator-Year 2004. [online: http://data.bls.gov/LOCATION_QUOTIENT/servlet/lqc.ControllerServlet. Accessed November 5, 2005.]

United States Bureau of Transportation Statistics (US BTS). "BTS Releases February Transportation Services Index (TSI) Index Reverses One-Month Decline to Reach Second Highest Level." May 2004.

United States Government Accountability Office (US GAO). "Highway and Transit Investments-Options for Improving Information on Projects' Benefits and Costs and Increasing Accountability for Results." GAO-05-172, Washington D.C., January 2005.

Voytek, K., and L. Ledebur. "Is Industry Targeting a Viable Economic Development Strategy?" In Dilemmas of Urban Economic Development: Issues in Theory and Practice, edited by Richard D. Bingham and Robert Mier, Sage, Newbury Park, CA, 1997.

Wardrop, J.G. "Some Theoretical Aspects of Road Traffic Research." Proceedings, Institute of Civil Engineers, Part II, Vol. 1, 1952, pp. 325-378.

Washington, S.P., M.G. Karlaftis, and F.L. Mannering. Statistical and Econometric Methods for Transportation Data Analysis. Chapman \& Hall, New York, NY, 2003.

Weisbrod, G. "Current Practices for Assessing Economic Development Impacts from Transportation Investments." NCHRP Synthesis 290, Transportation Research Board, National Research Council, Washington, D.C., 2000. 
Weisbrod, G., and J. Beckwith. "Measuring Economic Development Benefits for Highway Decision-Making in Wisconsin." Transportation Research Record 1262. Transportation Research Board, National Research Council, Washington, D.C., 1990, pp. 57-68.

Weisbrod, G., and B. Weisbrod. "Measuring Economic Impacts of Projects and Programs." Economic Development Research Group, Boston, Massachusetts, 1997.

Weisbrod, G., and F. Treyz. "Productivity and Accessibility: Bridging Project-Specific and Macroeconomic Analyses of Transportation Investments." Journal of Transportation and Statistics, Vol. 1, No. 3, 1998, pp. 65-79.

Weisbrod, G., and M. Grovak. "Alternative Methods for Valuing Economic Benefits of Transportation Projects." Prepared for the Transportation Association of Canada, Benefit Cost Analysis Symposium, February 2001.

Weisbrod, G., and M. Gupta. "Overview of State Economic Development Highway Programs." Prepared for FHWA, USDOT, Washington D.C., May 2003. [online: http://www.edrgroup.com/pages/pdf/fhwa-states.pdf. Accessed February 2, 2005.]

Weisbrod, G., and M. Gupta. "Case Studies and National Summary of State Economic Development Highway Programs." Prepared for FHWA, USDOT, Washington D.C., March 2005. [online: http://www.fhwa.dot.gov/planning/econdev/taskcde.htm. Accessed May 4, 2005.]

Weisbrod, G., D.Vary, and G. Treyz. "Economic Implications of Congestion." NCHRP Report 463, Transportation Research Board, National Research Council, Washington, D.C., 2001.

Weiss, M.H. "Economic Growth from Transportation Investments: Does it or Doesn't it?" Federal Highway Administration, Washington D.C., 2002. 
Weiss, M.H. "Economic Effects of Selected Rural Interstates at the County Level." Federal Highway Administration, Washington D.C., 2005. [online: http://www.fhwa.dot.gov/ planning/econdev/county.htm. Accessed December 10, 2005.]

Weiss, M.H., and R. Figura. "Provisional Typology of Highway Economic Development Projects." Transportation Research Record 1839, Transportation Research Board, National Research Council, Washington, D.C., 2003, pp. 115-119.

Wilbur Smith Associates, Inc. (WSA). "Appalachian Development Highways Economic Impact Study." Prepared for the Appalachian Regional Commission, Washington, D.C., July 1998.

Wisconsin Department of Transportation (WisDOT). "Transportation Assistance Program (TEA)", 1986. [online: http://www.dot.state.wi.us/localgov/aid/tea.htm Accessed February $25,2005$.

Wisconsin Department of Transportation (WisDOT). "Economic Development and the State Trunk Highway System: A Technical Report." Division of Transportation Investment Management, Economic Planning and Development, Madison, Wisconsin, 1998.

Wisconsin Department of Transportation (WisDOT). "Major Highway Project Numerical Evaluation Process." Chapter Trans 210, Wisconsin Administrative Code, January 1999.

Zografos, K.G., and Y.J. Stephanedes. "Impact of State Highway Investment on Employment along Major Highway Corridors." Transportation Research Record 1359, Transportation Research Board, National Research Council, Washington, D.C., 1992, pp. 151-155. 
Appendix A.

Table A.1 Summary of State Economic Development Highway Funding Programs and Policies (Adapted from: Weisbrod and Gupta, 2003)

\begin{tabular}{|c|c|c|c|c|}
\hline \multirow[b]{2}{*}{ State } & \multicolumn{3}{|c|}{ Economic Development Highway Funding } & \multirow{2}{*}{$\begin{array}{c}\text { Formal Economic De- } \\
\text { velopment Highway } \\
\text { Policies }\end{array}$} \\
\hline & $\begin{array}{l}\text { State Corri- } \\
\text { dors }\end{array}$ & Local Roads & ARC Programs & \\
\hline Alabama & & $\mathrm{X}$ & $\mathrm{X}$ & \\
\hline Alaska & & & & $\mathrm{X}$ \\
\hline Arizona & & $\mathrm{X}$ & & \\
\hline \multicolumn{5}{|l|}{ Arkansas } \\
\hline California & & & & (D) \\
\hline \multicolumn{5}{|l|}{ Colorado } \\
\hline \multicolumn{5}{|l|}{ Connecticut } \\
\hline Delaware & & & & $\mathrm{X}$ \\
\hline Florida & $\mathrm{X}$ & & & \\
\hline Georgia & $\mathrm{X}$ & & $\mathrm{X}$ & \\
\hline \multicolumn{5}{|l|}{ Hawaii } \\
\hline Idaho & & & & $\mathrm{X}$ \\
\hline Illinois & & $\mathrm{X}$ & & \\
\hline Indiana & & & & $\mathrm{x}$ \\
\hline lowa & & $\mathrm{X}$ & & \\
\hline Kansas & & $\mathrm{x}$ & & $\mathrm{x}$ \\
\hline Kentucky & & (B) & $\mathrm{X}$ & \\
\hline Louisiana & $\mathrm{X}$ & & & \\
\hline \multicolumn{5}{|l|}{ Maine } \\
\hline Maryland & & & $\mathrm{X}$ & $\mathrm{X}$ \\
\hline Massachusetts & & $\mathrm{X}$ & & \\
\hline Michigan & & $\mathrm{X}$ & & \\
\hline Minnesota & $(\mathrm{A})$ & & & \\
\hline Mississippi & $x$ & & $\mathrm{X}$ & \\
\hline Missouri & & $x$ & & \\
\hline Montana & & & & $x$ \\
\hline Nebraska & & & & $x$ \\
\hline Nevada & & & & $x$ \\
\hline \multicolumn{5}{|l|}{ New Hampshire } \\
\hline New Jersey & & & & $X$ \\
\hline New Mexico & & & & $x$ \\
\hline New York & & $x$ & $\mathrm{X}$ & \\
\hline North Carolina & & $x$ & $\mathrm{X}$ & \\
\hline North Dakota & & & & $x$ \\
\hline
\end{tabular}


Table A.1 (Continued)

\begin{tabular}{|l|c|c|c|c|}
\hline \multirow{2}{*}{ State } & \multicolumn{2}{|c|}{ Economic Development Highway Funding } & $\begin{array}{c}\text { Formal Economic De- } \\
\text { velopment Highway } \\
\text { Policies }\end{array}$ \\
\cline { 2 - 5 } & $\begin{array}{c}\text { State Corri- } \\
\text { dors }\end{array}$ & Local Roads & ARC Programs & X \\
\hline Ohio & & & $\mathrm{X}$ & \\
\hline Oklahoma & & $\mathrm{X}$ & & \\
\hline Oregon & & $\mathrm{X}$ & $\mathrm{X}$ & \\
\hline Pennsylvania & & $(\mathrm{B})$ & $\mathrm{X}$ & \\
\hline Rhode Island & & & $\mathrm{X}$ & \\
\hline South Carolina & & $\mathrm{B})$ & & \\
\hline South Dakota & & $\mathrm{X}$ & $\mathrm{X}$ & \\
\hline Tennessee & & $\mathrm{X}$ & $\mathrm{D})$ \\
\hline Texas & & $\mathrm{C})$ & \\
\hline Utah & & $\mathrm{C})$ & $\mathrm{X}$ & \\
\hline Vermont & & $\mathrm{X}$ & & \\
\hline Virginia & & $\mathrm{X}$ & & \\
\hline Washington & & $\mathrm{X}$ & & \\
\hline West Virginia & & & & \\
\hline Wisconsin & & & & \\
\hline Wyoming & & & & \\
\hline
\end{tabular}

(A) Funded for "interregional corridor system" to connect trade centers, but no special targeting to economically depressed locations.

(B) Annual set-aside funding exists to support road and highway projects based on economic development justifications, but no formal "program" is in place.

(C) No annual set-aside funding exists to support road and highway projects; however other informal alternatives are considered for economic development related transportation projects.

(D) Currently working on development of a formal policy for economic development $\mathrm{road} / \mathrm{highway}$ funding. 
Table A.2 Summary of State Set-Asides for Economic Development Related Projects (Adapted from: Weisbrod and Gupta, 2003)

\begin{tabular}{|l|l|}
\hline Minnesota Department of Transportation & $\begin{array}{l}\text { Provides efficient connection among regional } \\
\text { trade centers through Interregional Corridor } \\
\text { System }\end{array}$ \\
\hline Kentucky Transportation Cabinet & $\begin{array}{l}\text { Sets aside \$2 million for various industrial ac- } \\
\text { cess projects }\end{array}$ \\
\hline Pennsylvania Department of Transportation & $\begin{array}{l}\text { Sets aside \$25 million/year in state funds for } \\
\text { Governor's Action Team economic devel- } \\
\text { opment opportunities }\end{array}$ \\
\hline Texas Department of Transportation & $\begin{array}{l}\text { Adjusts the minimum local matching funds } \\
\text { requirements for projects in economically } \\
\text { disadvantaged counties }\end{array}$ \\
\hline South Carolina Department of Transportation & $\begin{array}{l}\text { Uses 1 percent of gas tax revenue (about } \$ 3 \\
\text { million) in coordination with the state eco- } \\
\text { nomic development office for transportation } \\
\text { projects in the economic development cate- } \\
\text { gory }\end{array}$ \\
\hline Vermont Department of Transportation & $\begin{array}{l}\text { Operates state infrastructure bank oriented to } \\
\text { support economic development projects }\end{array}$ \\
\hline
\end{tabular}

Table A.3 Summary of States Using Economic Development as a Highway Decision Factor (Adapted from: Weisbrod and Gupta, 2003)

\begin{tabular}{|c|c|}
\hline Alaska Department of Transportation & $\begin{array}{l}\text { Uses economic development justification to } \\
\text { select projects }\end{array}$ \\
\hline Delaware Department of Transportation & $\begin{array}{l}\text { Incorporated a set of objective supporting } \\
\text { economic development policies }\end{array}$ \\
\hline Idaho Department of Transportation & $\begin{array}{l}\text { Planned several strategies to support eco- } \\
\text { nomic development goals }\end{array}$ \\
\hline Indiana Department of Transportation & $\begin{array}{l}\text { Includes economic development as decision } \\
\text { criterion on project-to-project basis }\end{array}$ \\
\hline Kansas Department of Transportation ${ }^{1,2}$ & $\begin{array}{l}\text { Gives } 20 \text { percent weight to economic devel- } \\
\text { opment enhancement in project selection. }\end{array}$ \\
\hline Maryland Department of Transportation & $\begin{array}{l}\text { Selects economic development projects and } \\
\text { programs on project-to-project basis }\end{array}$ \\
\hline Montana Department of Transportation & $\begin{array}{l}\text { Adopted a series of policies and actions to } \\
\text { support economic development }\end{array}$ \\
\hline Nebraska Department of Transportation & $\begin{array}{l}\text { Considers economic development just as one } \\
\text { factor, along with many other factors, in its } \\
\text { annual highway need assessment program }\end{array}$ \\
\hline Nevada Department of Transportation & $\begin{array}{l}\text { Uses benefit/cost analysis and REMI models } \\
\text { to consider the economic effect of highway } \\
\text { projects }\end{array}$ \\
\hline New Jersey Department of Transpor & $\begin{array}{l}\text { Includes economic development as a cate- } \\
\text { gory factor in selecting Federal Aid High- } \\
\text { way projects }\end{array}$ \\
\hline
\end{tabular}


Table A.3 (Continued)

\begin{tabular}{|l|l|}
\hline New Mexico Department of Transportation & $\begin{array}{l}\text { Considers economic development factor in } \\
\text { transportation projects selection process }\end{array}$ \\
\hline North Dakota Department of Transportation & $\begin{array}{l}\text { Intends to engage local government and pri- } \\
\text { vate sectors in examining and identifying } \\
\text { collaborative economic development oppor- } \\
\text { tunities }\end{array}$ \\
\hline Ohio Department of Transportation ${ }^{3}$ & $\begin{array}{l}\text { Uses a scoring methodology to identify eco- } \\
\text { nomic development projects; gives up to } 30 \\
\text { percent weight to economic development } \\
\text { enhancement in project selection. }\end{array}$ \\
\hline Rhode Island Department of Transportation & $\begin{array}{l}\text { Considers economic impact as an important } \\
\text { factor in selecting projects }\end{array}$ \\
\hline Wisconsin Department of Transportation & $\begin{array}{l}\text { Ranks each candidate project on the basis of } \\
\text { five categories of measures, economic } \\
\text { measures are assigned up to 40 percent } \\
\text { weight in project selection. }\end{array}$ \\
\hline
\end{tabular}

also has a formal highway economic development program.

${ }^{2}$ discussed in more detail in Section 3.4.4.

${ }^{3}$ discussed in more detail in Section 3.4.5.

${ }^{4}$ discussed in more detail in Section 3.4.3.2. 


\section{Appendix B.}

The Highway Performance Monitoring System (HPMS) is an inventory system that requires reported data to represent both directions of roadway condition and operation. Certain basic inventory information is required to be reported for all open-to-traffic, public road systems in the universe portion of the HPMS data set (Items 1-46). Additional detailed information is required for a statistically chosen sample of roadways on major functional systems. The sampled functional systems include all but the rural minor collector, rural local and urban local systems. The additional detailed data are reported for the standard sample portion of the HPMS data set (Items 47-98). The standard sample is intended to represent all applicable systems both on and off the State highway system. The following tables (Tables B.1 and B.2) summarize the data reported in HPMS (FHWA, 2000). 
Table B.1 Universe Data Summary

\begin{tabular}{|c|c|c|c|c|c|c|c|c|c|c|}
\hline \multirow{3}{*}{$\begin{array}{l}\text { Item } \\
\text { No. }\end{array}$} & \multicolumn{8}{|c|}{ Required Universe Items } & \multirow{3}{*}{ Data Item } & \multirow{3}{*}{ Data Type } \\
\hline & \multirow{2}{*}{\begin{tabular}{|l|} 
Rural \\
PAS/ \\
NHS \\
\end{tabular}} & \multicolumn{7}{|c|}{ Urban } & & \\
\hline & & MA & $\mathrm{MaC}$ & $\begin{array}{l}\text { MiC \& } \\
\text { Loc }\end{array}$ & $\begin{array}{l}\text { PAS/ } \\
\text { NHS }\end{array}$ & MA & Col & Loc & & \\
\hline \multicolumn{11}{|c|}{ IDENTIFICATION } \\
\hline 1 & $A$ & $A$ & A & $A$ & $A$ & A & $A$ & $A$ & Year of Data & Numeric; Integer \\
\hline 2 & A & $A$ & $A$ & $A$ & A & $A$ & A & $A$ & State Code & Numeric; Codes \\
\hline 3 & A & A & A & A & A & A & A & A & $\begin{array}{l}\text { Reporting } \\
\text { Units- Metric } \\
\text { or English }\end{array}$ & Numeric; Codes \\
\hline 4 & A & A & A & $A$ & $A$ & A & $A$ & $A$ & County Code & Numeric; Codes \\
\hline 5 & A & A & $A$ & A & A & A & A & $A$ & $\begin{array}{l}\text { Section Iden- } \\
\text { tification }\end{array}$ & Character Field \\
\hline 6 & & & & & & & & & $\begin{array}{l}\text { Is Standard } \\
\text { Sample }\end{array}$ & Numeric; Codes \\
\hline 7 & & & & & & & & & $\begin{array}{l}\text { Is Donut } \\
\text { Sample }\end{array}$ & Numeric; Codes \\
\hline 8 & & & & & & & & & $\begin{array}{l}\text { State Control } \\
\text { Field }\end{array}$ & Character Field \\
\hline 9 & A & A & $A$ & A & A & A & A & A & $\begin{array}{l}\text { Is } \quad \text { Section } \\
\text { Grouped? }\end{array}$ & Numeric; Codes \\
\hline 10 & A & A & & & A & & & & $\begin{array}{l}\text { LRS Identifi- } \\
\text { cation* }\end{array}$ & Character Field \\
\hline 11 & $A$ & A & & & A & & & & $\begin{array}{l}\text { LRS Begin- } \\
\text { ning Point* }\end{array}$ & $\begin{array}{l}\text { Numeric; } \text { Deci- } \\
\text { mal }\end{array}$ \\
\hline 12 & $A$ & A & & & A & & & & \begin{tabular}{|l} 
LRS $\quad$ Ending \\
Point*
\end{tabular} & $\begin{array}{l}\text { Numeric; Deci- } \\
\text { mal }\end{array}$ \\
\hline 13 & A & A & A & A & A & $A$ & A & A & $\begin{array}{l}\text { Rural/Urban } \\
\text { Designation }\end{array}$ & Numeric; Codes \\
\hline 14 & $A$ & A & A & A & A & A & A & $A$ & 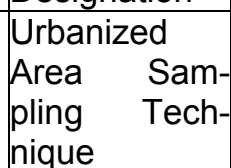 & Numeric; Integer \\
\hline 15 & A & A & A & A & A & A & $A$ & A & $\begin{array}{l}\text { Urbanized } \\
\text { Area Code }\end{array}$ & Numeric; Codes \\
\hline 16 & $A$ & A & A & A & A & A & A & $A$ & $\begin{array}{l}\text { NAAQS Non- } \\
\text { attainment } \\
\text { Area Code }\end{array}$ & Numeric; Codes \\
\hline \multicolumn{11}{|c|}{ SYSTEM } \\
\hline 17 & $A$ & A & $A$ & $A$ & A & $A$ & $A$ & A & $\begin{array}{l}\text { Functional } \\
\text { System Code }\end{array}$ & Numeric; Codes \\
\hline 18 & $A$ & A & $A$ & $A$ & A & A & A & $A$ & $\begin{array}{l}\text { Generated } \\
\text { Functional } \\
\text { System Code }\end{array}$ & $\begin{array}{l}\text { Software Calcu- } \\
\text { lated }\end{array}$ \\
\hline 19 & $A$ & A & A & $A$ & A & A & A & $A$ & $\begin{array}{l}\text { National } \\
\text { Highway Sys- } \\
\text { tem (NHS) }\end{array}$ & Numeric; Codes \\
\hline
\end{tabular}


Table B.1 (Continued)

\begin{tabular}{|c|c|c|c|c|c|c|c|c|c|c|}
\hline \multirow{3}{*}{\begin{tabular}{|l} 
Item \\
No.
\end{tabular}} & \multicolumn{8}{|c|}{ Required Universe Items } & \multirow{3}{*}{ Data Item } & \multirow{3}{*}{ Data Type } \\
\hline & \multirow{2}{*}{\begin{tabular}{|l|} 
Rural \\
PAS/ \\
NHS \\
\end{tabular}} & \multicolumn{7}{|c|}{ Urban } & & \\
\hline & & MA & $\mathrm{MaC}$ & $\begin{array}{l}\text { MiC \& } \\
\text { Loc }\end{array}$ & $\begin{array}{l}\text { PAS/ } \\
\text { NHS }\end{array}$ & MA & Col & Loc & & \\
\hline & & & & & & & & & & \\
\hline 20 & A & & & & A & & & & $\begin{array}{l}\text { Planned Un- } \\
\text { built Facility }\end{array}$ & Numeric; Codes \\
\hline 21 & A & & & & A & & & & $\begin{array}{ll}\text { Official } & \text { Inter- } \\
\text { state } & \text { Route } \\
\text { Number } & \end{array}$ & Character Field \\
\hline 22 & A & A & & & A & & & & $\begin{array}{l}\text { Route } \\
\text { ing* }\end{array}$ & Numeric; Codes \\
\hline 23 & A & A & & & A & & & & $\begin{array}{l}\text { Route Signing } \\
\text { Qualifier* }\end{array}$ & Numeric; Codes \\
\hline 24 & A & A & & & A & & & & $\begin{array}{l}\text { Signed Route } \\
\text { Number* }\end{array}$ & Character Field \\
\hline \multicolumn{11}{|c|}{ JURISDICTION } \\
\hline 25 & A & A & A & A & A & A & A & A & $\begin{array}{l}\text { Governmental } \\
\text { Ownership }\end{array}$ & Numeric; Codes \\
\hline 26 & A & A & A & A & A & $A$ & A & $A$ & $\begin{array}{l}\text { Special Sys- } \\
\text { tems }\end{array}$ & Numeric; Codes \\
\hline \multicolumn{11}{|c|}{ OPERATION } \\
\hline 27 & $A$ & A & A & $A$ & A & A & A & A & $\begin{array}{l}\text { Type of Facil- } \\
\text { ity }\end{array}$ & Numeric; Codes \\
\hline 28 & A & A & A & A & A & A & A & A & \begin{tabular}{|l|} 
Designated \\
Truck Route
\end{tabular} & Numeric; Codes \\
\hline 29 & $A$ & A & A & A & A & A & A & A & Toll & Numeric; Codes \\
\hline \multicolumn{11}{|c|}{ OTHER } \\
\hline 30 & $A$ & A & A & A & A & A & $A$ & A & $\begin{array}{l}\text { Section } \\
\text { Length }\end{array}$ & $\begin{array}{l}\text { Numeric; Deci- } \\
\text { mal }\end{array}$ \\
\hline 31 & & A & A & & & $A$ & A & & $\begin{array}{l}\text { Donut rea } \\
\text { Sample AADT } \\
\text { Volume } \\
\text { Group Identi- } \\
\text { fier }\end{array}$ & Numeric; Integer \\
\hline 32 & $A$ & A & A & & A & $A$ & $A$ & & \begin{tabular}{|l|} 
Standard \\
Sample AADT \\
Volume \\
Group Identi- \\
fier
\end{tabular} & Numeric; Integer \\
\hline 33 & A & S\&D & S\&D & & A & S\&D & S\&D & & $\mathrm{AADT}^{*}$ & Numeric; Integer \\
\hline 34 & $A$ & A & A & & A & A & A & & $\begin{array}{l}\text { Number of } \\
\text { Through } \\
\text { Lanes }\end{array}$ & Numeric; Integer \\
\hline 35 & $A$ & $s$ & & & A & & & & \begin{tabular}{|l} 
Measured \\
Pavement \\
Roughness \\
$(\mathrm{IRI})^{*}$
\end{tabular} & $\begin{array}{l}\text { Numeric; Deci- } \\
\text { mal }\end{array}$ \\
\hline
\end{tabular}


Table B.1 (Continued)

\begin{tabular}{|c|c|c|c|c|c|c|c|c|c|c|}
\hline \multirow{3}{*}{$\begin{array}{l}\text { Item } \\
\text { No. }\end{array}$} & \multicolumn{8}{|c|}{ Required Universe Items } & \multirow{3}{*}{ Data Item } & \multirow{3}{*}{ Data Type } \\
\hline & \multicolumn{4}{|l|}{ Rural } & \multirow[b]{2}{*}{ PAS/ } & \multirow[b]{2}{*}{ MA } & \multirow[b]{2}{*}{ Col } & \multirow[b]{2}{*}{ Loc } & & \\
\hline & $\begin{array}{l}\text { PAS/ } \\
\text { NHS }\end{array}$ & MA & $\mathrm{MaC}$ & $\begin{array}{l}\text { MiC \& } \\
\text { Loc }\end{array}$ & & & & & & \\
\hline & & & & & & & & & & \\
\hline 36 & & & $s$ & & & $s$ & s & & $\begin{array}{l}\text { Present Ser- } \\
\text { viceability } \\
\text { Rating (PSR) }\end{array}$ & $\begin{array}{l}\text { Numeric; Deci- } \\
\text { mal }\end{array}$ \\
\hline 37 & A & A & A & A & A & A & A & A & $\begin{array}{l}\text { High Occu- } \\
\text { pancy Vehicle } \\
\text { (HOV) Opera- } \\
\text { tions }\end{array}$ & Numeric; Codes \\
\hline 38 & A & A & A & A & A & A & A & A & \begin{tabular}{|l|} 
Electronic \\
Surveillance
\end{tabular} & Numeric; Codes \\
\hline 39 & A & A & A & A & A & A & A & A & $\begin{array}{l}\text { Metered } \\
\text { Ramps }\end{array}$ & Numeric; Codes \\
\hline 40 & A & A & A & A & A & A & A & A & $\begin{array}{l}\text { Variable Mes- } \\
\text { sage Signs }\end{array}$ & Numeric; Codes \\
\hline 41 & A & A & A & A & A & A & A & A & $\begin{array}{l}\text { Highway Ad- } \\
\text { visory Radio }\end{array}$ & Numeric; Codes \\
\hline 42 & A & A & A & A & A & A & A & A & \begin{tabular}{|l|}
$\begin{array}{l}\text { Surveillance } \\
\text { Cameras }\end{array}$ \\
\end{tabular} & Numeric; Codes \\
\hline 43 & A & A & A & A & A & A & A & A & $\begin{array}{l}\text { Incident } \quad \text { De- } \\
\text { tection }\end{array}$ & Numeric; Codes \\
\hline 44 & A & A & A & A & A & A & A & A & $\mid \begin{array}{ll}\begin{array}{l}\text { Free } \\
\text { Phone }\end{array} & \text { Cell } \\
\end{array}$ & Numeric; Codes \\
\hline 45 & A & A & A & A & A & A & A & A & $\begin{array}{l}\text { On-Call Ser- } \\
\text { vice Patrol }\end{array}$ & Numeric; Codes \\
\hline 46 & A & A & A & A & A & A & A & A & $\begin{array}{l}\text { In-Vehicle } \\
\text { Signing }\end{array}$ & Numeric; Codes \\
\hline 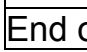 & gi & & it & & & & & & & \\
\hline
\end{tabular}

sections.

A = Code for "All" universe, standard sample, and supplementary donut area sample

$\mathrm{S}=$ Code for all "Standard" sample sections.

$\mathrm{D}=$ Code for all "Donut" area supplementary sample sections.

* $=$ See individual data item for exceptions. 
Table B.2 Sample Data Summary

\begin{tabular}{|c|c|c|c|c|c|c|c|c|c|c|c|}
\hline \multirow{3}{*}{$\begin{array}{l}\text { Item } \\
\text { No. }\end{array}$} & \multicolumn{9}{|c|}{ Required Sample Items } & \multirow{3}{*}{ Data Item } & \multirow{3}{*}{ Data Type } \\
\hline & \multicolumn{4}{|c|}{ Rural } & \multicolumn{5}{|c|}{ Urban } & & \\
\hline & Int & OPA & MA & MAC & Int & OFE & OPA & MA & Col & & \\
\hline \multicolumn{11}{|c|}{ IDENTIFICATION } & \\
\hline 47 & $S$ & S & S\&D & S\&D & $S$ & S & S & S\&D & \begin{tabular}{|c|}
$S \&$ \\
$D$
\end{tabular} & Sample Identifier & Character Field \\
\hline \multicolumn{11}{|c|}{ COMPUTATIONAL } & \\
\hline 48 & & & D & $\mathrm{D}$ & & & & $\mathrm{D}$ & D & $\begin{array}{c}\text { Donut Area } \\
\begin{array}{c}\text { Sample Expan- } \\
\text { sion Factor }\end{array} \\
\end{array}$ & $\begin{array}{c}\text { Software Calcu- } \\
\text { lated }\end{array}$ \\
\hline 49 & $S$ & S & $S$ & $\mathrm{~s}$ & $\mathrm{~s}$ & $S$ & $S$ & $S$ & $S$ & $\begin{array}{c}\text { Standard Sample } \\
\text { Expansion Fac- } \\
\text { tor }\end{array}$ & $\begin{array}{c}\text { Software Calcu- } \\
\text { lated }\end{array}$ \\
\hline \multicolumn{11}{|c|}{ PAVEMENT } & \\
\hline 50 & $S$ & $\mathrm{~s}$ & $s$ & $\mathrm{~s}$ & $\mathrm{~s}$ & $\mathrm{~s}$ & $\mathrm{~s}$ & $s$ & $\mathrm{~s}$ & $\begin{array}{c}\text { Sur- } \\
\text { face/Pavement } \\
\text { Type }\end{array}$ & Numeric; Codes \\
\hline 51 & $S$ & $S$ & $S$ & $S$ & $\mathrm{~S}$ & $S$ & $S$ & $S$ & $S$ & SN or D & Numeric; Decimal \\
\hline 52 & $S$ & $\mathrm{~s}$ & $\mathrm{~s}$ & $\mathrm{~s}$ & $S$ & $\mathrm{~s}$ & $\mathrm{~s}$ & $S$ & $S$ & $\begin{array}{c}\text { General Climate } \\
\text { Zone }\end{array}$ & Software Set \\
\hline 53 & $S$ & S & $S$ & $S$ & $S$ & $S$ & $S$ & $S$ & $S$ & $\begin{array}{l}\text { Year of Surface } \\
\text { Improvement }\end{array}$ & Numeric; Integer \\
\hline \multicolumn{11}{|c|}{ GEOMETRICS } & \\
\hline 54 & $S$ & $S$ & S & S & $S$ & $S$ & $S$ & S & $S$ & Lane Width & Numeric; Decimal \\
\hline 55 & $S$ & $S$ & $\mathrm{~S}$ & $S$ & $\mathrm{~S}$ & $S$ & $S$ & $S$ & $S$ & Access Control & Numeric; Codes \\
\hline 56 & $\mathrm{~S}$ & $\mathrm{~S}$ & $\mathrm{~S}$ & $\mathrm{~S}$ & $\mathrm{~S}$ & $\mathrm{~S}$ & $\mathrm{~S}$ & $\mathrm{~S}$ & $\mathrm{~S}$ & Median Type & Numeric; Codes \\
\hline 57 & $\mathrm{~S}$ & $\mathrm{~S}$ & $\mathrm{~S}$ & $\mathrm{~S}$ & $\mathrm{~S}$ & $\mathrm{~S}$ & $\mathrm{~S}$ & $\mathrm{~S}$ & $\mathrm{~S}$ & Median Width & Numeric; Decimal \\
\hline 58 & $\mathrm{~S}$ & $S$ & $\mathrm{~S}$ & $\mathrm{~S}$ & $\mathrm{~S}$ & $\mathrm{~S}$ & $\mathrm{~S}$ & $\mathrm{~S}$ & $S$ & Shoulder Type & Numeric; Codes \\
\hline 59 & $S$ & S & S & $S$ & $\mathrm{~S}$ & S & S & S & $S$ & $\begin{array}{c}\text { Shoulder Width - } \\
\text { Right }\end{array}$ & Numeric; Decimal \\
\hline 60 & $S$ & S & S & $S$ & $\mathrm{~s}$ & $\mathrm{~s}$ & $\mathrm{~s}$ & $\mathrm{~s}$ & $\mathrm{~s}$ & $\begin{array}{c}\text { Shoulder Width - } \\
\text { Left }\end{array}$ & Numeric; Decimal \\
\hline 61 & & & & & $S$ & $S$ & $S$ & $S$ & $S$ & Peak Parking & Numeric; Codes \\
\hline 62 & $S$ & $s$ & $s$ & $s$ & $\mathrm{~s}$ & $\mathrm{~s}$ & $s$ & $\mathrm{~s}$ & S & $\begin{array}{c}\text { Widening Feasi- } \\
\text { bility }\end{array}$ & Numeric; Codes \\
\hline 63 & $S$ & $s$ & $s$ & & $\mathrm{~s}$ & $\mathrm{~s}$ & $\mathrm{~s}$ & & & $\begin{array}{c}\text { Length Class A } \\
\text { Curves }\end{array}$ & Numeric; Decimal \\
\hline 64 & $S$ & $s$ & $s$ & & $\mathrm{~s}$ & $\mathrm{~s}$ & $\mathrm{~s}$ & & & $\begin{array}{c}\text { Length Class B } \\
\text { Curves }\end{array}$ & Numeric; Decimal \\
\hline 65 & s & $\mathrm{s}$ & $s$ & & $\mathrm{~s}$ & S & $\mathrm{s}$ & & & $\begin{array}{c}\text { Length Class C } \\
\text { Curves }\end{array}$ & Numeric; Decimal \\
\hline 66 & s & $\mathrm{s}$ & $s$ & & $\mathrm{~s}$ & $\mathrm{~s}$ & $\mathrm{~s}$ & & & $\begin{array}{c}\begin{array}{c}\text { Length Class D } \\
\text { Curves }\end{array} \\
\end{array}$ & Numeric; Decimal \\
\hline 67 & s & $\mathrm{s}$ & $\mathrm{s}$ & & $\mathrm{s}$ & S & S & & & $\begin{array}{c}\text { Length Class E } \\
\text { Curves }\end{array}$ & Numeric; Decimal \\
\hline 68 & $S$ & S & $S$ & & $\mathrm{~S}$ & $S$ & $S$ & & & \begin{tabular}{|c}
$\begin{array}{c}\text { Length Class F } \\
\text { Curves }\end{array}$ \\
\end{tabular} & Numeric; Decimal \\
\hline 69 & & & & $\mathrm{~s}$ & & & & & & $\begin{array}{c}\text { Horizontal } \\
\text { Alignment Ade- } \\
\text { quacy }^{*}\end{array}$ & $\begin{array}{c}\text { Software Calcu- } \\
\text { lated }\end{array}$ \\
\hline 70 & $\mathrm{~S}$ & $\mathrm{~S}$ & $\mathrm{~S}$ & $\mathrm{~S}$ & & & & & & Type of Terrain & Numeric; Codes \\
\hline & & & & & & & & & & & \\
\hline
\end{tabular}


Table B.2 (Continued)

\begin{tabular}{|c|c|c|c|c|c|c|c|c|c|c|c|}
\hline \multirow{3}{*}{$\begin{array}{l}\text { Item } \\
\text { No. }\end{array}$} & \multicolumn{9}{|c|}{ Required Sample Items } & \multirow{3}{*}{ Data Item } & \multirow{3}{*}{ Data Type } \\
\hline & \multicolumn{4}{|c|}{ Rural } & \multicolumn{5}{|c|}{ Urban } & & \\
\hline & Int & OPA & MA & MAC & Int & OFE & OPA & MA & Col & & \\
\hline 71 & & & & $\mathrm{~s}$ & & & & & & \begin{tabular}{|c|} 
Vertical Align- \\
ment Adequacy*
\end{tabular} & $\begin{array}{c}\text { Software Calcu- } \\
\text { lated }\end{array}$ \\
\hline 72 & $S$ & S & $S$ & & $S$ & $S$ & S & & & $\begin{array}{c}\text { Length Class A } \\
\text { Grades }\end{array}$ & Numeric; Decimal \\
\hline 73 & $S$ & S & $S$ & & $S$ & $S$ & $S$ & & & \begin{tabular}{|c|}
$\begin{array}{c}\text { Length Class B } \\
\text { Grades }\end{array}$ \\
\end{tabular} & Numeric; Decimal \\
\hline 74 & $S$ & S & $\mathrm{s}$ & & $\mathrm{s}$ & S & $S$ & & & $\begin{array}{c}\text { Length Class C } \\
\text { Grades }\end{array}$ & Numeric; Decima \\
\hline 75 & $S$ & S & $S$ & & $S$ & S & S & & & $\begin{array}{c}\text { Length Class D } \\
\text { Grades }\end{array}$ & Numeric; Decimal \\
\hline 76 & $S$ & S & $S$ & & $\mathrm{~S}$ & S & S & & & $\begin{array}{c}\text { Length Class E } \\
\text { Grades }\end{array}$ & Numeric; Decimal \\
\hline 77 & $\mathrm{~s}$ & $\mathrm{~s}$ & $\mathrm{~s}$ & & $\mathrm{~s}$ & $\mathrm{~s}$ & $\mathrm{~s}$ & & & $\begin{array}{c}\text { Length Class F } \\
\text { Grades }\end{array}$ & Numeric; Decimal \\
\hline 78 & $\mathrm{~s}$ & $\mathrm{~s}$ & $\mathrm{~s}$ & $s$ & & & & & & $\begin{array}{l}\text { Percent Passing } \\
\text { Sight Distance* }\end{array}$ & Numeric; Integer \\
\hline \multicolumn{11}{|c|}{ TRAFFIC/CAPACITY } & \\
\hline 79 & & & & & & & & & & $\begin{array}{c}\text { Weighted Design } \\
\text { Speed }\end{array}$ & $\begin{array}{c}\text { Software Calcu- } \\
\text { lated }\end{array}$ \\
\hline 80 & $\mathrm{~S}$ & $S$ & $S$ & $\mathrm{~S}$ & $\mathrm{~S}$ & $\mathrm{~S}$ & $\mathrm{~S}$ & $\mathrm{~S}$ & $\mathrm{~S}$ & Speed Limit & Numeric; Integer \\
\hline 81 & $\mathrm{~s}$ & $\mathrm{~s}$ & $S$ & $\mathrm{~s}$ & $\mathrm{~s}$ & $\mathrm{~s}$ & $\mathrm{~s}$ & $\mathrm{~s}$ & $\mathrm{~s}$ & $\begin{array}{c}\text { Percent Single } \\
\text { Unit Trucks - } \\
\text { Peak }\end{array}$ & Numeric; Integer \\
\hline 82 & $\mathrm{~s}$ & $\mathrm{~s}$ & $\mathrm{~s}$ & $\mathrm{~s}$ & $\mathrm{~s}$ & $\mathrm{~s}$ & $\mathrm{~s}$ & $\mathrm{~s}$ & $\mathrm{~s}$ & $\begin{array}{l}\text { Percent Single } \\
\text { Unit Trucks - } \\
\text { Average Daily }\end{array}$ & Numeric; Integer \\
\hline 83 & $\mathrm{~s}$ & $\mathrm{~s}$ & $\mathrm{~s}$ & $\mathrm{~s}$ & $\mathrm{~s}$ & $\mathrm{~s}$ & $\mathrm{~s}$ & $\mathrm{~s}$ & $\mathrm{~s}$ & $\begin{array}{c}\text { Percent Combi- } \\
\text { nation Trucks - } \\
\text { Peak }\end{array}$ & Numeric; Integer \\
\hline 84 & $\mathrm{~s}$ & $\mathrm{~s}$ & $S$ & $\mathrm{~s}$ & $\mathrm{~s}$ & $\mathrm{~s}$ & $\mathrm{~s}$ & $\mathrm{~s}$ & $\mathrm{~s}$ & $\begin{array}{l}\text { Percent Combi- } \\
\text { nation Trucks - } \\
\text { Average Daily }\end{array}$ & Numeric; Integer \\
\hline 85 & $S$ & $S$ & $S$ & $S$ & $\mathrm{~S}$ & $S$ & $S$ & S & $S$ & K-Factor & Numeric; Integer \\
\hline 86 & $S$ & $S$ & $S$ & $S$ & $S$ & $\mathrm{~s}$ & $\mathrm{~s}$ & S & $S$ & \begin{tabular}{|c|}
$\begin{array}{c}\text { Directional Fac- } \\
\text { tor }\end{array}$ \\
\end{tabular} & Numeric; Integer \\
\hline 87 & $S$ & $\mathrm{~s}$ & $\mathrm{~s}$ & $s$ & $S$ & $\mathrm{~s}$ & $\mathrm{~s}$ & S & $S$ & $\begin{array}{c}\text { Number of Peak } \\
\text { Lanes }\end{array}$ & Numeric; Integer \\
\hline 88 & & & & & $\mathrm{~S}$ & $S$ & $S$ & S & $S$ & $\begin{array}{l}\text { Left Turning } \\
\text { Lanes }\end{array}$ & Numeric; Codes \\
\hline 89 & & & & & $\mathrm{~S}$ & S & S & S & $S$ & $\begin{array}{l}\text { Right Turning } \\
\text { Lanes }\end{array}$ & Numeric; Codes \\
\hline 90 & & & & & $\mathrm{~s}$ & $\mathrm{~s}$ & $\mathrm{~s}$ & $\mathrm{~s}$ & $S$ & $\begin{array}{l}\text { Prevailing Type } \\
\text { of Signalization }\end{array}$ & Numeric; Codes \\
\hline 91 & & & & & $S$ & $S$ & $S$ & $\mathrm{~s}$ & $\mathrm{~s}$ & $\begin{array}{c}\text { Typical Peak } \\
\text { Percent Green } \\
\text { Time* }^{*}\end{array}$ & Numeric; Integer \\
\hline 92 & $\mathrm{~s}$ & $\mathrm{~S}$ & $S$ & $\mathrm{~s}$ & $\mathrm{~s}$ & $\mathrm{~s}$ & $\mathrm{~s}$ & $\mathrm{~s}$ & $\mathrm{~s}$ & $\begin{array}{c}\text { Number At- } \\
\text { Grade Intersec- } \\
\text { tions - Signals }\end{array}$ & Numeric; Integer \\
\hline
\end{tabular}


Table B.2 (Continued)

\begin{tabular}{|c|c|c|c|c|c|c|c|c|c|c|c|}
\hline \multirow{3}{*}{$\begin{array}{l}\text { Item } \\
\text { No. }\end{array}$} & \multicolumn{9}{|c|}{ Required Sample Items } & \multirow{3}{*}{ Data Item } & \multirow{3}{*}{ Data Type } \\
\hline & \multicolumn{4}{|c|}{ Rural } & \multicolumn{5}{|c|}{ Urban } & & \\
\hline & Int & OPA & MA & MAC & Int & OFE & OPA & MA & Col & & \\
\hline 93 & $\mathrm{~S}$ & $\mathrm{~S}$ & $\mathrm{~S}$ & $\mathrm{~s}$ & $\mathrm{~S}$ & $\mathrm{~S}$ & $\mathrm{~s}$ & $\mathrm{~s}$ & $S$ & \begin{tabular}{|c|} 
Number At- \\
Grade Intersec- \\
tions - Stop Sign
\end{tabular} & Numeric; Integer \\
\hline 94 & $\mathrm{~s}$ & $\mathrm{~s}$ & $\mathrm{~s}$ & $\mathrm{~s}$ & S & $s$ & $\mathrm{~s}$ & $\mathrm{~s}$ & $\mathrm{~s}$ & $\begin{array}{c}\text { Number At- } \\
\text { Grade Intersec- } \\
\text { tions - Other/No } \\
\text { Control }\end{array}$ & Numeric; Integer \\
\hline 95 & $\mathrm{~S}$ & S & $S$ & $\mathrm{~S}$ & $\mathrm{~S}$ & $\mathrm{~s}$ & $\mathrm{~S}$ & $S$ & $\mathrm{~S}$ & Peak Capacity & $\begin{array}{c}\begin{array}{c}\text { Software Calcu- } \\
\text { lated }\end{array} \\
\end{array}$ \\
\hline 96 & $S$ & S & $\mathrm{S}$ & $\mathrm{S}$ & $\mathrm{S}$ & $\mathrm{s}$ & $\mathrm{S}$ & S & S & $\begin{array}{c}\text { Volume/Service } \\
\text { Flow Ratio } \\
\text { (V/SF) }\end{array}$ & $\begin{array}{c}\text { Software Calcu- } \\
\text { lated }\end{array}$ \\
\hline 97 & $\mathrm{~S}$ & $\mathrm{~s}$ & $\mathrm{~S}$ & $\mathrm{~S}$ & $S$ & $\mathrm{~S}$ & $\mathrm{~S}$ & $\mathrm{~S}$ & $\mathrm{~S}$ & Future AADT & Numeric; Integer \\
\hline 98 & $S$ & $S$ & S & $S$ & S & $\mathrm{s}$ & $\mathrm{s}$ & $S$ & $S$ & $\begin{array}{c}\text { Year of Future } \\
\text { AADT }\end{array}$ & Numeric; Integer \\
\hline
\end{tabular}

A = Code for "All" universe, standard sample, and supplementary donut area sample sections.

$S=$ Code for all "Standard" sample sections.

$D=$ Code for all "Donut" area supplementary sample sections.

* $=$ See individual data item for exceptions.

Table B.3 Indiana Annual Employment, Year 2001

(Source: US Bureau of Economic Analysis

Provided by: Indiana Business Research Center, IU Kelley School of Business)

This table was produced by STATS Indiana: 9/5/2005 12:31:50 PM 


\begin{tabular}{|c|c|c|c|c|c|c|c|}
\hline NAICS & Industry & INDIANA & $\%$ & MSA & $\%$ & NON-MSA & $\%$ \\
\hline 0 & Total employment & $3,611,302$ & & $2,725,812$ & & 885,490 & \\
\hline 0 & Wage and salary employment & $3,053,716$ & & $2,347,236$ & & 706,480 & \\
\hline NA & Proprietor's employment & 557,586 & & 378,576 & & 179,010 & \\
\hline 0 & Farm proprietors employment & 62,898 & & 24,087 & & 38,811 & \\
\hline 0 & Nonfarm proprietors employment (see note $2 /$ below) & 494,688 & & 354,489 & & 140,199 & \\
\hline 0 & Farm employment & 77,322 & & 29,822 & & 47,500 & \\
\hline NA & Nonfarm employment & $3,533,980$ & & $2,695,990$ & & 837,990 & \\
\hline 0 & Private employment & $3,103,167$ & & $2,377,711$ & & 725,456 & \\
\hline 0 & Forestry, fishing, related activities, and other (see note $3 /$ below) & 8,373 & 0.270 & 1,328 & 0.056 & 1,105 & 0.152 \\
\hline 210000 & Mining & 9,518 & 0.307 & 2,057 & 0.087 & 3,446 & 0.475 \\
\hline 220000 & Utilities & 15,373 & 0.495 & 9,271 & 0.390 & 2,993 & 0.413 \\
\hline 230000 & Construction & 213,719 & 6.887 & 166,427 & 6.999 & 45,961 & 6.335 \\
\hline $31-33$ & Manufacturing & 627,897 & 20.234 & 416,219 & 17.505 & 211,177 & 29.110 \\
\hline 420000 & Wholesale trade & 132,877 & 4.282 & 107,930 & 4.539 & 18,520 & 2.553 \\
\hline $44-45$ & Retail Trade & 429,915 & 13.854 & 327,134 & 13.758 & 102,781 & 14.168 \\
\hline $48-49$ & Transportation and warehousing & 138,859 & 4.475 & 95,027 & 3.997 & 24,405 & 3.364 \\
\hline 510000 & Information & 51,676 & 1.665 & 42,678 & 1.795 & 8,860 & 1.221 \\
\hline 520000 & Finance and insurance & 138,268 & 4.456 & 116,368 & 4.894 & 21,026 & 2.898 \\
\hline 530000 & Real estate and rental and leasing & 98,379 & 3.170 & 79,180 & 3.330 & 18,622 & 2.567 \\
\hline 540000 & Professional and technical services & 142,377 & 4.588 & 118,802 & 4.996 & 16,933 & 2.334 \\
\hline 550000 & Management of companies and enterprises & 27,527 & 0.887 & 21,200 & 0.892 & 2,743 & 0.378 \\
\hline 560000 & Administrative and waste services & 168,862 & 5.442 & 138,739 & 5.835 & 24,865 & 3.427 \\
\hline 610000 & Educational services & 58,615 & 1.889 & 44,080 & 1.854 & 7,988 & 1.101 \\
\hline 620000 & Health care and social assistance & 338,122 & 10.896 & 260,129 & 10.940 & 41,768 & 5.757 \\
\hline 710000 & Arts, entertainment, and recreation & 67,327 & 2.170 & 51,392 & 2.161 & 9,147 & 1.261 \\
\hline 720000 & Accommodation and food services & 235,016 & 7.573 & 182,526 & 7.677 & 47,051 & 6.486 \\
\hline 810000 & Other services, except public administration & 200,467 & 6.460 & 150,326 & 6.322 & 48,786 & 6.725 \\
\hline 0 & Government and government enterprises & 430,813 & & 318,279 & & 112,534 & \\
\hline 0 & Federal, civilian & 37,573 & & 28,082 & & 9,491 & \\
\hline 0 & Military & 21,980 & & 16,135 & & 5,845 & \\
\hline 0 & State and local & 371,260 & & 274,062 & & 97,198 & \\
\hline 0 & State government & 111,330 & & $71,358^{*}$ & & $18,371^{*}$ & \\
\hline NA & Local government & 259,930 & & $173,750^{*}$ & & $76,812^{*}$ & \\
\hline
\end{tabular}


Table B.4 County-level Location Quotients for Selected Industries in Indiana, Year 2004 (Source: US BLS, 2005)

\begin{tabular}{|c|c|c|c|c|c|}
\hline \multirow[b]{2}{*}{ County / Industry } & \multicolumn{5}{|c|}{ LOCATION QUOTIENTS } \\
\hline & $\begin{array}{l}\text { NAICS } \\
23 \text { Con- } \\
\text { struction }\end{array}$ & $\begin{array}{c}\text { NAICS 31-33 } \\
\text { Manufactur- } \\
\text { ing }\end{array}$ & $\begin{array}{c}\text { NAICS } 42 \\
\text { Wholesale } \\
\text { trade }\end{array}$ & $\begin{array}{l}\text { NAICS } \\
44-45 \\
\text { Retail } \\
\text { trade }\end{array}$ & $\begin{array}{l}\text { NAICS 48-49 } \\
\text { Transporta- } \\
\text { tion and } \\
\text { warehousing }\end{array}$ \\
\hline Indiana_Statewide & 0.95 & 1.77 & 0.94 & 0.98 & 1.12 \\
\hline Allen County & 1.03 & 0.79 & 1.36 & 0.92 & 1.02 \\
\hline Bartholomew County & 0.74 & 1.73 & 0.54 & 0.86 & 1.06 \\
\hline Boone County & 2.57 & 0.67 & 1.8 & 0.92 & 1.76 \\
\hline Brown County & ND & 0.44 & 0.32 & 1.5 & ND \\
\hline Carroll County & 0.91 & 1.89 & 0.9 & 0.81 & ND \\
\hline Clark County & 1.18 & 0.87 & 0.79 & 1.25 & 2.85 \\
\hline Clinton County & 0.79 & 1.95 & 0.5 & 0.78 & ND \\
\hline Daviess County & 1.56 & 1.03 & 1.23 & 0.97 & 1.44 \\
\hline Decatur County & 0.49 & 1.96 & 0.7 & 0.87 & 0.47 \\
\hline Dubois County & 0.75 & 1.96 & 0.96 & 0.89 & 0.87 \\
\hline Elkhart County & 0.66 & 2.34 & 1.06 & 0.59 & 0.39 \\
\hline Hamilton County & 1.52 & 0.31 & 1.42 & 1.06 & 0.14 \\
\hline Hancock County & 1.85 & 0.87 & 1.16 & 1.06 & 0.86 \\
\hline Harrison County & 0.69 & 1.06 & 0.53 & 1.17 & 0.41 \\
\hline Hendricks County & 1.41 & 0.27 & 1.66 & 1.5 & 3.04 \\
\hline Henry County & 1.09 & 1.12 & 0.76 & 1.45 & 0.33 \\
\hline Howard County & 0.52 & 1.8 & 0.45 & 1.11 & 0.31 \\
\hline Jackson County & 0.59 & 1.64 & 0.57 & 0.94 & 3.21 \\
\hline Jasper County & 1.7 & 0.62 & ND & 1.08 & 2.51 \\
\hline Jay County & 0.5 & 1.96 & 0.54 & 0.76 & ND \\
\hline Jennings County & 1.72 & 1.43 & 0.61 & 0.73 & 3.19 \\
\hline Johnson County & 1.32 & 0.72 & 0.6 & 1.61 & 1.13 \\
\hline Lake County & 1.27 & 0.69 & 0.78 & 1.12 & 0.94 \\
\hline La Porte County & 0.96 & 1.06 & ND & 1.11 & ND \\
\hline Lawrence County & 0.65 & 1.4 & 0.37 & 1.28 & 0.49 \\
\hline Madison County & 0.75 & 0.85 & ND & 1.15 & 1.09 \\
\hline Marion County & 0.98 & 0.61 & 1.21 & 0.83 & 1.48 \\
\hline Marshall County & 0.6 & 1.75 & 0.65 & 0.84 & ND \\
\hline Martin County & ND & 0.96 & 0.57 & 0.98 & 2.22 \\
\hline Monroe County & 1.08 & 0.72 & 0.72 & 1.16 & 0.41 \\
\hline Montgomery County & 0.54 & 1.74 & 1.01 & 0.88 & 0.9 \\
\hline Morgan County & 1.97 & 0.81 & 0.51 & 1.51 & 0.26 \\
\hline Owen County & 0.92 & 1.81 & ND & 1.01 & 0.7 \\
\hline Porter County & 1.45 & 0.87 & 1.14 & 1.07 & ND \\
\hline Putnam County & 0.6 & 1.26 & 0.31 & 0.95 & ND \\
\hline
\end{tabular}


Table B.4. (Continued)

\begin{tabular}{|c|c|c|c|c|c|}
\hline & \multicolumn{5}{|c|}{ LOCATION QUOTIENTS } \\
\hline County / Industry & $\begin{array}{c}\text { NAICS } \\
\text { 23 Con- } \\
\text { struction }\end{array}$ & $\begin{array}{c}\text { NAICS 31-33 } \\
\text { Manufactur- } \\
\text { ing }\end{array}$ & $\begin{array}{c}\text { NAICS 42 } \\
\text { Wholesale } \\
\text { trade }\end{array}$ & $\begin{array}{c}\text { NAICS } \\
44-45 \\
\text { Retail } \\
\text { trade }\end{array}$ & $\begin{array}{c}\text { NAICS 48-49 } \\
\text { Transporta- } \\
\text { tion and } \\
\text { warehousing }\end{array}$ \\
\hline Randolph County & 0.75 & 1.65 & 1 & 0.81 & 0.59 \\
\hline Ripley County & 0.9 & 1.08 & 0.2 & 0.71 & 1.09 \\
\hline Rush County & 1.2 & 1.45 & 0.93 & 0.99 & 1.35 \\
\hline Shelby County & 1.05 & 1.63 & 0.84 & 0.83 & 1.33 \\
\hline St. Joseph County & 0.92 & 0.72 & 1.15 & 1.02 & ND \\
\hline Spencer County & 0.61 & 1.13 & 1.56 & 0.69 & ND \\
\hline Tippecanoe County & 0.98 & 1.11 & 0.49 & 1.18 & 0.61 \\
\hline Vanderburgh County & 1.2 & 0.68 & 1.02 & 1 & 1.12 \\
\hline Vigo County & 0.93 & 0.78 & 0.62 & 1.3 & 0.6 \\
\hline Wabash County & 0.74 & 1.66 & 0.74 & 0.85 & 0.25 \\
\hline Warrick County & 1.71 & 1.08 & 0.61 & 0.85 & 0.75 \\
\hline Washington County & 1.23 & 1.79 & 0.71 & 1.02 & 0.36 \\
\hline Wayne County & 0.55 & 1.23 & 0.76 & 1.16 & 0.89 \\
\hline
\end{tabular}


Table B.5 Freeway Speeds on an Average Weekday (miles per hour) (Source: Choocharukul, 2000)

\begin{tabular}{|c|c|c|c|c|c|c|c|c|c|c|c|c|c|c|c|c|}
\hline \multirow{2}{*}{$\begin{array}{l}\text { Hour } \\
\text { Ending }\end{array}$} & \multicolumn{16}{|c|}{ Ratio of Average Weekday Traffic to Capacity (AWDT/C) } \\
\hline & 1 & 2 & 3 & 4 & 5 & 6 & 7 & 8 & 9 & 10 & 11 & 12 & 13 & 14 & 15 & 16 \\
\hline 1 & 59.94 & 59.89 & 59.84 & 59.78 & 59.72 & 59.67 & 59.61 & 59.55 & 59.49 & 59.43 & 59.37 & 59.30 & 59.22 & 58.96 & 58.65 & 58.27 \\
\hline 2 & 59.97 & 59.94 & 59.90 & 59.87 & 59.84 & 59.80 & 59.77 & 59.74 & 59.70 & 59.66 & 59.64 & 59.60 & 59.55 & 59.30 & 59.00 & 58.65 \\
\hline 3 & 59.97 & 59.95 & 59.93 & 59.90 & 59.87 & 59.85 & 59.82 & 59.80 & 59.77 & 59.75 & 59.72 & 59.70 & 59.67 & 59.42 & 59.13 & 58.78 \\
\hline 4 & 59.97 & 59.95 & 59.93 & 59.91 & 59.88 & 59.86 & 59.84 & 59.82 & 59.80 & 59.78 & 59.77 & 59.76 & 59.73 & 59.50 & 59.21 & 58.87 \\
\hline 5 & 59.96 & 59.93 & 59.89 & 59.86 & 59.82 & 59.78 & 59.75 & 59.71 & 59.69 & 59.66 & 59.64 & 59.63 & 59.59 & 59.35 & 59.06 & 58.71 \\
\hline 6 & 59.89 & 59.80 & 59.69 & 59.58 & 59.47 & 59.35 & 59.23 & 59.12 & 59.01 & 58.91 & 58.80 & 58.69 & 58.57 & 58.29 & 57.98 & 57.66 \\
\hline 7 & 59.70 & 59.41 & 59.08 & 58.73 & 58.37 & 57.98 & 57.56 & 57.15 & 56.73 & 56.25 & 55.69 & 54.99 & 53.83 & 52.51 & 50.16 & 48.57 \\
\hline 8 & 59.54 & 59.09 & 58.56 & 57.99 & 57.37 & 56.73 & 55.93 & 54.28 & 50.56 & 45.38 & 40.77 & 36.86 & 33.74 & 30.01 & 27.34 & 25.30 \\
\hline 9 & 59.65 & 59.33 & 58.94 & 58.54 & 58.11 & 57.66 & 57.09 & 55.52 & 50.75 & 43.57 & 37.21 & 31.99 & 27.87 & 24.56 & 22.23 & 20.58 \\
\hline 10 & 59.74 & 59.49 & 59.21 & 58.92 & 58.60 & 58.28 & 57.94 & 57.53 & 56.10 & 51.18 & 42.26 & 33.40 & 27.54 & 24.01 & 21.74 & 19.98 \\
\hline 11 & 59.74 & 59.50 & 59.22 & 58.93 & 58.62 & 58.30 & 57.97 & 57.61 & 57.20 & 56.43 & 53.15 & 44.21 & 33.55 & 27.24 & 23.88 & 21.31 \\
\hline 12 & 59.72 & 59.46 & 59.16 & 58.84 & 58.51 & 58.16 & 57.79 & 57.40 & 56.97 & 56.51 & 55.73 & 52.24 & 42.13 & 32.77 & 26.97 & 23.04 \\
\hline 13 & 59.71 & 59.43 & 59.12 & 58.78 & 58.43 & 58.06 & 57.67 & 57.26 & 56.82 & 56.35 & 55.83 & 54.14 & 47.63 & 38.06 & 29.75 & 24.01 \\
\hline 14 & 59.70 & 59.42 & 59.10 & 58.76 & 58.39 & 58.01 & 57.62 & 57.19 & 56.73 & 56.24 & 55.69 & 54.42 & 50.14 & 41.55 & 31.60 & 24.47 \\
\hline 15 & 59.67 & 59.35 & 58.99 & 58.60 & 58.20 & 57.76 & 57.31 & 56.83 & 56.34 & 55.79 & 55.02 & 53.21 & 48.32 & 40.17 & 30.24 & 23.18 \\
\hline 16 & 59.59 & 59.20 & 58.74 & 58.26 & 57.73 & 57.17 & 56.59 & 56.00 & 55.32 & 54.17 & 51.64 & 46.85 & 40.12 & 32.39 & 24.88 & 19.91 \\
\hline 17 & 59.52 & 59.06 & 58.52 & 57.92 & 57.29 & 56.62 & 55.80 & 54.49 & 52.00 & 47.41 & 40.97 & 34.47 & 28.87 & 23.98 & 19.70 & 17.11 \\
\hline 18 & 59.52 & 59.06 & 58.51 & 57.91 & 57.27 & 56.59 & 55.54 & 53.38 & 48.91 & 42.11 & 34.96 & 28.97 & 24.31 & 20.74 & 17.79 & 16.12 \\
\hline 19 & 59.67 & 59.35 & 59.00 & 58.62 & 58.20 & 57.78 & 57.14 & 55.59 & 51.35 & 43.65 & 35.04 & 28.17 & 23.30 & 20.01 & 17.40 & 15.91 \\
\hline 20 & 59.77 & 59.55 & 59.31 & 59.05 & 58.78 & 58.49 & 58.20 & 57.85 & 56.99 & 53.65 & 45.43 & 34.53 & 26.26 & 21.79 & 18.37 & 16.34 \\
\hline 21 & 59.82 & 59.65 & 59.46 & 59.26 & 59.05 & 58.84 & 58.62 & 58.39 & 58.15 & 57.77 & 55.98 & 49.27 & 37.48 & 28.67 & 22.29 & 18.19 \\
\hline 22 & 59.83 & 59.68 & 59.51 & 59.33 & 59.14 & 58.95 & 58.75 & 58.54 & 58.29 & 58.02 & 57.71 & 56.74 & 52.66 & 43.71 & 32.53 & 23.25 \\
\hline 23 & 59.86 & 59.74 & 59.60 & 59.46 & 59.31 & 59.16 & 59.00 & 58.82 & 58.61 & 58.39 & 58.18 & 57.92 & 57.33 & 54.59 & 46.24 & 32.38 \\
\hline 24 & 59.90 & 59.81 & 59.71 & 59.60 & 59.49 & 59.38 & 59.27 & 59.14 & 58.99 & 58.83 & 58.68 & 58.52 & 58.33 & 57.79 & 55.68 & 45.68 \\
\hline Peak & 59.59 & 59.20 & 58.74 & 58.24 & 57.71 & 57.14 & 56.39 & 54.88 & 51.27 & 45.16 & 38.26 & 32.07 & 27.27 & 23.52 & 20.57 & 18.69 \\
\hline Off-Peak & 59.74 & 59.50 & 59.21 & 58.92 & 58.60 & 58.27 & 57.92 & 57.56 & 57.12 & 56.38 & 54.57 & 50.31 & 43.23 & 36.40 & 30.20 & 25.44 \\
\hline Daily & 59.68 & 59.37 & 59.02 & 58.64 & 58.23 & 57.80 & 57.28 & 56.43 & 54.58 & 51.24 & 46.62 & 41.11 & 35.30 & 30.31 & 25.95 & 22.71 \\
\hline
\end{tabular}




\section{Counties}

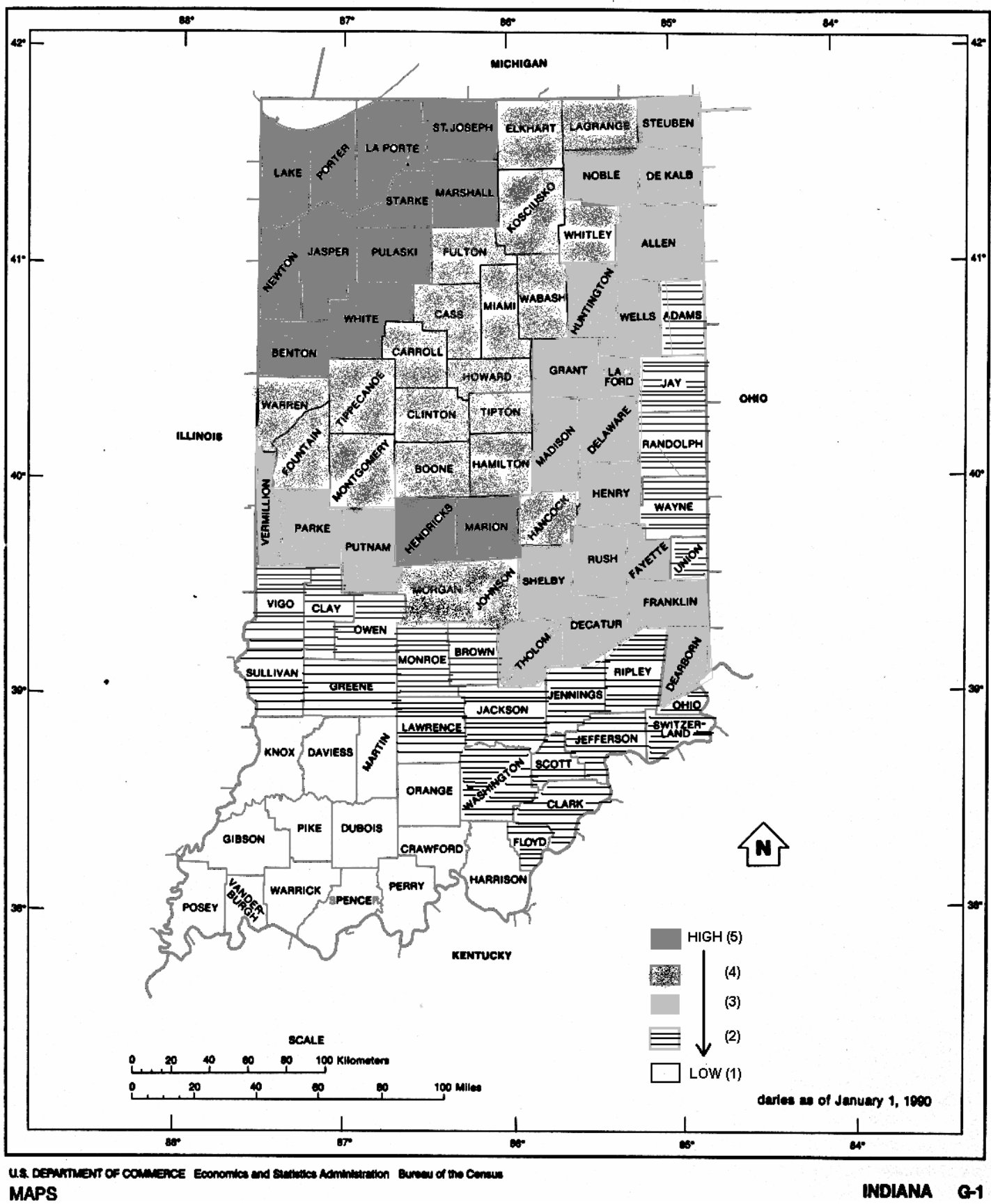

Figure B.1 Indiana Accessibility to Major Airports

(Adapted from: CSI and BLA, 2003) 
Counties

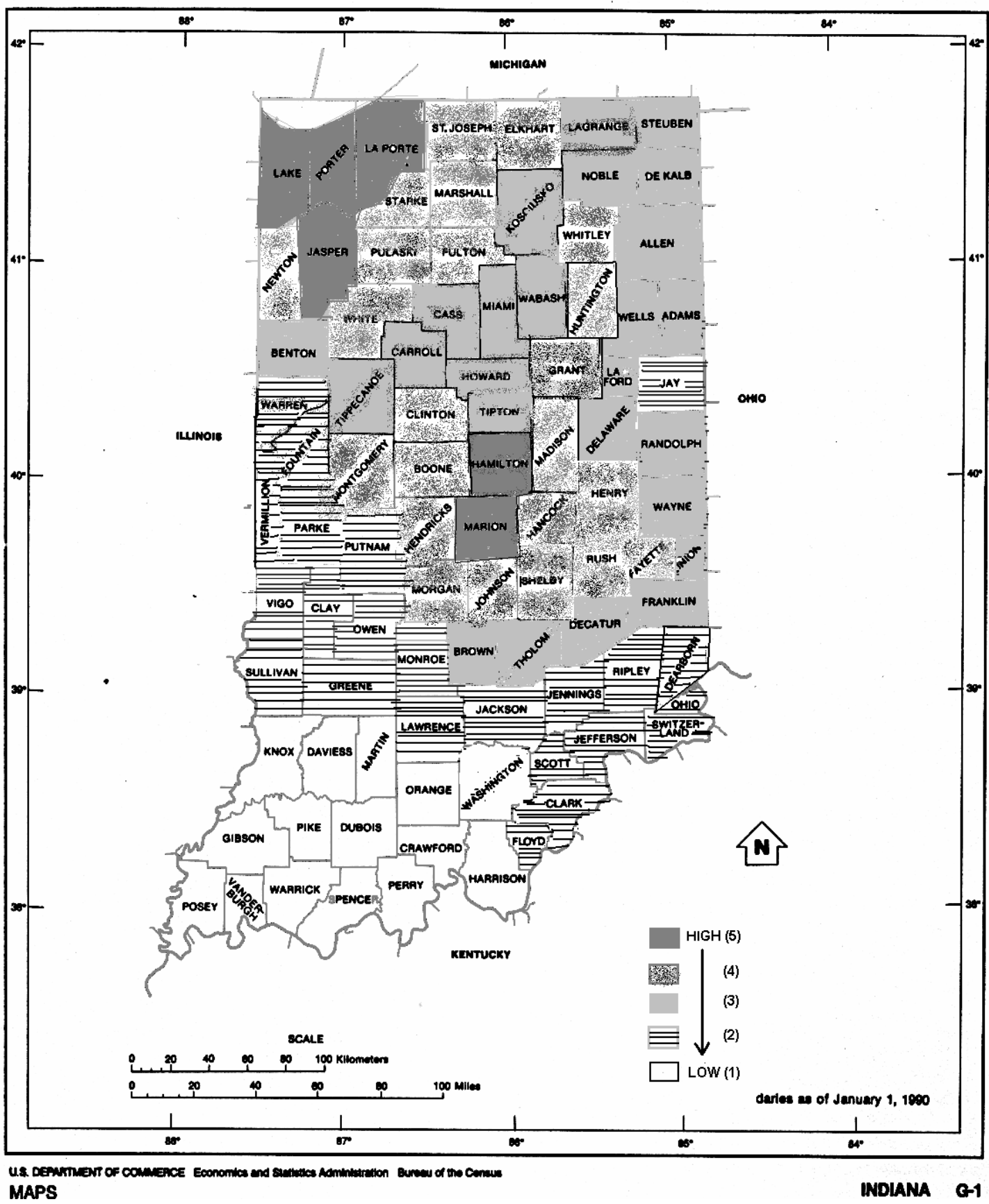

Figure B.2 Indiana Accessibility to Employment

(Adapted from: CSI and BLA, 2003) 


\section{Counties}

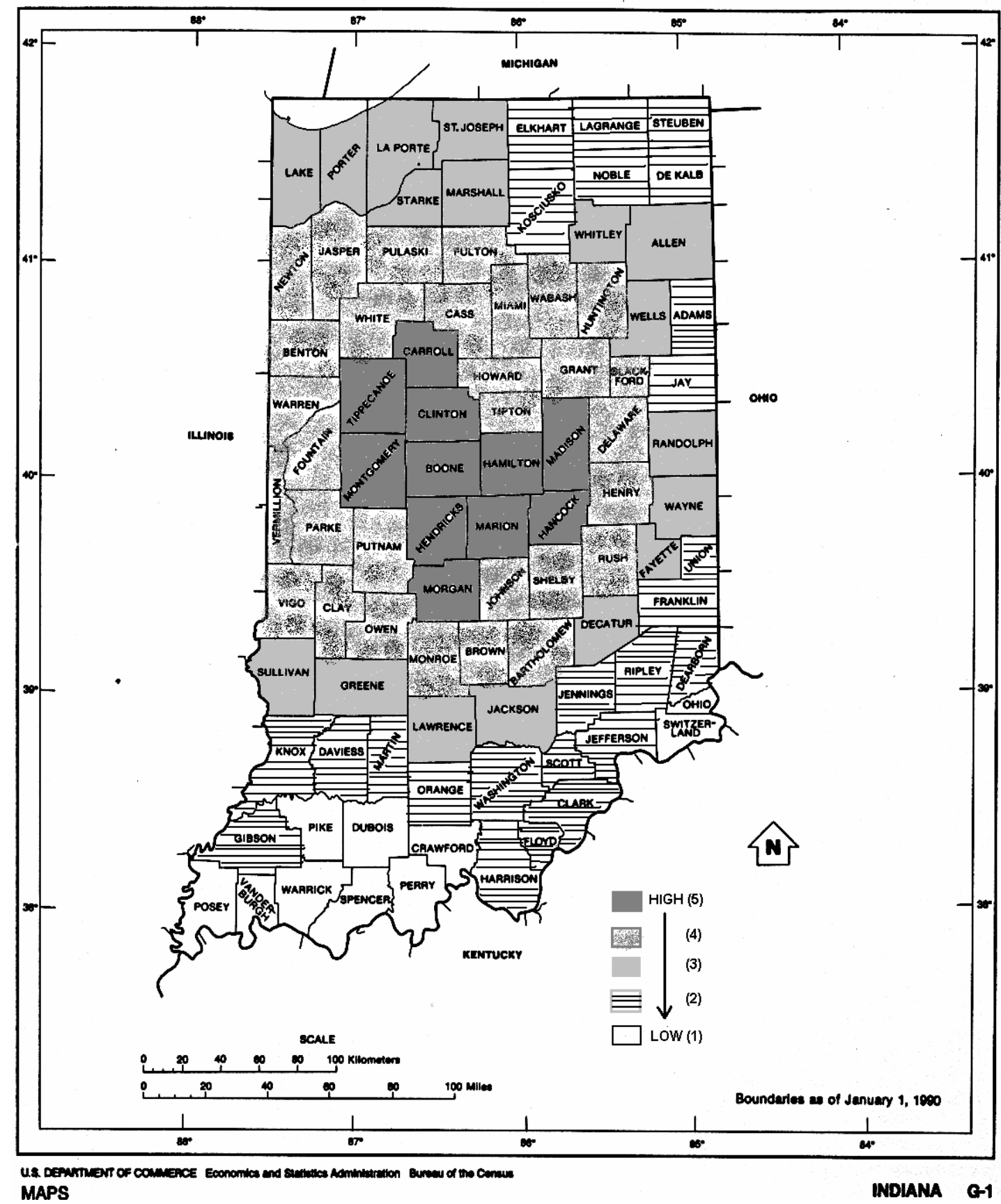

Figure B.3 Indiana Accessibility to Institutions of Higher Education

(Adapted from: CSI and BLA, 2003) 
Counties

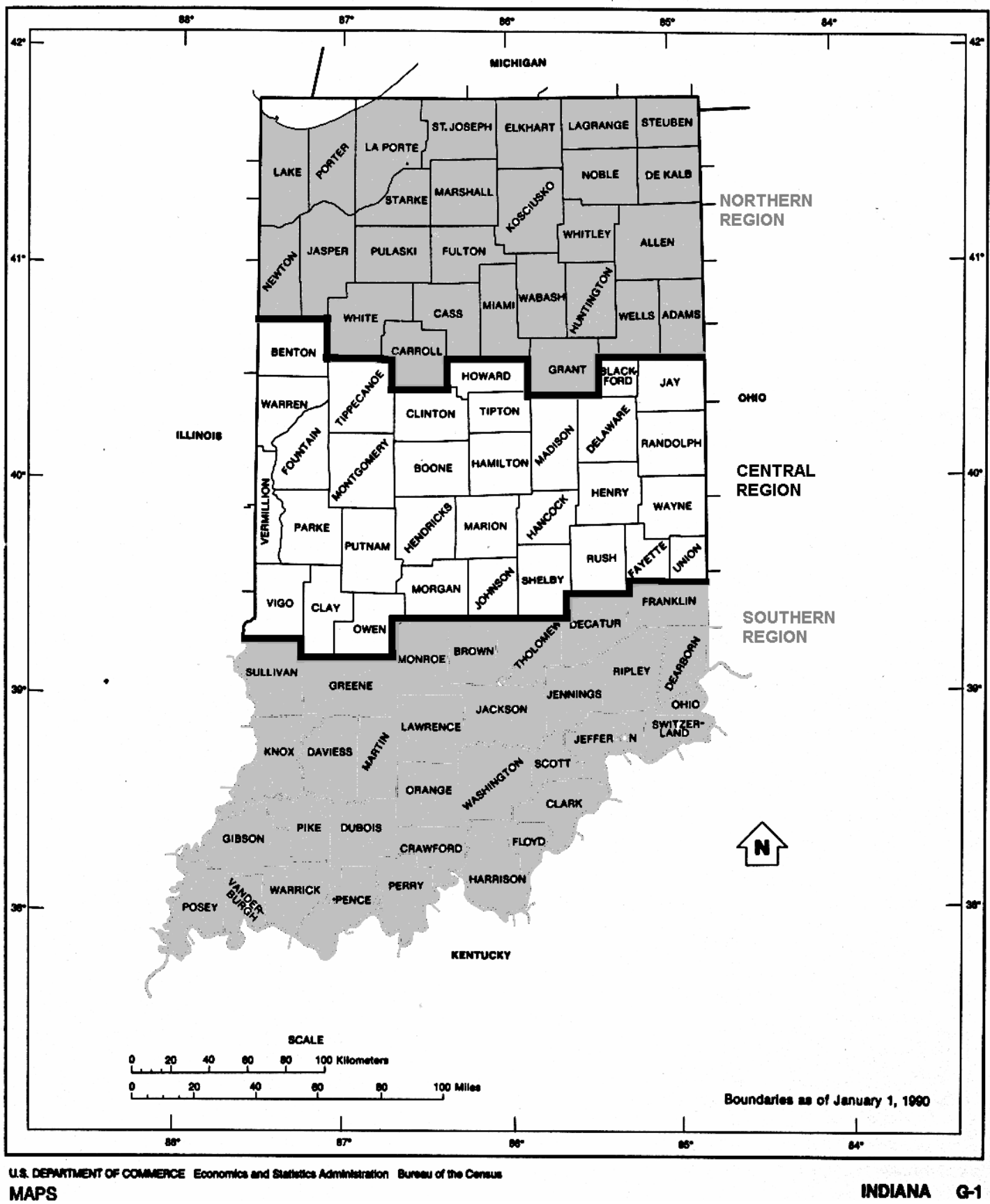

Figure B.4 Indiana County Classification 


\section{Countios}

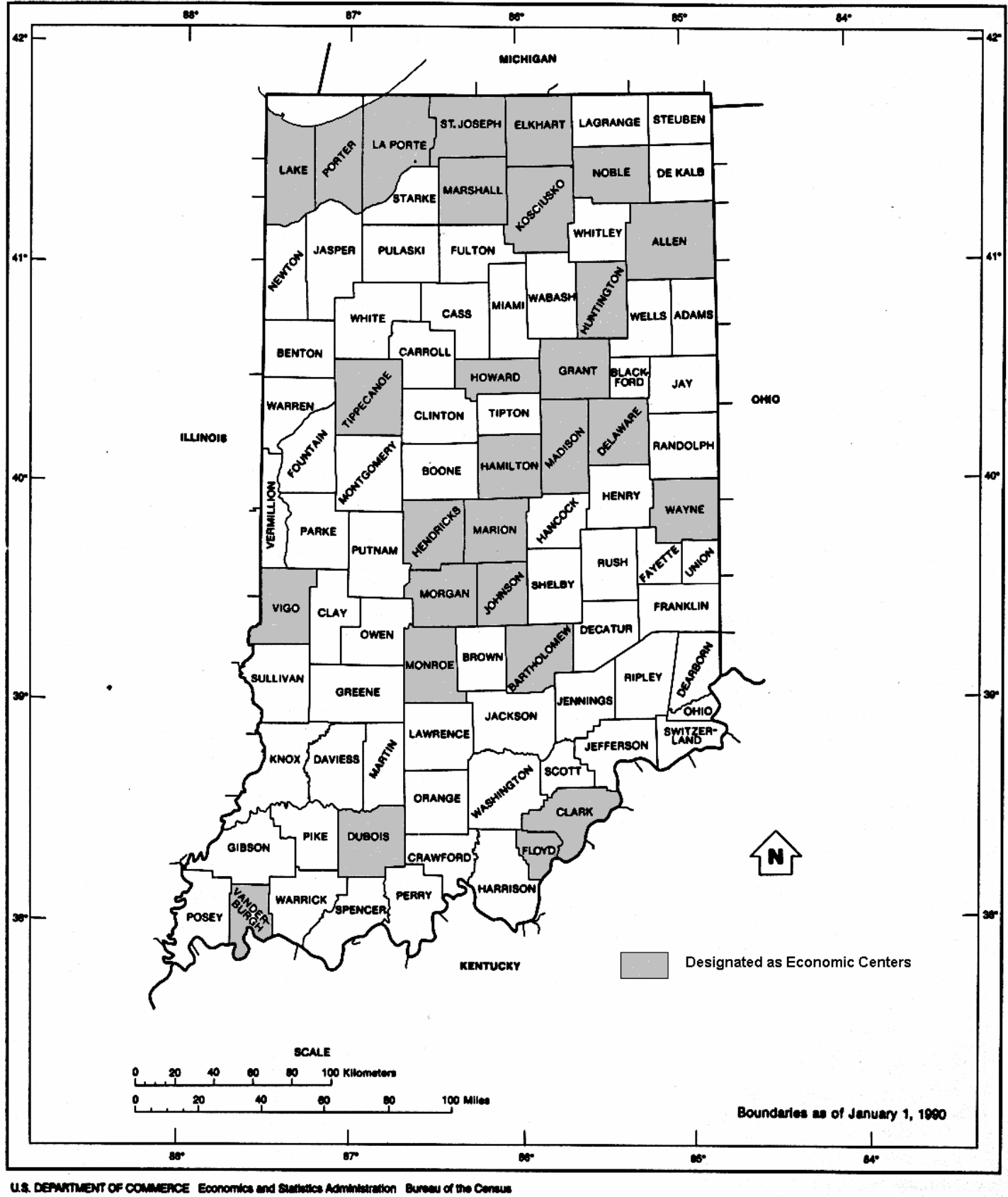

MAPS

WDIANA G-1

Figure B.5 Indiana Counties Designated as Economic Centers for Transportation Planning Purposes (Adapted from: CSI and BLA, 2003) 


\section{Appendix C.}

Table C.1 Regression Model Estimation Results for Long term Change in Business Sales (in millions 2001\$)

\begin{tabular}{|c|c|c|c|}
\hline & Coefficient & $t$-ratio & $P$-value \\
\hline Constant & -260 & -3.443 & 0.004 \\
\hline Project Costs (in millions 2001\$) & 0.179 & 5.697 & 0.000 \\
\hline Economic Center Indicator & 3.239 & 3.253 & 0.005 \\
\hline Number of observations & \multicolumn{3}{|c|}{17} \\
\hline$R^{2}$ & & 0.732 \\
\hline Adjusted $R^{2}$ & \multicolumn{3}{|c}{0.697} \\
\hline
\end{tabular}

Table C.2 Regression Model Estimation Results for Long term Change in Employment

\begin{tabular}{|c|c|c|c|}
\hline & Coefficient & $t$-ratio & $P$-value \\
\hline Constant & -2629.466 & -2.311 & 0.035 \\
\hline Project Length & 34.592 & 4.296 & 0.001 \\
\hline Interstate Indicator & 1240.806 & 2.167 & 0.046 \\
\hline $\begin{array}{l}\text { Geographic Location Indicator } 1 \text { (1 if Southeast } \\
\text { Indiana, 0 otherwise) }\end{array}$ & 1964.924 & 1.982 & 0.065 \\
\hline $\begin{array}{c}\text { Geographic Location Indicator } 2 \text { (1 if Central } \\
\text { Indiana, 0 otherwise) }\end{array}$ & 955.029 & 1.128 & 0.276 \\
\hline Number of observations & \multicolumn{3}{|c|}{21} \\
\hline$R^{2}$ & \multicolumn{3}{|c|}{0.914} \\
\hline Adjusted $R^{2}$ & \multicolumn{3}{|c|}{0.892} \\
\hline
\end{tabular}


Table C.3 Regression Model Estimation Results for Long term Change in Real Disposable Income (in millions 2001\$)

\begin{tabular}{|c|c|c|c|}
\hline & Coefficient & $t$-ratio & $P$-value \\
\hline Constant & -20.0 & -2.828 & 0.011 \\
\hline Project Costs (in millions 2001\$) & 0.098 & 17.279 & 0.000 \\
\hline $\begin{array}{c}\text { Geographic Location Indicator 1 } \\
\text { (1 if Southeast Indiana, 0 otherwise) }\end{array}$ & 24.0 & 2.246 & 0.038 \\
\hline Number of observations & \multicolumn{3}{|c|}{21} \\
\hline$R^{2}$ & \multicolumn{3}{|c|}{0.953} \\
\hline Adjusted $R^{2}$ & \multicolumn{3}{|c}{} \\
\hline
\end{tabular}

Table C.4 Regression Model Estimation Results for Potential Business Attraction (in millions $2001 \$$ in business sales)

\begin{tabular}{|c|c|c|c|}
\hline & Coefficient & $t$-ratio & $P$-value \\
\hline Constant & -40 & -0.271 & 0.792 \\
\hline Project Length & 2.53 & 1.659 & 0.131 \\
\hline Business Cost Savings (in millions 2001\$) & 14.62 & 2.838 & 0.019 \\
\hline Number of observations & \multicolumn{3}{|c|}{12} \\
\hline$R^{2}$ & \multicolumn{3}{|c|}{0.930} \\
\hline Adjusted $R^{2}$ & 0.864 \\
\hline
\end{tabular}

Table C.5 Regression Model Estimation Results for Potential Tourism Attraction (change in annual visitor-days)

\begin{tabular}{|c|c|c|c|}
\hline & Coefficient & $t$-ratio & $P$-value \\
\hline Constant & - & - & - \\
\hline $\begin{array}{c}\text { Potential Business Attraction } \\
\text { (in millions 2001\$ in business sales) }\end{array}$ & 0.996 & 39.306 & 0.000 \\
\hline Number of observations & \multicolumn{3}{|c|}{12} \\
\hline$R^{2}$ & \multicolumn{3}{|c|}{0.996} \\
\hline Adjusted $R^{2}$ & \multicolumn{3}{|c|}{093} \\
\hline
\end{tabular}




\section{Appendix D.}

Table D.1 SURE Estimation Results for Highway Investments Involving Adding Travel Lanes (Scenario $4^{*}$ )

\begin{tabular}{|c|c|c|}
\hline \multicolumn{3}{|c|}{ Dependent Variable: REMIEMP } \\
\hline & Coefficient & $t$-statistic \\
\hline Constant & -156.0 & -1.36 \\
\hline NEWLNMI & 10.561 & 4.42 \\
\hline URBAN & -168.400 & -6.91 \\
\hline I & 347.207 & 4.90 \\
\hline ACCAIRP & 43.747 & 1.60 \\
\hline CENTRAL & -90.862 & -2.63 \\
\hline \multicolumn{3}{|c|}{ Dependent Variable: REMINCMI } \\
\hline Constant & -8.713 & -1.46 \\
\hline NEWLNMI & 0.514 & 4.16 \\
\hline RESTURBAN & -4.510 & -4.19 \\
\hline $\mathrm{I}$ & 14.075 & 3.82 \\
\hline ACCAIRP & 2.041 & 1.44 \\
\hline CENTRAL & -3.784 & -2.21 \\
\hline PRCOSTMI & 0.022 & 1.75 \\
\hline \multicolumn{3}{|c|}{ Dependent Variable: REMIOUTMI } \\
\hline Constant & -77.005 & -2.35 \\
\hline NEWLNMI & 3.007 & 4.35 \\
\hline URBAN & -17.934 & -1.69 \\
\hline I & 65.847 & 3.33 \\
\hline ACCAIRP & 15.972 & 2.08 \\
\hline \multicolumn{3}{|c|}{ Dependent Variable: REMIGRPMI } \\
\hline Constant & -27.211 & -1.12 \\
\hline NEWLNMI & 2.177 & 4.79 \\
\hline RESTURBAN & -16.155 & -1.48 \\
\hline I & 21.425 & 1.42 \\
\hline ST & -19.253 & -1.48 \\
\hline ACCAIRP & 8.126 & 1.56 \\
\hline CENTRAL & -22.437 & -1.79 \\
\hline Number of Observations & \multicolumn{2}{|c|}{58} \\
\hline Adjusted R-squared-Equation for REMIEMP & \multicolumn{2}{|c|}{0.545} \\
\hline Adjusted R-squared-Equation for REMIINCMI & \multicolumn{2}{|c|}{0.470} \\
\hline Adjusted R-squared-Equation for REMIOUTMI & \multicolumn{2}{|c|}{0.465} \\
\hline Adjusted R-squared-Equation for REMIGRPMI & \multicolumn{2}{|c|}{0.399} \\
\hline
\end{tabular}

potential of business attraction for rural projects based on (CSI, 1996b). 
Table D.2 SURE Estimation Results for Highway Investments Involving Adding Travel Lanes (Scenario $3^{*}$ )

\begin{tabular}{|c|c|c|}
\hline \multicolumn{3}{|c|}{ Dependent Variable: REMIEMP } \\
\hline & Coefficient & $t$-statistic \\
\hline Constant & -205.567 & -1.98 \\
\hline NEWLNMI & 6.921 & 3.22 \\
\hline URBAN & -36.035 & -2.76 \\
\hline I & 150.427 & 2.39 \\
\hline ACCAIRP & 33.831 & 1.38 \\
\hline CENTRAL & -21.900 & -1.61 \\
\hline \multicolumn{3}{|c|}{ Dependent Variable: REMINCMI } \\
\hline Constant & -10.871 & -2.08 \\
\hline NEWLNMI & 0.306 & 2.84 \\
\hline URBCENTR & 2.160 & 2.58 \\
\hline I & 8.195 & 2.59 \\
\hline ACCAIRP & 2.099 & 1.71 \\
\hline ACUNIVNS & 0.438 & 1.78 \\
\hline \multicolumn{3}{|c|}{ Dependent Variable: REMIOUTMI } \\
\hline Constant & -67.350 & -2.44 \\
\hline NEWLNMI & 1.967 & 3.46 \\
\hline I & 40.976 & 2.47 \\
\hline ACCAIRP & 11.411 & 1.75 \\
\hline \multicolumn{3}{|c|}{ Dependent Variable: REMIGRPMI } \\
\hline Constant & -29.140 & -2.36 \\
\hline NEWLNMI & 0.925 & 3.64 \\
\hline RESTURBAN & -2.029 & -2.38 \\
\hline I & 22.038 & 2.97 \\
\hline ACCAIRP & 5.152 & 1.77 \\
\hline CENTRAL & -3.257 & -2.77 \\
\hline Number of Observations & \multicolumn{2}{|c|}{58} \\
\hline Adjusted R-squared-Equation for REMIEMP & \multicolumn{2}{|c|}{0.252} \\
\hline Adjusted R-squared-Equation for REMIINCMI & \multicolumn{2}{|c|}{0.290} \\
\hline Adjusted R-squared-Equation for REMIOUTMI & \multicolumn{2}{|c|}{0.319} \\
\hline Adjusted R-squared-Equation for REMIGRPMI & \multicolumn{2}{|c|}{0.339} \\
\hline
\end{tabular}

potential of business attraction proportional to that of business expansion by a factor of $L Q$. 
Table D.3 SURE Estimation Results on Economic Development Benefit/Cost Ratios of Added-Capacity Projects (Scenario $4^{*}$ )

\begin{tabular}{|c|c|c|}
\hline \multicolumn{3}{|c|}{ Dependent Variable: JOBPER96\$ } \\
\hline & Coefficient & $t$-statistic \\
\hline Constant & 1.423 & 0.97 \\
\hline NEWLNMI & 0.073 & 2.68 \\
\hline URBAN & -4.263 & -4.27 \\
\hline $\mathrm{I}$ & 1.299 & 2.89 \\
\hline ACCAIRP & 0.723 & 2.04 \\
\hline RURSOUTH & 1.007 & 1.96 \\
\hline \multicolumn{3}{|c|}{ Dependent Variable: INCPER96\$ } \\
\hline Constant & 0.127 & 1.52 \\
\hline URBAN & -0.191 & -2.79 \\
\hline ACCAIRP & 0.062 & 2.47 \\
\hline ACUNIVNS & 0.040 & 3.08 \\
\hline RURST & -0.073 & -1.44 \\
\hline \multicolumn{3}{|c|}{ Dependent Variable: OUTPER96\$ } \\
\hline Constant & -0.074 & -0.20 \\
\hline NEWLNMI & 0.023 & 3.88 \\
\hline URBAN & -0.765 & -2.83 \\
\hline ACCAIRP & 0.250 & 2.42 \\
\hline ACEMP345 & 0.305 & 2.40 \\
\hline \multicolumn{3}{|c|}{ Dependent Variable: GRPPER96\$ } \\
\hline Constant & 0.082 & 0.27 \\
\hline NEWLNMI & 0.018 & 3.02 \\
\hline URBAN & -0.493 & -2.51 \\
\hline ACCAIRP & 0.160 & 2.34 \\
\hline CENTRAL & -0.214 & -1.48 \\
\hline RURST & -0.335 & -1.78 \\
\hline \multicolumn{3}{|l|}{ Number of Observations } \\
\hline Adjusted R-squared-Equation for JOBPER96\$ & \multicolumn{2}{|c|}{0.366} \\
\hline Adjusted R-squared-Equation for INCPER96\$ & \multicolumn{2}{|c|}{0.115} \\
\hline Adjusted R-squared-Equation for OUTPER96\$ & \multicolumn{2}{|c|}{0.250} \\
\hline Adjusted R-squared-Equation for GRPPER96\$ & \multicolumn{2}{|c|}{0.279} \\
\hline
\end{tabular}

potential of business attraction for rural projects based on (CSI, 1996b). 
Table D.4 SURE Estimation Results on Economic Development Benefit/Cost Ratios of Added-Capacity Projects (Scenario $3^{*}$ )

\begin{tabular}{|c|c|c|}
\hline \multicolumn{3}{|c|}{ Dependent Variable: JOBPER96\$ } \\
\hline & Coefficient & $t$-statistic \\
\hline Constant & -0.924 & -1.15 \\
\hline NEWLNMI & 0.055 & 3.44 \\
\hline ACCAIRP & 0.369 & 2.21 \\
\hline \multicolumn{3}{|c|}{ Dependent Variable: INCPER96\$ } \\
\hline Constant & -0.023 & -0.36 \\
\hline ACCAIRP & 0.049 & 2.80 \\
\hline ACUNIVNS & 0.008 & 1.44 \\
\hline \multicolumn{3}{|c|}{ Dependent Variable: OUTPER96\$ } \\
\hline Constant & -0.385 & -1.90 \\
\hline NEWLNMI & 0.013 & 4.21 \\
\hline ACCAIRP & 0.177 & 3.52 \\
\hline ACEMP345 & 0.071 & 1.70 \\
\hline \multicolumn{3}{|c|}{ Dependent Variable: GRPPER96\$ } \\
\hline Constant & -0.150 & -1.58 \\
\hline NEWLNMI & 0.006 & 4.43 \\
\hline ACCAIRP & 0.088 & 3.74 \\
\hline RURST & -0.022 & -1.48 \\
\hline Number of Observations & \multicolumn{2}{|c|}{58} \\
\hline Adjusted R-squared-Equation for JOBPER96\$ & \multicolumn{2}{|c|}{0.111} \\
\hline Adjusted R-squared-Equation for INCPER96\$ & \multicolumn{2}{|c|}{0.096} \\
\hline Adjusted R-squared-Equation for OUTPER96\$ & \multicolumn{2}{|c|}{0.148} \\
\hline Adjusted R-squared-Equation for GRPPER96\$ & \multicolumn{2}{|c|}{0.130} \\
\hline
\end{tabular}

potential of business attraction proportional to that of business expansion by a factor of $L Q$. 
Table D.5 SURE Estimation Results for Highway Investments Involving New Construction-Related Projects (Scenario 4*)

\begin{tabular}{|c|c|c|}
\hline \multicolumn{3}{|c|}{ Dependent Variable: REMIEMP } \\
\hline & Coefficient & $t$-statistic \\
\hline Constant & 10.418 & 0.64 \\
\hline PRLENNRC & 4.022 & 1.75 \\
\hline I & 225.242 & 4.54 \\
\hline ACEMPI45 & 175.443 & 3.55 \\
\hline SOUTHNRC & 18.412 & 2.73 \\
\hline \multicolumn{3}{|c|}{ Dependent Variable: REMINCMI } \\
\hline Constant & 2.142 & 1.86 \\
\hline PRLENNRC & 0.284 & 1.59 \\
\hline $\mathrm{I}$ & 19.366 & 5.05 \\
\hline ACEMPI45 & 19.337 & 4.98 \\
\hline URBU & 0.648 & 2.12 \\
\hline $\mathrm{MC}$ & -0.604 & -1.10 \\
\hline STNRC & -0.668 & -1.70 \\
\hline \multicolumn{3}{|c|}{ Dependent Variable: REMIOUTMI } \\
\hline Constant & 4.957 & 0.94 \\
\hline PRLENNRC & 1.352 & 1.62 \\
\hline I & 106.619 & 5.86 \\
\hline ACEMPI45 & 80.677 & 4.41 \\
\hline \multicolumn{3}{|c|}{ Dependent Variable: REMIGRPMI } \\
\hline Constant & 2.319 & 0.97 \\
\hline PRLENNRC & 0.637 & 1.70 \\
\hline 1 & 48.477 & 5.82 \\
\hline ACEMPI45 & 40.317 & 4.81 \\
\hline Number of Observations & \multicolumn{2}{|c|}{59} \\
\hline Adjusted R-squared-Equation for REMIEMP & \multicolumn{2}{|c|}{0.560} \\
\hline Adjusted R-squared-Equation for REMIINCMI & \multicolumn{2}{|c|}{0.662} \\
\hline Adjusted R-squared-Equation for REMIOUTMI & \multicolumn{2}{|c|}{0.686} \\
\hline Adjusted R-squared-Equation for REMIGRPMI & \multicolumn{2}{|c|}{0.701} \\
\hline
\end{tabular}

potential of business attraction for rural projects based on (CSI, 1996b). 
Table D.6 SURE Estimation Results for Highway Investments Involving New Construction-Related Projects (Scenario 3*)

\begin{tabular}{|c|c|c|}
\hline \multicolumn{3}{|c|}{ Dependent Variable: REMIEMP } \\
\hline & Coefficient & $t$-statistic \\
\hline Constant & 16.592 & 1.34 \\
\hline PRLENNRC & 1.403 & 2.40 \\
\hline I & 172.843 & 3.54 \\
\hline ACEMPI45 & 82.493 & 1.69 \\
\hline \multicolumn{3}{|c|}{ Dependent Variable: REMINCMI } \\
\hline Constant & 3.077 & 2.68 \\
\hline I & 14.250 & 3.18 \\
\hline ACEMPI45 & 11.347 & 2.53 \\
\hline URBU & 0.664 & 1.31 \\
\hline$M C$ & -1.323 & -2.78 \\
\hline \multicolumn{3}{|c|}{ Dependent Variable: REMIOUTMI } \\
\hline Constant & 8.260 & 1.52 \\
\hline PRLENNRC & 0.266 & 1.66 \\
\hline I & 82.184 & 3.89 \\
\hline ACEMPI45 & 50.600 & 2.39 \\
\hline URBAN & -2.121 & -1.27 \\
\hline \multicolumn{3}{|c|}{ Dependent Variable: REMIGRPMI } \\
\hline Constant & 3.245 & 1.33 \\
\hline 1 & 37.142 & 3.81 \\
\hline ACEMPI45 & 25.605 & 2.63 \\
\hline Number of Observations & \multicolumn{2}{|c|}{59} \\
\hline Adjusted R-squared-Equation for REMIEMP & \multicolumn{2}{|c|}{0.357} \\
\hline Adjusted R-squared-Equation for REMIINCMI & \multicolumn{2}{|c|}{0.406} \\
\hline Adjusted R-squared-Equation for REMIOUTMI & \multicolumn{2}{|c|}{0.440} \\
\hline Adjusted R-squared-Equation for REMIGRPMI & \multicolumn{2}{|c|}{0.470} \\
\hline
\end{tabular}

potential of business attraction proportional to that of business expansion by a factor of LQ. 
Table D.7 SURE Estimation Results on Economic Development Benefit/Cost Ratios of New Construction-Related Projects (Scenario $4^{*}$ )

\begin{tabular}{|c|c|c|}
\hline \multicolumn{3}{|c|}{ Dependent Variable: JOBPER96\$ } \\
\hline & Coefficient & $t$-statistic \\
\hline Constant & 3.469 & 2.82 \\
\hline I & 10.007 & 3.23 \\
\hline ACEMPI45 & 13.120 & 4.17 \\
\hline URBAN & -2.753 & -1.80 \\
\hline SOUTHNRC & 2.903 & 3.51 \\
\hline \multicolumn{3}{|c|}{ Dependent Variable: INCPER96\$ } \\
\hline Constant & 0.414 & 3.62 \\
\hline $\mathrm{I}$ & 0.842 & 2.75 \\
\hline ACEMPI45 & 1.722 & 5.55 \\
\hline URBAN & -0.262 & -1.76 \\
\hline \multicolumn{3}{|c|}{ Dependent Variable: OUTPER96\$ } \\
\hline Constant & 1.621 & 3.48 \\
\hline $\bar{T}$ & 5.294 & 4.24 \\
\hline ACEMPI45 & 6.837 & 5.41 \\
\hline URBAN & -1.384 & -2.29 \\
\hline \multicolumn{3}{|c|}{ Dependent Variable: GRPPER96\$ } \\
\hline Constant & 0.738 & 3.40 \\
\hline I & 2.366 & 4.07 \\
\hline ACEMPI45 & 3.423 & 5.81 \\
\hline URBAN & -0.609 & -2.16 \\
\hline Number of Observations & \multicolumn{2}{|c|}{59} \\
\hline Adjusted R-squared-Equation for JOBPER96\$ & \multicolumn{2}{|c|}{0.536} \\
\hline Adjusted R-squared-Equation for INCPER96\$ & \multicolumn{2}{|c|}{0.598} \\
\hline Adjusted R-squared-Equation for OUTPER96\$ & \multicolumn{2}{|c|}{0.666} \\
\hline Adjusted R-squared-Equation for GRPPER96\$ & \multicolumn{2}{|c|}{0.676} \\
\hline
\end{tabular}

potential of business attraction for rural projects based on (CSI, 1996b). 
Table D.8 SURE Estimation Results on Economic Development Benefit/Cost Ratios of New Construction-Related Projects (Scenario $3^{*}$ )

\begin{tabular}{|c|c|c|}
\hline \multicolumn{3}{|c|}{ Dependent Variable: JOBPER96\$ } \\
\hline & Coefficient & $t$-statistic \\
\hline Constant & 3.970 & 2.98 \\
\hline $\mathrm{I}$ & 7.845 & 2.20 \\
\hline ACEMPI45 & 6.768 & 1.87 \\
\hline URBAN & -3.851 & -2.22 \\
\hline \multicolumn{3}{|c|}{ Dependent Variable: INCPER96\$ } \\
\hline Constant & 0.399 & 3.07 \\
\hline 1 & 0.472 & 1.35 \\
\hline ACEMPI45 & 1.174 & 3.33 \\
\hline URBAN & -0.297 & -1.76 \\
\hline \multicolumn{3}{|c|}{ Dependent Variable: OUTPER96\$ } \\
\hline Constant & 1.422 & 2.62 \\
\hline 1 & 3.689 & 2.54 \\
\hline ACEMPI45 & 4.679 & 3.18 \\
\hline URBAN & -1.461 & -2.07 \\
\hline \multicolumn{3}{|c|}{ Dependent Variable: GRPPER96\$ } \\
\hline Constant & 0.646 & 2.55 \\
\hline I & 1.593 & 2.35 \\
\hline ACEMPI45 & 2.383 & 3.46 \\
\hline URBAN & -0.644 & -1.95 \\
\hline Number of Observations & \multicolumn{2}{|c|}{59} \\
\hline Adjusted R-squared-Equation for JOBPER96\$ & \multicolumn{2}{|c|}{0.262} \\
\hline Adjusted R-squared-Equation for INCPER96\$ & \multicolumn{2}{|c|}{0.315} \\
\hline Adjusted R-squared-Equation for OUTPER96\$ & \multicolumn{2}{|c|}{0.406} \\
\hline Adjusted R-squared-Equation for GRPPER96\$ & \multicolumn{2}{|c|}{0.414} \\
\hline
\end{tabular}

potential of business attraction proportional to that of business expansion by a factor of LQ. 
Appendix E.

\section{E.1. NCHRP Project B25-19 (2001): "Assessing the Social and Economic Effects of Transportation Projects"}

NCHRP Project B25-19 was completed In February 2001 by David J. Forkenbrock, Shauna Benshoff, and Glen Weisbrod. The objective of this report was to develop a practical guidebook capable of assisting transportation professionals in assessing the social and economic effects of transportation projects. The survey participants included 51 state transportation agencies, and 63 metropolitan planning organizations and regional planning agencies. The survey inquired as to the nature and level of use of a series of general categories of methods, tools and techniques. The survey participants were also asked for their assessment of the quality and usability of these modes of analysis. The scope of this survey included not only roadway transportation, but also, rail, transit, and water.

The following sections summarize a series of questions posed to the survey respondents regarding the economic effects of road transportation system changes. Among the examples of economic impacts considered are effects on neighborhood businesses, employment effects, and changes in property values. Total may surpass $100 \%$ due to agencies indicating more than one statement/response.

\section{E.1.1. Impact Assessment Process (Part 1)}

1. Under which of the following circumstances does your agency estimate the economic impacts of transportation projects? 


\section{DOT participants}

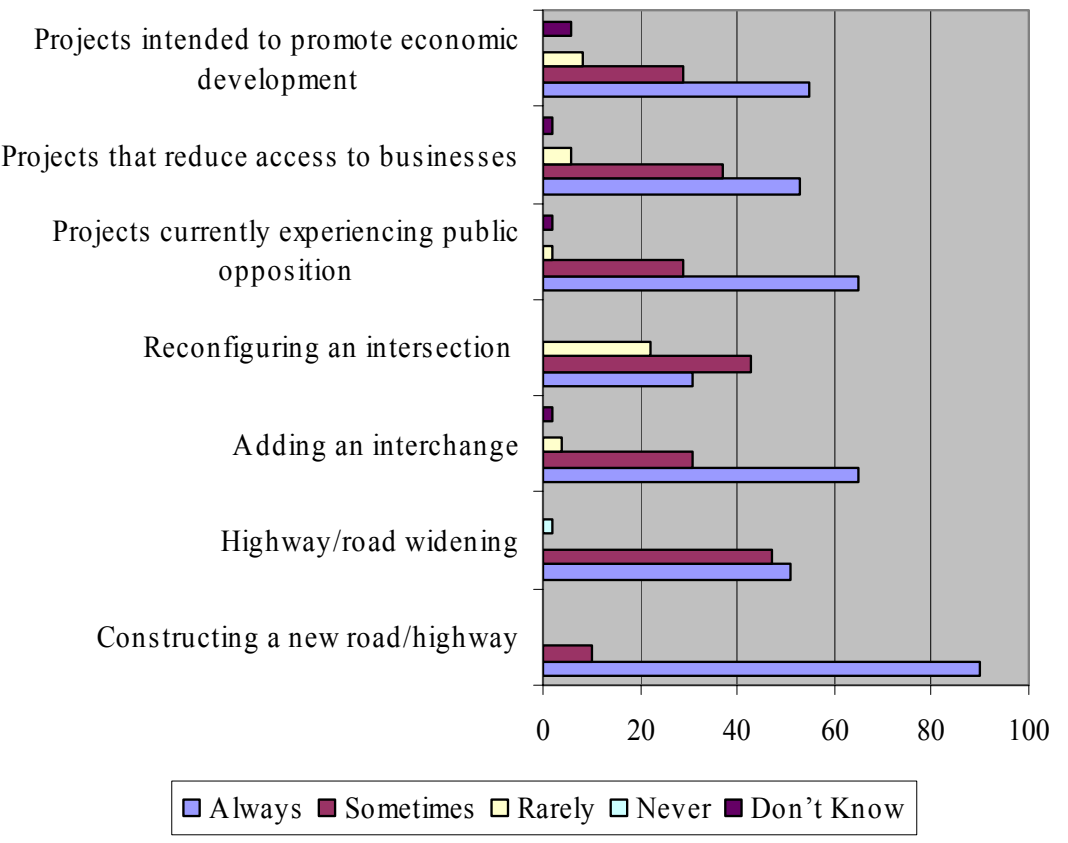

MPO participants 
Projects intended to promote economic development

Projects that reduce access to businesses

Projects currently experiencing public opposition

Reconfiguring an intersection

Adding an interchange

Highway/road widening

Constructing a new road/highway

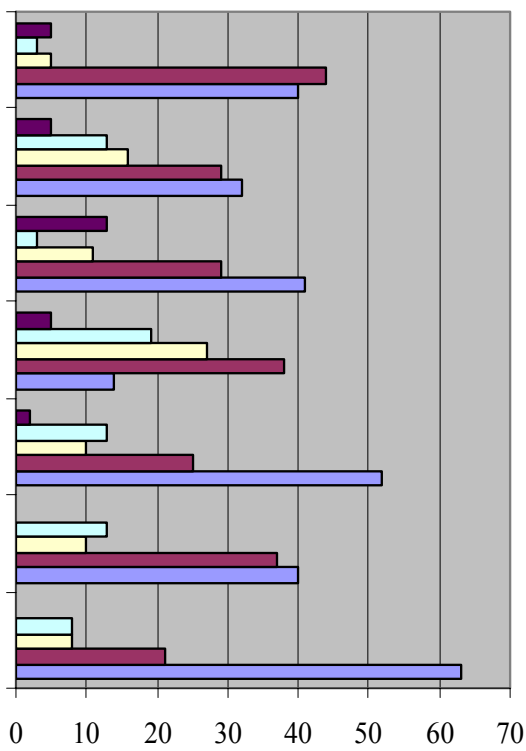

$\square$ Always $\square$ Sometimes $\square$ Rarely $\square$ Never $\square$ Don’t Know

2. What is the primary motivation within your agency for analyzing the economic effects of transportation projects? (check all that apply)

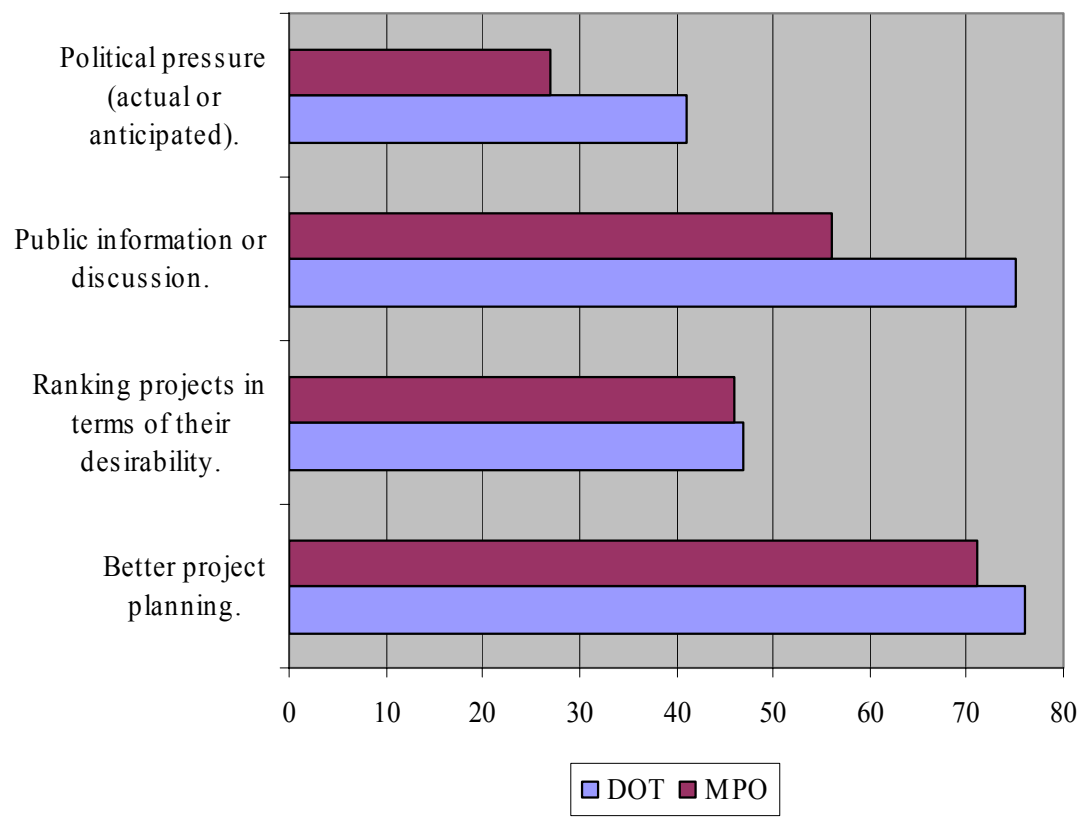


3. Which of the following statements best describes the role of economic effects in projects evaluations? (check all that apply)



4. When carrying out an analysis of the likely economic effects of a potential transportation improvement, which of the following best describes your agency's current practices? (check all that apply) 


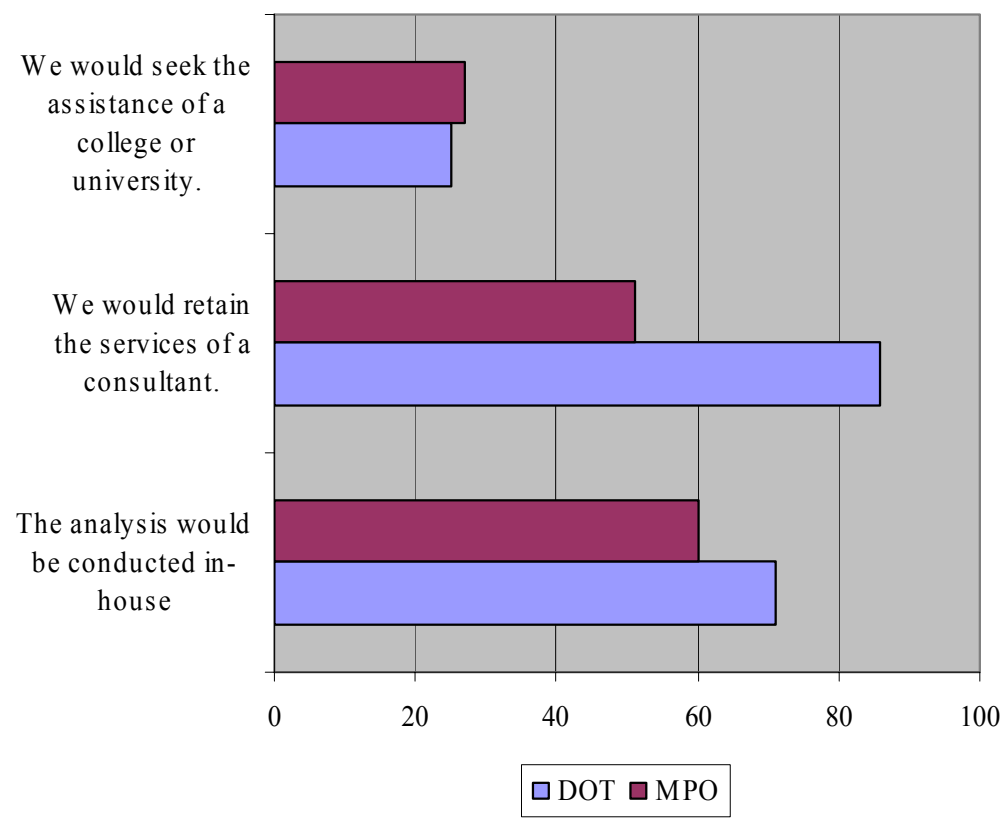

5. Over the past 5 years, how has your agency's analysis of the economic effects of transportation projects changed? (check only one response)

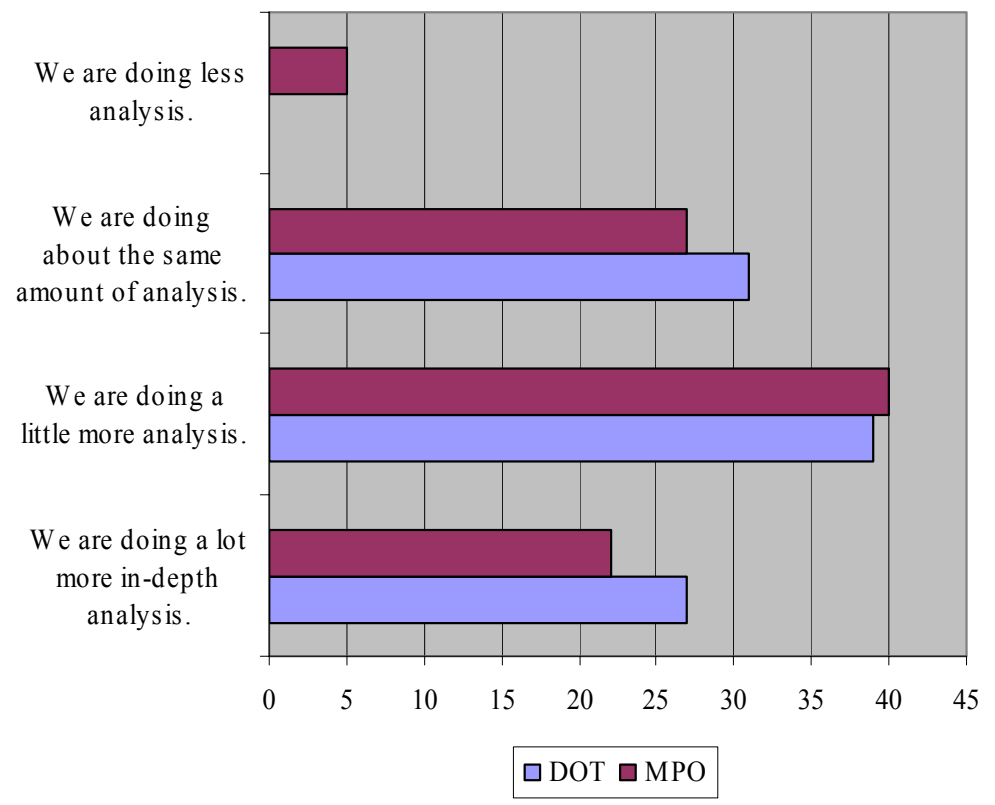


6. In circumstances when your agency does not analyze the economic effects of a transportation project, which of the following best describes the main reasons why? (check all that apply)

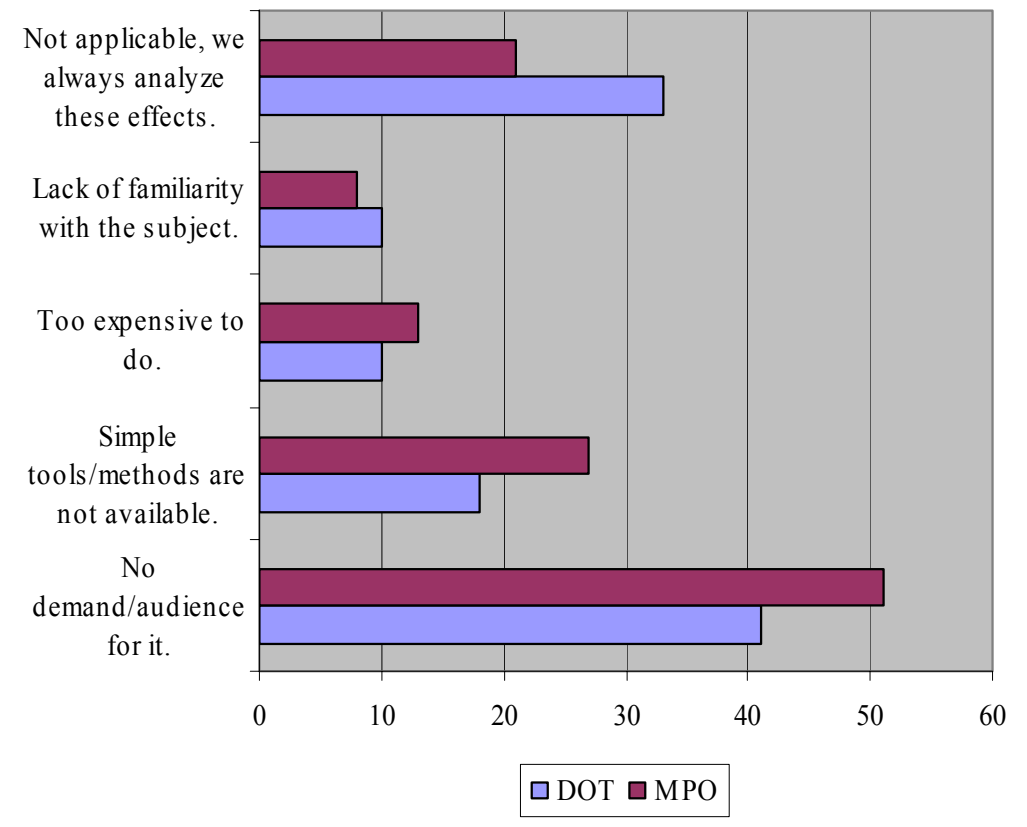

7. What is the nature of the economic analyses of potential major transportation projects carried out in your agency? (check all that apply) 


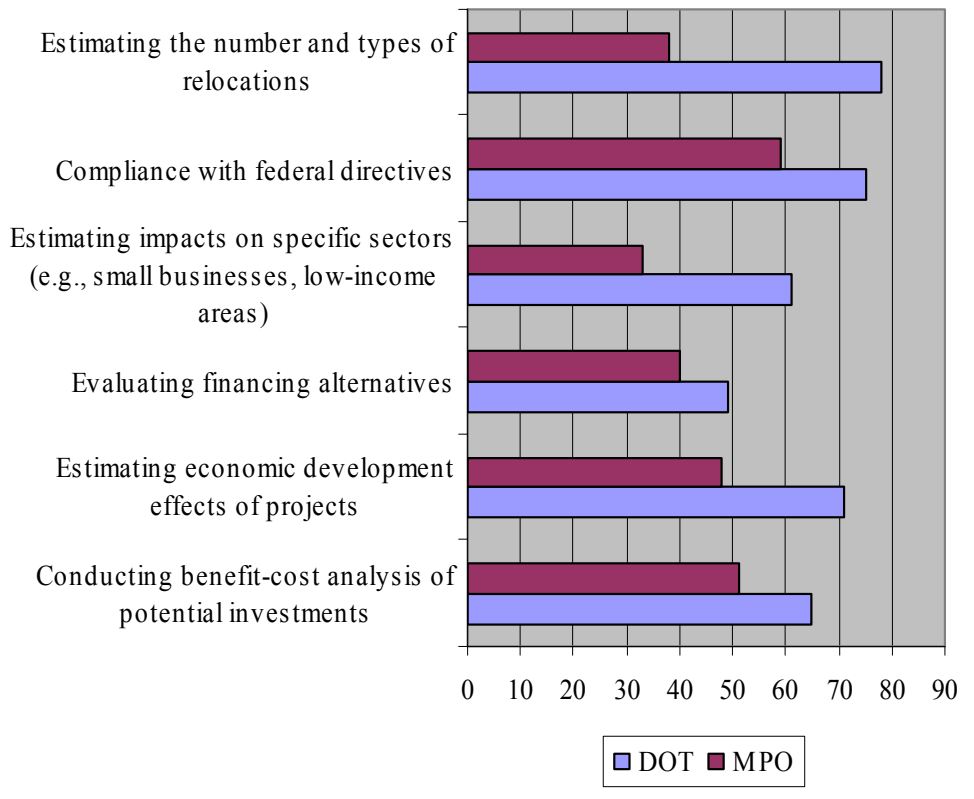

E.1.2. Use of Specific Methods for Assessing Impacts (Part 2)

1. What is your opinion as to the use of specific methods, tools and techniques to assess the economic effects of transportation system changes?

\section{DOT participants}


Integrated transportation -land-use models

Business dislocation analysis
Business interviews
Computer economic models
Traditional benefit-cost analys is

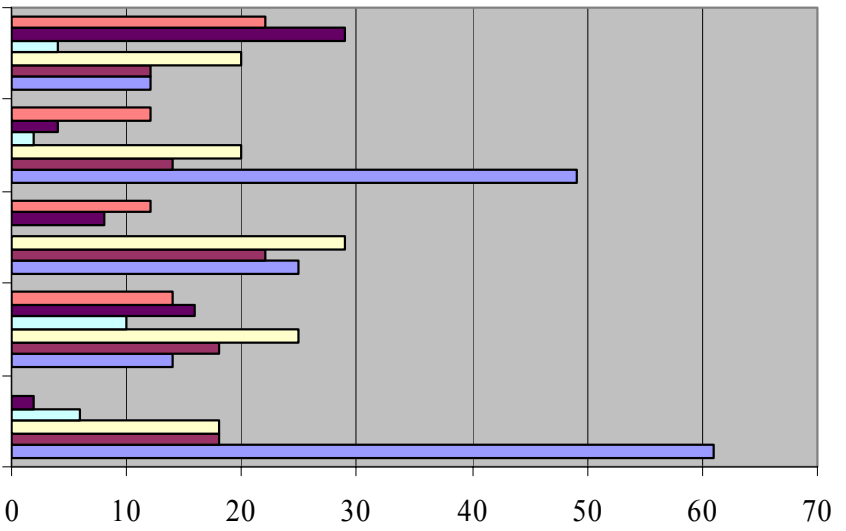

$\square$ Don't know.

Never, because we are not familiar with the technique. $\square$ Never, because we don't think this technique is useful. $\square$ Rarely (once every two years or less)

$\square$ Occasionally (once a year)

$\square$ Frequently (3 or more times a year) 


\section{MPO participants}

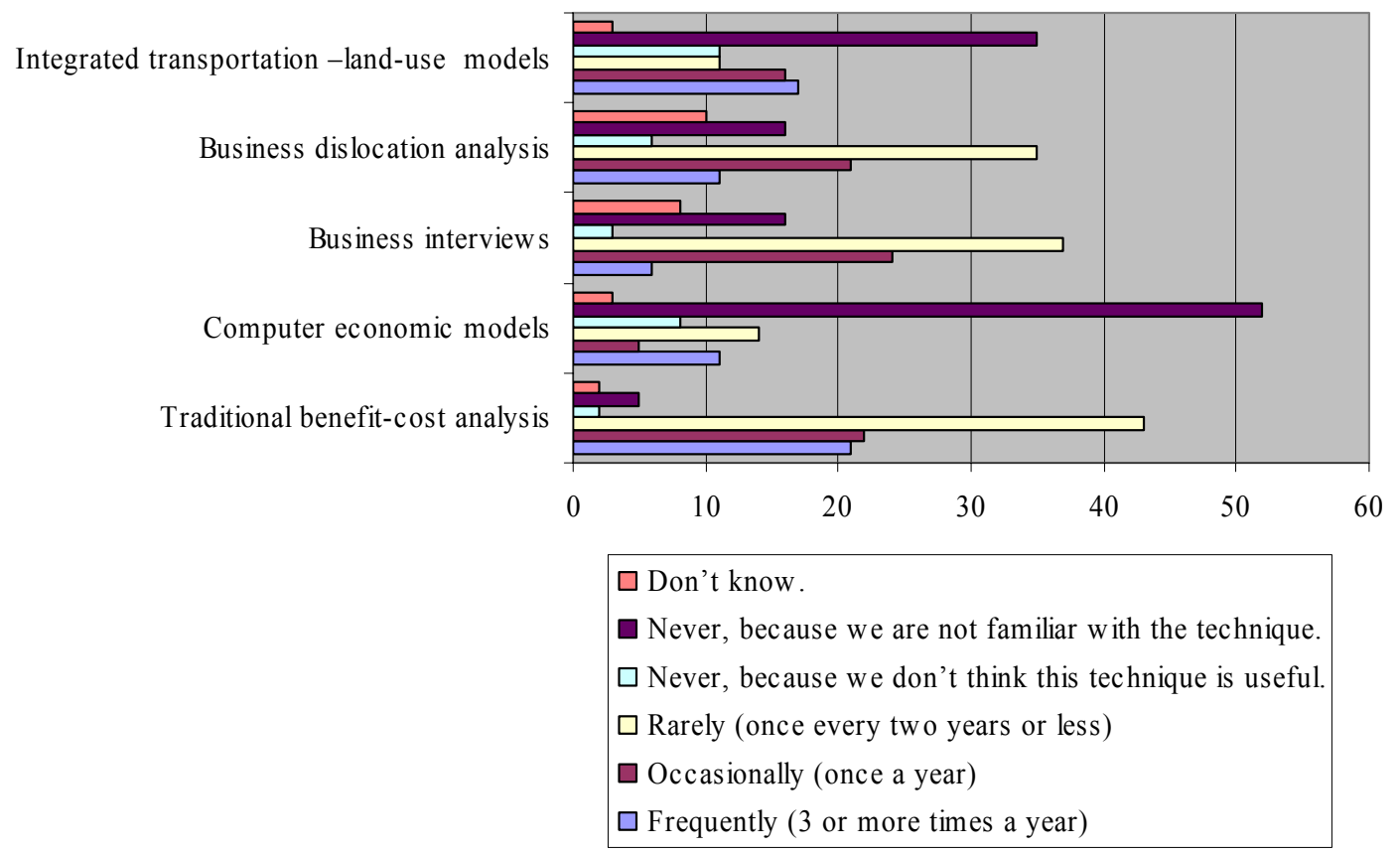

E.1.3. Adequacy of Available Methods, Tools, and Techniques (Part 3)

1. What is your opinion as to the adequacy of current methods, tools and techniques summarized in the following statements? 


\section{DOT participants}

I am interested in learning more about the methods, tools, and techniques that would help my agency conduct economic impact analys es of proposed

There is a problem communicating rigorus analyses in ways that are understandable to the public.

Our ability to carry out economic analyses of potential transportation projects has improved because of the availability of more useful approaches

The tools for estimating economic effects tend to be too difficult to apply for routine use by my agency.

The methods, tools, and techniques currently available often are too complex for my agency to use.

Generally speaking, my agency has the capacity to estimate the economic development effects of highway projects accurately and comprehensively.

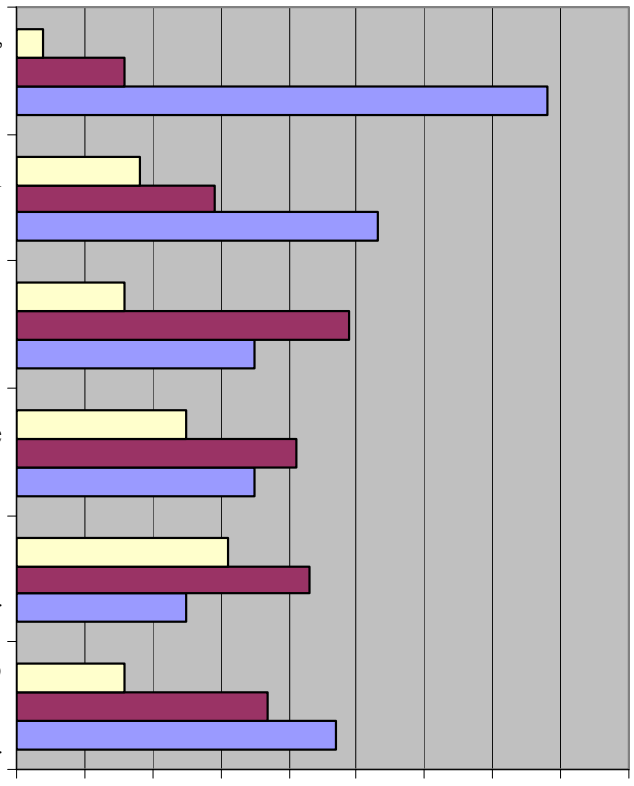

$\begin{array}{llllllllll}0 & 10 & 20 & 30 & 40 & 50 & 60 & 70 & 80 & 90\end{array}$

$\square$ Agree $\square$ Neither agree nor disagree $\square$ Disagree

\section{MPO participants}


I am interested in learning more about the methods, tools, and techniques that would help my agency conduct economic impact analyses of proposed

There is a problem communicating rigorus analyses in ways that are understandable to the public.

Our ability to carry out economic analyses of potential transportation projects has improved because of the availability of more useful approaches

The tools for estimating economic effects tend to be too difficult to apply for routine use by my agency.

The methods, tools, and techniques currently available often are too complex for my agency to use.

Generally speaking, my agency has the capacity to estimate the economic development effects of highway projects accurately and comprehensively.
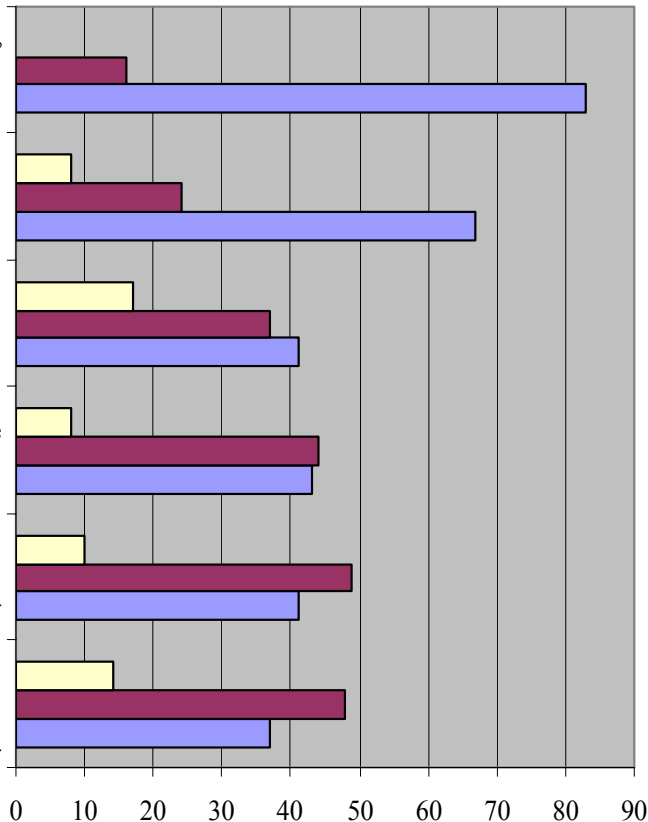

$\square$ Agree $\square$ Neither agree nor disagree $\square$ Disagree

2. To enhance your agency's ability to evaluate the economic development effects of transportation system changes, which of the following are needed?

\section{DOT participants}




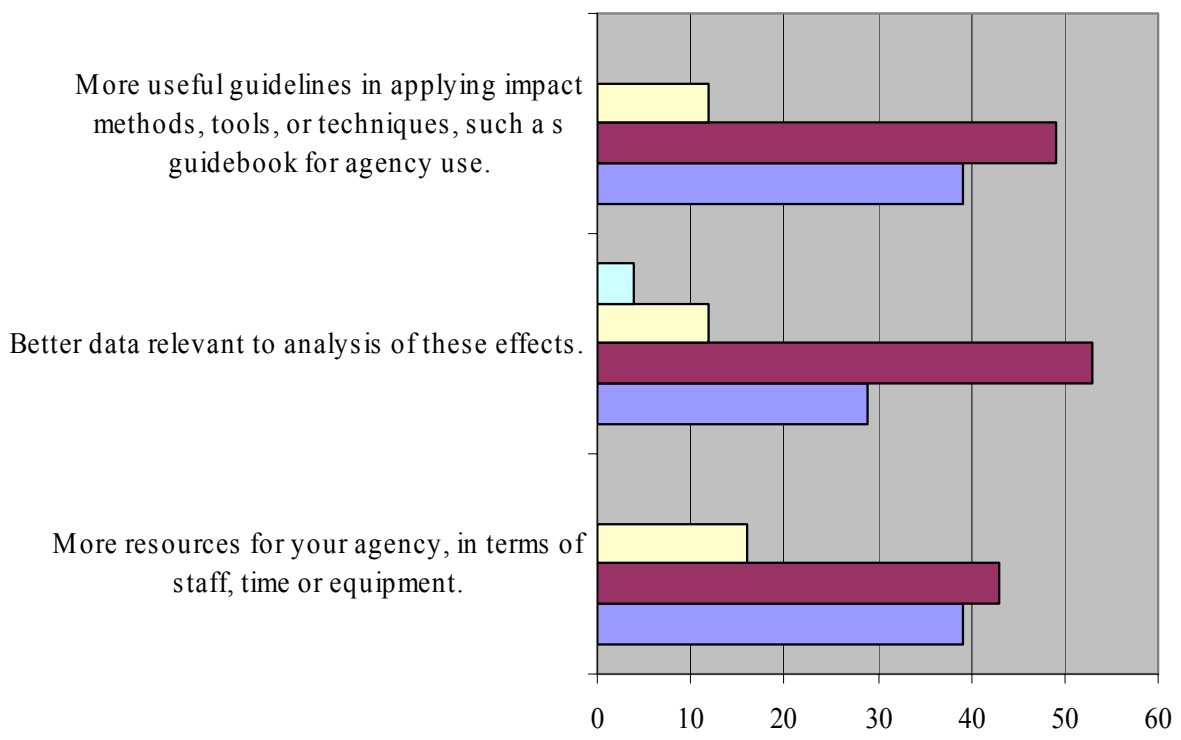

$\square$ Badly needed $\square$ Would help some $\square$ Not a big need $\square$ Don’t Know

\section{MPO participants}

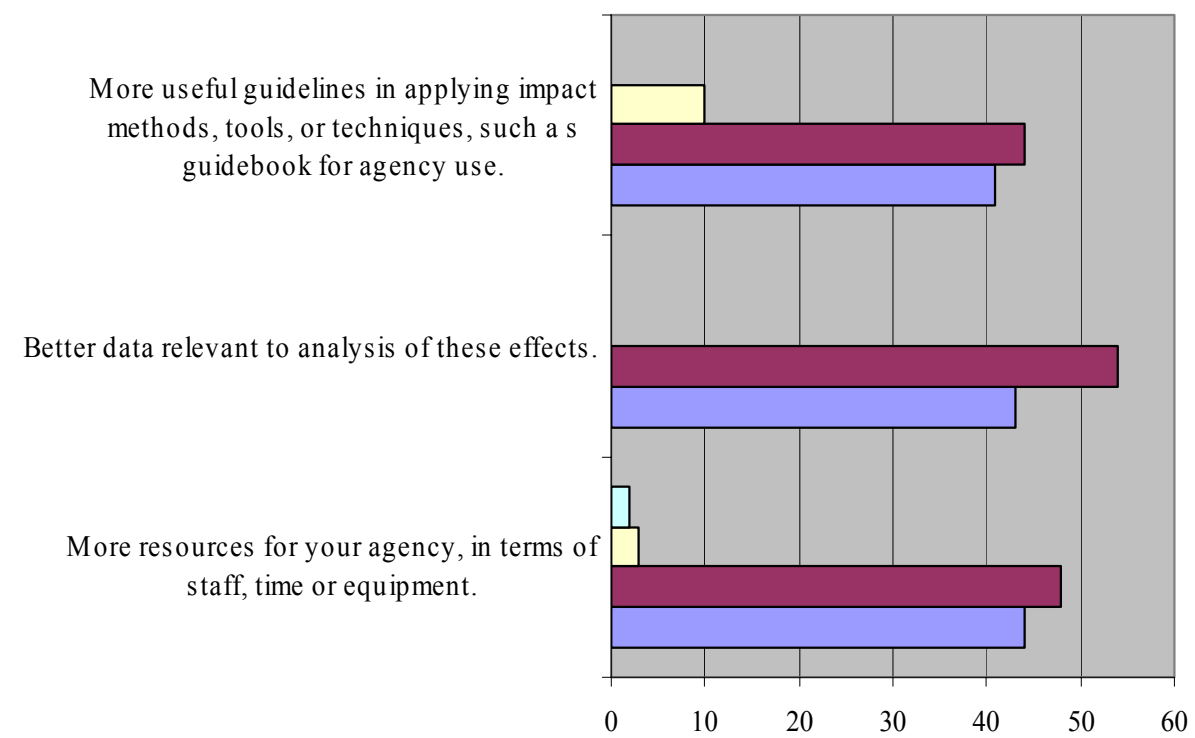

$\square$ Badly needed $\square$ Would help some $\square$ Not a big need $\square$ Don’t Know 


\section{E.1.4. Conclusions}

Overall conclusions made by this report indicate the following:

- State DOT's in general are much more involved in the assessment of economic effects than are MPO's.

- Both types of agencies tend to take into account economic development effects when assessing proposed transportation projects. Most frequently, they estimate the economic impacts of new road construction or interchange construction projects, followed by projects currently experiencing public opposition.

- Though economic effects are analyzed more frequently that are social effects, fairly basic methods of economic analysis are the most commonly used (i.e., benefit/cost analysis).

- Not all state agencies seem to have in-house capability of analyzing such effects.

- A preponderance of both types of agencies would like to see better guidelines for assessing economic effects.

- State agencies are more likely to feel that they need additional staff resources to analyze these effects. 


\section{E.2. NCHRP 290: "Synthesis of Highway Practice: Procedures for Assessing Eco- nomic Development Impacts from Transportation Investments"}

NCHRP Synthesis Report 290 was completed in June 2000 by Glen Weisbrod of the Economic Development Group, Inc. The purpose of this report was to survey government agencies to summarize the state-of-the-practice in assessing economic development impacts from transportation investments. The survey respondents included 36 state transportation agencies, 8 metropolitan planning organizations, and 7 Canadian Provinces. The scope of this survey includes not only roadway transportation, but also air, water, and rail. In the following smary, where possible, roadway data has been separated and subsequently noted in the document when exclusively represented.

The following sections summarize a series of questions posed to the survey respondents with the results tabulated in an effort to ease in understanding the concepts analyzed.

\section{E.2.1. Question Topics and Results}

1. How often does your agency assess the value of impacts or benefits associated with transportation projects or programs?

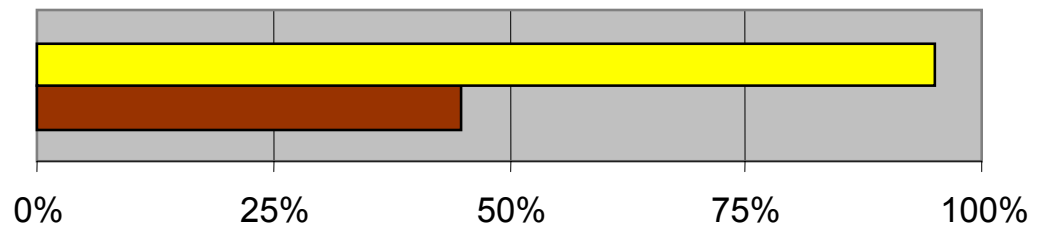

Participating agencies

$95 \%$ have at some point assessed the value of road impacts $45 \%$ regularly assess value of roadway impact 
Original Source: Figure 4, page 34.

2. What needs motivated the specific study of economic development impacts?

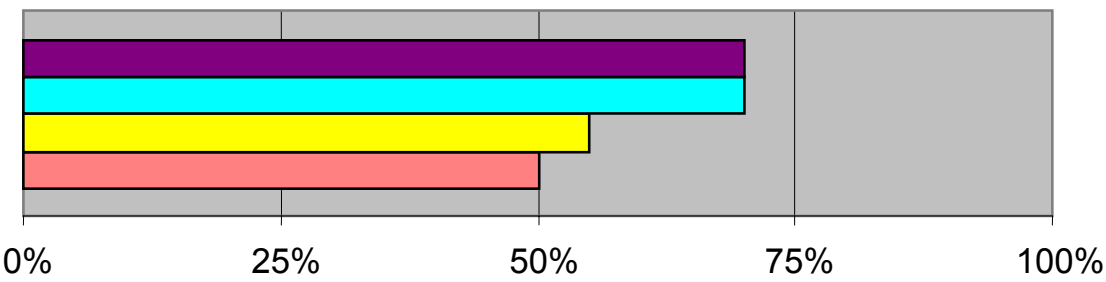

Total surpasses $100 \%$ due to agencies indicating more than one need

$\square 70 \%$ Response to local concerns

$\square 70 \%$ Project ranking

$\square 55 \%$ Public relations

$\square 50 \%$ Environmental Impact Statement requirement

Original Source: Figure 5, page 35; only US states, multiple responses.

3. Is economic development impact analysis a regular component of your agency's project evaluation procedures?

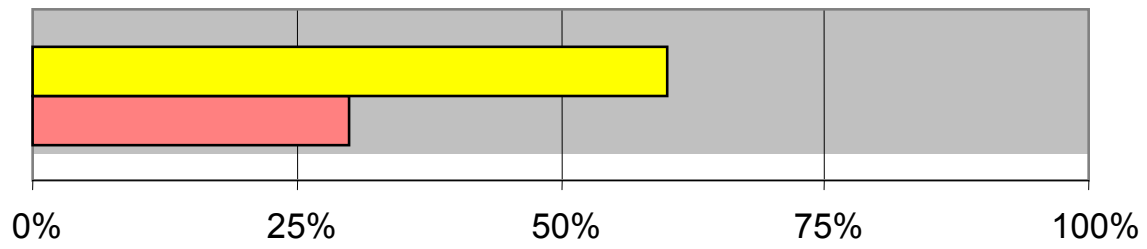

$\square 60 \%$ Occasional use as Project Justification

$\square 30 \%$ Use in Standard Project Evaluation Criterion

Original Source: Figure 7, page 36. 
4. What measure have you used in the past, or would consider using in the future to represent economic value of projects (or programs)? Which measures appear to be of most importance for communicating findings on economic impacts to the public? To decision-makers?
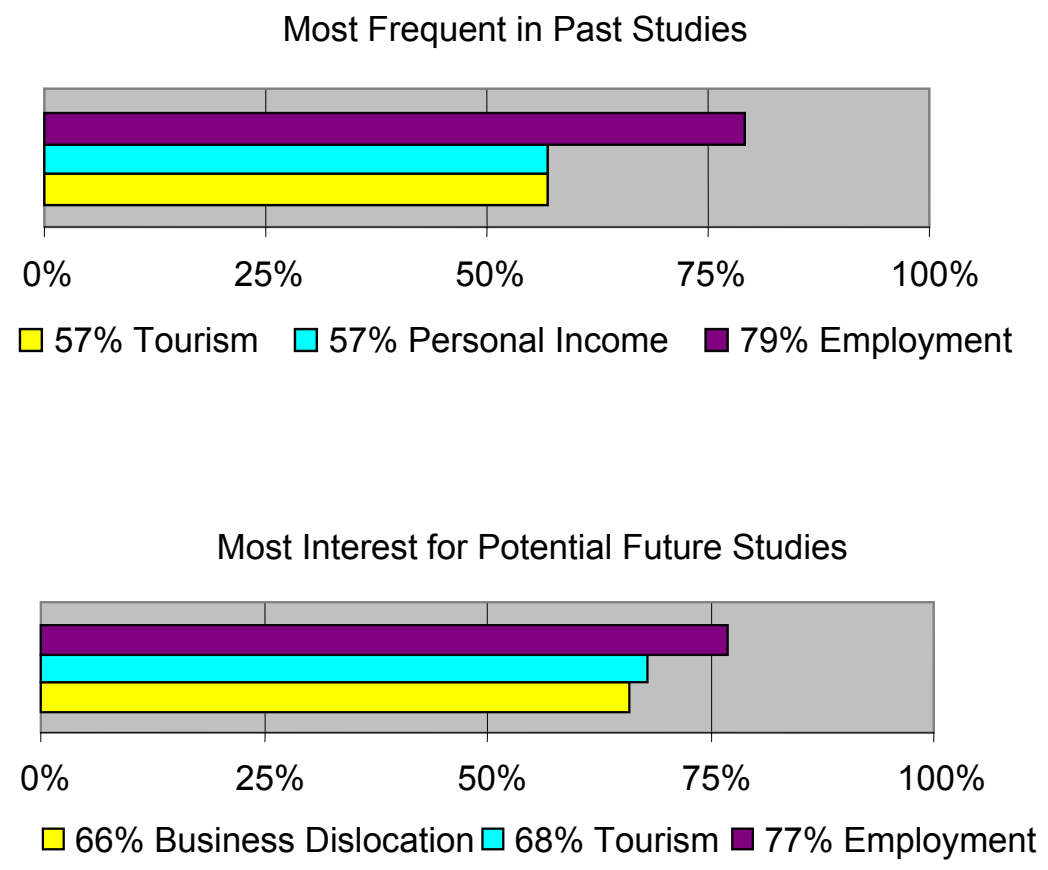

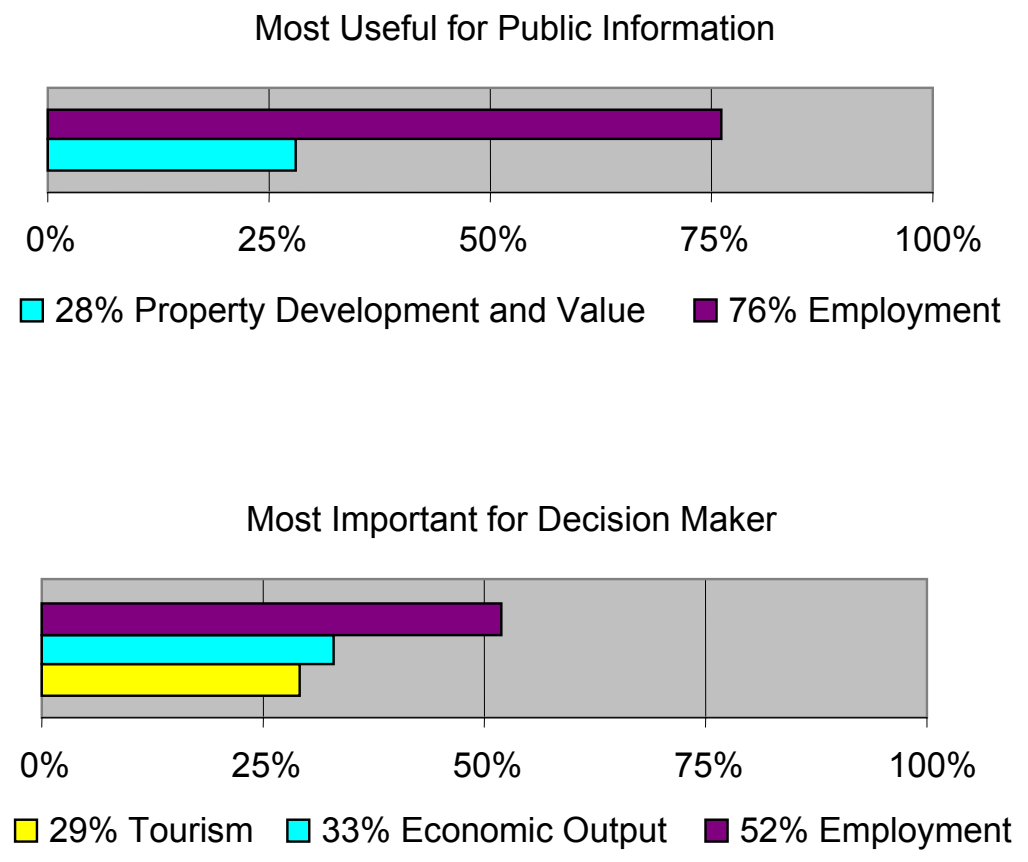

Original Source: Page 37; percentages reflect portion of all agencies which have conducted a study of economic development impacts.

5. What analysis tools or methods were used? 


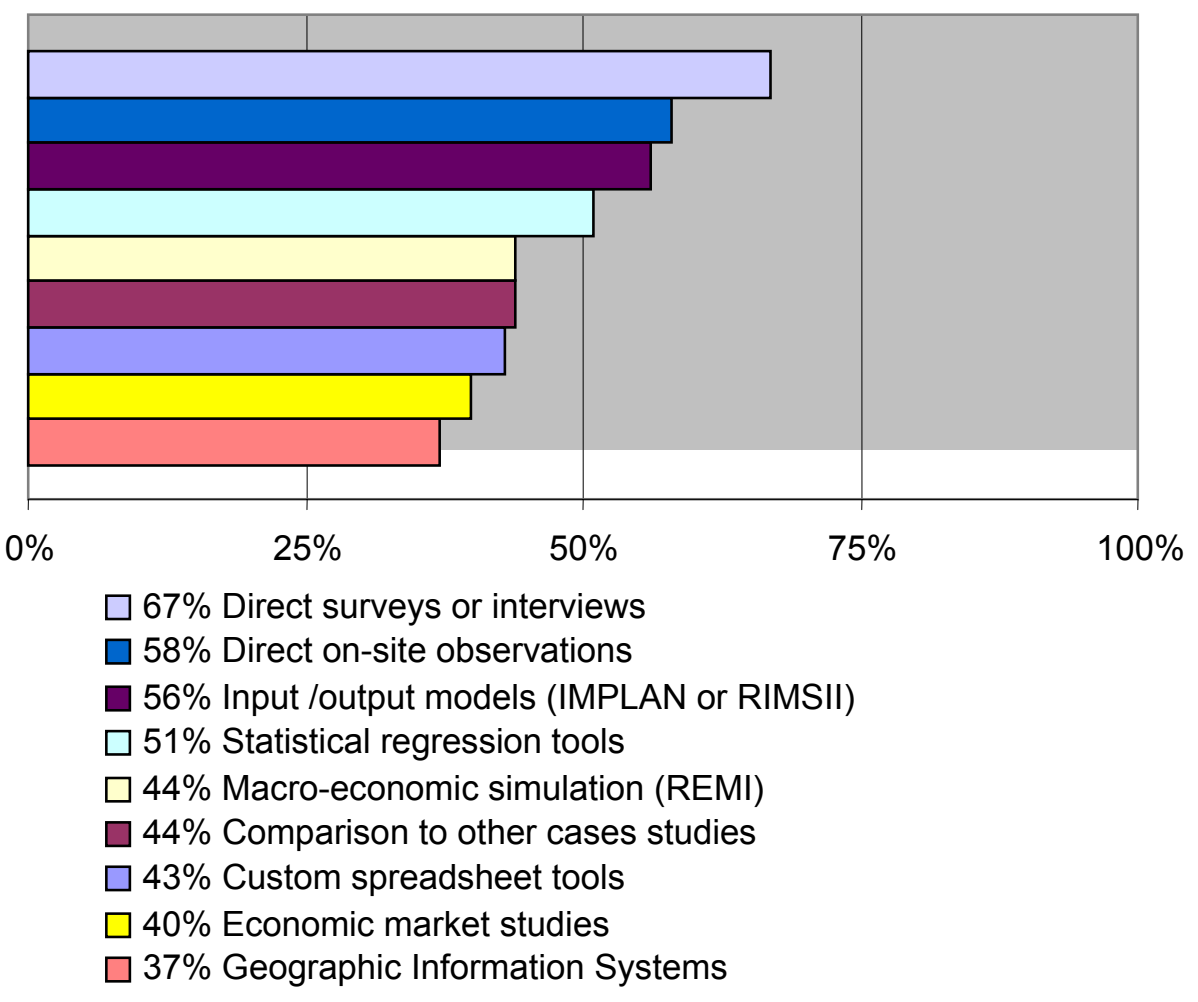

Original Source: Table 4, page 39. 
6. Who were the primary individuals conducting the economic development impact analysis?

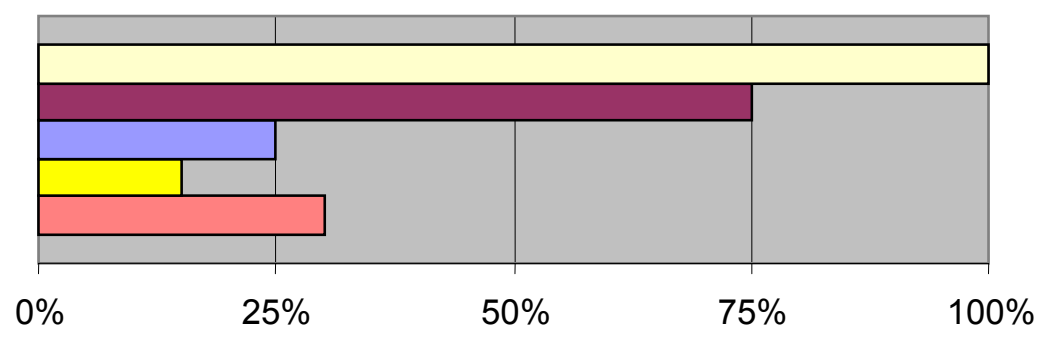

Agencies indicated more than one individual

$\square 100 \%$ Outside contractor

$\square 75 \%$ In-house planner/engineer

$\square 25 \%$ In-house economist

$\square 15 \%$ Other in-house staff

$\square 30 \%$ Other agencies

Original Source: Figure 8, page 40; only US states, multiple responses.

\section{E.2.2. Conclusions}

Overall conclusions made by this report indicate the following:

- Most transportation agencies recognize economic development as an important consideration for road transport investments.

- Most agencies conduct detailed studies of economic development impacts only when warranted by specific needs, the most common motivation being a response to local concerns.

- While confusion remains about how agencies should select among economic impacts and the meaning of "economic impacts" or "economic development impacts," evaluations are most frequently measured in terms of changes in associated employment (jobs), income (wages), and business output (sales) within some region. 
- The type of analysis conducted depends on the purpose of the analysis. Specifically asking, is the report for decision-making, planning and/or regulatory review, public education, etc.?

o Public education $\rightarrow$ employment and property values

o Decision-makers $\rightarrow$ employment, economic output, and tourism

o Future planning $\rightarrow$ employment, tourism and business location

- Perceived barriers to conducting more economic development impact analysis reported are:

o Results not accepted universally;

o Inadequate data or high level of complexity in data collection requirements;

o Complexity of analysis methods;

o Lack of consistency in analytic methods and interpretation of results; and

o Inexperience of agency staff. (The survey showed that the primary individuals conducting the analyses were outside contractors).

o Further economic development associated with transportation projects is not always welcome, particularly in congested metropolitan areas as well as other high density regions.

- Surveyed agencies indicated a remaining need for future work to address the following:

o Validate the link between transportation and economic development at the project corridor or facility level;

o Develop more complete and understandable analysis tools; and

o Develop better staff training and standards for measurement. 
E.3. Highway and Transit Investments: Options for Improving Information on Projects' Benefits and Costs and Increasing Accountability for Results

The Government Accountability Office (GAO) survey was conducted from August through October 2004 (GAO, 2005). In this study, transportation agencies were contacted via telephone and e-mail to solicit responses on the inclusion of economic impacts in the decision making process. The initial deadline in September was extended to October to allow additional agencies to submit completed questionnaires. Overall, 43 of the 50 state Departments of Transportation (DOT's) responded to the survey and 20 of 28 transit agencies. The scope of this survey included not only roadway transportation, but also, transit.

The following sections summarize a series of questions posed to the survey respondents regarding highway investments and in particular capacity adding projects.

E.3.1. Summary of Survey Responses of Frequency of Economic Analysis Completed for Proposed Project Alternatives by State DOT's

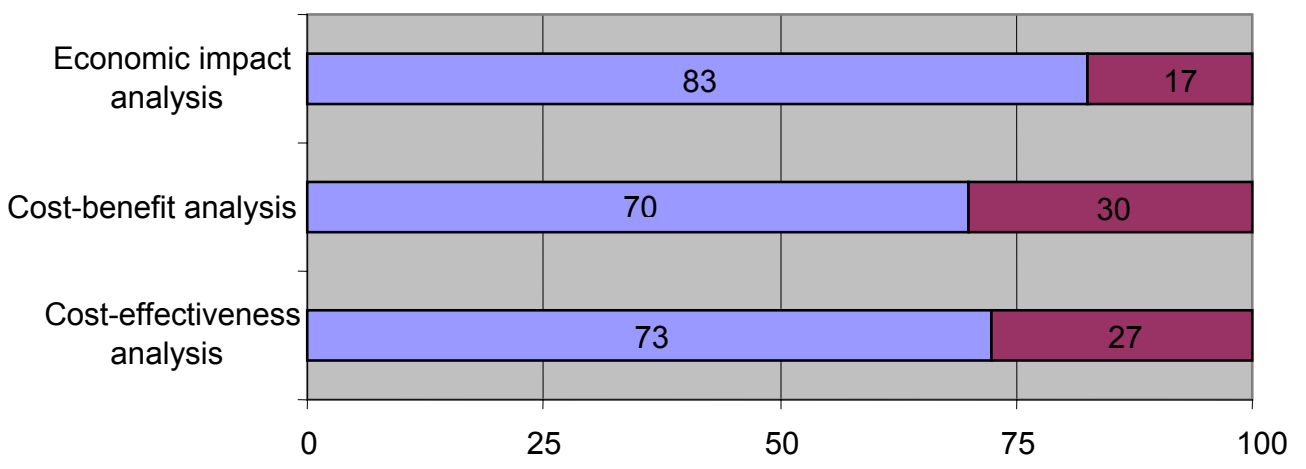

$\square$ Percent of agencies that did not complete analysis more than half of the time $\square$ Percent of agencies that completed analysis more than half of the time 
Original Source: Figure 1, page 2.

\section{E.3.2. Summary of State DOTs' Survey Responses of Factors of Great or Very Great importance in the Decision to Recommend a Highway Capacity Project}

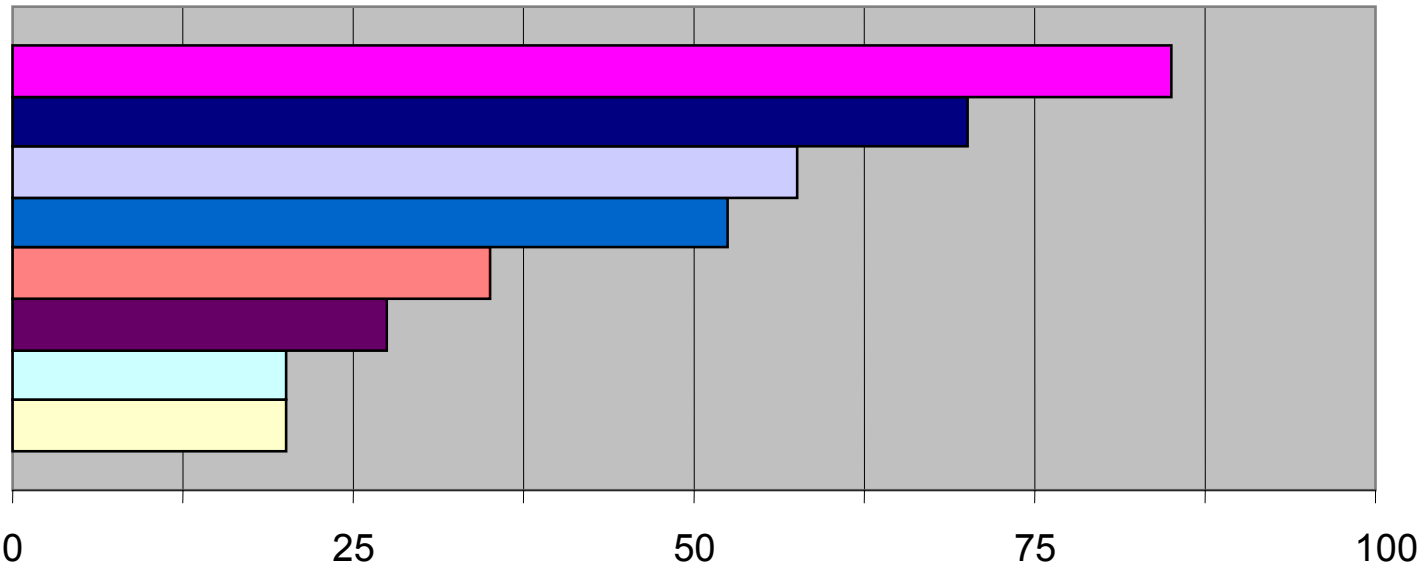

$\square 79 \%$ Political support/public opinion

- $65 \%$ Availability of state funds

$\square 53 \%$ Availability of federal matching funds

$\square 48 \%$ Cost-effectiveness

$\square 33 \%$ Distribution of impacts across social groups

$\square 25 \%$ Availability of local funds

$\square 18 \%$ Ratio of benefits to costs

$\square 18 \%$ Economic Impacts

Original Source: Figure 3, page 28.

\section{E.3.3. Conclusions}

Overall conclusions made by this report indicate the following: 
- A primary lesson learned from the survey is that economic analyses are done more for transit than for highway projects, due mostly to federal "New Start" requirements.

- Benefits and costs of highway investments depend on local circumstances and type of improvement. Measuring and properly counting some benefits and costs can prove difficult because once a project is completed it becomes part of an entire transportation system and therefore, the effects of the individual project become difficult to isolate, evaluate and attribute to the individual project.

- Analysis of benefits and costs are considered but not always systematically; results of analysis are only one factor among many considered in decision-making (i.e. public support or the availability of funding).

- Because state and local funding is limited and these studies can be costly and difficult, local officials indicated that studies of completed projects were not as high a priority as pursuing and conducting studies on future projects.

- Comprehensive data on the projected and actual costs and usage of all highway projects examined were not readily available.

- Even if steps are taken to improve the analytic information available to decision makers, however, overarching issues, such as the structure of the federal highway and transit programs, will affect the extent to which this information is used. Nevertheless, the increased use of economic analysis, such as benefit/cost analysis, could improve the information available, and ultimately, lead to betterinformed transportation investment decision making.

- Panel experts indicated a remaining need for future work to address the following:

o Improve the quality of data and transportation modeling; consistent data and measures are more important than perfect ones;

o Improve the quality and utility of benefit/cost analysis methods and tools; and

o Evaluate the outcomes of completed transportation projects to better determine what a particular project accomplished, but also to improve decisions on other projects. 


\section{E.4. Brigham Young University and Utah Department of Transportation: Transporta-} tion Professional and Decision Maker Survey

Brigham Young University, in conjunction with the Utah Department of Transportation and the Steering Committee, prepared and sent out a survey to Transportation Professionals and Transportation Decision Makers to assess the state-of-the-practice for including economic development impacts in the transportation decision making process (BYU, 2006). The survey participants included 20 National Transportation Professionals, 8 Utah Transportation Decision Makers, and 7 Utah Transportation Professionals.

The following section summarizes the results of this survey accompanied by a discussion on each of the primary sections of the survey and their results. It should be noted that these are preliminary results; the report is expected to be finalized in the next few months.

E.4.1. Survey Response of the Weight of Economic Impact Analysis (EIA) in Project Selection Process

\begin{tabular}{|l|l|l|l|l|}
\hline \multirow{2}{*}{ Survey Group } & \multicolumn{4}{|l|}{$\begin{array}{l}\text { Weight of Economic Impact Analysis in Selection } \\
\text { Process (of agencies performing EIAs) }\end{array}$} \\
\cline { 2 - 5 } & $\begin{array}{l}\text { Greater } \\
\text { than } 10 \%\end{array}$ & $10 \%$ & $\begin{array}{l}\text { Less than } \\
10 \%\end{array}$ & $\begin{array}{l}\text { No set } \\
\text { weight }\end{array}$ \\
\hline National Transportation Professional & $36 \%$ & $14 \%$ & $7 \%$ & $43 \%$ \\
\hline $\begin{array}{l}\text { Utah Commissioner and Decision } \\
\text { Maker }\end{array}$ & $13 \%$ & $38 \%$ & $38 \%$ & $13 \%$ \\
\hline Utah Transportation Professional & $29 \%$ & $43 \%$ & $0 \%$ & $29 \%$ \\
\hline
\end{tabular}


Weight of economic impact analysis in selection process

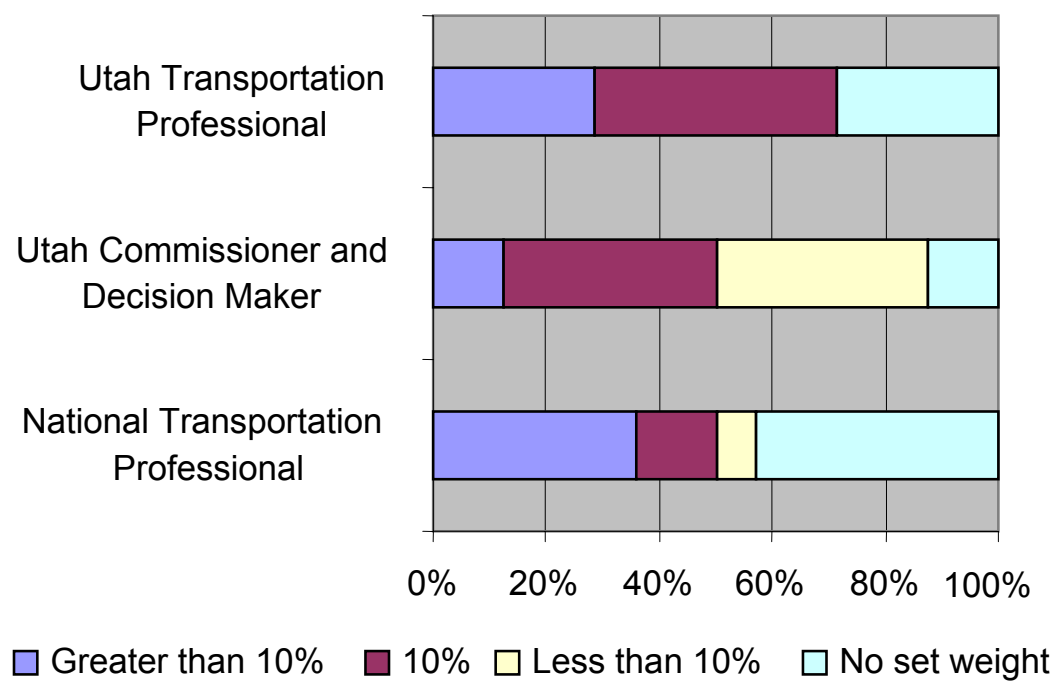

E.4.2. Summary of Decision Maker Survey

The following graphs summarize the responses of the decision-makers that participated in the survey.

1. What factors should be included in an economic impact analysis? 


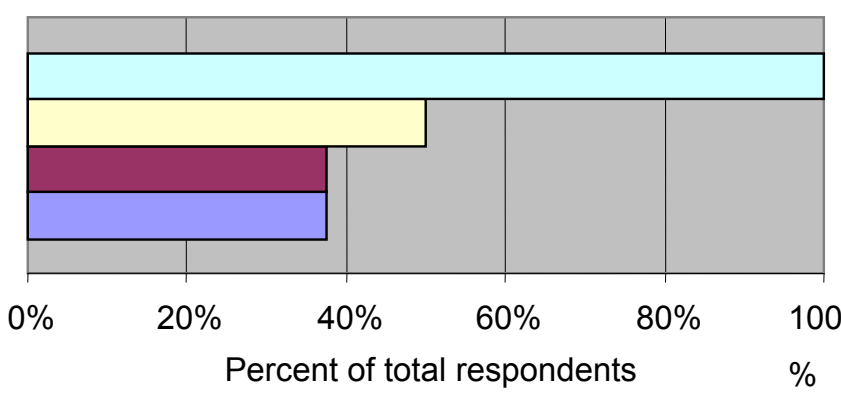

$\begin{array}{ll}\square 38 \% \text { Tax revenue } & \square 38 \% \text { Location of jobs } \\ \square 50 \% \text { Job retention } & \square 100 \% \text { Job creation }\end{array}$

2. What factors of economic development impacts would the public be most interested in?

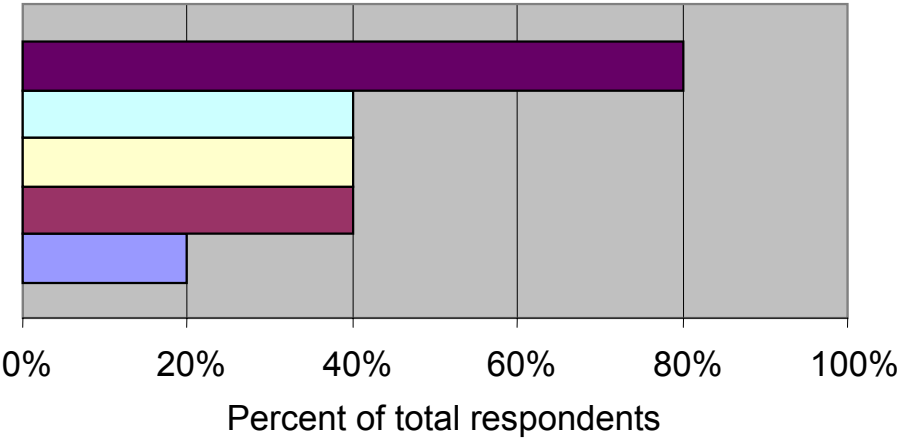

$\square 20 \%$ Wage

$\square 40 \%$ Environmental Impact

$\square 40 \%$ Commute time

$\square 40 \%$ Location

- $80 \%$ Job creation

\section{E.4.3. Summary of Transportation Professional Survey}

The following graphs summarize the responses of the transportation professionals that participated in the survey. 
1. What factors are considered in your agencies economic development score? (Responses are noted as to how many times they were repeated)

- Job Creation (iv)

- Business competitive factors, travel times, reliability (iv)

- Level of economic distress (ii)

- Industry type activity (ii)

- Support strategic economic corridor (i)

- Tax Revenue (i)

- Location (i)

- Capital investments (i)

- Supports regional plans

- Community Support

- Local Financial Contribution

- State Economic Development Support

- Encouraging tourism

- Rehabilitation of brownfield sites

- Employment income

- Quality of job

- Export versus local service industry

- Compliance to air quality

2. What level of investment, if any, has been used as a cutoff value for including economic impacts as selection criteria in the transportation planning process?

National Survey

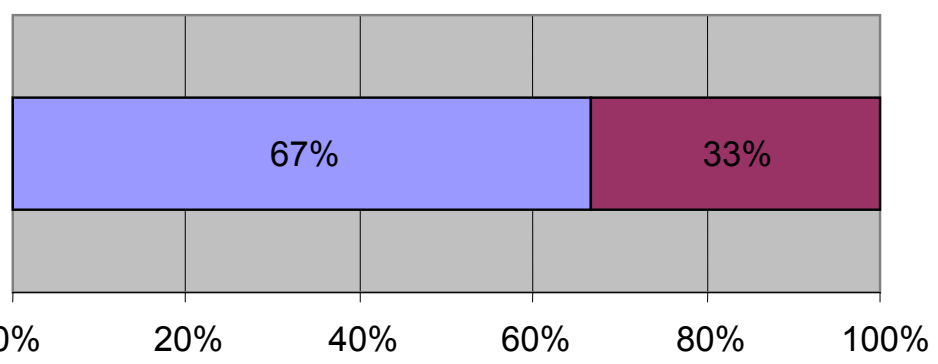

$\square$ No limit but focus on projects greater than $\$ 5$ million

$\square$ Generally will evaluate projects less than $\$ 5$ million 
3. If economic development impacts are included in your decision making process, are other agencies utilized to aid in the economic analysis process (e.g., Office of Planning and Budget, Economic Development Office, etc.)?

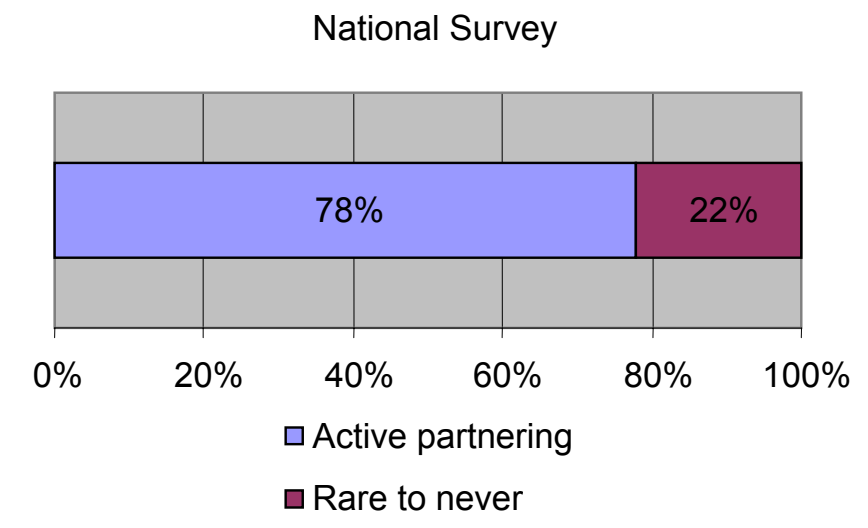

4. What tools have been used by your agency in the past for analyzing economic development impacts (e.g., input-output models, simulation models, other economic models)?

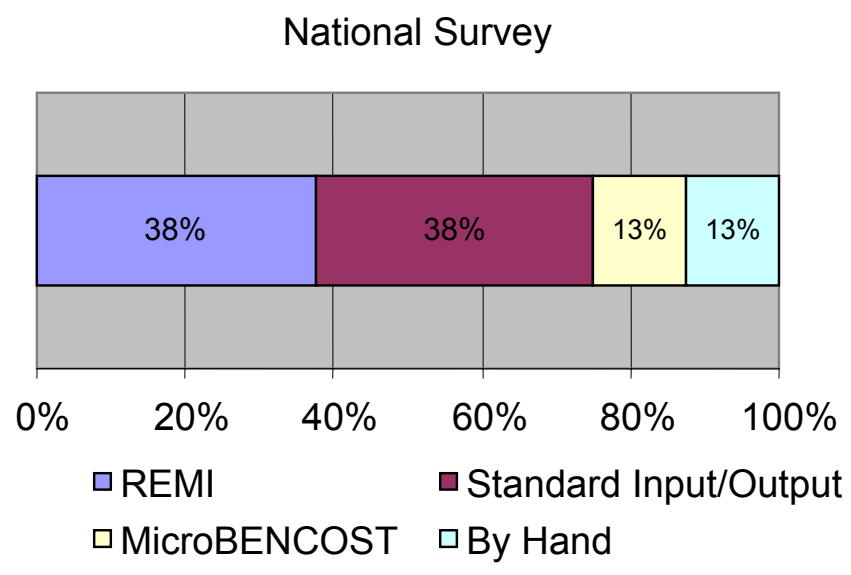


5. How much of your agencies total budget is dedicated to external consulting required to complete an economic impact analysis?

External consulting for economic impact analysis

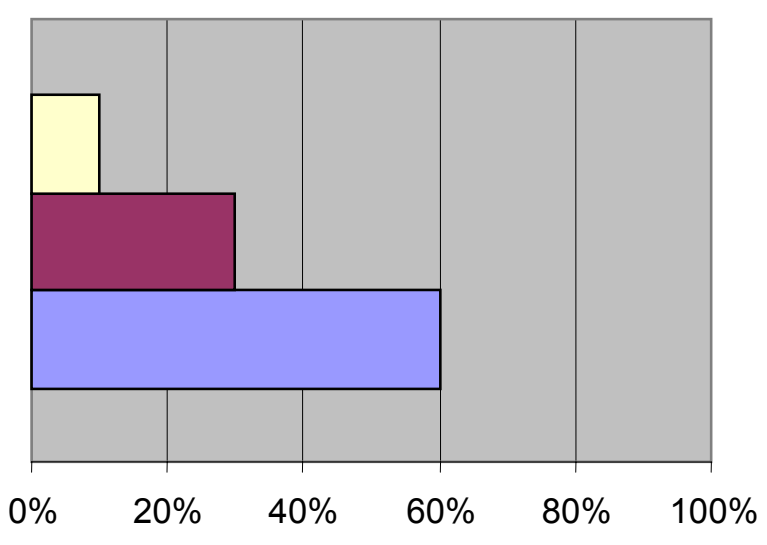

$\square 10 \%$ spend less than $0.2 \%$ of the total agency budget on external economic consulting

$\square 30 \%$ spend less than $0.02 \%$ of the total agency budget on external economic consulting

$\square 60 \%$ spend $0 \%$ of the total agency budget on external consulting

6. How much consulting or in-house labor has been required to include economic development impacts in the decision making process?

Full Time Equivalent In-house Specialists

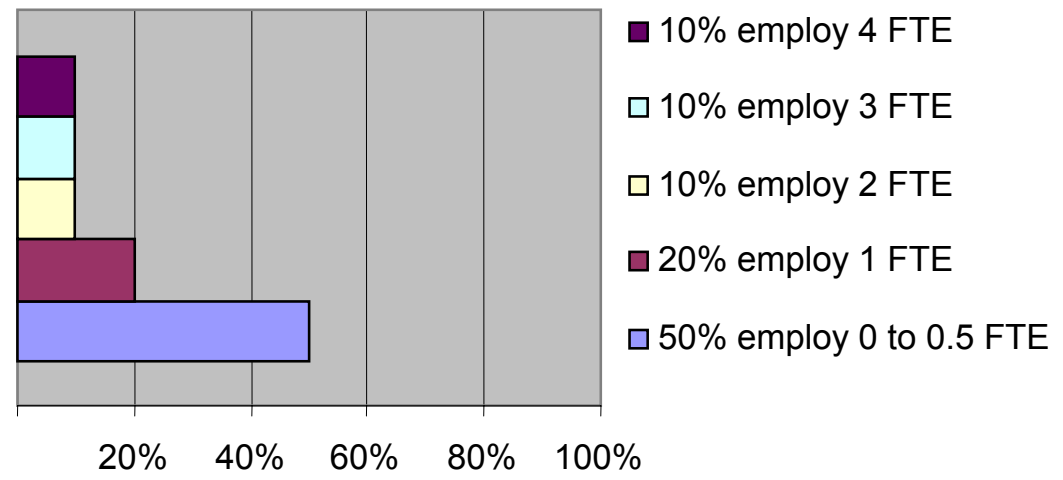




\section{E.4.4. Key Findings}

- In most practices, economic development impact analysis is conducted for projects greater than $\$ 5$ million.

- Most National transportation professionals recommended economic development impacts to carry a greater than 10 percent weight in the selection process.

- Job creation appears to be the most important factor of economic development impacts that both agencies and public are interested in. Job retention, tax revenue, and location of jobs were the next leading factors.

- Most agencies have used either input-output or computer simulation models in the past for analyzing economic development impacts. 
Appendix F.

\section{SURVEY OF ECONOMIC DEVELOPMENT ORGANIZATIONS IN INDIANA}

We are conducting a research study for the Indiana Department of Transportation (INDOT) to develop a tool capable of incorporating economic evaluation measures more explicitly into the transportation decision making process. One of the tasks in this project is to collect information from transportation agencies and organizations across Indiana that may have interests in economic development aspects. Economic development occurs when the income generated within a region increases. Transportation projects can affect real disposable income levels for individuals, overall production costs and productivity for businesses, as well as regional competitiveness and business market shares (i.e. attracting businesses and tourists). The assessment of economic development impacts resulting from transportation projects may be conducted for: transportation facilities that specifically provide or enhance access to markets and resources (labor, materials, and suppliers); a specific transportation project or policy; or entire transportation funding programs.

This survey is intended to address the following questions:

1. Under what circumstances do or should economic developers and transportation agencies in Indiana conduct economic development impact assessments?

2. What measures for economic development impacts are or should typically be used?

3. What strategies/tools are or should be used among economic developers and transportation agencies in Indiana?

This survey is targeted towards researchers and development practitioners, public organization staff, economic development organization staff, and private sector consultants and market analysts who are engaged in promoting the economic welfare of Indiana.

Please be assured that regardless of whether your particular organization actively assesses the economic development impacts of transportation projects, the insights generated through your participation in this survey will be very much appreciated, and your answers will be relevant and important. Responses will be kept confidential.

Our experience with this survey indicates that it will take approximately $\mathbf{2 0}$ minutes to complete. In appreciation for your efforts in completing the survey, I would be happy to send you a copy of the survey results once they have been tabulated. Once you have completed the survey, please return the completed document and any supporting documentation by January 27, 2006 to:

Konstantina Gkritza

Graduate Research Assistant

Fax: 765-496-7996

School of Civil Engineering

Phone: 765-409-2204

Purdue University

550 Stadium Mall Dr.,

West Lafayette, Indiana 47906

E-mail: kgkritza@purdue.edu

If you wish, you may fax your response or submit your answers by telephone. If you would prefer a telephone interview, please email us your telephone number indicating a good time to be contacted. If you have any questions regarding this survey, please feel free to contact the research team via e-mail or telephone at the contact information listed above. Thank you in advance for your assistance with this survey.

Sincerely,

Kumares C. Sinha, Olson Distinguished Professor of Civil Engineering, Director, Joint Transportation Research Program 


\section{PART 1: ORGANIZATION PROFILE}

1.1. What best describes your organization?

a. Transportation Agency

b. Economic Development Agency

c. Planning Agency

d. Transportation Consultant

e. Economic Development Consultant

f. University

Others (please specify)

1.2. Does your organization get involved in evaluating economic development impacts of transportation projects?

$$
\text { Yes } \quad \text { No | }
$$

Even if your organization does not get involved in transportation projects, we would like to have your inputs to the rest of the questions.

\section{PART 2: ECONOMIC DEVELOPMENT PRACTICES}

2.1. What evaluation criteria should be considered when choosing one transportation project to fund over another, and what weight (\%) do you think each factor should carry? (Please check all that apply)

\begin{tabular}{|l|l|}
\hline FACTOR & WEIGHT (\%) \\
\hline Mobility & \\
\hline Accessibility & \\
\hline Safety & \\
\hline Economic Development & \\
\hline Environmental Protection & \\
\hline Quality of Life & \\
\hline Others (please specify) & \\
\hline
\end{tabular}

2.2. Under which of the following circumstances, should economic development impacts of transportation projects be estimated?

\begin{tabular}{|l|l|l|l|l|l|}
\hline & Always & Sometimes & Rarely & Never & $\begin{array}{c}\text { Don't } \\
\text { know }\end{array}$ \\
\hline Constructing a new road/highway & & & & & \\
\hline Highway/road widening & & & & & \\
\hline Adding an interchange & & & & & \\
\hline $\begin{array}{l}\text { Reconfiguring an intersection } \\
\text { sition }\end{array}$ & & & & & \\
\hline $\begin{array}{l}\text { Projects that reduce access to businesses } \\
\text { Projects intended to promote economic de- } \\
\text { velopment }\end{array}$ & & & & & \\
\hline $\begin{array}{l}\text { Altering traffic patterns in an area of a city } \\
\text { significantly }\end{array}$ & & & & & \\
\hline $\begin{array}{l}\text { Projects on routes with heavy truck/freight } \\
\text { use }\end{array}$ & & & & & \\
\hline \begin{tabular}{l} 
Potentially controversial projects \\
\hline
\end{tabular}
\end{tabular}


2.3. What should be the primary motivation for analyzing the economic development impacts of transportation projects? (Please check all that apply)

Better project planning

Ranking projects in terms of their desirability

Public information or discussion

Federal directives (e.g. NEPA)

Political pressure (actual or anticipated)

Evaluate prior investment (after the construction of a project)

2.4. Which of the following statements best describe the role of economic development impacts in project evaluations? (Please check all that apply)

They potentially could cause a project to be abandoned.

They could be used to mitigate at least the most significant negative impacts.

The project would be redesigned to address these impacts.

Economic development impacts would be taken into account but they would not be major factors in a project's fate.

If it is thought the political pressures are likely to be great enough, at least a limited analysis of economic development impacts would be conducted.

Economic development impacts are often not taken into account.

2.5. What should be the primary criteria to evaluate a transportation project's impact on economic development? (Please check all that apply)

\begin{tabular}{|l|l|}
\hline i. Job creation & \\
\hline ii. Job retention & \\
\hline iii. Impact on area's unemployment rate & \\
\hline iv. Projected total wage effect & \\
\hline v. Impact on local tax base & \\
\hline vi. Impact on land values & \\
\hline vii. Cost-benefit ratio & \\
\hline viii. Cost-effectiveness of investment & \\
\hline ix. Level of private investment & \\
\hline x. Ratio of public to private investment & \\
\hline xi. Freight mobility improvements & \\
\hline xii. Impact on regional output & \\
\hline xiii. Impact on real disposable income & \\
\hline xiv. Impact on regional competition & \\
\hline xv. Impact on tourism & \\
\hline xvi. Others (please specify) & \\
\hline
\end{tabular}

a. Which measures (listed in Q.2.5) appear to be of most importance for communicating findings:

I. To the public?

II. To decisionmakers? 
b. Please list factors that are important to consider as part of the economic development score from Q.2.5, and the weight (\%) that each factor should be expected to carry. (All weights should add to $100 \%)$

\begin{tabular}{|l|l|}
\hline FACTOR & WEIGHT (\%) \\
\hline & \\
\hline & \\
\hline & \\
\hline & \\
\hline & \\
\hline & \\
\hline & \\
\hline & \\
\hline & \\
\hline
\end{tabular}

2.6. If your organization were to carry out an analysis of the likely economic development impacts of a potential highway improvement, which of the following would best describe your practices? (Please check all that apply)

The analysis would be conducted in-house*. We would retain the services of a consultant. We would seek the assistance of a college or univer sity.

* If conducted in house, please specify if conducted by planner/engineer, economist or other staff.

2.7. Over the past 5 years, how has your organization's involvement in the analysis of the economic development impacts of transportation projects changed? (Please check one)

We are doing a lot more in-depth analysis.

We are doing a little more analysis.

We are doing about the same amount of analy-

sis.

We are doing less analysis.

We do not do any analysis.

2.8. In circumstances when your organization does not analyze the economic development impacts of a transportation project, which of the following best describe the reasons why? (Please check all that apply)

No demand/audience for it.

The size and scope of the investment does not justify such

analysis.

Simple tools/methods are not available.

Too expensive to do.

Lack of familiarity with the subject.

Not applicable, we always analyze these impacts.

2.9. How many full-time professional staff members are engaged solely in economic development in your organization? 


\section{PART 3: USE OF SPECIFIC METHODS FOR ASSESSING ECONOMIC DEVELOPMENT IM- PACTS}

3.1. How often does your organization use the following economic impact analysis tools?

\begin{tabular}{|c|c|c|}
\hline \multirow{6}{*}{$\begin{array}{l}\text { A. Traditional benefit/cost } \\
\text { analysis }\end{array}$} & Frequently ( 3 or more times a year) & Please Check \\
\hline & Occasionally (once a year) & \\
\hline & Rarely (once every two years or less) & \\
\hline & Never, because we don't think this technique is useful. & \\
\hline & Never, because we are not familiar with the technique. & \\
\hline & Don't know. & \\
\hline \multirow{6}{*}{$\begin{array}{l}\text { B. Multiplier analysis/In- } \\
\text { put-Output analysis }\end{array}$} & Frequently ( 3 or more times a year) & \\
\hline & Occasionally (once a year) & \\
\hline & Rarely (once every two years or less) & \\
\hline & Never, because we don't think this technique is useful. & \\
\hline & Never, because we are not familiar with the technique. & \\
\hline & Don't know. & \\
\hline \multirow{6}{*}{$\begin{array}{l}\text { C. Computer economic } \\
\text { models }\end{array}$} & Frequently ( 3 or more times a year) & \\
\hline & Occasionally (once a year) & \\
\hline & Rarely (once every two years or less) & \\
\hline & Never, because we don't think this technique is useful. & \\
\hline & Never, because we are not familiar with the technique. & \\
\hline & Don't know. & \\
\hline \multirow{6}{*}{$\begin{array}{l}\text { D. Business interviews or } \\
\text { surveys }\end{array}$} & Frequently ( 3 or more times a year) & \\
\hline & Occasionally (once a year) & \\
\hline & Rarely (once every two years or less) & \\
\hline & Never, because we don't think this technique is useful. & \\
\hline & Never, because we are not familiar with the technique. & \\
\hline & Don't know. & \\
\hline \multirow{6}{*}{$\begin{array}{l}\text { E. Business dislocation } \\
\text { analysis }\end{array}$} & Frequently ( 3 or more times a year) & \\
\hline & Occasionally (once a year) & \\
\hline & Rarely (once every two years or less) & \\
\hline & Never, because we don't think this technique is useful. & \\
\hline & Never, because we are not familiar with the technique. & \\
\hline & Don't know. & \\
\hline \multirow{6}{*}{$\begin{array}{l}\text { F. Integrated travel de- } \\
\text { mand-economic models }\end{array}$} & Frequently ( 3 or more times a year) & \\
\hline & Occasionally (once a year) & \\
\hline & Rarely (once every two years or less) & \\
\hline & Never, because we don't think this technique is useful. & \\
\hline & Never, because we are not familiar with the technique. & \\
\hline & Don't know. & \\
\hline
\end{tabular}

3.2. What criteria determine the use of one tool over the other? (Check all that apply)

\begin{tabular}{|l|l|}
\hline Project size & \\
\hline Duration of construction & \\
\hline Size of impact area & \\
\hline Local concerns & \\
\hline Staff expertise on specific tool & \\
\hline Cost of specific tool & \\
\hline Available time for analysis & \\
\hline Other organizations' experience & \\
\hline Others (please specify) & \\
\hline
\end{tabular}




\section{PART 4: ADEQUACY OF AVAILABLE METHODS, TOOLS, AND TECHNIQUES}

4.1. What is your opinion as to the adequacy of current methods, tools and techniques summarized in the following statements?

\begin{tabular}{|l|l|l|l|}
\hline & Agree & $\begin{array}{c}\text { Neither } \\
\text { agree nor } \\
\text { disagree }\end{array}$ & Disagree \\
\hline $\begin{array}{l}\text { Generally speaking, my organization has the capacity to esti- } \\
\text { mate the economic development impacts of transportation pro- } \\
\text { jects accurately and comprehensively. }\end{array}$ & & & \\
\hline $\begin{array}{l}\text { The methods, tools, and techniques currently available often are } \\
\text { too complex for my organization to use. }\end{array}$ & & & \\
\hline $\begin{array}{l}\text { The tools for estimating economic impacts tend to be too diffi- } \\
\text { cult to apply for routine use by my organization. }\end{array}$ & & & \\
\hline $\begin{array}{l}\text { There has been significant progress over the past decade or so } \\
\text { in the ability of organizations to estimate the economic devel- } \\
\text { opment impacts of highway projects. }\end{array}$ & & & \\
\hline $\begin{array}{l}\text { We are interested in learning more about the methods, tools, } \\
\text { and techniques that would help my organization conduct eco- } \\
\text { nomic impact analyses of proposed transportation projects. }\end{array}$ & & & \\
\hline
\end{tabular}

4.2. To enhance your organization's ability to evaluate the economic development impacts of transportation system changes, which of the following are needed?

\begin{tabular}{|l|l|l|l|l|}
\hline & $\begin{array}{c}\text { Badly } \\
\text { needed }\end{array}$ & $\begin{array}{c}\text { Would help } \\
\text { some }\end{array}$ & $\begin{array}{c}\text { Not a big } \\
\text { need }\end{array}$ & Don't know \\
\hline $\begin{array}{l}\text { More resources for the organization, in } \\
\text { terms of staff, time or equipment. }\end{array}$ & & & & \\
\hline $\begin{array}{l}\text { Better data relevant to analysis of } \\
\text { these impacts. }\end{array}$ & & & & \\
\hline $\begin{array}{l}\text { More useful guidelines in applying im- } \\
\text { pact methods, tools, or techniques, } \\
\text { such as guidebooks. }\end{array}$ & & & & \\
\hline
\end{tabular}

\section{PART 5: INDIANA' S ECONOMIC DEVELOPMENT PROFILE}

5.1. What are the features that you believe make your jurisdiction (state, county or city) most attractive to an outside firm seeking a business location? (Please check all that apply)

\begin{tabular}{|l|l|}
\hline Skilled/trained work force & \\
\hline Highly-motivated/hard-working work force & \\
\hline Low wage rates/cost of labor & \\
\hline Low cost of energy or other utilities & \\
\hline Available low cost land/buildings & \\
\hline Amenities/generally high quality of life in the county & \\
\hline Availability of tax abatements and other financial incentives & \\
\hline Convenient location for shipping/access to markets or suppliers & \\
\hline Existing base of business support services & \\
\hline Existing infrastructure, including telecommunications capacity & \\
\hline Cooperative/"Business Friendly" nature of local governments & \\
\hline Proximity to a college or university & \\
\hline Others (Please describe) & \\
\hline
\end{tabular}


5.2. What are the features that you believe make your jurisdiction (state, county or city) least attractive to an outside firm seeking a business location? (Please check all that apply)

\begin{tabular}{|l|l|}
\hline Lack of a skilled/trained work force & \\
\hline Lack of a highly-motivated/hard-working work force & \\
\hline High wage rates/cost of labor & \\
\hline High cost of energy or other utilities & \\
\hline Lack of low cost land/buildings & \\
\hline Lack of amenities/generally low quality of life in the county & \\
\hline Lack of tax abatements and other financial incentives & \\
\hline Inconvenient location for shipping/access to markets or suppliers & \\
\hline Lack of existing base of business support services & \\
\hline Lack of existing infrastructure, including telecommunications capacity & \\
\hline Uncooperative/"Business hostile" nature of local governments & \\
\hline Distance from a college or university & \\
\hline Others (Please describe) & \\
\hline
\end{tabular}

5.3. Which of the following have been built in your jurisdiction (state, county or city) in the last five years? (Please check all that apply)

New highway infrastructure/ highway improvements

Industrial park

New industrial infrastructure (including water, sewer, or telecommunications capacity)

Visitor/convention center

Business incubator facility

5.4. In the last ten years, which of the following has generated the most job growth in your jurisdiction (state, county or city)? (Please check one)

The creation of new businesses

The expansion of existing businesses

The recruitment of new businesses from other areas

Others (Please explain)

5.5. In the next ten years, which of the following do you expect to generate the most job growth in your jurisdiction (state, county or city)? (Please check one)

The creation of new businesses

The expansion of existing businesses

The recruitment of new businesses from other areas

Others (Please explain)

5.6. If your organization has an economic development program, does it target any specific industries (e.g. high technology, manufacturing) or infrastructure projects for the next five years?

\begin{tabular}{|r|r|r|}
\hline Yes* $^{*}$ & No & Not applicable \\
\hline
\end{tabular}

* If yes, please specify the targets. 
5.7. If you have additional comments that you would like to express related to the assessment of economic development impacts of transportation projects, please provide these comments here or attach additional sheets as needed. 